\title{
Proposta de um Modelo de Processo de Planejamento
}

\author{
Waine Teixeira Junior
}

Orientadora: Profa. Dra. Rosely Sanches

Dissertação apresentada ao Instituto de Ciências Matemáticas e de Computação - ICMC-USP, como parte dos requisitos para obtenção do título de Mestre em Ciências - Área: Ciências de Computação e Matemática Computacional.

USP - São Carlos

Outubro de 2000 
À minha esposa Eglen, que me dá forças para atingir os mais altos objetivos. Aos meus pais, Waine e Tereza. 


\section{Agradecimentos}

À Rosely Sanches, pela paciência, dedicação, compreensão e amor.

Aos meus pais Waine e Tereza, aos meus irmãos Chrys e Marco, e à Wanessa, pelo incentivo e pelo carinho.

Aos colegas: Enzo, Willian, Clándio, Cláudia, Janaina, Walter, Adenilson, Mayb e Daniela, pela amizadc sincera e pclo companheirismo.

Aos amigos Andréia, Dinamérico, Mirla, Marisa, Rudnei, Silvio, Tatiana, Jorge, Andreza, Jusane, Rodrigo, Camilo, Zé Eduardo, Fabiana, Fernando, Igor, Vangrei e muitos outros amigos pelos momentos tão felizes e inesquecíveis vividos no mestrado.

À Selma e à Flávia, companheiras de república, pela amizade, companheirismo, e apoio na reta final.

À Beth, Laura e Marilia, pela dedicação com que sempre me atenderam.

A todos os professores e funcionários do ICMSC, pela dedicação.

A CAPES pelo apoio financeiro. 


\section{Sumário}

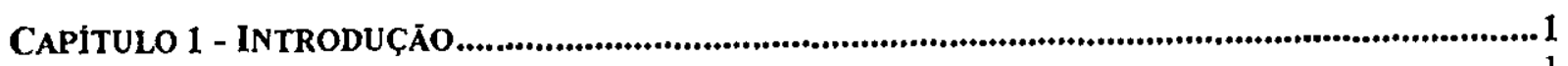

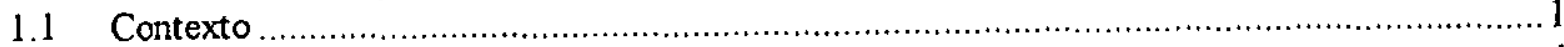

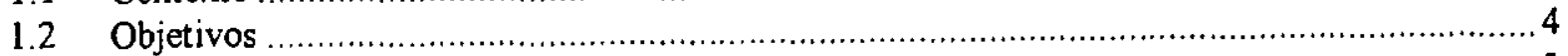

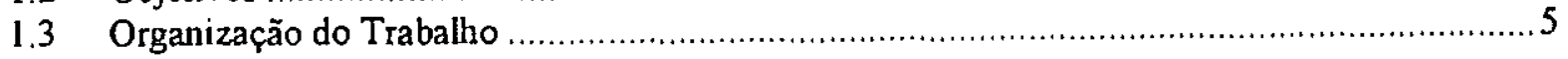

CAPITUlo 2 - PlaneJamento de Projeto de SofTWARE ........................................................ 7

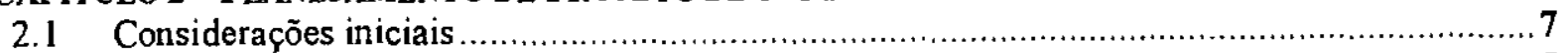

2.2 Conceitos Fundamentais de Planejamento de Projeto de Software ................................... 7

2.3 Atividades Fundamenta is de Planejamento de Projeto de Software .....................................9

2.3.1 Determinaçđo do Ciclo de Vida ............................................................................ 10

2.3.2 Elaboração da Estrutura de Divisão de Trabalho ..................................................16

2.3.3 Elaboração de Estimativas de Projeto ................................................................ 19

2.3.4 Elaboração do Cronograma do Projeto ...............................................................19

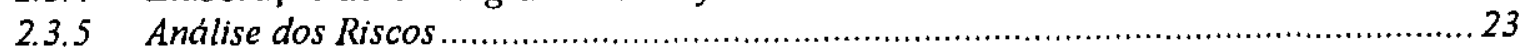

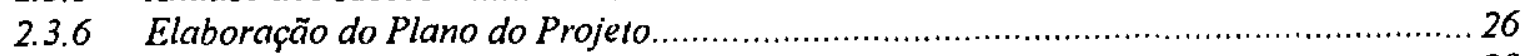

2.3.7 Aprovação do Plano do Projeto ....................................................................... 28

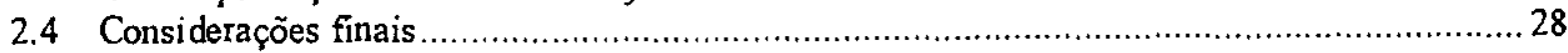

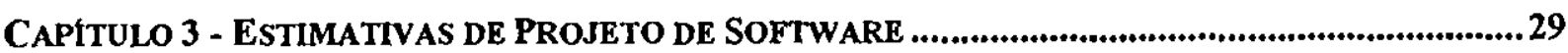

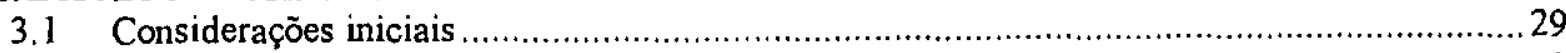

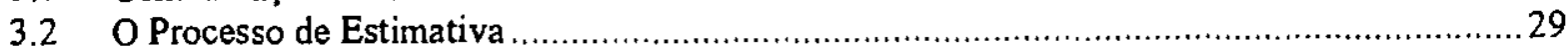

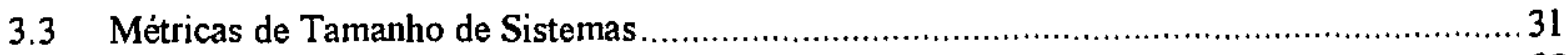

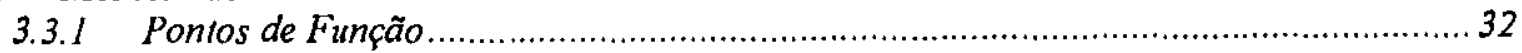

3.3.2 Contagem de Pontos de Função segındo o IFPUG ................................................. 34

3.3.3 Contagens de Pontos de Função segundo o NESMA ............................................. 38

3.4 Técnicas para elaboração de Estimativas de Projeto ................................................... 41

$3.5 \quad \mathrm{O}$ uso de Dados Históricos no Processo de Estimativas...................................................45

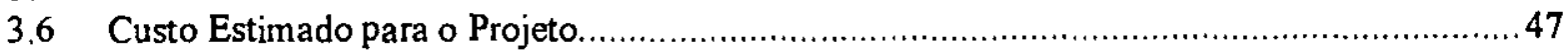

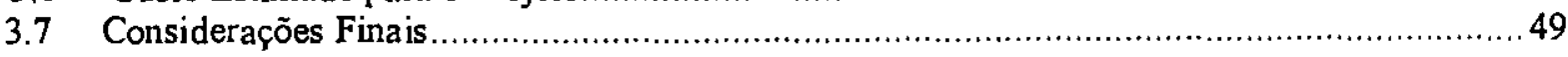

CaPtTUlO 4 - OS MODElos de ESTIMATIVA COCOMO E COCOMO II ...................................49

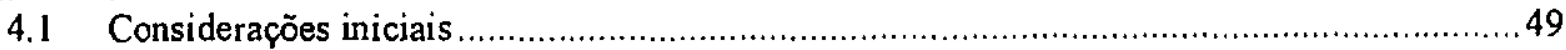

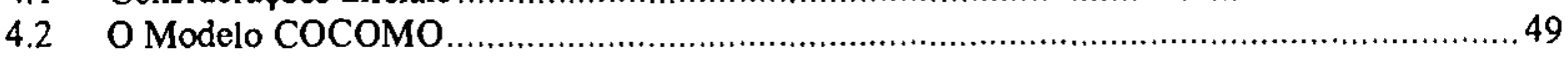

4.2.1 Fórmulas de Cálculo do COCOMO 81 ..................................................................... 51

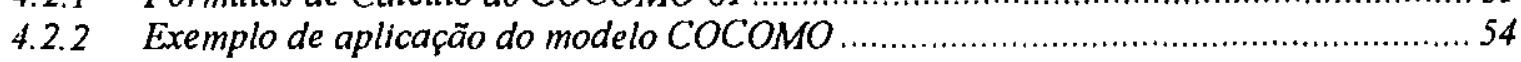

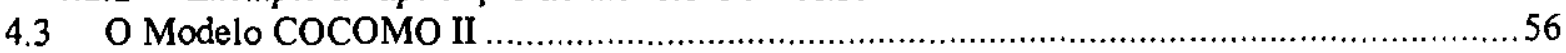

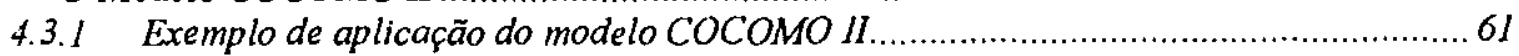

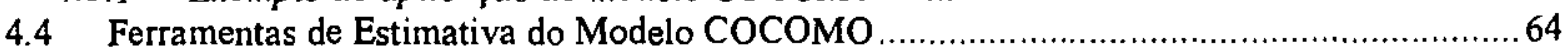

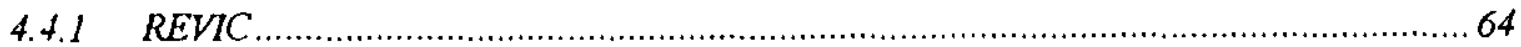

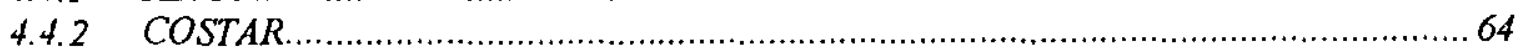

4.4.3 USC COCOMO 2000.0

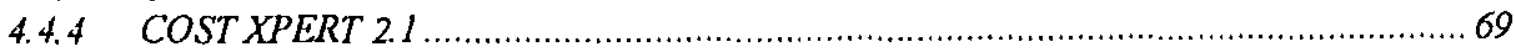

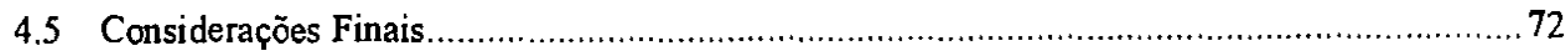


CaPitulo 5 - Proposta de UM Modelo Processo de Planejamento...................................73

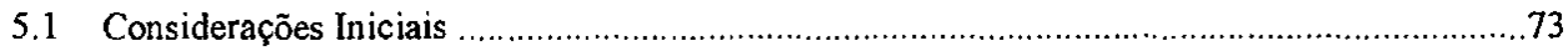

5.2 O Modelo de Processo de Planejamento Proposto ............................................................ 73

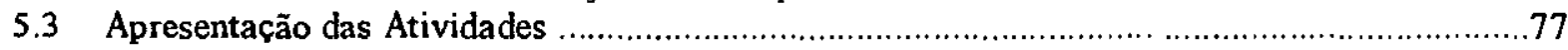

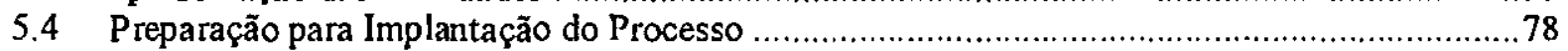

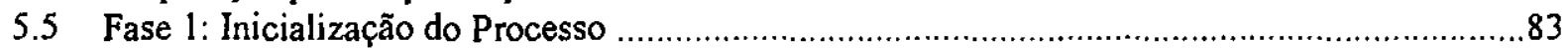

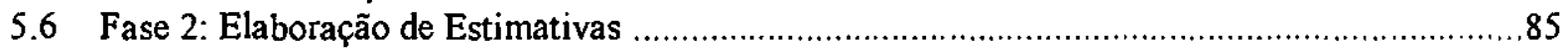

5.6.1 Fase 2: Elaboração de Estimativas: Tamanho do Sistema .......................................... 88

5.6.2 Fase 2: Elaboração de Estimativas: Esforço de Desenvolvimento ................................91

5.6.3 Fase 2: Elaboração de Estimativas: Tempo de Desenvolvimento ............................... 9.t

5.7 Fase 3: Avaliação dos Riscos do Projeto .......................................................................97

5.8 Fase 4: Elaboração do Cronograma do Projeto ...............................................................99

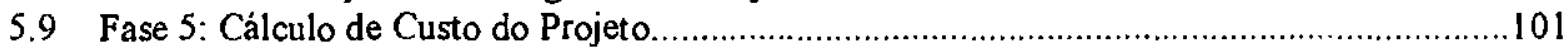

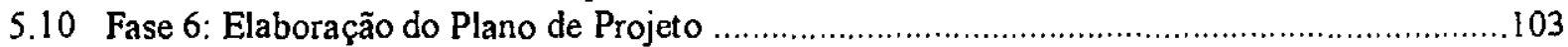

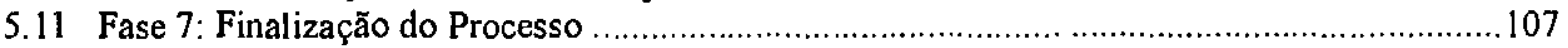

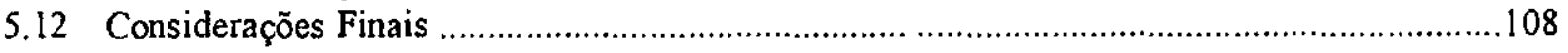

Capitulo 6 - Planejamento de UM Projeto: Um estudo de CaSo ....................................... 109

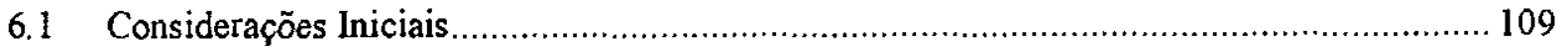

6.2 O Ambiente de Desenvolvimento de Software do Estudo de Caso ................................... 109

6.3 Aplicação do Modelo de Processo em um Planejamento de Projeto ..................................110

6.3.1 A fase de Preparação para a Implantação do Processo...............................................1 10

6.3.2 A fase de Inicialização do Processo ..................................................................... $11 \mathrm{l}$

6.3.3 A fase de Elaboração de Estimativas: Tamanho do Sistema .....................................11t

6.3.4 As fases de Elaboração de listimativas: Esforço e Tempo ...................................... 115

6.3.5 A fase de Avaliação dos Riscos do Projeto ........................................................... 119

6.3.6 A fase de Elaboração do Cronograma do Projeto ................................................. 119

6.3.7 A fase de Cálculo de Custo do Projeto ............................................................. l l20

6.3.8 Elaboração do Plano de Projeto....................................................................... 120

6.3.9 A fase de Finalização do Processo............................................................. $l 24$

6.4 Comentários Finais sobre o Estudo de Caso ....................................................... 124

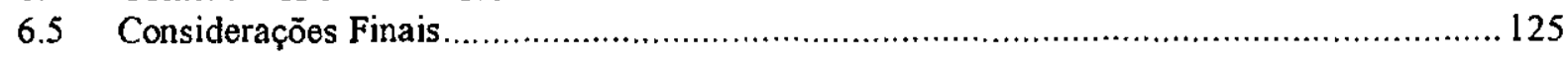

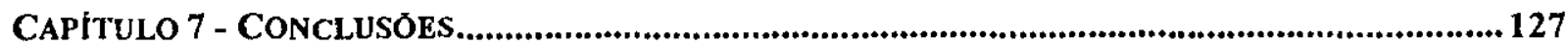

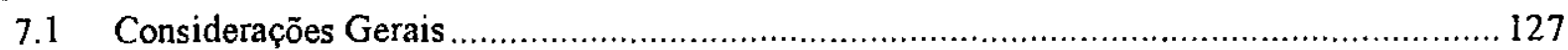

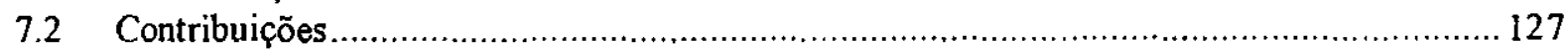

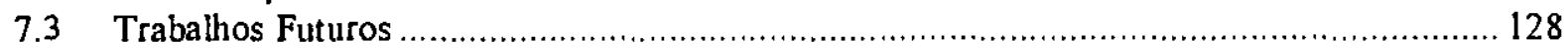

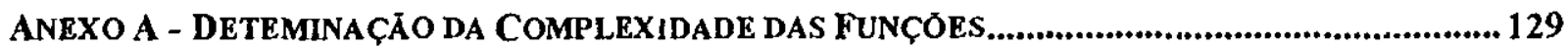

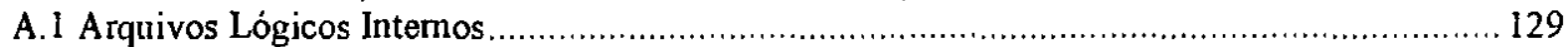

Complexidade de Arquivo Lógico Interno................................................. I29

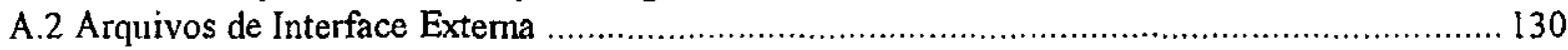

Complexidade de Arquivo de Interface Extema ............................................ 130

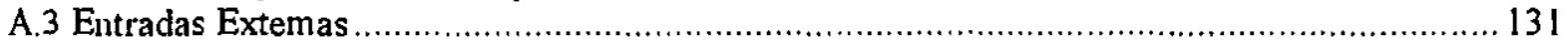

Complexidade de Entradas Extemas ........................................................ 131

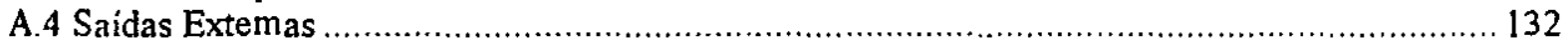

Complexidade de Saidas Extemas.......................................................... 132

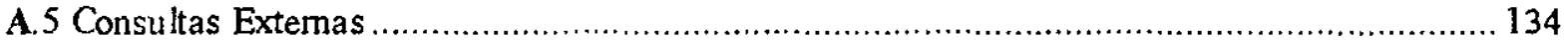

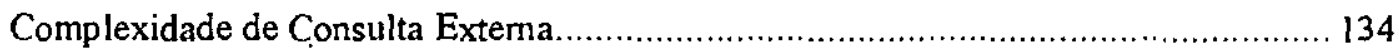


ANexo B - Determinação do Fator de AJuste de Pontos de FUnÇÃo...............................137

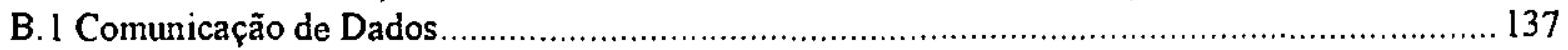

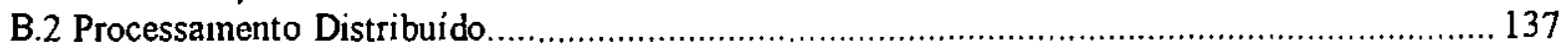

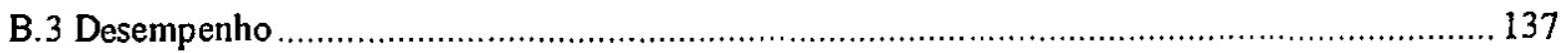

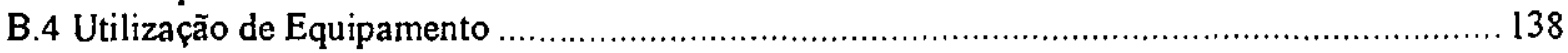

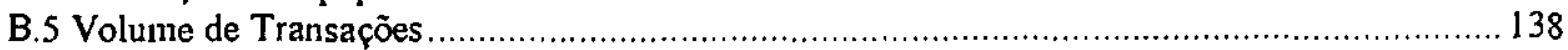

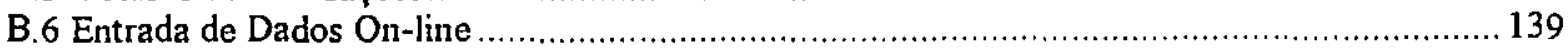

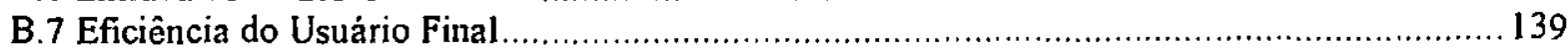

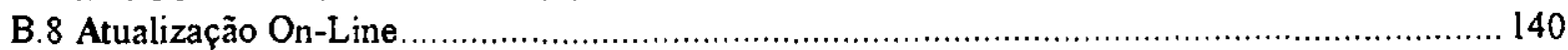

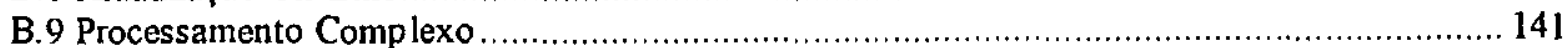

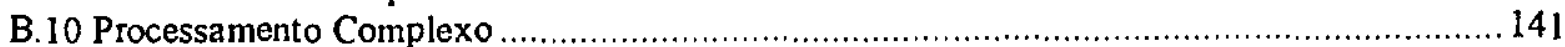

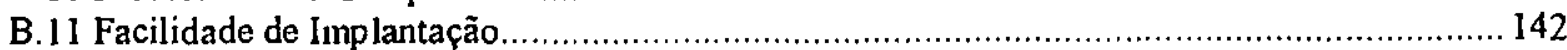

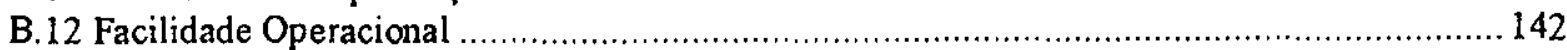

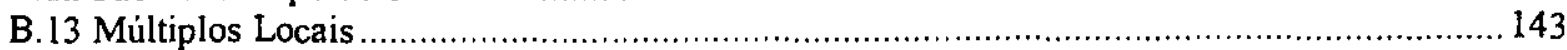

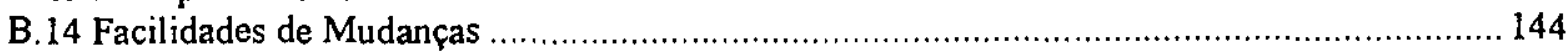

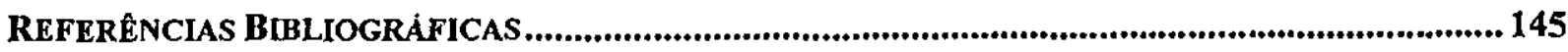

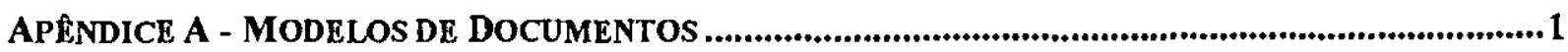

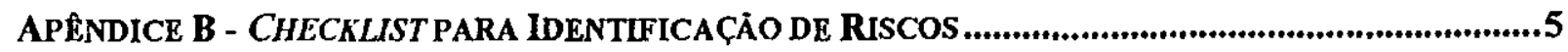




\section{Lista de Figuras}

Figura 2.1 - O Ciclo de Planejanento de Desenvolvimento de Soft ware [Humpley, 1989] .............................. 8

Figura 2.2 - Diagrama de Fluxo do Processo de Planejamento [Groarke. 1997] .............................................. 8

Figura 2.3 - Ciclo de Vida Clássico [Pressman. 1995] ........................................................................... 11

Figura 2.4 - Ciclo de Vida Incremental [Description, 1999] ............................................................... 12

Figura 2.5 - Ciclo de Vida Evolucionário [Description, 1999] ................................................................ 13

Figura 2.6 - Modo de Desenvolvinento Prototipado [Pressman. 1995] .......................................................... 14

Figura 2.7 - Estrutura de Divisão de Trabalho (WBS) |Vargas, 2000] ....................................................... 17

Figura 2.8 - Exemplo de Aprescntação de Estrutura de Divisão de Trabalho ................................................... 18

Figura 2.9 - Gráfico PERT de um Projeto de Software Siniples [Boelum. 198 1] ........................................... 21

Figura 2.10 - Gráfico de Gantt para um Plano de Projeto de Soft ware [Boehm, 1981] ..................................22

Figura 2.11 - Paradigma de Gerenciamento de Risco da SEI [Higuera. 1996]................................................ 25

Figura 3.1 - Diagrama de Fluxo do Processo de Estimativa [Software. 1996] ..............................................29

Figura 3.2 - Componentes de Pontos de Funcão em relação à aplicação [Dekkers, 1998] ................................. 32

Figura 3.3 - Visão Gcral do Processo de Análise de Pontos de Função ......................................................... 34

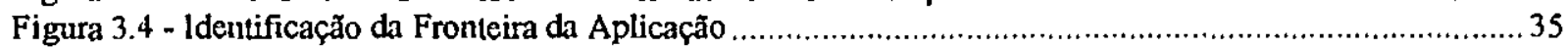

Figura 3.5 - Modelo de Formulário lterativo [Boehm, 1981] .............................................................. 43

Figura 3.6 - Base de dados históricos para estimativas [Fernandes, 1995] .................................................46

Figura 3.7 - WBS como ferramenta para cálculo do custo do projeto [Vargas, 2000] ....................................... 48

Figura 4.1 - Tela de Entrada de Pontos de Funcão da Ferramenta COSTAR ……...........................................65

Figura 4.2 - COSTAR - Seleção da Linguagein de desenvolvimento........................................................65

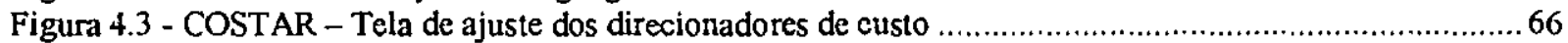

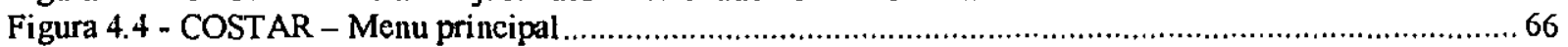

Figura 4.5 - COSTAR - Relatório de Estimativa por Fase .......................................................................67

Figura 4.6 - COSTAR - Relatónio de Estimativa por Atividade....................................................................67

Figura 4.7 - USC COCOMO - Menu principal do sistema ............................................................................68

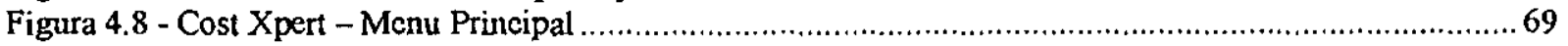

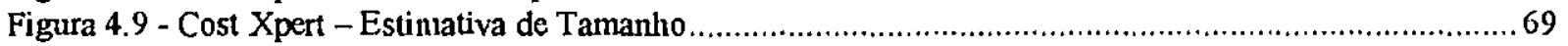

Figura 4.10 - Cost Xpert - Direcionadores de Custo ...................................................................... 70

Figura 4.11 - Cost Xpert - Outros Fatores Direcionadores de Custo …...................................................... 70

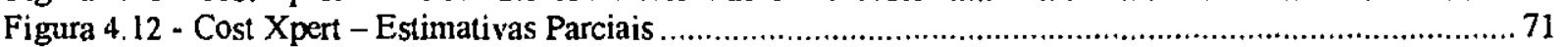

Figura 4.13 - Cost Xpert - Gráfico de Distribuição ............................................................................... 71

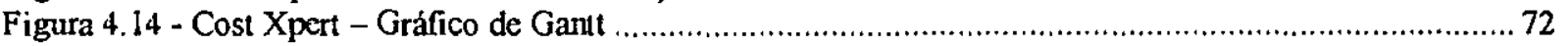

Figura 5.1 - Diagrama de Fluxo do Modclo de Processo de Planejamento ................................................74

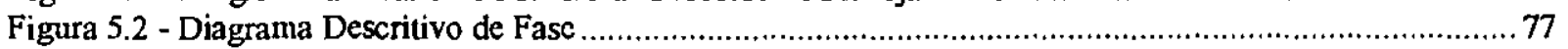

Figura 5.3 - Diagrama Descritivo da Fase de Preparação ............................................................................. 78

Figura 5.4 - Diagrama Desc ritivo da Fase de Inicialização ........................................................................ 83

Figura 5.5 - O uso integrado de Pontos de função e COCOMO ................................................................ 87

Figura 5.6 - Diagrama de Fluxo da Fase de Elaboração de Estinativas......................................................... 88

Figura 5.7 - Diagrama Descritivo da Fase de Elaboração de Esti nativa de Tamanho ..................................... 89

Figura 5.8 - Diagrama Descritivo da Atividade de Estimativa de Esforço .................................................. 92

Figura 5.9 - Diagrama Descritivo da Atividade de Estimativa de Tempo ...................................................... 94

Figura 5.10 - Diagrama Descritivo da Fase de Análise de Riscos do Projeto ................................................... 97

Figura 5.11 - Diagrama Descritivo da Fase de Estimativa de Tempo ...............................................................99

Figura 5.12 - Diagrama Descritivo da Fase de Estimativa de Custo do Projeto ............................................ 101

Figura 5.13 - Diagrama Descritivo da Fase de Elaboração do Plano de Projeto ............................................. 103

Figura 5.14 - Diagrama Descritivo da Fase de Finalização do Processo …................................................. 107

Figura 6.1 - Plano de Treinamento Proposto o Processo de Planejamento .................................................. 112

Figura 6.2 - Estrutura de Divisão de Trabalho do Projeto Desenhos......................................................... 113

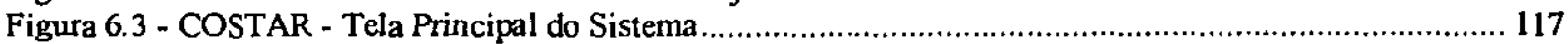

Figura 6.4 - COSTAR - Tela de Ajuste dos Direcionadores de Custo do COCOMO II ................................. 117

Figura 6.5 - COSTAR - Estimativas de Esforço e Duração do Módulo Tabclas .......................................... 118

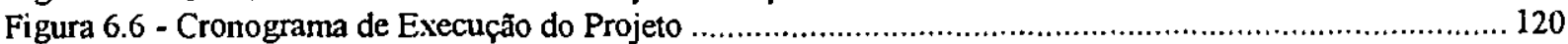

Figura 6.7 - Plano do Projeto Módulo Desenhos .................................................................................... 121

Figura 6.8 - Modelo de Documento de Registro de Estimativas.................................................................... 123 
Figura Apêndice A.l - Modelo de Plano de Treinamento ........................................................................

Figura Apêndice A.2 - Modelo de Documento de Registro de Estimativas ....................................................... 2

Figura Apêndice A.3 - Modelo de Plano de Projeto de Software ................................................................... 3

Figura Apêndice A.4 - Modelo de Cronograma de Desenvolvimento ......................................................... 


\section{Lista de Tabelas}

Tabela 1.1 Conhecimento de Modelos e Norma de Qualidade [Evolução, 1999]............................................

Tabcla 3.1 - Determinação de Pontos de Função Não Ajustados [Fernandes, 1995] ......................................... 36

Tabela 3.2 - Conversão de Pontos de Furção em Linhas de Código [Jones, 1996] ........................................... 38

Tabela 3.3 - Exemplo de Contagem Indicativa de Pontos de Função [NESMA, 2000] ..................................... 39

Tabela 3.4 - Exemplo de Contagem Estimada de PF [NESMA, 2000] .........................................................40

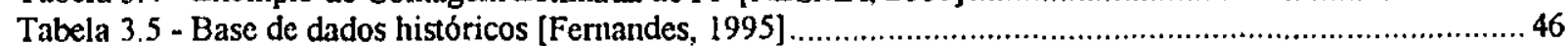

Tabela 4.1 - Parâmetros do COCOMO - Estimativa de Esforç̧o [Conte, 1985] ................................................ 51

Tabela 4.2 - Parânetros do COCOMO - Estimativa de Prazo [Fernandes, 1995] ...........................................5 52

Tabela 4.3 - Distribuição de Prazo [Fernandes. 1995] ........................................................................5

Tabcla 4.4 - Distribuição de Esforço [Fernandes. 1995] .......................................................................... 54

Tabela 4.5 - Fatores de Escala do Modelo COCOMO II [Teixeira, 2000b] ....................................................59

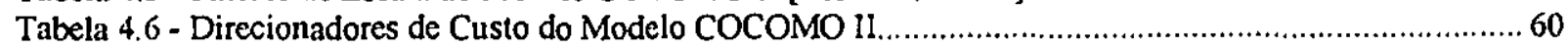

Tabela 4.7 - Percentuais de Distribuição de Esforço do COCOMO II [Trindade, 2000a] ..................................60

Tabela 4.8 - Percentuais de Distribuição de Prazo do COCOMO Il [Trindade, 2000a] .....................................61

Tabela 6.1 - Resultado da Análise de Pontos de Função .................................................................. 114

Tabcla 6.2 - Resultado da Avaliação das 14 Características Gerais do Sistemn ............................................ 114

Tabela 6.3 - Totais das Estimativas de Esforço e Duração (Ferramenta COSTAR) ..................................... 118

Tabela 6.4 - Ajuste de Estimativas de Duração de Fases ..................................................................... 119

Tabela Anexo A.1 - Classificação de Arquivo Lógico Interno ............................................................... 130

Tabela Anexo A. 2 - Grau de Complexidade Funcional - Arquivo Lógico Interno ….................................... 130

Tabela Anexo A. 3 - Grau de Complexidade Funcional - Arquivo Interface Externa...................................... I I30

Tabela Anexo A.4 - Complexidade de Entradas Externas......................................................................... 132

Tabela Anexo A.5 - Grau de Complexidade Funcional - Entrada Externa .................................................. 132

Tabela Anexo A.6 - Complexidade de Saidas Externas ...................................................................... I33

Tabela Anexo A.7 - Grau de Complexidade Funeional - Saida Externa ...................................................... 133

Tabela Aucxo A.8 - Complexidade da Parte de Entrada de una Consulta Externa........................................ 134

Tabela Anexo A.9 - Complexidade da Parte de Saida de una Consulta Externa ........................................... 135

Tabcla Anexo A. I0 - Grau de Complexidade Funcional - Consulta Externa ................................................. 135

Tabela Anexo B.1 - Niveis de Influência de Conunicação de Dados.......................................................... 137

Tabela Anexo B.2 - Niveis de Influência do Processamento Distribuído................................................. 138

Tabela Anexo B.3 - Niveis de Influêneia do Desempenho.................................................................. 138

Tabela Anexo B.4 - Niveis de Influência de Utilização de Equipamento ................................................. 139

Tabela Anexo B.5 - Niveis de Influência do Volume de Transaçðes .............................................................. 139

Tabela Anexo B.6 - Níveis de Influência de Entrada de Dados On-line ......................................................... I39

Tabela Anexo B.7 - Considerą̧ðes do Ambiente Orientado a Documento - Usuário Final ............................. 140

Tabela Anexo B.8 - Níveis de Influência de Eficiência Final................................................................ 140

Tabela Anexo B.9 - Niveis de Influência de Atualização On-line ............................................................ 141

Tabela Anexo B.10 - Niveis de Influência de Processamento Complexo ...................................................... 141

Tabela Anexo B.11 - Niveis de Influência de Reutilização de Código ...................................................... 142

Tabela Anexo B.12 - Níveis de Influência de Faeilidade de Implantação ................................................... 142

Tabcla Anexo B.13 - Niveis de Influência de Faeilidade Operacional......................................................... 143

Tabela Anexo B.14 - Niveis de Influência de Múltiplos Locais ............................................................. 143

Tabela Anexo B.15 - Niveis de Influência de Facilidades de Mudanças......................................................... 144 


\section{Lista de Quadros}

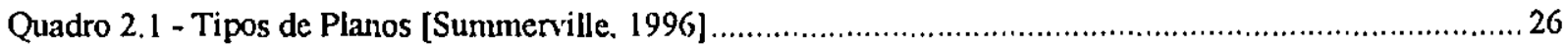

Quadro 3.1 - Tipos de Função da Análise de Pontos de Função ............................................................. 36

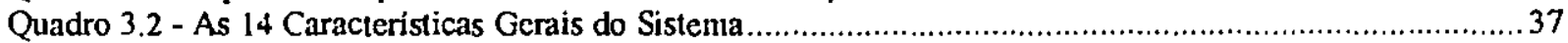

Quadro 3.3 - Etapas da Técnica Wideband Delphi [Boclum, 1981] ........................................................42

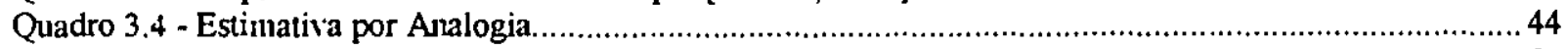

Quadro 4.1 - Atributos Direcionadores de Custo do COCOMO [Conte, 1985]............................................. 52

Quadro 5.1 - Ferramentas de Estinativas de Software............................................................................... 81

Quadro 5.2 - Ferramentas de Planejamento e Gerenciannento de Projetos ..................................................... 81

Quadro 5.3 - Técnicas e modelos de estimativas [Fcrnandes, 1995] ....................................................... 86

Quadro 6.1 - Fatores de Escala Ponderados para o Projeto ................................................................. 116

Quadro 6.2 - Direcionadores de Custo Ponderados para o Projeto .......................................................... 116 


\section{Resumo}

O planejamento déprojeto de software é uma prática gerencial vital para o sucesso da gestão de um projeto. A ausência dé práticas gerenciais no desenvolvimento de software é a principal causa de sérios problemas enfrentados pelas organizações: atraso em cronogramas, custo maior do que o esperado e presença de defeitos. Tais problemas ocasionam inconveniências aos usuários e perda de tempo e de recursos dos desenvolvedores. Segundo os modelos e padrões de qualidade ISO, SPICE e CMM, planejamento de projeto é um dos itens básicos para que uma empresa inicie a melhoria de processo de desenvolvimento de software. Este trabalho apresenta um modelo de processo de planejamento que define, relaciona e organiza as principais atividades que devem ser realizadas para planejar um projeto de software. O trabalho também apresenta um estudo de caso que mostra a aplicação do modelo de processo em um centro de desenvolvimento de sistemas de uma empresa privada. 


\begin{abstract}
The software project planning is a vital managerial practice for a successful project management. The absence of managerial practices in the software development is the main cause of serious problems faced by the organizations: delay in schedules, cost higher than the expected and presence of defects. Such problems cause inconveniences for users and enormous losses of time for developers. According to the models and quality patterns ISO, SPICE and CMM, project planning is one of the basic items for a company to start the software process improvement. This work presents a planning process model that defines, relates and organizes the main activities that a company should accomplish in order to plan a software project. The work also presents a case study that shows an application of the planning process model in a development center of a private company.
\end{abstract}




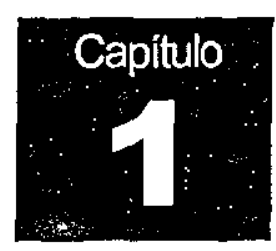

\section{INTRODUÇÃO}

\subsection{Contexto}

A qualidade está se tornando rapidamente um requisito crítico para a sobrevivência e o sucesso de empresas no mercado de software. Uma organização de software não sobressairá no mercado, que está se desenvolvendo de forma global, a menos que seus clientes vejam produtos e serviços de boa qualidade. A busca da indústria de software brasileira pela competitividade deve passar, necessariamente, pelo alcance de padrões de qualidade internacionalmente aceitos.

Observa-se nos últimos dados apresentados pelas pesquisas do SEPIN/MCT'l (Quadro 1.1) que, embora muitas empresas brasileiras já reconheçam a importância da qualidade de software, grande parte ainda não conhece ou não utiliza normas ou modelos para qualidade de processo de software e para avaliação do produto. Um dos modelos de qualidade mais conhecidos mundialmente, o Capability Maturity Model - CMM, desenvolvido pelo Software Engineering Institute - SEI, da Universidade de Carniegie Melon, para a melhoria da qualidade do processo de desenvolvimento de software, era conhecido, em 1999, por $37 \%$ das empresas pesquisadas e utilizado por apenas $10 \%$ delas [Evolução, 1999].

Tabela 1.1 Conhecimento de Modelos e Norma de Qualidade [Evolução, 1999]

\begin{tabular}{|l|c|c|c|}
\hline \multicolumn{1}{|c|}{ Norma ou Modelo } & Conhece e usa & Conhece, mas náo usa & Năo conhece \\
\hline CMMSEI & $10 \%$ & $37 \%$ & $53 \%$ \\
\hline SPICE (ISO/IEC TR 15.504) & $4 \%$ & $27 \%$ & $69 \%$ \\
\hline ISO IEC 12.207 & $16 \%$ & $27 \%$ & $57 \%$ \\
\hline
\end{tabular}

1 Num esforço conjunto do governo e entidades representativas do setor de informática, pesquisas com periodicidade bienal, sob a responsabilidade da Secretaria de Política de Informática e Automação do Ministério da Ciência e Tecnologia - SEPIN/MCT - vêm sendo realizadas, objetivan do acompanhar a evolução do setor de software no Brasil, quanto a aspectos de gestão da qualidade, gestão de recursos humanos, atendimento a clientes e procedimentos para a qualidade de produtos e serviços de software. Com base nos resultados dessas pesquisas, a SEPIN elabora a publicação "Qualidade no Setor de Software Brasileiro" [Qualidade, 1997]. 
A implantação de um modelo de qualidade em uma empresa não é uma tarefa fácil. Para melhorar a qualidade, é necessário, primeiro, conhecer a situação real em que se encontra a organização em matéria de produção de software, isto é, fazer um diagnóstico do processo de software corrente [Grady, 1997]. A partir dos resultados da avaliação e de acordo.com os objetivos de negócio da organização, elabora-se um plano de ação que leve à implementação de melhorias, preferencialmente nos pontos que proporcionarão benefícios diretos no negócio. Entre outras coisas, o plano de melhoria pode definir, por exemplo, qual a ordem das práticas profissionais que devem ser implantadas ou melhoradas na organização [Belloquim, 1999].

A ausência de práticas gerenciais no desenvolvimento de software é a principal causa de sérios problemas enfrentados pelas organizações: atraso em cronogramas, custo maior do que o esperado e presença de defeitos, ocasionando uma série de inconveniências para os usuários e enorme perda de tempo e de recursos dos desenvolvedores [Humphrey, 1989]. Na maioria das vezes não há sequer um planejamento de como a idéia modelada pelo levantamento de requisitos e necessidades dos clientes pode ser transformada em produto. Na atual cultura das organizações, o planejamento, quando ocorre, é feito de forma superficial, entre outros motivos, devido à ausência de treinamento dos engenheiros de software [Weber, 1999]. A falta de planejamento adequado, aliada a uma estimativa de custo e tempo defíciente, é uma das principais causas das falhas de projetos de software [Jones, 1998].

O planejamento de projeto de software é uma prática gerencial vital para o sucesso da gestão de um projeto. Sem objetivos claramente definidos, orçamento e cronograma realistas, a base para o comprometimento do gerente com o projeto não existe e, portanto, há pouca esperança de se chegar a algum lugar [Maciariello, 1974]. Planejamento é também determinante para a definição dos prazos, que em última instância, é o que mais interessa ao cliente, desde que o produto lhe seja entregue com a qualidade desejada e, principalmente, que cumpra de forma efetiva com os propósitos para os quais foi contratado [Moreno, 1999].

Por esses motivos, os principais órgãos certifícadores de qualidade de software: ISO, SPICE e CMM destacam o planejamento de projeto como um dos requisitos básicos para que uma empresa inicie a melhoria de processo.

A série de normas ISO 9000, criada pela International Organization for Standardization - ISO, é composta por um conjunto de cinco normas internacionais individuais, porém correlacionadas. 
A ISO 9001 refere-se aos processos de desenvolvimento e manutenção de software e, devido à sua generalidade, tanto para a área de produção quanto para a área de serviços, documentos complementares foram desenvolvidos: a ISO 9002 - Modelo para garantia da qualidade em produção e instalação e a ISO 9003 - Modelo para garantia da qualidade em inspeção e ensaios finais [Oskarsson, 1996].

A norma ISO 9000-3 "Diretrizes para Aplicação da ISO 9001 ao Desenvolvimento, Fornecimento e Manutenção de Software", documento complementar para aplicação da norma ISO 9001, é dividida em três partes: Estrutura do Sistema de Qualidade, Atividades do Ciclo de Vida e Atividades de Suporte. As atividades de desenvolvimento de software são descritas dentro da parte Atividades do Ciclo de Vida. Segundo essa norma, o desenvolvimento de software deve ser feito de acordo com um modelo de ciclo de vida definido pela organização e as atividades relacionadas à qualidade devem ser planejadas e implementadas de acordo com a natureza desse modelo utilizado. O planejamento do projeto deve ser feito a partir da definição de um processo ou metodologia disciplinada, para transformar a especificação dos requisitos do comprador num produto de software. A norma ISO 12207 Software Life Cycle Process é específica para orientar o processo de desenvolvimento de software.

O projeto Software Process Improvement and Capability dEtermination - SPICE foi criado em 1993 com o objetivo de gerar normas para avaliação de processos de software, visando a determinação da capacidade do processo e a sua melhoria contínua. Foi elaborado um documento estruturado em nove partes destinado a proporcionar meios para examinar e avaliar processos de software. A Parte 2 - Descrição de um Modelo Idealizado de Processo define un modelo ideal que propõe, em alto nível, um conjunto de processos fundamentais agrupados em categorias, onde são descritas atividades exigidas pela engenharia de software: Cliente-Fornecedor, Projeto, Planejamento, Suporte e Organização. O planejamento de projeto de software está inserido dentro da categoria de processo Projeto, cujo foco é o planejamento e uso eficaz de recursos (tempo, esforço, pessoas, dinheiro) para obtenção dos propósitos e objetivos do projeto. De acordo com a Parte 2 do SPICE, o planejamento de projeto, logo após a definição do ciclo de vida do software, tem como objetivo definir um plano para execução das atividades de engenharia de software e formar a base para o gerenciamento do projeto [SPICE 2, 1997]. 
O CMM é um modelo de qualidade centralizado na capacidade de uma organização em definir, gerenciar e melhorar seus processos. Segundo Kan [Kan, 1995] esse modelo procura avaliar a equipe de desenvolvimento de software em níveis de maturidade, a partir de sua habilidade, experiência e estágio de amadurecimento, considerando fatores da organização como gerência de processo e tecnologia, padrões e processos de trabalho, procedimentos de especificação e implementação, métricas e mensurações.

O CMM classifica organizações em cinco níveis de maturidade (1-Caótico, 2Repetivel, 3-Definido, 4-Gerenciado e 5-Otimizado), através de um instrumento de avaliação na forma de um questionário. Cada nível de maturidade ajuda a predizer a habilidade ou capacidade de um projeto em atingir suas metas [Humphrey, 1992]. Exceto o nível 1, cada nível de maturidade é decomposto em áreas-chave, ou Key Process Areas - KPAs, que indicam as áreas que cada organização deve focalizar para melhorar o seu processo de software. $O$ Planejamento de Projeto de Software é uma das áreas-chave do nível 2-Repetível, cujo propósito é garantir que, a cada projeto, sejam elaborados planos adequados ao desenvolvimento. Segundo o CMM, a empresa deve definir um ciclo de vida de sistemas e possuir um processo de planejamento e gerenciamento de projeto de software documentado, treinado e controlado, de acordo com políticas e procedimentos institucionalizados e padronizados, envolvendo todas as áreas interessadas no planejamento de projetos [Paulk et al., 1992].

Um dos pontos críticos com relação à utilização de modelos propostos pelos órgãos que certificam qualidade de software é o fato de terem sido originalmente desenvolvidos para o âmbito de empresas bem estruturadas e departamentalizadas. Sabe-se, por exemplo, que, apesar do esforço para que o texto do CMM fosse genérico, de modo a permitir a aplicação do modelo em organizações de qualquer porte e de existirem registros de organizações avaliadas nos níveis 2 e 3 com menos de 20 desenvolvedores, ainda é grande a dificuldade da aplicação do modelo pelas organizações [Belloquim, 1999].

\subsection{Objetivos}

A realidade das empresas brasileiras de software em relação à ausência de práticas gerenciais no desenvolvimento de software, comentada brevemente, é um dos principais focos dcste trabalho. 
A ausência de planejamento nas organizações é uma importante deficiência a ser suprida, sem o qual qualquer outro esforço de melhoria torna-se ineficaz. Uma equipe que desenvolve seu trabalho aleatoriamente não poderá se beneficiar de técnicas de inspeção, metodologias de desenvolvimento ou métricas de software [Belloquim, 1997].

Uma das dificuldades encontradas para implantar esse processo advém do fato de que as atividades de planejamento de projetos, na forma como estão apresentadas nos modelos de qualidade de processo de software, são grandes c complexas, aliadas ao fato de que modelos ideais de processo de software definem processos e procedimentos que devem ser executados, porém não definem a forma como devem ser executados. Portanto, a existência de procedimentos padronizados que sejam de fácil compreensão, pode ser de grande valor, evitando que os gerentes de projetos se sintam perdidos e acabem cometendo falhas graves de plancjamento, por falta de experiência.

O objetivo deste trabalho é auxiliar as empresas a definir e implantar um processo formal de planejamento de projetos. É apresentado um modelo de processo de planejamento que define, passo a passo, atividades e práticas envolvidas. Também faz parte do trabalho, apresentar de forma organizada e didática, os conceitos relacionados ao tema.

\subsection{Organização do Trabalho}

Este trabalho é dividido em 6 capitulos. Ncste capítulo apresentam-se o contexto e os objetivos principais do trabalho.

A revisão bibliográfica compreende os capítulos 2,3 e 4 .

No Capítulo 2, apresentam-se um modelo de processo de planejamento e as principais atividades que o compõem.

No Capítulo 3, uma atenção especial é dada à discussão sobre estimativas de projeto. Apresentam-se um modelo de processo de elaboração de estimativas de projeto de software e alguns dos modelos e técnicas de estimativa que podem ser utilizados nesse processo.

No Capítulo 4, descrevem-se, detalhadamente, os modelos de estimativa COCOMO e COCOMO II. Algumas ferramentas que implementam esses modelos também são apresentadas. 
O Capítulo 5 apresenta, detalhadamente, um modelo de processo de planejamento de projeto de software, procedimentos de implantação e execıção das atividades.

O Capítulo 6 apresenta um estudo de caso de aplicação do modelo proposto.

No Capítulo 7 - Conclusões e Trabalhos Futuros - são apresentadas as conclusões deste trabalho, bem como propostas para futuras pesquisas que podem ser desenvolvidas. 


\section{Capitulo \\ 2}

\section{Planejamento de Projeto de Software}

\subsection{Consideraçōes iniciais}

Neste capítulo são apresentados os conceitos gerais do processo de planejamento de projeto de software e uma ênfase maior é dada às principais atividades desse processo.

\subsection{Conceitos Fundamentais de Planejamento de Projeto de Software}

O gerenciamento efetivo de um projeto de software depende totalmente do seu planejamento. Planejar é decidir antecipadamente o que fazer, como fazer, quando e quem vai executar determinadas tarefas [Ghezzi et. al,, 1991]. Com o planejamento, construímos uma ponte na lacuna entre onde estamos e aonde desejamos chegar [Reifer, 1986].

O planejamento é um processo que começa nas etapas iniciais de um projeto, com a declaração do escopo do projeto, e prossegue com refinamentos ou iterações que objetivam a descoberta e atualização de informações até que o projeto seja concluído [Sommerville, 1996].

Segundo Humphrey [Humphrey, 1989], o processo de planejamento de projeto de software é um ciclo (Figura 2.1) que inicia com os requisitos funcionais iniciais do sistema $\mathrm{O}$ plano do projeto é produzido a partir da composição da estrutura de divisão de trabalho (Work Breakdown Structure - WBS), ou seja, a divisão do trabalho total do projeto em fases e atividades independentes. Em seguida, são elaboradas estimativas do sistema. A utilização de uma base de dados históricos é fundamental para o aumento da precisão das estimativas. Em seguida, os recursos humanos e materiais para a execução do projeto são identificados e alocados e um cronograma é elaborado. O cronograma é um documento que consolida várias informações elaboradas anteriormente e é utilizado como base para negociar compromissos e estabelecer metas. Depois de passar por uma etapa de revisão e aprovação, o plano é executado. À medida que o projeto avança e mais informações se tornam disponíveis para o gerente de projeto, o plano é atualizado. 


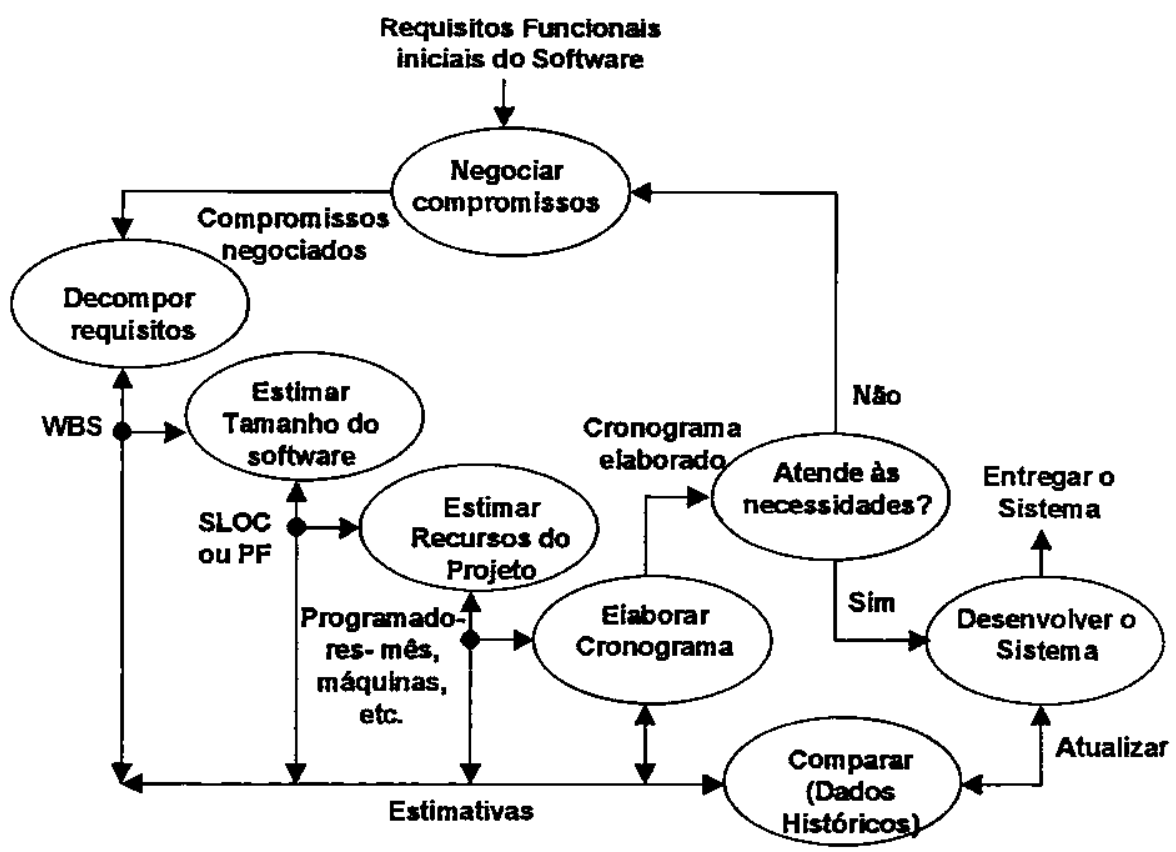

Figura 2.1 - O Cicio de Planejamento de Desenvolvimento de Software [Humphey, 1989]

De acordo com requisitos da KPA Planejamento de Projeto de Software do nível 2Repetível do CMM, é importante que o plano de projeto de software seja elaborado de acordo com um procedimento documentado [Paulk et. al., 1997]. Com esse objetivo, um modelo de processo de planejamento padrão foi elaborado e adotado pelo Space and Naval Warfare Systems Center, San Diego (Figura 2.2) [Groarke, 1997].

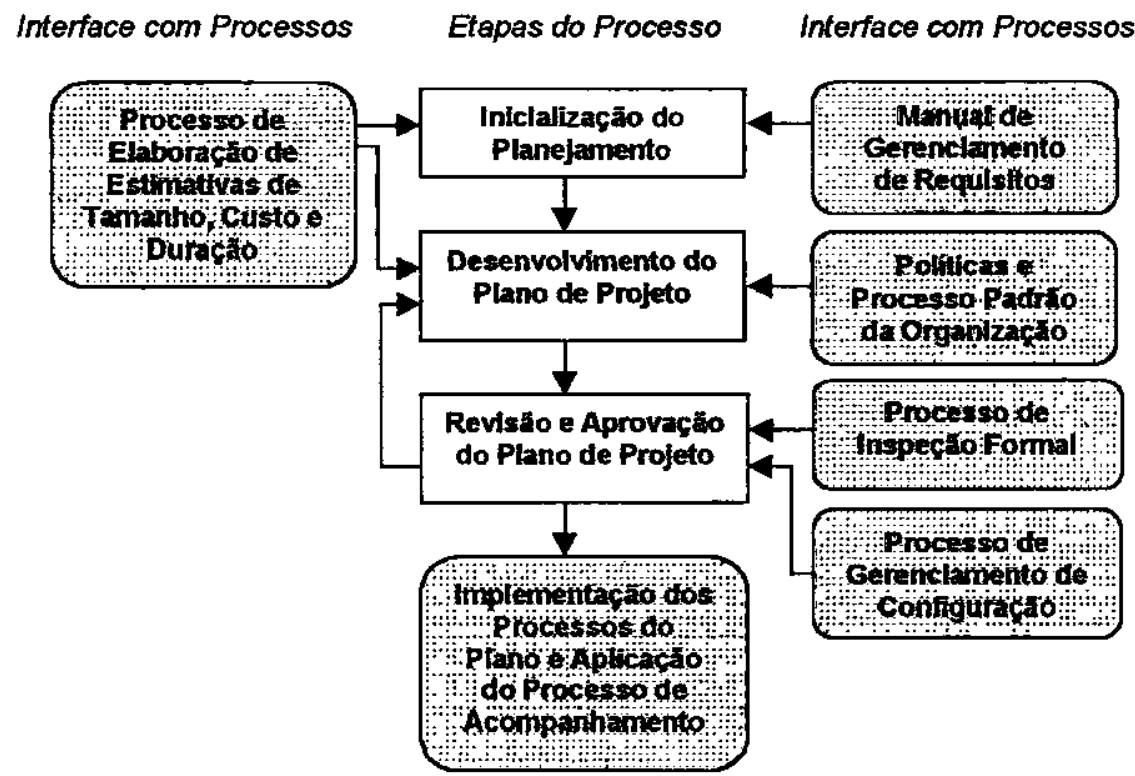

Figura 2.2 - Diagrama de Fluxo do Processo de Planejamento [Groarke, 1997]

Esse modelo de processo é estruturado em 3 etapas principais: Inicialização, Desenvolvimento e Revisão/Aprovação. 
Durante a execução do processo de planejamento, outros processos ocorrem em paralclo: o Processo de Estimativa, o Processo de Gerenciamento de Requisitos, o Processo de Inspeção Formal e o Processo de Gerenciamento de Configuração.

A primeira etapa do processo é a etapa de Inicialização. Nessa fase, um gerente é designado para o projeto e recursos são alocados ao planejamento (pessoas treinadas em técnicas de estimativas e planejamento, equipamentos, etc.). O Gerenciamento de Requisitos, executado paralelamente, é um processo importante nessa fase, visto que os requisitos funcionais do sistema constituem a maior força dirccionadora das atividades de planejamento. Sem requisitos bem definidos, é impossível saber o que planejar ou o que estimar. O ciclo de vida do projeto é definido c uma estrutura de divisão de trabalho é elaborada. O processo de elaboração de estimativas, executado paralelamente, fornece informações necessárias à essa etapa do processo: tamanho do sistema, esforço, tempo e custo de desenvolvimento, avaliação de riscos e cronograma estimado.

A etapa seguinte é o Desenvolvimento do Plano para o projeto. Estimativas de projeto são refinadas, recursos são identificados e alocados e o cronograma também é refinado. Um modelo padrão é utilizado como guia para elaboração do plano, que inclui itens como a estrutura de divisão de trabalho, as estimativas, riscos de projeto, recursos, cronograma, ambiente e metodologia de desenvolvimento, etc..

Na terceira etapa, o plano é submetido a um processo de Revisão e Aprovação. O processo de Inspeção Formal é utilizado para revisão do plano e inclui todos os grupos, envolvidos direta ou indiretamente com o projeto, sejam eles internos ou externos à organização. Depois de aprovado, o plano é incorporado como documento de configuração do software, através do processo de Gerenciamento de Configuração. O plano é então implementado c o processo de Acompanhamento é executado.

\subsection{Atividades Fundamentais de Planejamento de Projeto de Software}

O ciclo do processo de planejamento e o modelo de processo de planejamento sugerem um conjunto de atividades fundamentais: Elaboração da Estrutura de Divisão de Trabalho, Elaboração de Estimativas, Análise de Riscos, Elaboração de Cronograma, Elaboração do Plano e Aprovação. Essas atividades iniciam com a Identificação do Ciclo de Vida do Software. 


\subsubsection{Determinação do Ciclo de Vida}

De acordo com Juran, [Juran, 1993] o software é classificado como uma categoria de produto e, como tal, é o resultado de uin processo de desenvolvimento. Esse processo pode ser definido como um conjunto de atividades, métodos e práticas (numa sequiência predeterminada) utilizados na produção e evolução do software [Pressman, 1997]. O resultado desse processo é um produto (release) cujos atributos são derivados de requisitos e especificações que visam a satisfação das necessidades implícitas e explícilas dos clientes [Fernandes, 1995].

Um processo de software existe em qualquer empresa, independentemente de seu nível de organização. Os processos podem ser organizados de diversas formas, porém alguns são mais adequados do que outras para determinados tipos de aplicação. A cada uma dessas formas dá-se o nome de modelo de processo ou paradigma de ciclo de vida [Pressman, 1997].

A escolha do ciclo de vida de software, segundo os principais modelos de qualidade de processo de softivare, é um passo fundamental no planejamento do projeto. Um ciclo de vida apropriado ao projeto deve ser escolhido através de um processo de seleção, levando-se em consideração o escopo, a magnitude e a complexidade do projeto. O documento de entrada desse processo é o contrato ol acordo efetuado entre o desenvolvedor e o cliente, que identifica os objetivos do projeto em relação ao custo, cronograma e qualidade do softwarc. $O$ resultado do processo de seleção é a definição de um modelo de ciclo de vida que descreve as fases e atividades que serão executadas e também os métodos de controle do projeto (revisões técnicas, etc.). As atividades relacionadas à qualidade devem ser planejadas e implementadas de acordo com a natureza do modelo de ciclo de vida, independentemente do modelo adotado [SPICE 2, 1997].

Alguns modelos de ciclo de vida encontrados na literatura são: o Modelo Clássico, o Modelo Incremental, o Modelo Evolucionário, o Modelo de Prototipação e o Modelo Espiral.

O Ciclo de Vida Clássico, também conhecido como modelo Cascata, é o mais básico, mais antigo e mais utilizado paradigma da engenharia de software [Pressman, 1955]. Elaborado em função do ciclo da engenlaria convencional, esse modelo foi concebido no início dos anos setenta para melhorar o método indisciplinado de desenvolvimento e manutenção de software [Description, 1999]. 
O modelo Cascata é composto por seis fases seqüenciais, sendo que cada fase deve ser finalizada para que a próxima seja iniciada (Figura 2.3).

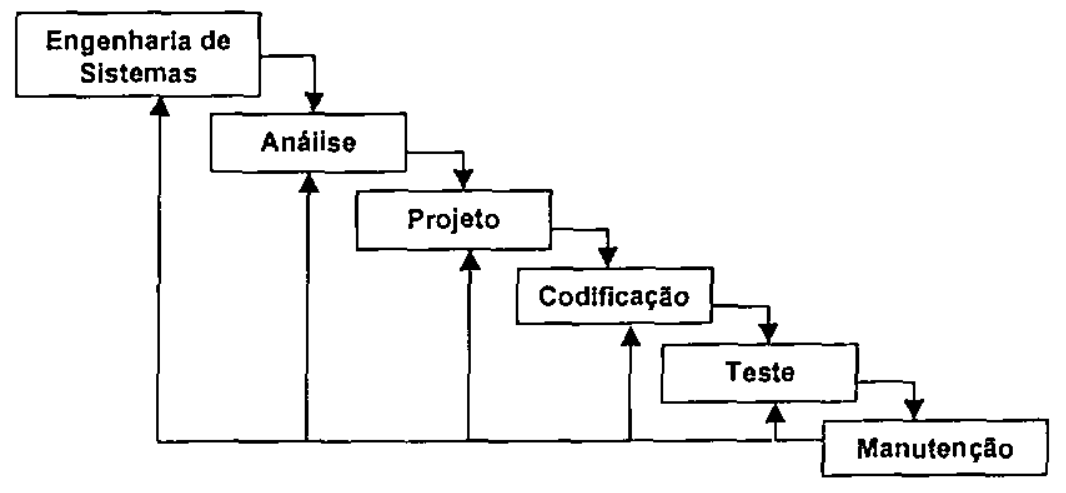

Figura 2.3 - Ciclo de Vida Clássico [Pressman, 1995]

A Etapa de Engenharia de Sistemas envolve a coleta dos requisitos funcionais em nível de sistema, com uma pequena parcela de projeto e análise de alto nivel. Na Análise de Requisitos, o analista de softwarc compreende o domínio da informação para o software, função, desempenho e interface exigidos. A etapa de Projeto focaliza-se na estrutura de dados, arquitetura do software, detalhes procedimentais e caracterização da interface. Durante a etapa de Codificação, o projeto é traduzido para uma linguagem de programação. A etapa de Teste concentra-se nos aspectos lógicos internos do software, garantindo que todas as instruções tenham sido testadas; concentra-se também nos aspectos funcionais externos, realizando testes para descobrir erros e garantir que a entrada definida produza resultados reais condizentes aos resultados exigidos. $\mathrm{Na}$ fase de Manutenção, reaplicam-se cada uma das etapas precedentes do ciclo de vida a um programa existente.

O modelo Cascata proporciona uma estrutura básica para desenvolvimento de software disciplinado, adequada ao desenvolvimento de pequenos projetos e projetos de manutenção de software, porém sua estrutura rígida não se apresenta adequada a todas as classes de projeto, o que fez com que novos modelos fossem propostos.

O Ciclo de Vida Incremental (Figura 2.4) é um modelo de desenvolvimento de projetos baseado na idéia de divisão do sistema em múltiplos incrementos e construção de múltiplas versões do sistema, uma de cada vez. A fase de planejamento e análise de requisitos é efetuada apenas uma vez e as fases de projeto, codificação e teste são repetidas para cada nova versão. A primeira vcrsão do sistema implementa um subconjunto das funções planejadas; a segunda versão agrega outro subconjunto de funções planejadas e assim por diante, até que todos os incrementos incorporem o sistema completo. 


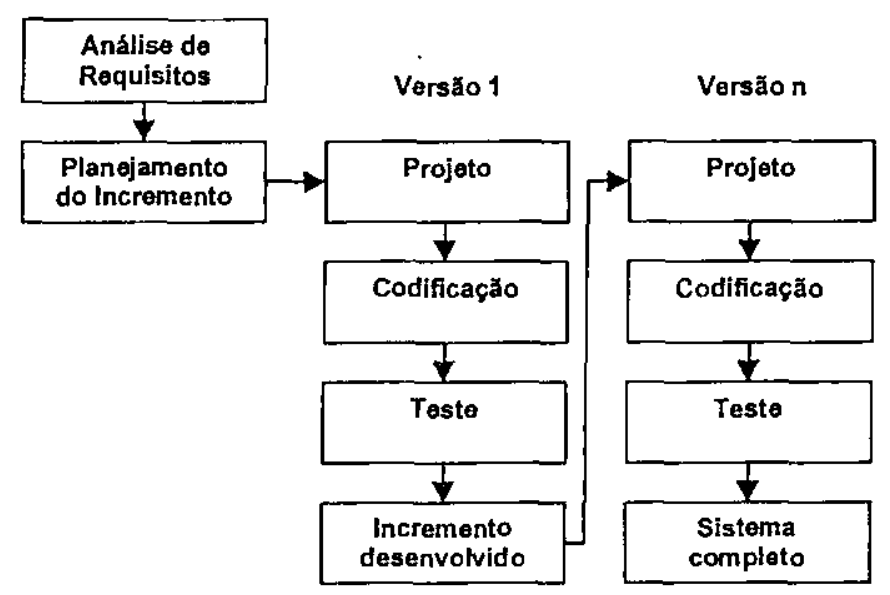

Figura 2.4 - Ciclo de Vida Incremental [Description, 1999]

A vantagem do desenvolvimento Iscremental em relação ao modelo Cascata é o uso de múltiplos ciclos de desenvolvimento. Essa abordagem facilita o gerenciamento de grandes projetos, pois os incrementos são mais fáceis de administrar individualmente do que o sistema como um todo [Description, 1999]. A principal desvantagem do modo Incremental é a grande dependência de requisitos funcionais completamente definidos e compreendidos logo no início do projeto.

Esse modèlo de desenvolvimento não leva em consideração a mudança dos requisitos funcionais por parte do cliente. Ao escolher o ciclo de desenvolvimento Incremental, o gerente de projeto deve trabalhar com o cliente ou patrocinador do projeto para determinar o número de increinentos, o tamanho e o cronograma para o sistema completo.

O Ciclo de Vida Evolucionário (Figura 2.5) também é utilizado para desenvolver um sistema em blocos, porém, diferentemente do modo de desenvolvimento Incremental, os requisitos fincionais não são especificados detalhadamente pelo cliente/usuárjo no início do projeto e, consequentemente, a fase de análise de requisitos é repetida mais de uma vez.

Nesse modo de desenvolvimento, o primeiro incremento é uma versão operacional que implementa um conjunto inicial de requisitos funcionais do sistema. Baseando-se no feedback do isuário, o projeto é retomado. As fases de análise de requisitos, projeto, codificação e teste são repetidas, resultando em uma segunda versão mais cvoluída, desenvolvida para atender aos requisitos do usuário, dessa vez um pouco mais claros e definidos. Esse processo continua até que os requisitos funcionais do sistema estejam completamente especificados e compreendidos e o produto final seja desenvolvido. 


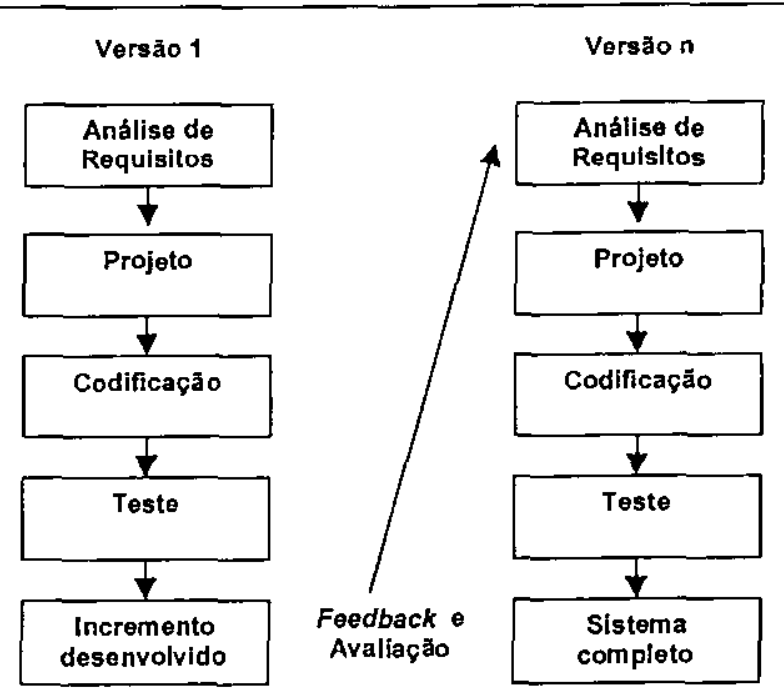

Figura 2.5 - Ciclo de Vida Evolucionário [Description, 1999]

O modo de desenvolvimento Evolucionário é adequado a situações onde, embora a natureza do sistema scja conhecida, os detalhes e os requisitos funcionais do sistema são dificeis de screm conhecidos, definidos ou caracterizados. Uma das desvantagens desse modelo é que o usuário/cliente pode aceitar prematuramente uma das versões intermediárias como a versão final do sistema. Além disso, pode ocorrer o aumento excessivo de requisitos funcionais, ocasionando atraso no cronograma ou aumento dos custos de desenvolvimento.

O desenvolvimento de software de forma cvolutiva requer um cuidado especial na manipulação de documentos, programas e dados de teste gerados em cada nova versão. A cada desenvolvimento, a documentação deve ser facilmente recuperável e as mudanças devem ser feitas controladamente. O gerente de projeto deve acompanhar de perto a evolução do sistema, antecipar problemas com os requisitos que possam comprometer o projeto e trabalhar em conjunto com o cliente ou com o patrocinador do projeto para determinar o número de incrementos, tamanho e cronograma de desenvolvimento que levará à implementação do sistema completo [Description, 1999].

O Modelo de Prototipação (Figura 2.6) é uma estratégia de desenvolvimento que utiliza os requisitos iniciais do cliente para construir rapidamente um protótipo do sistema desejado. Um modelo do sistema, usualmente implementado em software, é desenvolvido para executar parte ou toda a função desejada para ser avaliado pelos usuários/clientes e desenvolvedores, porém ainda possui características que serão melhoradas em uma outra etapa de desenvolvimento. Cada versão posterior do software tem a probabilidade de ser mais eficiente e completa. No final, o protótipo é descartado e o software real é projetado [Pressman, 1997]. 


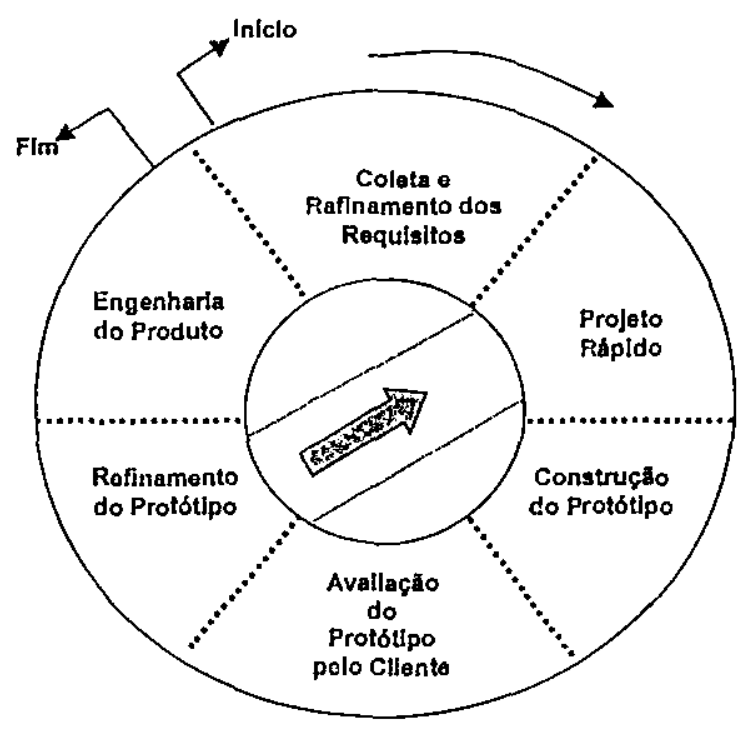

Figura 2.6 - Modo de Desenvolvimento Prototipado [Pressman، 1995]

O modelo Prototipação pode ser combinado com qualquer estratégia de descrnvolvimento; pode ser usado na fase de Análise de Requisitos, combinado com o modclo Cascata e é altamente recomendável na abordagem de desenvolvimento evolucionária [Description, 1999].

Muitos usụários e clientes consideram mais fácil prover feedback de informações manipulando um protótipo do que ler um documento de especificação de requisitos, potencialmonte ambíguo e extenso. O cliente é estimulado a definir os detalhes do sistema, quando os requisitos funcionais ainda não estão claramente definidos. Ao mostrar alternativas para a solução do problema ao cliente, tempo e recursos podem ser poupados. Protótipos podem ser ferramentas valiosas nas atividades de análise de riscos para definir e verificar requisilos de sistema.

A desvantagem é que muita ênfase pode ser dada na construção do protótipo e pouca no levantamento dos requisitos, o que pode impedir a pesquisa de soluções alternativas e como consequiência, a qualidade do sistema pode diminuir. Há também o risco do protótipo ser decretado "operacional" antes que o ciclo de desenvolvimento formal seja cumprido e a documentação adequada seja feita. A documentação incompleta pode clevar os custos de manutenção.

O Modelo Espiral é um processo iterativo de desenvolvimento de software que combina as características do ciclo de vida clássico e do paradigma de prototipação com o acréscimo da atividade de análise de riscos. 
O modelo Espiral é utilizado para minimizar os riscos do projeto, através da identificação de incertezas do próximo estágio e uso protótipos para levantamento de informações. Esse modelo é adequado ao desenvolvimento de sistemas em grande escala, onde versões progressivamente mais completas do software são construídas de acordo com as seguintes etapas: (1) o problema $\mathrm{e}$ as possiveis soluções são investigados; (2) as soluções são avaliadas e os riscos identificados; (3) os riscos são resolvidos através de expcrimentações com o protótipo; (4) o produto é desenvolvido e testado; (5) a próxima atividade é planejada, incluindo possíveis partições de esforços pessoais ou da função do software; (6) os resultados são revisados e os planos para a próxima iteração são confirmados.

Como apresentados anteriormente, modelos de ciclo de vida de software são basicamente macro modelos de processo, onde as fases e as atividades de desenvolvimento são descritas, constituindo um framework para o gerente administrar o desenvolvimento do projeto. A partir da definição de um modelo de ciclo de vida adequado ao projeto, custos e recursos para as diversas fases são estimados e pontos de controle são definidos para que 0 avanço do projeto possa ser monitorado [Fernandes, 1995].

De acordo com Fernandes [Fernandes, 1995], toda empresa de software, grande ou pequena, deve possuir un ciclo de vida para o desenvolvimento do produto, visto que padronizar o processo de desenvolvimento de software traz beneficios do ponto de vista da gestão do ambiente de desenvolvimento: possibilita a constituição de uma base para 0 planejamento e gestão de projetos; possibilita a redução de problemas de treinamento; etc..

Segundo Humphrey [Humphrey, 1989], apesar da adequação de projetos em macroprocessos semelhantes, freqüentemente, a adoção de novas tecnologias de hardware, métodos e abordagens de desenvolvimento, ambiente orientado a eventos e a finalidade do software, podem requer um conjunto de atividades diferenciadas. Isso significa que 0 detalhamento do macroprocesso torna-se específico conforme a combinação destes fatores.

Para atender as necessidades conflitantes de padronização e "customização" de processos de desenvolvimento, pode-se definir uma arquitetura de processo. A arquitetura do processo de software é o arcabouço dentro do qual o processo de software de um projeto específico é definido. Um conjunto de unidades (etapas do processo) é definido pela organização e, conforme as características do projeto, a "customização" pode ser obtida com a seleção ou inclusão de etapas especificas. 
Em muitos ambientes de desenvolvimento de software, os paradigmas da engenharia de software são combinados durante o desenvolvinıento de software. O conjunto de etapas que compõem um modelo de ciclo de vida pode ser escolhido tendo-se como base a natureza do projeto e da aplicação, os métodos e as ferramentas a serenı usados, os controles e os produtos que precisam ser entregues [Pressman, 1995].

O importante é que haja uma seqüĉncia predeterminada de atividades relacionadas entre si, para guiar os desenvolvedores na produção e evolução do software. Quanto maior o nível de detalhamento da arquitctura do processo e do processo em si, maior é a possibilidade de aperfeiçoar a maneira como o trabaho é feito e de antecipar problemas e visualizar alternativas para prevenção ou minimização [Fernandes, 1995].

\subsubsection{Elaboração da Estrutura de Divisão de Trabalho}

As fases definidas no modelo de ciclo de vida são agnupamentos de atividades genéricas grandes e complexas. Para o planejamento do projeto, essas atividades devem ser "quebradas" ou divididas em atividarles menores, de forma que se possam identificar tarefas básicas e então estimar e atribuir pessoas para execução. Essa técnica é conhecida como estrutura de divisão de lrabalho'.

A estrutura de divisão de trabalho é uma ferramenta de gerenciamento do escopo do projeto $^{2}$, representando também um guia para cálculo de custos. Uma boa estrutura e, principalmente, sua coerência com o processo de desenvolvimento, é fator crítico para o sucesso do projeto, pois na rede de tarcfas que a compõem pode-se identificar desde uma simples lista de verificação das atividades por realizar até a seqüência temporal e lógica de desenvolvimento [Mello, 1999].

Segundo Humphrey [Humphrey, 1989], quanto mais detalhada a estrutura de divisão de trabalho, as estimativas são mais precisas, o plano é melhor e o projeto pode ser acompanhado mais precisanente. $O$ detalhamento da estrutura pode ser realizado até que seja obtida uma unidade de trabalho cujo tamanho seja suficiente para permitir total compreensão da unidade.

l'Também é conhecido Work Breakclown Structure - WBS, estrutura analítica do projeto ou ainda como plano estruturado do projeto (PEP) [Vargas, 2000].

2 o escopo de um projeto é definido como o trabalho que precisa ser desenvolvido para garanlir a entrega de um determinado produto dentro de todas as suas especificaçōes e funções [Vargas, 2000] 
Cada unidade pode então ser estimada e planejada individualmente [Ghezzi et. al., 1991]. Usualmente, o último nivel de detalhes é o pacote de trabalho ${ }^{3}$ (Figura 2.7).

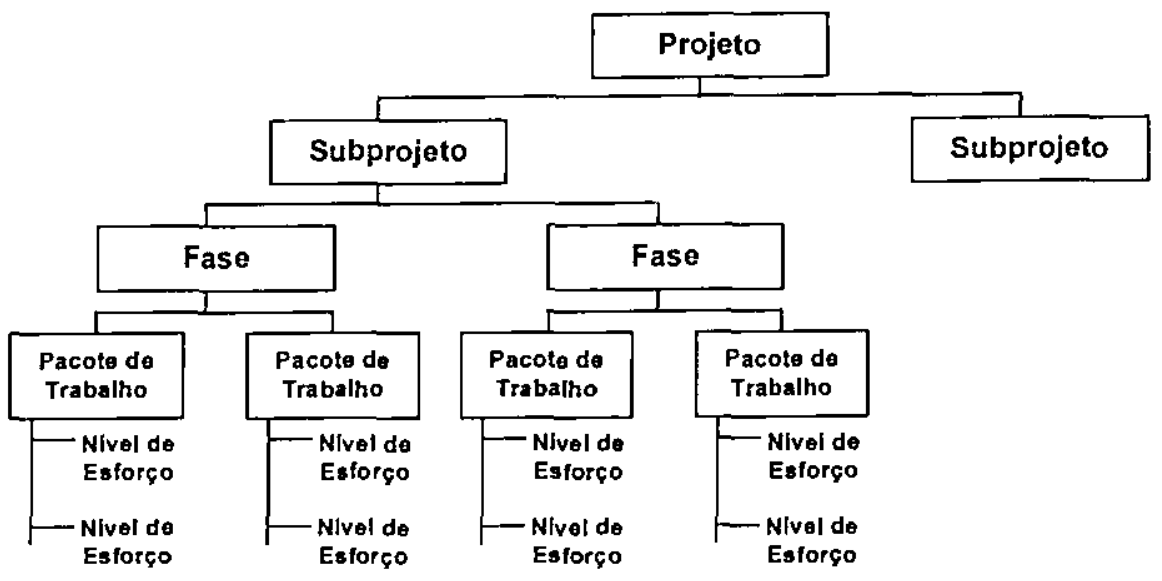

Figura 2.7 - Estrutura de Divisão de Trabalho (WBS) [Vargas, 2000]

A forma de estruturação das atividades partindo-se de grandes etapas ou fases de projeto é conhecida como técnica Top-to-Bottom ou decomposição. De acordo com essa técnica, a estrutura de divisão de trabalho deve ser criada de cima para baixo, partindo-se das grandes fases do projcto. As etapas de construção da estrutura são:

1. Identificam-se as grandes fases do projeto;

2. Para cada fase identificada, detalham-se as entregas desejadas;

3. Para cada entrega, detalha-se o pacote de trabalho necessário para a sua conclusão;

4. Se necessário, para cada pacote de traballho, detalha-se o nível de esforço definido para a conclusão do respectivo pacote;

5. Agregam-se os conjuntos.

Em um projeto de software, a estrutura de divisão de trabalho em atividades tem como objetivo principal identificar as atividades incluidas nas etapas do modelo de ciclo de vida adotado e as atividades não diretamente relacionadas ao desenvolvimento (viagens, por exemplo).

A estrutura de divisão de trabalho em atividades também pode ser apresentada na forma de itens de trabalho, estruturados hierarquicamente (Figura 2.8).

${ }^{3}$ Pacote de trabalho é o produto a ser entregue no mais baixo nivel da estrutura de divisão em atividades e pode ser repartido em atividades menores. As entregas são todos os produtos intermediários, obtidos ao longo do 


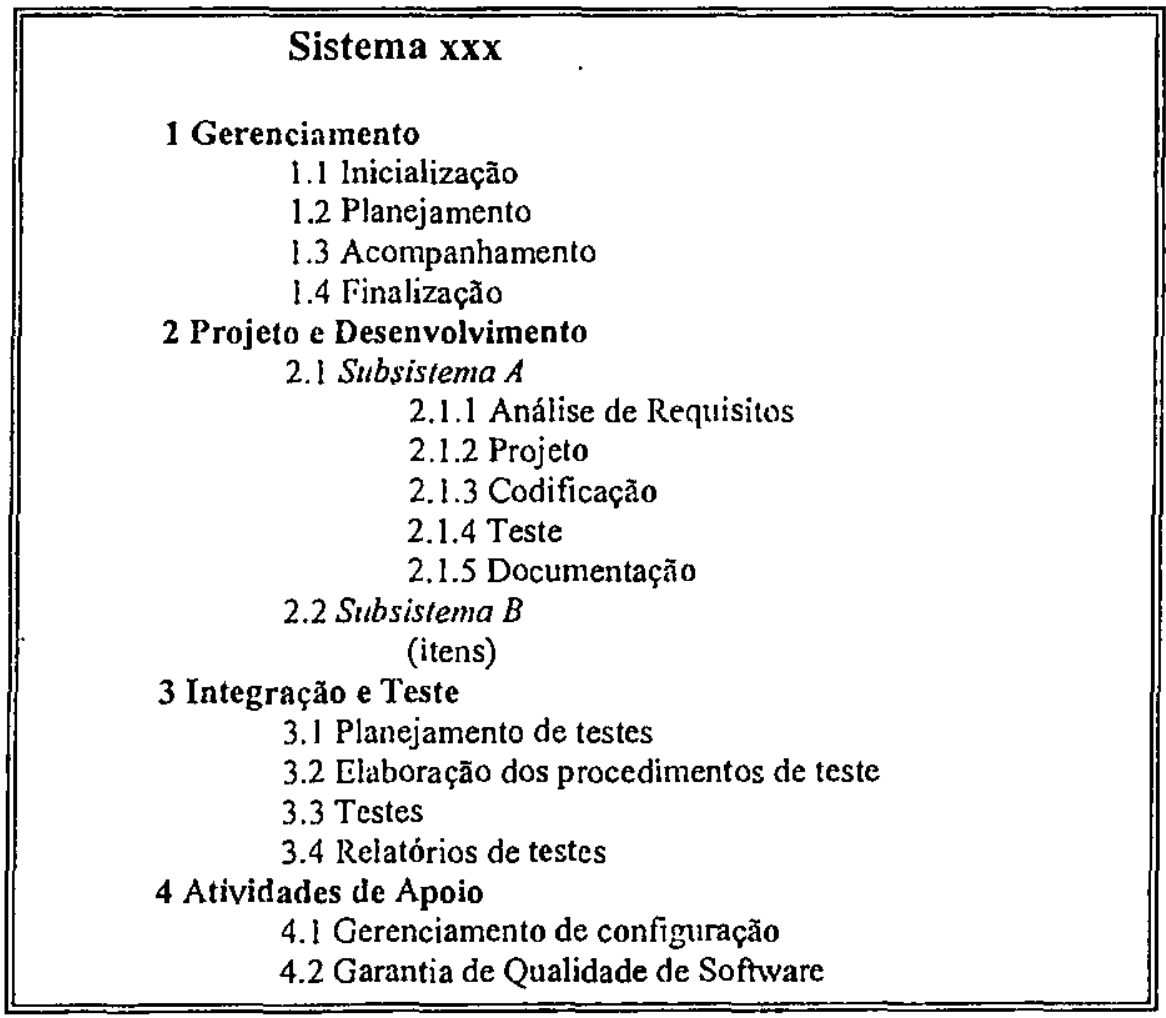

Figura 2.8 - Exemplo de Apresentação de Estrutura de Divisão de Trabalho

Após a definição da estrutura de divisão de trabalho, todos os pacotes identificados são subdivididos em atividades, que podem ocorrer seqüencialmente ou simultaneamente. Três categorias de atividades podem surgir:

- Atividades executivas. São atividades relacionadas diretamente com a ação dentro do projeto. Exemplos: preparar o plano do projeto, revisar o plano.

- Marcos (Milestones). O marco representa um evento, ou condição, que identifica a executção de um grupo de atividades relacionadas entre si, ou o término de uma fase de projeto. Servem também para identificar as entregas dos pacotes de trabalho. Exemplos: teste do produto realizado, conclusão do manual do usuário.

- Atividades resumo. São atividades que englobam outras atividades, denominadas subatividades. Elas representam um conjunto de atividades, totalizando duração, datas e custo das atividades a elas pertencentes e podem também ser denominadas pacotes de trabalho. Exemplos: fase de planejamento, codificação. 
Um projeto também pode ser dividido de acordo com as funções do sistema que será desenvolvido (divisão funcional) [Humphrey, 1989]. A Estrutura de Divisão Funcional do sistema apresenta como os vários componentes do software estão organizados para compor o sistema que será desenvolvido. Em grandes projetos, um sistema é normalmente estruturado em forma hierárquica, constituida de vários niveis intermediários e cada hierarquia de subsistema pode conter outras unidades, na forma de sistemas, subsistemas, produtos, componentes, módulos, etc.

Depois de identificadas as fases e tarefas, as estimativas de esforço e tempo necessárias ao desenvolvimento do projeto são elaboradas.

\subsubsection{Elaboração de Estimativas de Projeto}

Estimativas de tamanho do sistema, esforço, tempo e custo de desenvolvimento devem ser elaboradas para todas as fases do ciclo de vida e demais atividades do projeto. Estimativas são necessárias para que um projeto possa ser planejado e conduzido com sucesso, constituindo o principal desafio para o gerente de projeto.

As estimativas são elaboradas dentro de um plano de tempo limitado ao início de um projeto de software e também devem ser regularmente atualizadas à medida que o projeto progride. É importante que as estimativas para o projeto sejam derivadas de acordo com um procedimento definido e documentado e que gerentes, engenheiros de software e outros profissionais envolvidos no planejamento do projeto sejam treinados em estimar software e procedimentos de planejamento [Paulk et. al., 1992].

Devido à sua complexidade, o processo para elaboração de cstimativas, métodos e técnicas utilizados são conceituados e detalhados no capítulo 3 .

\subsubsection{Elaboração do Cronograma do Projeto}

A elaboração do cronograma do projeto inicia com a identificação e seleção de recursos e profissionais para o projeto. Recursos humanos e materiais são identificados e selecionados, de modo que estejam disponiveis para a execução das atividades presentes na estrutura de divisão de trabalho. Essa atividade é a base de todo o cálculo de orçamentos e custos do projeto, usualmente executada em paralelo com a elaboração de estimativas [Vargas, 2000]. 
A definição desses recursos é importante para a negociação de custo e prazo do projeto com o cliente, para decidir pela execução ou não do projeto e para evitar que um mesmo recurso (salas, equipamentos, ctc.) sejam alocados em mais de um projeto ao mesmo tempo, alén de identificar a necessidade de aquisição de algum deles [Vaz, 2000].

Os recursos podem ser subdivididos em três categorias: mão-de-obra (profissionais), materiais (papel, etc.), e equipamentos (computadores, ferramentas de software, etc.). É importante destacar que a etapa de codificação é apenas uma pequena parte do esforço total do projeto. A força de trabalho necessária deve incluir as atividades (programação, documcntação, construção de protótipos, teste, garantia de qualidade, etc.) necessárias para que o software possa ser entregue no prazo, dentro do orçamento previsto e com todas as funções especificadas [Standish, 1999].

Depois de identificados, os recursos que serão empregados no projeto são atribuídos a cada atividade do projeto. A elaboração de cronograma de projeto é uma atividade cujo objetivo é atribuir tempo de exccução necessário a cada uma das atividades identificadas na estrutura de divisão de trabalho [Sommerville, 1996]. Nessa atividade são determinadas as datas de inicio e término das atividades e, consequentemente, as datas de início e término do projeto.

A elaborasão de cronograma inicia com a associação e o estabelecimento de precedências entre atividades da estrutura de divisão de trabalho. Em seguida, o período de tempo necessário para realizar cada atividade do projeto é estimado. A estrutura de divisão de trabalho e as estimativas de esforço e tempo são os principais elementos de entrada para esse processo.

Uma atividade que deve iniciar ou finalizar para que outra possa começar é chamada predecessora. A atividade que depende do início ou do final de outra atividade é chamada sucessora. As atividades podem ser inter-relacionadas de várias formas. As mais comuns são: término para o inicio - a atividade sucessora somente se inicia com o término da atividade predecessora; início para início - a atividade sucessora somente se inicia com o início da atividade predecessora; término para término - a atividade sucessora somente tcrmina com o final da atividade predecessora; e inicio para térnino - ocorre quando o fim de uma atividade depende do início de uma atividade anterior. 
Atrasos e adiantamentos podem ocorrer nos inter-relacionamentos de atividades, podendo interferir na duração de tempo de execução de atividades e da duração global do projeto. A succssão de atividades inter-relacionadas compðe uma rede de atividades, que por sua vez pode ser melhor desenvolvida c controlada o auxílio da técnica PERT - Program Evaluation and Review Techinique. Essa técnica de representação gráfica de cronograma evidencia as ligações entre as atividades do projeto e seus tempos de execução associados. Cada nó representa uma atividade e sua duração em um período de tempo expresso em dias, mescs, etc.. As ligações entre os nós representam a precedência entre as atividades: se houver uma ligação do nó $A$ para o nó $B$, significa que a atividade $A$ deve ser completada antes que a atividade $B$ seja iniciada.

A Figura 2.9 apresenta um gráfico PERT para um conjunto de atividades de desenvolvimento de projeto de software, mostrando, por exemplo, que a atividades de teste de dados possui a duração de 2 meses.

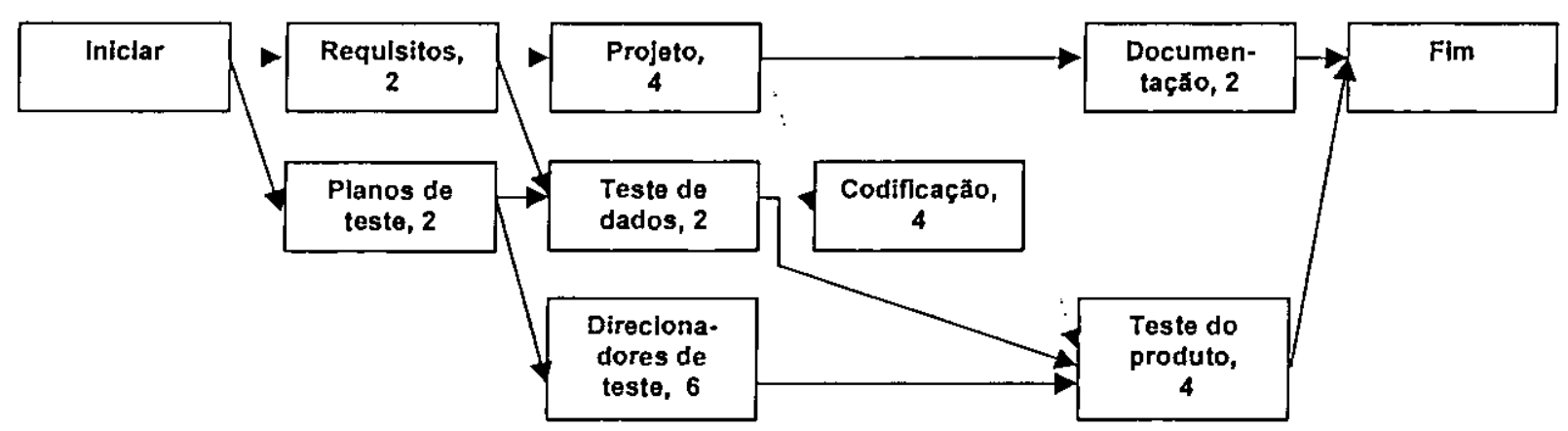

Figura 2.9 - Gráfico PERT de um Projeto de Software Simples [Boehm, 1981]

A distribuição de tempo em um gráfico PERT pode ser definida com o auxílio da técnica de Análise de PERT (What-if Analysis). Essa técnica possibilita uma precisão muito maior para elaboração de estimativas de durações de atividades [Vargas, 2000]. A técnica pressupõe uma distribuição que considera três valores: uma estimativa de tempo otimista (a); uma estimativa de tempo mais provável (m), e uma estimativa de tempo pessimista (b). Esse cálculo é obtido com a equação 2.1 [Acosta, 2000].

$$
\begin{aligned}
& T_{e}(Z)=\frac{a+4 m+b}{6} \\
& \sigma(Z)=\frac{b-a}{6}
\end{aligned}
$$


As equações de estimativa de tempo de execução $\left(T_{e}\right)$ para a atividade $(Z)$, e o desvio padrão $(\sigma)$, são utilizadas para o cálculo da estimativa de tempo provável (T) estará entre a estimativa otimista $(T-\sigma)$ e a estimativa pessimista $(T+\sigma)$. Por exemplo, para uma determinada atividade $F$, as estimativas de tempo de execução são: $a=3, m=4$ e b $=5$ meses. $O$ valor resultante é: $T(F)=4$ e desvio padião $\sigma(Z)=0.33$. Isso significa que a estimativa de tempo varia de $3,67(4-0,33)$ e $4,33(4+0,33)$.

Depois de elaborado o gráfico PERT, duas questões importantes devem ser respondidas: Qual é o tempo mínimo necessário para terminar o projeto? Quais atividades são críticas para que o projeto seja completado no menor tempo possivel?

Para determinar o tempo mínimo necessário para terminar o projeto, devem-se identificar as atividades críticas que estão estabelecidas em um determinado caminho, percorrido entrc o nó inicial e o nó final. Esse caminho, chamado caminho crítico, é o trajeto mais longo percorrido na rede, em termos de duração das atividades. O cronograma global do projeto depende dessc trajeto, pois o atraso em qualquer uma das atividades que constituem o caminho crítico provoca atraso no prazo final estabelecido.

A técnica para determinação do caminho crítico é conhecida como CPM - Critical Path Method. Esse mćtodo é um processo administrativo de planejamento, programação, execuçĩo c controle das atividades do projeto que devem ser desenvolvidas dentro de restrições de tempo e custo [Acosta, 2000]. A análise do caminho crítico auxilia o gerente a tomar decisões caso haja variações nas atividades que fazem parte do trajeto.

O gráfico de Gantt é uma forma alternativa de representação de cronograma de projeto (Figura 2.10). Essa técnica gráfica, utilizada para planejar, monitorar e coordenar projetos, é basicamentc uma grade que relaciona atividades e prazos finais. $O$ diagrama utiliza barras horizontais, colocadas dentro de uma escala de tempo. O tamanho das barras é proporcional à duração de tempo planejada para as respectivas atividades.

\begin{tabular}{|c|c|c|c|c|c|c|c|c|c|c|c|c|c|c|c|c|}
\hline \multirow[b]{2}{*}{ Ativldade } & \multirow[b]{2}{*}{ Resp. } & \multicolumn{12}{|c|}{1984} & \multicolumn{3}{|c|}{1985} \\
\hline & & $\mathrm{J}$ & $F$ & $M$ & $A$ & $M$ & $\mathrm{~J}$ & 了 & A & $\mathrm{s}$ & 0 & $N$ & $D$ & J & $F$ & $\bar{M}$ \\
\hline Requisitos & ES & & & & & & & & & & & & & & & \\
\hline Planejamento de Tesles & $w$ & & 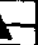 & 7 & & & & & & & & & & & & \\
\hline Projeto & ES & & & 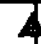 & & & -1 & -4 & & & & & & & & \\
\hline Codificaçăa & PR & & & & & & & & 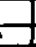 & & & & 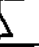 & & & \\
\hline Teste de dados & $w$ & & & & & & & & & & & 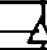 & 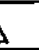 & & & \\
\hline Teste do Produto & $w$ & & & & & & & & & & & & 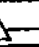 & & & \\
\hline Documentação & ES & & & & & & & & & & & & & 1 & & \\
\hline
\end{tabular}

Figura 2.10 - Gráfico de Gantt para um Plano de Projelo de Software [Boehm, 1981] 
Boehm [Boehm, 1981] comparou as duas abordagens para desenvolvimento de cronograma: PERT e Gantt. Scgundo ele, ao utilizar o gráftco PERT os planejadores são estimulados a pensar na dependência das relações entre as tarefas e também na duração de tempo de cada uma. Por outro lado, o uso do gráfico de Gantt traz algumas vantagens adicionais: é mais facilmente descnvolvido e mais fácil de ser atualizado. Contudo, é prefcrivel utilizar o gráfico de Gantt em situações de desenvolvimento de cronogramas simplcs, quando as dependências entre tarefas forem intuitivamente claras e, nas partes do projeto onde cxistirem relações de dependência complexas, o gráfico PERT é mais adequado.

\subsubsection{Análise dos Riscos}

Estimativas não são dados de uma ciência exata. Requisitos funcionais incertos ou mal compreendidos constituem riscos de projeto, pois podem fazer com que as estimativas mudem. Além disso, muitas variáveis (humanas, técnicas, políticas, ambientats) podem afetar o custo final do software e o esforço aplicado no seu desenvolvimento e constituem elementos de risco ao projeto [Software, 1996].

A possibilidade de ocorrência de algo que possa comprometer, de alguma forma, o esforço de desenvolvimento, constitui um risco de projeto. Ao planejar, o gerente deve analisar os riscos de projeto e antecipar problemas que possam surgir, para, previamente, preparar soluções altcrnativas caso esscs problemas se concretizem [Sommerville, 1996].

O Project Management Institute, $\mathrm{cm}$ seu Universo de Conhecimento de Gerenciamento de Projeto - PMBOK (Project Management Body of Knowledge) [PMBOK, 1996], trata de nove áreas de conhecimento de gerenciamento; o Gerenciamento de Risco é uma delas. O PMBOK define quatro processos para o Gerenciamento de Riscos de Projetos: identificação do risco, quantificação, desenvolvimento da resposta e controle das respostas.

A identificação do risco consiste em determinar quais riscos são relevantes e podem afetar o projeto, além de documentar suas características. A identificação ocorre ao longo de todo o projeto e verifica riscos internos e externos. Uma lista de verificação de riscos possiveis é uma boa orientação para o gerente de projetos iniciar essa tarefa, considerando-se também que nem todos os riscos são conhecidos.

De acordo com Pressman [Pressinan, 1997], em nível macroscópico, os riscos podem ser agrupados em três categorias: riscos de projeto, riscos técnicos e riscos de negócio. 
Os riscos de projeto são constituídos por problemas orçamentários, riscos de cronograma, riscos de pessoal (composição de equipe e organização), riscos de recursos, riscos de clientes, riscos de requisitos e o impacto dos mesmos sobre o projeto. A complexidade, o tamanho e a estrutura do projeto também são identificados como fatores de risco. Os riscos técnicos são constituídos por problemas potenciais de implementação, interface, verificação e manutenção. Os riscos de negócio são constituídos por eventuais problemas com o mercado, estratégias mal sucedidas e dificuldades organizacionais. A fraca aceilação do produto pelo mercado ou a perda do comprometimento c apoio da alta administração são exemplos de riscos de negócio que podem ocorrer. Uma lista detalhada de verificação é apresentada no Apêndice $\mathbf{x}$.

$\Lambda$ quantificação dos riscos é uma etapa que envolve uma avaliação do risco e sua interação com os resultados do projeto. A cada situação de risco podem ser analisados os valores pertinentes ao projeto, levando-se em conta as probabilidades de que o risco ocorra e do que pude representar en termos de alteração de custos e de prazos.

Algumas técnicas matennáticas de simulação podem ser usadas, como a Análise de Monte Carlo $^{4}$, cálculos estatísticos e árvores de decisão. Os números apresentados por essas técnicas são apenas indicadores, de forma que a análise de um especialista é fundamental para uma correta interpretação e entendimento dos riscos e suas conseqüências [Krause, 1999].

Na etapa de desenvolvimento da resposta ao risco, os devidos tratamentos são dados às ações para minimizar os efeitos dos riscos negativos ${ }^{5}$ e para aproveitar melhor os riscos positivos.

O controle das respostas ao risco é a fase de acompanhamento dos resultados. Sempre que um risco se tornar fato real, o controle provê informações ao processo.

O gerenciamento de risco está em fase de incorporação ao modelo CMM [Risk, 1997]. A abordagem da SEI com relação ao gerenciamento de risco é baseada no paradigma de gerenciamento de risco, que é, em essência, um framework para a administração de riscos dc software (Figura 2.11).

4 A Análise de Monte Carlo é uma técnica de risco em cronograma, que executa a simulação do projeto calculando a distribuição provável dos resultados [Vargas, 2000].

5 Os riscos poden ser negativos, como por exemplo, um aumento dos custos, ou positivos, como atraso de cronograma que propiciou a chegada de uma nova tecnologia mais eficiente e barala [Krause, 1999]. 


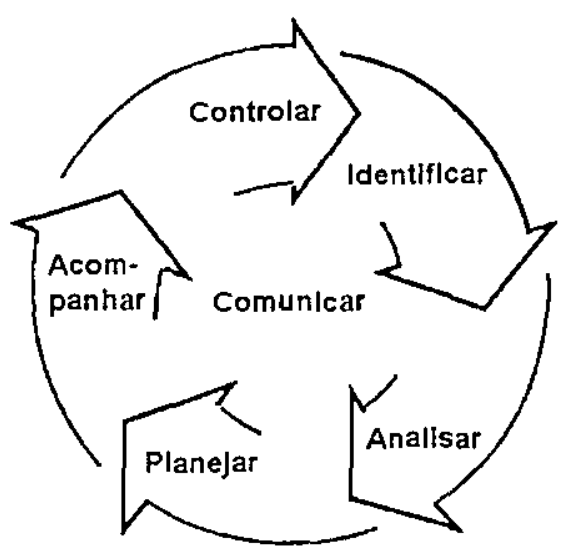

Figura 2.11 - Paradigma de Gerenciamento de Risco da SEl [Higuera, 1996]

O paradigma é representado por um círculo, para enfatizar que a administração de risco é um processo contínuo; as setas mostram o fluxo lógico de informação entre as atividades, que se inicia com a atividade de identificação. A Comunicação é situada no centro do paradignı porque é o canal de transmissão do fluxo de informação e, freqüentemente, é o maior obstáculo para a administração. [Higuera, 1996]. Um resumo breve de cada atividade do paradigma de administração de risco é descrito abaixo.

- Identificação. Antes que possam ser administrados, os riscos devem ser identificados. O Software Engineering Institute desenvolveu técnicas para identificação de riscos pela aplicação de um processo sistemático que encoraja o pessoal do projeto a expor preocupações e questões relativas a riscos. O método proposto é o $S R E$ - Software Risk Evaluation Practice.

- Análise. Etapa de conversão de dados de riscos em informações de riscos. A análise provê a base para o gerente de projeto trabalhar no risco "certo" e na maior parte dos riscos críticos.

- Planejamento. A fase de planejamento transforma as informações de riscos em decisões e ações. Ações são elaboradas para atacar os riscos individuais, priorizando ações de maior risco e criando um plano de gerenciamento de risco integrado.

- Acompanhamento. Essa fase consiste em monitorar o estado dos riscos e das ações realizadas para amenizá-los. Métricas de risco adequadas são identificadas e monitoradas para possibilitar avaliação do estado dos riscos e do plano de mitigação de riscos. 
- Controle. O controle de riscos corrige divergências de ações planejadas. Variações de planos são corrigidas c eventos são controlados. O gerenciamento do risco é melhorado.

u Comunicação. Para serem analisados e administrados corretamente, os riscos devem ser comunicados entre os níveis organizacionais apropriados. Scm comunicação efetiva, nenhuma administração de risco pode ser viável.

É importante observar que os passos de administração dos riscos acarretanı custos adicionais ao projeto. As atividades de identificação, avaliação c administração de risco tomam tempo e podem absorver uma significativa quantidade de esforço de planejamento [Pressman, 1997].

\subsubsection{Elaboração do Plano do Projeto}

O plano do projeto é um documento que registra o ciclo de vida adotado, a estrutura dc divisão de trabalho em atividades, as estinuativas, os riscos, os recursos, o cronograma, e todas as informações pertincntes ao projeto. O plano é uma formalização ou declaração de o que se pretende que aconteça eın determinado momento no futuro [Slack, 1997].

Em algumas organizações, o plano do projeto é um documento que inclui todos os tipos de planos utilizados, em outras, trata apenas dos processos de lcsenvolvimento do software, fazendo referência aos outros planos incluídos no projeto. De acorclo com Agresti [Agresti et. al., 1990], $\mathrm{cm}$ muitos ambientes de desenvolvimento de software são elaborados vários tipos de planos, apresentados no Quadro 2.1 .

Quadro 2.1 - Tipos de Planos [Summerville, 1996]

\begin{tabular}{|c|c|}
\hline Plano & Descriģäo \\
\hline Piano de Qualidade & Descreve os procedimentos e padroes de qualidade utilizados no projeto. \\
\hline Plano de Gerenciamento & Descreve métodos a procedimentos utilizados na administraçăo do projeto. \\
\hline Plano de Desenvolvimento & Descreve métodos e procedimentos utlizados na produçâo do software. \\
\hline Plano de :'ulidaçăo & $\begin{array}{l}\text { Descreve as abordagens, recursos e cronograma utilizados para validar o } \\
\text { sistema. }\end{array}$ \\
\hline $\begin{array}{l}\text { Plano de Gerenciamento de } \\
\text { Configuraçấo }\end{array}$ & $\begin{array}{l}\text { Descreve a estrutura e os procedimentos de gerenciamento de } \\
\text { configuraçăo do software utilizados. }\end{array}$ \\
\hline Piaro da Manuterçăo & $\begin{array}{l}\text { Descreve a previsấo dos recursos necessários para manutençẩo do } \\
\text { sistema, custos e esforço. }\end{array}$ \\
\hline $\begin{array}{l}\text { Plano de Gerenciamento de } \\
\text { Riscos }\end{array}$ & $\begin{array}{l}\text { Descreve os procedimentos necessários para gerenciar os riscos alcavés } \\
\text { do projelo. }\end{array}$ \\
\hline Plano de Equipe & $\begin{array}{l}\text { Descreve como serăo desenvolvidas as habilidades e experiéncia dos } \\
\text { membros da equipe. }\end{array}$ \\
\hline
\end{tabular}


Entre todos os tipos de planos, os dois mais importantes são o Plano de Gerenciamento e o Plano de Desenvolvimento de Software. O primeiro é voltado aos aspectos relativos à administração e controle do projeto, utilizado, por exemplo, para monitorar despesas de recursos utilizados e o segundo, o Plano de Desenvolvimento de Software, aborda métodos e procedimentos utilizados nas etapas de produção do software, onde são descritas, por exemplo, metodologias de programação e estratégias de teste que serão utilizadas no projeto [Agresti et. al., 1990].

Embora existam diferenças entre esses dois planos, há também muito conteúdo em comum. De acordo com a neccssidade de adequação a um determinado ambiente de desenvolvimento, os dois planos poden ser combinados em um documento único, referenciado apenas como Plano de Projeto. Esse documento é a base para negociação do comprometimento de todas as pessoas envolvidas no projeto. Por isso ele deve definir precisamente qual é o trabalho envolvido no desenvolvimento do projeto de software e como esse trabalho pode ser realizado.

Modelos de referência como o IEEE Std 1058.1-1987 (IEEE Standard for Software Project Management Plans) [IEEE, 1991] pode ser utilizado como guia para a elaboração de planos e pode ser utilizado por todos os tipos de projeto de software. De acordo com as características e necessidades do projeto, novas seções e subseções podem ser adicionadas ou modificadas. O conjunto mínimo de elementos apresentado pelo modelo deve ser o seguinte:

口 Introdução. Nessa seção são descritos os objetivos do projeto e as restrições de desenvolvimento (orçamento, tempo, etc.).

- Organização do Projeto. Nessa seção são descritos a forma com que a equipe de desenvolvimento é organizada, as pessoas envolvidas e seus respectivos papéis.

a Análise dos Riscos. Nessa seção são descritos os riscos inerentes ao projeto e as estratégias para minimizá-los.

- Requisitos de Hardware e Software. Nessa seção são descritos os recursos de hardware e o software, necessários para a realização das atividades.

- A Estrutura de Divisão de Trabalho. Nessa seção é descrita a divisão de trabalho do projeto, os marcos de referência identificados e os resultados associados a cada atividade. 
- Clonograma do Projeto. Nessa seção as dependências entre as atividades do projeto, o tempo necessário estimado para alcançar cada marco de referência e a alocação de pessoas para as atividades são descritos.

- Mecanismos de Acompanhamento e Relatórios. Nessa seção são dcscritos os relatórios de gerenciamento, quando esses de ‘enr ser produzidos e os mecanismos de monitoração que devem ser utilizados.

\subsubsection{Aprovação do Plano do Projeto}

As informações descritas no plano do projeto devem proporcionar uma visão global do projeto, de forma que compromissos factiveis sejam estabelecidos. Sem objetivos claramente definidos, orçamento e cronograma realistas, a base para o comprometimento do gerente com o piojeto não existe [Maciariello, 1974].

Para que o plano possa espelhar de forma clara e precisa todas as informações necessárias para que o projeto possa ser executado, é importante que aconteça uma etapa de revisão e/ou auditoria. Um processo de revisão formal pode ser executado para checagem de dados, checagem das atividades de preparação do plano, checagem das técnicas empregadas, etc..

A aprovação do plano do projeto ocorre depois da verificação e correção de eventuais discrepâncias ou erros detectados na fase de revisão. O plano deve ser aprovado por todos os envolvidos no projeto, direta e indiretamente, incluindo clientes, fonecedores e outros elemcntos da organização.

\subsection{Considerações finais}

Neste capítulo foram apresentados o processo de planejamento de projetos e um estudo das atividades mais importantes que devem ser realizadas. No capítulo 3 , o processo de estimativa de software é abordado com mais ênfase. 


\section{Estimativas de Projeto de Software}

\subsection{Considerações iniciais}

Estc capítulo apresenta o processo de elaboração de estimativas de software. A métrica de pontos de função e algumas técnicas de estimativa de projetos de software são apresentadas com o objetivo de claborar estimativas para as atividades pertinentes diretamente ao desenvolvimento de softıvare. A utilização de uma base de dados históricos para elaboração de estimativas mais precisas também é discutida.

\subsection{O Processo de Estimativa}

Para que un projeto de software possa ser efetivamente planejado, estimativas de tamanho, esforço, prazo e recursos, devem ser derivadas através dc um processo bem definido - o processo de estimativa de software (Figura 3.1)[Paulk et. al., 1992].

(utilizar 2 ou mais pessoas no processo)

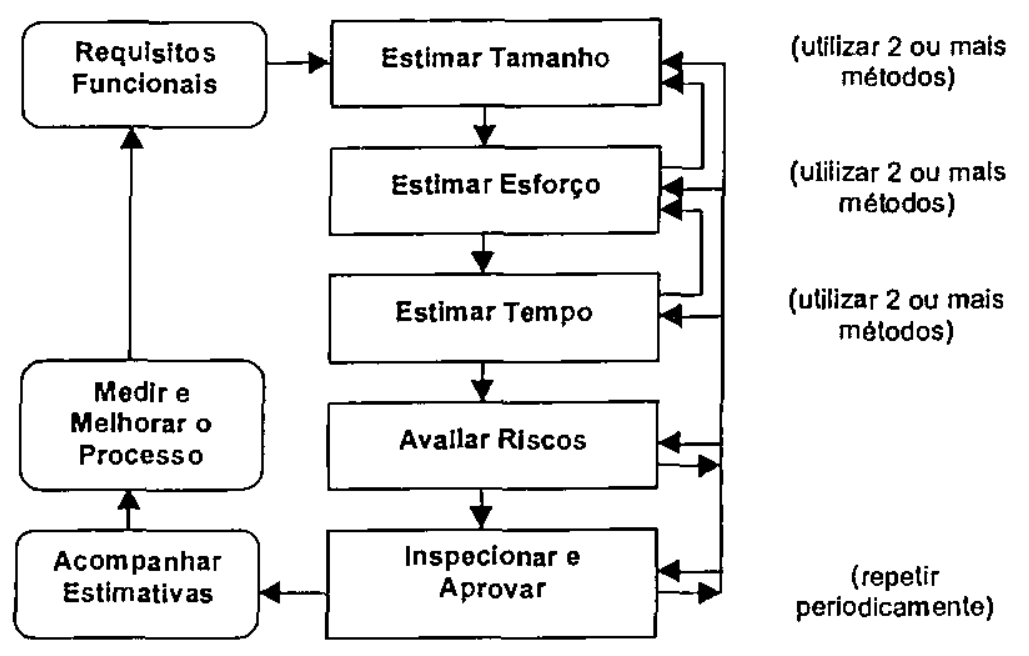

Figura 3.1 - Diagrama de Fluxo do Processo de Estimativa [Software, 1996]

Esse modelo foi elaborado pelo Software Engineering Process Office - SEPO com o objetivo de adcquar os processos executados pelos gerentes de projeto do Space and Naval Warfare Systems Center, San Diego, aos requisitos da prática chave Planejamento de Projeto de Software do nivel 2-Repctive] do CMM [Software, 1996]. 
Assim que os requisitos funcionais forem especificados, pessoas são designadas para as atividades de estinativa. É desejável que duas ou mais pessoas estejam envolvidas e a razĩo é simples: duas pessoas pensam melhor que uma. É importante que mais de um método seja utilizado para estimar tamanho do sistema, esforço e tempo de desenvolvimento, como forma de garantir melhor precisão dos resultados [Software, 1996].

O processo tem início com a estimativa do tamanho do sistema, tendo em vista uma declaração do escopo do software para estimativas iniciais de projeto. Mais tarde, quando o documento de estimativas estiver disponível, as estimativas iniciais serão refinadas. Métricas de linhas dc código (LOC - Lines of Code) ou pontos de função (PF) são utilizadas para dimensionar o tamanho de software.

Uma vez deturminado o tamanho do sistema a ser desenvolvido, o passo seguinte é calcular o esforço e depois o tempo de desenvolvimento, utilizando-se para isso a variável tamanho estimada previamente. Tamanho, esforço e tempo são variáveis inter-relacionadas, visto que qualquer mudança em uma delas pode causar efeito direto nas outras. $O$ esforço é ustalmente calculado em pessoas/mês e é utilizado para calcular o custo financeiro do projeto, enıpregando-se taxas e custos de trabalho. O custo do projeto normalmente está restrito às atividades de engenharia de software (análise de requisitos, projeto de sistema, codificação, teste, gerenciamento de configuração e garantia de qualidade de software). Oulros custos, tais como custos de instalações, equipamentos, custos de gerenciamento global de projeto, etc., tambénı podem ser considerados no cálculo da estimativa do custo global do projeto.

Depois que o tamanho, esforço, tempo e custo foram estimados, uma avaliação de riscos de projeto deve ser efetuada. Riscos associados ao projeto podem provocar mudanças nas estimativas e, por isso, devem ser documentados, acompanhados e atualizados durante todo o projeto.

As estimativas obtidas devem ser validadas através de um processo de inspeção $e$ aprovação. O propósito da validação é verificar os métodos utilizados no processo e garantir que as estimativas scjam razoáveis e possuam alto grau de precisão. A validação ć uma atividade usualmente executada pelo pessoal da administração do projeto ou pelo grupo de garantia de qualidade de software. 
Em seguida, as estimativas oficiais do projeto são registradas em um documento próprio. $\mathrm{O}$ documento de registro das estimativas contém informaçōes referentes ao processo executado, a data de validação das estinativas, os métodos utilizados para elaboração e os dados estimados de tamanho, esforço, tenıpo e custo registrados a cada vez que o processo é executado.

$\mathrm{O}$ gerente de projetos utiliza dados de estimativas nas etapas de planejamento e acompanhamento de projeto. Na fase de planejamento as estimativas constituem informações necessárias para decidir quantas pessoas irão trabalhar no projeto e quanto tempo será necessário para realização das tarefas. Na fase de acompanhamento, o gerente utiliza as estimativas atualizadas com dados reais do desenvolvimento do projeto para avaliar se as atividades executadas estão de acordo com o cronograma planejado e, se for necessário, tomar ações corretivas.

Após o encerramento, dados reais do projeto, em termos de tamanho final da aplicação, esforço e tempo de execução das fases e custo são registrados em uma base de dados, para melhorar o processo e a precisão de futuras estimativas. Além disso, várias técnicas e modelos utilizam dados históricos para elaboração de estimativas.

\subsection{Métricas de Tamanho de Sistemas}

O primeiro problema que os gerentes de projeto se deparam para elaborar estimativas é o dilema da escolha da métrica mais adequada para medir tamanho de aplicações. A forma familiar de se medir tamanho de software é através da contagem de linhas de código. Todavia, é muito dificil prever o total de linhas de código logo no início do projeto, quando devem ser elaboradas as estimativas.

Há um debate contínuo a respeito das melhores medidas de tamanho de software e não existe, de fato, una resposta unânime. De acordo com Jones [Jones, 1996a], a controvérsia quanto ao uso de linhas de código como medida chave surge quando o "estimador" se depara com questões do tipo: Como comparar linhas de código em programas escritos em linguagens diferentes? Esse tipo de comparação não faz sentido para os gerentes de projeto e, mesmo que uma mesma linguagem tenha sido utilizada no desenvolvimento de dois programas, ainda fica dificil fazer a comparação. 
Uma determinada função poderia ser codificada por um programador experiente em 200 linhas de código e um programador inexperiente codificaria a mesma função em 400 linhas de código. Como comparar dois programas que fazem exatamente a mesma coisa, mas um possuli o dobro de número de linhas de código do outro? A abordagem para contornar esses problemas é a métrica de pontos de função, apresentada a seguir.

\subsubsection{Pontos de Função}

A contagem de pontos de função é uma técnica utilizada para medir o tamanho do software através da quantificação da funcionalidade do processamento da aplicação. Os conccitos dessa técnica foram introduzidos por Allan J. Albrecht, em uma conferência do GUIDE - Grupo de Usuários IBM, em 1979. Mais tarde, esses conceitos foram refinados em uma matodologia formal e em 1984 foram publicados para domínio público [Teixeira, 2000a].

Scgundo Albrecht [Albrecht, 1983], cinco tipos de componentes lógicos ou funções da aplicação (Figura 3.2) afetam de formas distintas o tamanho de un sistema: filnções do tipo dados (Arquivos Lógicos Internos - ALI e Arquivos de Interface Externa - AIE) e funções do tipo transarões (Entradas Externas - EE, Saídas Externas - SE, e Consultas Externas $\mathrm{CE})$.

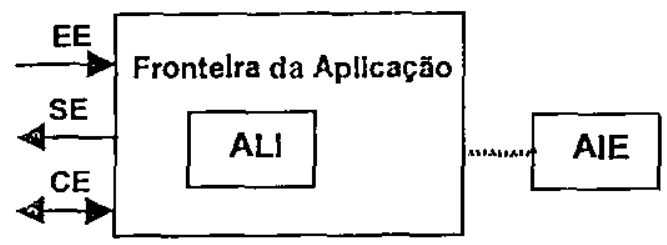

Figura 3.2 - Componenles de Pontos de Função em relaçăo à aplicaçăo [Dekkers, 1998]

A contagem de pontos de função é utilizada para medir sistemas e elaborar eslimativas en todas as fases do ciclo de vida de desenvolvimento, inclusive na manutenção. Além disso, a contagem de pontos de função é independente da maneira como o sistema é desenvolvido e implementado [Braga, 1996].

De acordo com a finalidade a que se destina, podem-se realizar três tipos de contagem: a contagem em projetos de desenvolvimento de software, a contagem de pontos de filnção de uma aplicação já desenvolvida e implantada, e a contagem de pontos de função em projetos de manutenção de software [Teixeira, 2000a]. 
A contagem em projetos de desenvolvimento é utilizada para dimensionar o tamanho provável de uma nova aplicação. O objetivo desse cálculo é quantificar as funções solicitadas, identificadas no modelo lógico do sistema, e que deverão ser entregues ao usuário pela nova aplicação.

Quando o projeto termina c a aplicação já se encontra implementada, ou até mesmo implantada na organização, a contagem de pontos de função instalados é efetuada.

Em projetos de manutenção, a contagem de pontos de função é utilizada para dimensionar o tamanho da modificação que deve ser efetuada em uma aplicação já existente. Em geral, a modificação é uma melhoria ou adição de funcionalidade a uma aplicação existente.

Uma das principais vantagens da contagem de pontos de função sobre outras técnicas de medição de aplicações é a possibilidade de estimar a dimensão de projetos desde as primeiras fases de análise e projeto de sistemas, quando se dispõe de poucas informações sobre o sistema. Segundo a empresa SPR - Software Productivity Research, ao final da fase de desenho do sistema, é possível fazcr cstimativas com uma margem de erro de $+/-10 \%$ [Azevedo, 1999].

Até 1984, a técnica de contagem de pontos de função era usada, basicamente, para identificar o tamanho de um sistema e auxiliar na estimativa de esforço de desenvolvimento. Atualmente, pontos de função também são utilizados na implantação de programas de métricas para melhorar estimativas, gerenciar a qualidade e para monitorar a produtividade. Em medições, a contagem de pontos de função pode servir como um instrumento para acompanhamento de estimativas de custo e rccursos requeridos para o desenvolvimento e manutenção de software, ajudando assim na implantação de um programa de métricas.

Pontos de função também ajudam as organizações a normalizar dados como custo, esforço, duração, defeitos, equipe, etc.. Ao basear-se uma análise apenas no número de defeitos, não se pode objetivamente comparar a qualidade de um sistema com a qualidade de outros. Todavia, utilizando pontos de função em combinação com dados de defeitos, pode-se comparar qualidade, em termos de densidade de defeitos do software, entre aplicações e linguagens [Furey, 1997]. 


\subsubsection{Contagem de Pontos de Função segundo o IFPUG}

Em 1986, uma comunidade de usuários resolveu efetuar padronizações adicionais nas regras de contagem de pontos de função. Foi então fundado o International Function Points Users Group - IFPUG [IFPUF, 2000], um grupo formalmente constituido e sein finalidades lucrativas [Dekkers, 1998].

O IFPUG tem sido líder no estabelecimento e publicação de documentos relacionados a pontos de função, incluindo o Manual de Práticas de Contagem, atualmente na versão 4.1 [IFPUG, 1994], o Guia para Medição de Sofnware e diversos estudos de caso detalhados. O Manual de Práticas de Contagem do IFPUG define o processo e as regras para contagem de pontos de função, fazendo com que o processo seja documentado para poder ser repctido, methorado e utilizado em treinamentos.

Desde a fundação do IFPUG, as regras de contagem evoluíram e melhoraram. A consistência entre os contadores também melhorou. Um estudo realizado em 1994 pelo Quality Assurance Institute c pelo IFPUG encontrou uma variância entre contadores treinados da ordem de menos de $11 \%$ [Furey, 1997]. No Brasil também existe uma organização de usuários de pontos de função, o Brazilian Function Points Users Group [BFPUG, 2000]. A contageın de pontos de função em sistemas, detalhada pelo manual de contagem do IFPUG, também conhecida como Análise de Pontos de Função (Function Point Analysis - FPA), é apresentada a seguir.

\section{口 Análise de Pontos de Funçäo}

Segundo o IFPUG, o processo de Análise de Pontos de Função, mostrado na Figura 3.3 é realizado em três etapas: na primeira etapa, a contagem de Pontos de Função Brutos ou Não Ajustados é realizada, em seguida, determina-se o Fator de Ajuste e, na última etapa, determinam-se os Pontos de Função Ajustados [Tcixeira, 2000a].

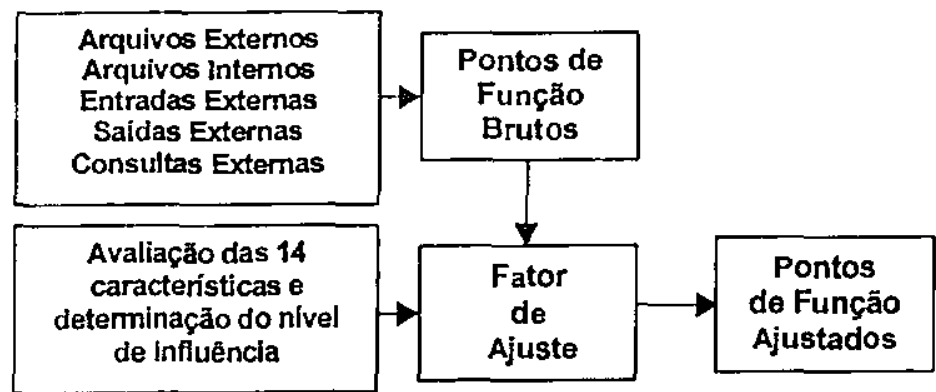

Figura 3.3 - Visāo Geral do Processo de Anáiise de Pontos de Funçāo 
Os pontos de função brutos, contados na primeira etapa do processo de Análise de Pontos de Função, refletem especificamente a contagem da funcionalidade provida ao usuário pela aplicação. Como documentação mínima exigida para a contagem, devem constar: o Modelo de dados da aplicação; o Layout dos relatórios; o Layout das telas de entrada de dados; o Layout das telas de consulta; o Layout dos arquivos de interface; e o Layout dos arquivos que são entrada para o sistema.

Para auxiliar na identificação das funções é preciso inicialmente identificar $a$ fronteira da aplicação. A fronteira da aplicação (Figura 3.4) é a linha que separa o projeto ou aplicação que está sendo contado de outras aplicações ou sistemas da organização. A determinação da fronteira é importante para que possam ser estabclecidos: o escopo do software que cstá sendo medido; a propriedade dos dados e das funções; e as informações necessárias ao processo de contagem.

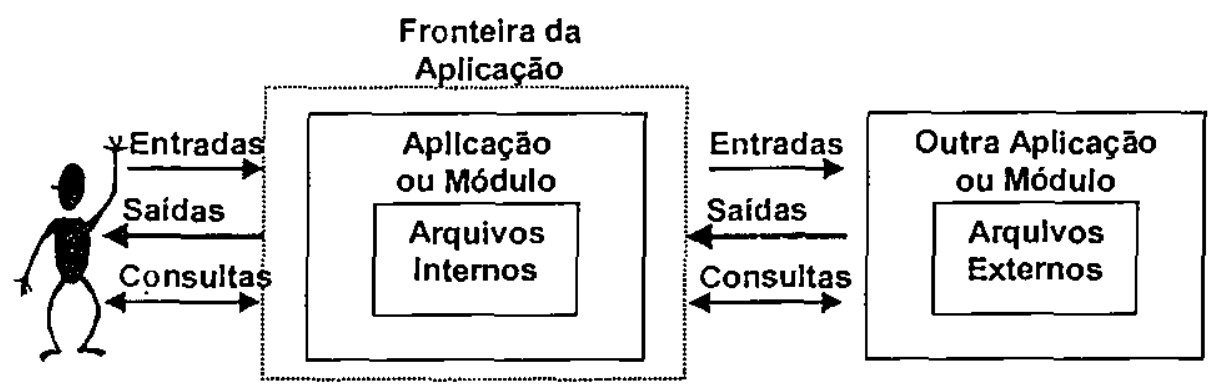

Figura 3.4 - Identificação da Fronteira da Aplicaçāo

As funções identificadas dentro da fronteira da aplicação são classificadas em funções do tipo dados c funções do tipo transação. Funções do tipo dados representam a funcionalidade provida ao usuário para atender requisitos cxternos e internos referentes a dados. Funções do tipo dados podem ser Arquivos Lógicos Internos (ALI) ou Arquivos de Interface Externa (AIE). Funções do tipo transação representam a funcionalidade da aplicação provida ao usuário pelo processamento de dados. Funções transacionais são definidas como Entradas Externas (EE), Saidas Externas (SE) c Consultas Externas (CE).

Depois de identificadas, cada função deve scr classificada quanto à sua complexidade funcional relativa: simples, média ou complexa. A classificação da complexidade das funções depende do número de elementos de registro (usualmente tabelas ou arquivos referenciados) e do número de elementos de dados (usualmente campos no arquivo ou tabela referenciada). 
O Quadro 3.1 apresenta uma breve descrição dos cinco tipos de funções.

Quadro 3.1 - Tipos de Função da Análise de Pontos de Função

\begin{tabular}{|c|c|c|}
\hline Tipo & Identiflcação & Exempio \\
\hline $\begin{array}{c}\text { Arquivo } \\
\text { Lógico } \\
\text { Interno }(A L I)\end{array}$ & $\begin{array}{l}\text { Grupo de dados logicamenle relacionados, idenìuicudo pelo usuário, } \\
\text { mantido e modificado dentro da fronteira da aplicaçăo que está sendo } \\
\text { conlada. }\end{array}$ & $\begin{array}{l}\text { Arquivos-mestres da aplicaçăo, tabelas } \\
\text { criadas para atender a aplicaçăo, dados de } \\
\text { segurança da aulıaçăo. }\end{array}$ \\
\hline $\begin{array}{c}\text { Arquivo de } \\
\text { Interface } \\
\text { Externa (AlE) }\end{array}$ & $\begin{array}{l}\text { Grupo do dados, logicamente relacionados, utilizado no sistema que } \\
\text { eslá sendo analisado, mas que náo é mantido nem modiflcado dentro } \\
\text { da fronteira da aplicaçăo que está sendo contada. }\end{array}$ & $\begin{array}{l}\text { Arquivos-mestres de outras aplicaçðes, } \\
\text { tabelas criadas para alender a outras } \\
\text { aplicaçōes, mensages de auxilio ou de erro } \\
\text { para atender a outras aplicaçסes. }\end{array}$ \\
\hline $\begin{array}{c}\text { Entrada } \\
\text { Externa }(E E)\end{array}$ & $\begin{array}{l}\text { Funçăo que processa dados ou informaçōes de controle geradas por } \\
\text { uma fonte externa à aplicaçăo que está sendo contada. Săo } \\
\text { transaçōes que efeluam manutençăo nos dados armazenados no } \\
\text { sistema. }\end{array}$ & $\begin{array}{l}\text { Entradas de dados on-line, entrada de } \\
\text { dados batch, funçōes rle inclusăo, alteraçăo } \\
\text { e exclusäo do sistema. }\end{array}$ \\
\hline $\begin{array}{c}\text { Saida } \\
\text { Externa (SE) }\end{array}$ & $\begin{array}{l}\text { Funçăo que fornoce dados ou informaçð̌es de controle para fora da } \\
\text { aplicaçăo que está sendo contada. Såo transaçóes que exdraem } \\
\text { informaçס̄es do sistema para outros aplicativos. }\end{array}$ & $\begin{array}{l}\text { Dados transferidos para outra aplicação, } \\
\text { relatórios, rejatórios on-line, gráficos } \\
\text { geracius em forma de lexto. }\end{array}$ \\
\hline $\begin{array}{c}\text { Consulta } \\
\text { Externa (CE) }\end{array}$ & $\begin{array}{l}\text { Transaçăo que combina transaçöes de entrada o salda, resultando } \\
\text { em recuperaçāo de dados. }\end{array}$ & $\begin{array}{l}\text { Recuperação de dados, consulta, consultas } \\
\text { de mensagens de help. }\end{array}$ \\
\hline
\end{tabular}

Eın seguida, os pontos de função não ajustados ou brutos são calculados através da aplicação de pesos cspecíficos para cada tipo de fitnção (Tabela 3.1). As regras e tabelas de classificação para cada tipo de função e para cálculo dos pontos de função não ajustados estão apresentadas no Anexo $\mathrm{A}$.

Tabela 3.1 - Determinação de Pontos de Funçāo Năo Ajustados [Fernandes, 1995]

\begin{tabular}{|c|c|c|c|c|}
\hline Tipo de função & Complexldade & Funcional & Total Complexidade & $\begin{array}{c}\text { Total tipo } \\
\text { função }\end{array}$ \\
\hline \multirow{3}{*}{ Arquivo Lógico Inlerno } & Simples & $\times 7=$ & 0 & \multirow{3}{*}{0} \\
\hline & Média & $\times 10=$ & 0 & \\
\hline & Complexa & $\times 15=$ & 0 & \\
\hline \multirow{3}{*}{ Arquivo de Interface Externa } & Simples & $\times 5=$ & 0 & \multirow{3}{*}{0} \\
\hline & Média & $\times 7=$ & 0 & \\
\hline & Complexa & $\times 10=$ & 0 & \\
\hline \multirow{3}{*}{ Entradas Externas } & Simples & $\times 3=$ & 0 & \multirow{3}{*}{0} \\
\hline & Média & $\times 4=$ & 0 & \\
\hline & Complexa & $\times 6=$ & 0 & \\
\hline \multirow{3}{*}{ Saidas Externas } & Simples & $\times 4=$ & 0 & \multirow{3}{*}{0} \\
\hline & Média & $\times 5=$ & 0 & \\
\hline & Complexa & $\times 7=$ & 0 & \\
\hline \multirow{3}{*}{ Consultas Externas } & Simples & $\times 3=$ & 0 & \multirow{3}{*}{0} \\
\hline & Média & $\times 4=$ & 0 & \\
\hline & Complexa & $\times 6=$ & 0 & \\
\hline
\end{tabular}


Na segunda etapa do processo de Análise de Pontos de Função, o fator de ajuste (FA) (Equação 3.1) é determinado.

$$
F A=(N I * 0,01)+0,65
$$

O fator de ajuste ć calculado a partir da análise de 14 Características Gerais do Sistema (Quadro 3.2) que avaliam a funcionalidade geral da aplicação. Os níveis de influência de cada uma delas varia de zero (nenhuma influchncia) até cinco (forte influência). As Características Gerais do Sistema estão descritas no Ancxo B.

Quadro 3.2 - As 14 Caracteristicas Gerais do Sistema

\begin{tabular}{|l|l|}
\hline \multicolumn{2}{|c|}{ Caracteristicas Gerais do Sistema } \\
\hline 1. Comunicaçäo de Dados & 8. Alualizaçăo On-line \\
\hline 2. Funçōes Oistribuidas & 9. Processamenlo Complexo \\
\hline 3. Performance & 10. Reusabilidade \\
\hline 4. Configuraçāo do Equipamento & 11. Facilidade de Implantação \\
\hline 5. Volume de Transaçōes & 12. Facilidade Operacional \\
\hline 6. Enlrada de Oados On-Line & 13. Mülliplos Locais \\
\hline 7. Interface com o Usuário & 14. Facilidade de Mudanças \\
\hline
\end{tabular}

Na terceira etapa do processo de Análise de Pontos de Função, os pontos de função ajustados (PFA) (Equação 3.2) são calculados multiplicando-se os pontos de função brutos pelo fator de ajuste. Fórmulas cspccíficas são utilizadas para cálculos de pontos de função em projetos de desenvolvimento, projetos de manutenção e aplicações já desenvolvidas ou instaladas.

$$
P F A=P F B r u t o S^{*} F A
$$

Pontos de função não ajustados podem ser convertidos na quantidade equivalente de linhas de código. A predição do número de instruçð̃es-fontes a partir do tamanho estimado em pontos de função é baseada na observação empírica do número de instruções requerido para implementar um ponto de função [Braga, 1996].

Depois da conversão de pontos de função em linhas de código, o tamanho do sistema pode então ser utilizado por modelos algorítnicos de estimativa para cálculo de esforço, tempo e custo financeiro. A Tabela 3.2 apresenta uma amostra com o número correspondente de instruções-fontes equivalentes para produzir um ponto de função. Uma tabela que abrange grande número de linguagens de programação pode ser encontrada em no site da empresa Software Productivity Research, Inc. [Jones, 19966]. 
Tabela 3.2 - Conversão de Pontos de Função em Linhas de Código [Jones, 1996]

\begin{tabular}{|l|c|l|c|}
\hline \multicolumn{1}{|c|}{ Linguagem } & SLOC/PF & \multicolumn{1}{c|}{ Linguagem } & SLOC/PF \\
\hline ACESS & 38 & FoxPro 2.5 & 34 \\
\hline Ansi SQL & 13 & HTML 3.0 & 15 \\
\hline Ansi COBOL 85 & 91 & JAVA & 53 \\
\hline C & 128 & LISP & 64 \\
\hline C++ & 53 & Natural 2 & 46 \\
\hline Clipper & 19 & Object Pascal & 29 \\
\hline COBOL II & 107 & Oracle & 40 \\
\hline dBase IV & 36 & Turbo C & 128 \\
\hline Delphi & 29 & Turbo Pascal V.5 & 49 \\
\hline Fortran 95 & 71 & Visual Basic 5 & 29 \\
\hline
\end{tabular}

\subsubsection{Contagens de Pontos de Função segundo o NESMA}

Além do IFPUG, outra organização que se destaca internacionalmente para promover o uso de pontos de função é o Netherlands Function Point Users Group - NESMA [NESMA, 2000], organização fundada en 1989 e, atualmente, o maior grupo de usuários de pontos de função da Europa, incluindo a Russia.

O NESMA publica seu próprio Manual de Práticas de Contagem, complacente com IFPUG CPM, do qual é complemento de grande valia. A primeira publicação do manual do NESMA incorporava as regras do manual do IFPUG (IFPUG CPM 2.0), particularmente aplicadas em medições de produtividade, cujo propósito era a contagem de pontos de função de aplicações já implementadas. Após a publicação do IFPL 'G CPM 4.1 em Janciro de 1999, as regras de contagem de pontos de função das duas organizaçðes foram unificadas, com exceção de pouquíssimas diretrizes. Os dois manuais, NESMA (NESMA CPM 2.0) e IFPUG (IFPUG CPM 4.1) agora utilizam a mesma filosofia, os mesmos conceitos e termos, as mesmas regras e diretrizes para contagem da Análise de Pontos de Função.

O manual do NESMA apresenta três tipos de contagem de pontos de função: a contagem indicativa de ponto de função, a contagem estimada de ponto de função e a contagem detalhada de pontos de função.

\section{ㅁ Contagem Indicativa de Pontos de Função}

$\Lambda$ Contagem Indicativa de Pontos de Função tem como resultado um valor aproximado da quantidade de pontos de função do sistema proposto. 
Essa forma de cálculo é utilizada na fase inicial da proposta de desenvolvimento, quando ainda não se conhccem as funções básicas do sistema, apenas um modelo de dados preliminar. A técnica de contagem indicativa é baseada somente nos arquivos lógicos presentes (ALIs e AIEs), utilizando-se pontuação referente à complexidade média. A fórmula simples assumc que cada ALI ( 10 ptos.) terá uma inclusão, uma alteração e uma exclusão ( $3 \mathrm{x}$ $4=12$ ptos.), duas consultas $(2 \times 4=8$ ptos.) e um relatório (5 ptos.). A fórmula completa assume tambćm que cada arquivo $\operatorname{AIE}(7$ ptos.) tenha 2 consultas $(2 \times 4=8$ ptos.).

- Fórmula 1 (simples): $\mathrm{PF}=$ Quantidade de Arquivos Lógicos * 35

- Fórmula 2 (completa): $\mathrm{PF}=($ Quantidade de Arquivos Lógicos * 35) + (Quantidade de Arquivos de Interface * 15)

Exemplo de Contagem Indicativa de Pontos de Função [NESMA, 2000].

O usuário quer armazcnar dados de clientes e produtos. O arquivo de fornecedores já existc em outra aplicação c será referenciado para consultas e emissão de relatório. Essa especificação superficial é suficiente para uma contagem indicativa de pontos de função. Podem-se identificar dois ALI (Clientes e Produtos) e um suposto AIE (Fornecedores). O resultado da contagem indicativa para o sistema proposto está apresentado na Tabela 3.3.

Tabela 3.3 - Exemplo de Contagem Indicativa de Pontos de Funçăo [NESMA, 2000]

\begin{tabular}{|l|c|c|}
\hline $\begin{array}{c}\text { Funçōes de } \\
\text { Dados }\end{array}$ & $\begin{array}{c}\text { Tipos de } \\
\text { Função }\end{array}$ & $\begin{array}{c}\text { Pontos de Função (por } \\
\text { defauh) }\end{array}$ \\
\hline Clienles & ALI & 35 \\
\hline Produtos & ALI & 35 \\
\hline Fornecedores & AlE & 15 \\
\hline Tamanho Funcional Indicativo & 85 PF \\
\hline
\end{tabular}

\section{口 Contagem Estimada de Pontos de Função}

A Contagem Estimada de Pontos de Função é utilizada na fase inicial da proposta de desenvolvimento, quando não se possuem dados detalhados do processo, apenas informações preliminares sobre os processos e o modelo de dados. Para executar contagem estimada de pontos de função são nccessárias informações um pouco mais detalhadas sobre a funcionalidade da aplicação, levantadas a partir das exigências do usuário (ou cliente). A contagem estimada é realizado atribuindo-se um grau de complexidade médio aos processos informados, e um grau baixo aos arquivos lógicos internos e de interface.

A contagem estimada de pontos de função é executada como segue.

- Determinar todos os tipos de funções (AIE, ALI, EE, SE, CE). 
a Determinar a complexidade das funções tipo dados (AIE, ALI) como Baixa, e das funções tipo transação (EE, SE, CE) como Média.

- Calcular o tota! da contagem dos pontos das funções.

Exemplo de Contagem Estimada de Pontos de Função [NESMA, 2000]

O usuário solicitou o desenvolvimento de um sistema que execute as scguintes funçoes (Tabela 3.4):

口 Incluir, alterar e excluir dados de clientes, efetuar consultas nos dados de Clientes e geração de quatro tipos de relatórios diferentes com dados calculados.

口 Incluir, alie. ar e excluir dados de produtos, efetuar consultas nos dados de Produtos, e geração de um rclatório com dados calculados.

- Efetuar consulta em Fornecedores, através do código do fomecedor e geração de um relatório com tolais de resultados.

Tabela 3.4 - Exemplo de Contagem Estimada de PF [NESMA, 2000]

\begin{tabular}{|l|c|c|c|}
\hline \multicolumn{1}{|c|}{$\begin{array}{c}\text { Funçöes de Dados ou } \\
\text { Transaclonals }\end{array}$} & Tipos de Funçäo & $\begin{array}{c}\text { Complexidade (por } \\
\text { default) }\end{array}$ & $\begin{array}{c}\text { Pontos de Funçăo (näo } \\
\text { ajustados) }\end{array}$ \\
\hline Clientes & ALI & Baixa & 7 \\
\hline Produtos & ALI & Baixa & 7 \\
\hline Fornecedores & AlE & Baixa & 5 \\
\hline Incluir Cliente & EE & Média & 4 \\
\hline Alteraçăo de dados de Clientes & EE & Média & 4 \\
\hline Exclusăo de Clientes & EE & Média & 4 \\
\hline Consulta a Clientes & CE & Média & 4 \\
\hline Relatório 1 de Clientes & SE & Média & 5 \\
\hline Relatório 2 de Clientes & SE & Média & 5 \\
\hline Relatório 3 de Clientes & SE & Média & 5 \\
\hline Relatório 4 de Clientes & SE & Média & 5 \\
\hline Incluir Produto & EE & Média & 4 \\
\hline Alteraçăo de dados de Produto & EE & Média & 4 \\
\hline Exclusăo de Produto & EE & Média & 4 \\
\hline Consulta a Produto & CE & Média & 4 \\
\hline Relatório de Produto & SE & Média & 5 \\
\hline Consulta a Fornecedores & CE & Média & 4 \\
\hline Relatório de Fornecedores & SE & Média & 5 \\
\hline & & & 85 PF \\
\hline
\end{tabular}

\section{口 Contagem Detalhada de Pontos de Função}

A Contagem Detalhada de Ponios de Função é a mesma técnica de Análise de Pontos de Função (FPA - Function Point Analysis), padronizada no manual do IFPUG. 
O NESMA fez uma pesquisa para verificar o grau de precisão dos três tipos de contagem dc pontos de função: indicativa, estimada e detalhada. Um banco de dados com de cerca dc 100 aplicações foi analisado e os resultados das contagens obtidas foram confrontados. Foram comparados dados da contagem detalhada com dados de contagens indicativa e estimada, separadamente. O resultado do confronto dos dados da contagem indicativa apresentou, em alguns casos, um desvio de cerca de $50 \%$, sugerindo que estimativas indicativas devem ser consideradas com o dcvido cuidado. A vantagem do uso da contagem indicativa é o pouco tempo despendido no processo de estimativa de tamanho. Por outro lado, os resultados das contagens estimativas comparados com os resultados das contagens dctalhadas foram muito próximos e um desvio muito pequeno foi constatado [NESMA, 2000].

Scgundo o NESMA [NESMA, 2000], a contagem detallıada de pontos de função é mais precisa que a contagem indicativa e a contagem estimativa, mas também é mais demorada, alćın de necessitar de especificações mais detalhadas do sistcma que será desenvolvido. Por outro lado, cm muitas aplicações a contagem indicativa de pontos de função pode resultar em uma cstimativa do tamanho da aplicação com grau de precisão satisfatório, em um curto pcríodo de tcmpo. Cabe ao gercnte de projeto decidir qual das técnicas deve ser utilizada, baseando-se $\mathrm{cm}$ critérios como documentos e informações disponíveis ou etapa do ciclo de vida em que a contagem será cfetuada.

\subsection{Técnicas para elaboração de Estimativas de Projeto}

Alćm da técnica de contagem de pontos de função para medir de tamanho de sistemas, existem diversos modelos para mensuração de sistemas computacionais, mais ou menos empíricos, desde algumas formas resumidas ao uso de expcriências passadas como único guia, até métodos complexos e relativamente completos, que associam experimentação, inferência e formulação matcmática na elaboração de formas scguras de se medir software.

Entre esses modclos, o Constructive Cost Model, mais conhecido pelo acrônimo COCOMO, destaca-se por scu significativo volume de pesquisa. Esse modelo para a mensuração de esforço, prazo e custos e sua versão atualizada, o COCOMO II, são estudados em detalhes no capítulo 4. 
Entre as técnicas de elaboração de estimativa usualmente utilizadas estão: o Julgamento de Especialistas, a Técnica Delphi, Estimativas por Analogia e Pert Sizing.

\section{․ Julgamento de Especialista}

A forma mais simples de elaborar estimativas é o uso da experiência acumulada ao longo do tempo com o desenvolvimento de sistemas. Esse método, conhecido como Julgamento tle Especialisła, é muito comum nas organizações de pequeno porte que trabalham com projetos pequenos e força de trabalho estável. Para estimar um projeto, consulta-se, preferencialmente, mais de uma pessoa com experiência em projetos semelhantes desenvolvidos anteriormente e com a devida compreensão do projeto proposto.

\section{ㅁ Delphi}

Quando as estimativas são elaboradas por vários espccialistas independentemente, é necessário um método para combiná-las em uma única estimativa. $\mathrm{O}$ mais indicado nesses casos é a técnica de consenso Delphi [Boehm, 1981]. Essa técnica orçamentária, criada na década de 1960, se resume à consulta a especialistas de uma determinada área, en uma determinada linguagen e/ou em um determinado assunto, para elaborar estimativas utilizando a experiência e entendimento do projeto proposto.

Uma variação dessa técnica é conhecida como Wideband Delphi. Nessa variação, discussões são introduzidas no decorrer de um processo iterativo, ro qual muitas estimativas gradualmente convergem a um valor mais próximo da realidade e a estimativa mais adequada pode então ser escolhida [Humphrey, 1989]. O processo é realizadlo em uma seqüêneia de passos resumidos no (Quadro 3.3).

Quadro 3.3 - Elapas da Técnica Wideband Delphi [Boehm, 1981]

\begin{tabular}{|c|c|}
\hline Passo & Ação \\
\hline 1. & O coordenador apresenta a cada especialisla a especificaçăo do projelo e o formulário de estimaliva. \\
\hline 2. & $\begin{array}{l}\text { O coordenador convoca uma reuniảo com os especialislas para discussão dos aspeclos relacionados ao tamanho do } \\
\text { sistema. }\end{array}$ \\
\hline 3. & Cada especialista preenche o formulário de estimativa anonimamente. \\
\hline 4. & $\begin{array}{l}\text { O coordenador prepara um resumo das estimativas em um formulário iterativo e comunica os resultados aos } \\
\text { especlalistas. }\end{array}$ \\
\hline 5. & O coordenador convoca outra reuriazo com os especialistas para discutir os resultados. \\
\hline 6. & Os especialistas revisam o resumo e preenchem outra estimaliva anónima no formulário iterativo. \\
\hline 7. & $\begin{array}{l}\text { Os passos } 4,5 \text { e } 6 \text { sảo repetidos alé que haja concenso enlre a eslimativa mais baixa e a es limativa mais alla } \\
\text { elaboradas pelos especiatistas. }\end{array}$ \\
\hline
\end{tabular}


Inicialmente, uma equipe de especialistas, usualmente pequena, é solicitada para elaborar estimativas. Cada participante elabora sua estimativa anonimamente, utilizando um formulário especifico (Figura 3.5).

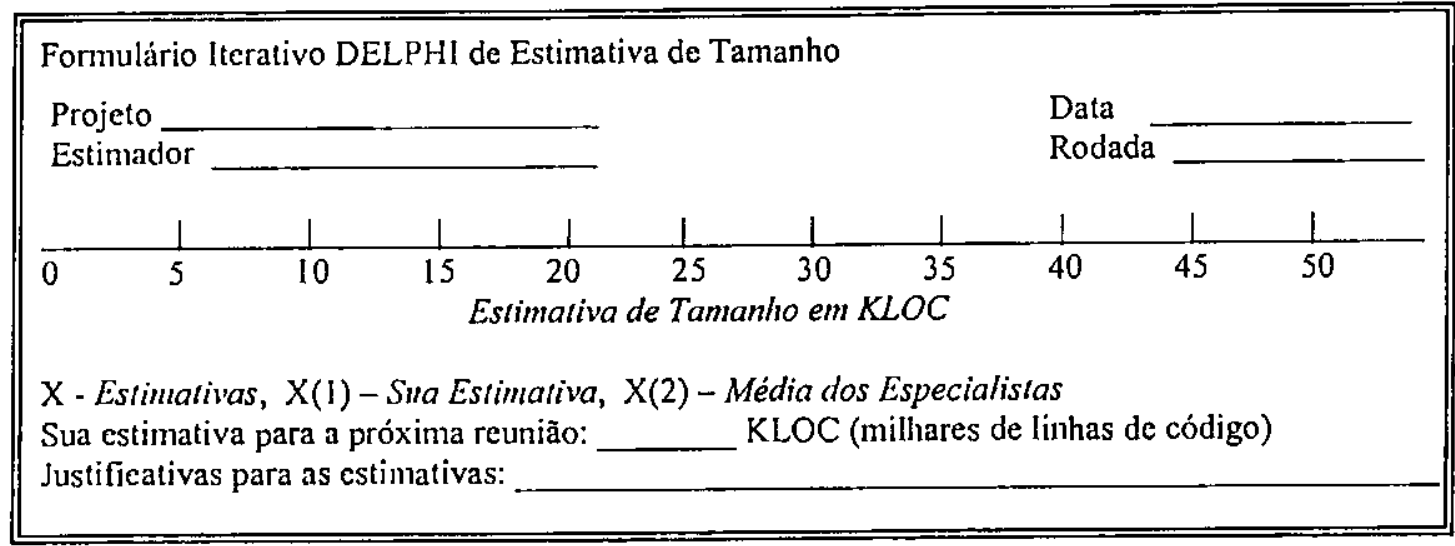

Figura 3.5 - Modelo de Formulário lterativo [Boehm, 1981]

Em seguida, todos se rcúncm, discutem o resultado e informam como suas estimativas se comparan umas às outras. Após a primeira reunião, os participantes recebem permissão para alterar suas estimativas. Esse processo iterativo continua até que as estimativas elaboradas pelos participantes fiquem próximas de um valor comum, ou então, até que haja um acordo entre os especialistas [Wiegers, 2000].

Segundo Boehm [Bochm, 1981], essa técnica tem a vantagem de "lapidar" as estimativas uniformetnente. No final do processo, obtém-se uma estimativa que, em tese, considera fatores diversos, conhecidos dos profissionais que julgam, e que, certamente, interferem na produtividade. Como pontos fracos, os membros da equipe podem ser influenciados por autoridades ou considcraçõcs políticas apresentadas nas reuniões. Além disso, em grandes projetos ou grandes organizações, é muito difícil estimar projetos bascando-se nas memórias dos desenvolvedores como única fonte de dados. Normalmente os projetos são de natureza mais complexa, as informações históricas são antigas e volumosas e o conhecimento acumulado ao longo do tempo é distribuído em um grande número de pessoas.

\section{- Estimativa por Analogia}

Pelo fato de ser totalmente baseada em experiências profissionais que, por sua vez, podem scr subjetivas demais, a precisão das estimativas obtidas pelo julgamento de especialistas pode ser não apresentar um grau satisfatório. O fator experiência pode ser beneficiado pclo simples fato da cultura organizacional manter registros históricos de projetos passados. 
O método para estimar tamanho de sistemas quando existirem disponíveis informações registradas de projetos passados é conhecido como Estimativa por Analogia. Estimativas por analogia podem ser obtidas para o projeto como um todo ou para módulos ou subsistemas que o compõem. Estimar o projeto globalmente apresenta a vantagem de que todos os componentes do sistcma. cstarão sendo considerados. Porém, ao estimar módulos ou subsistemas pode-se obter uma avaliação mais precisa das similaridades e diferenças entre o novo projeto e os projetos passados. Os passos básicos para executar estimativa de tamanho por analogia estão apresentados no Quadro 3.4.

\begin{tabular}{|c|l|}
\hline Passo & \multicolumn{1}{|c|}{ Quadro 3.4 - Estimativa por Analogia } \\
\hline 1. & $\begin{array}{l}\text { Elaboro } \\
\text { funçăo. }\end{array}$ \\
\hline 2. & $\begin{array}{l}\text { Identificar similaridades e diferenças entre as informaçōes da base de dados de projetos desenvolvidos } \\
\text { anteriormente e das funçōes do sistema que será desenvolvido. }\end{array}$ \\
\hline 3. & A partir dos dados obtidos nos passos 1 e 2, selecionar os dados nos quais as estimativas podem ser baseadas. \\
\hline 4. & Elaborar a estimativa de tamanho. \\
\hline
\end{tabular}

\section{Exemplo de estimativa por Analogia.}

Ao examinar as características do novo sistema observou-se que existe uma forte similaridade com outro desenvolvido no ano anterior cujo custo total foi $\$ 1.200 .000$. O novo sistema deve ser desenvolvido com cerca de $30 \%$ a mais de funções de geração de relatórios, portanto, serão adicionados custos de $\$ 360.000$. Por outro lado, a equipe de desenvolvimento será integrada por um número maior de pessoas e a estimativa de custo pode ser reduzida em cerca de $20 \%$, ou $\$ 240.000$. O novo sistema será desenvolvido com cerca de $20 \%$ de código reutilizado, ocasionando outra redução da ordem de $\$ 240.000$. A estimativa de custo para o sistema pode ser calculada cn: $\$ 1.200 .000+\$ 360.000-\$ 240.000-\$ 240.000=\$ 1.080 .000$

Um ponto forte desse método é que as estimativas são elaboradas baseando-se em informações reais de projetos. Um ponto fraco é a dificuldade de se medir o grau de influência de fatores do tipo: possíveis restrições; técnicas utilizadas; equipe de desenvolvimento; etc. [Boehm, 1981].

\section{PERT Sizing}

Outra técnica de cálculo de estimativas é a análise de PERT (What-if Analysis), onde a estimativa é obtida atravćs da média ponderada de três valores: um valor otimista, um pessimista e um mais provável [Software, 1996]. 
Por exemplo, para uma nova função de sistema, foram estimados três tamanhos, atribuidos a três variáveis: o tamanho otimista, estimado em $10 \mathrm{KLOC}$, o tamanho mais provável, estimado em $12 \mathrm{KLOC}$, e o tamanho pessimista, estimado em 15 KLOC. Utilizando-se as equações de estimativa para o tamanho esperado (Equação 2.1), e o desvio padrão (Equação 2.2), obtćm-se o tamanho: 12.167 Kloc e o desvio padrão 0.833 . O desvio padrão resultante do cálculo significa que a cstimativa de tamanho estará entre 11.334 (12.167 $-0.833)$ c $13 \operatorname{KLOC}(12.167+0.833)$.

\subsection{O uso de Dados Históricos no Processo de Estimativas}

Para que as organizações possam efctuar estimativas mais precisas, é necessário que possuam inforınações registradas de projetos anteriores [Wiegers, 2000]. A falta de informações de projetos passados e, às vezes, atć mesmo de dados das estimativas iniciais do projeto atual, impedem a análise sistemática por Analogia entre projetos e qualquer tentativa de melhoria na precisão das estimativas [Vigder, 1994]. Além disso, os principais modelos de predição para software foram desenvolvidos a partir de análises do contexto de um conjunto específico de dados. Portanto, para utilização precisa do modelo adotado, é necessário calibrar o modelo conforme a realidade da organização, o que somente é possível se a organização possuir uma base histórica de observações [Fenton, 1991].

A basc de dados é alimentada com a coleta de dados referentes a prazos, esforço e custos efetivamente realizados em projetos anteriormente desenvolvidos, agrupados de acordo com o tipo de plataforma de hardware/software e o tipo de processo de desenvolvimento. Dados sobre outros atributos, comno dados do processo de estimativas, eventuais suposições assumidas para o projcto, quantidade de defeitos encontrados, etc., tainbém podem ser coletados [Fernandes, 1995].

As estimativas são elaboradas através de um processo de inferência na base de dados. Portanto, é preciso considerar que a inferência deve ser realizada para o mesmo tipo de ambiente de hardware/software em que será desenvolvido o software e para o mesmo processo que servirá de base para o desenvolvimento [Fernandes, 1995]. A Figura 3.6 apresenta um framework de base de dados de estimativas de projetos. 


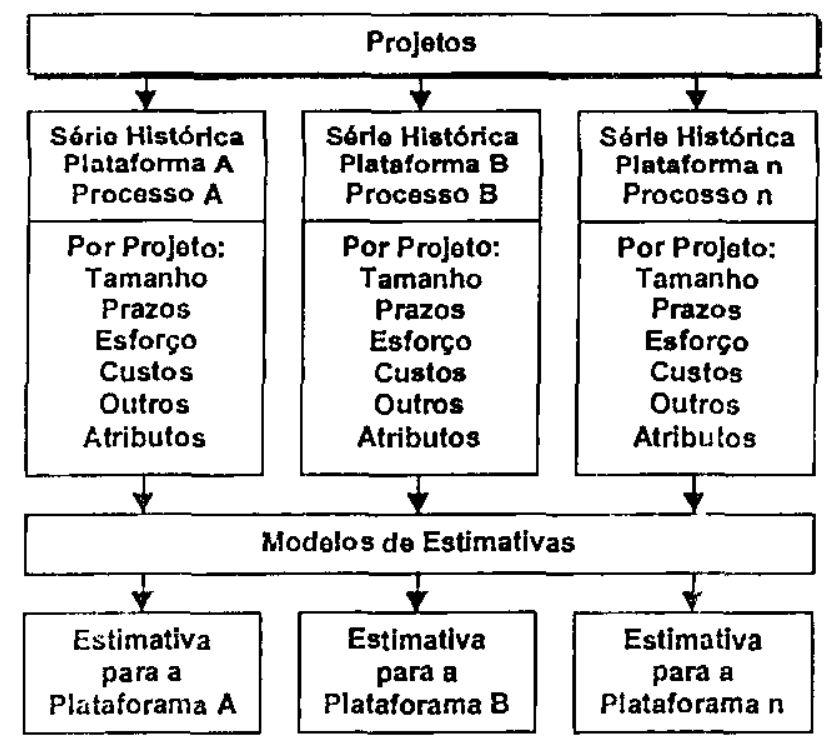

Figura 3.6 - Base de dados históricos para estimativas [Fernandes, 1995]

Para estimar prazo e esforço do projeto, será considerado o exemplo de base dc dados com uma série histórica hipotética, apresentado na Tabela 3.5. Os dados de tamanho de projetos e prolutividade estão registrados em pontos dc função, porém o mesmo procedimento é válido para linhas de código.

Tabela 3.5 - Base de dados históricos [Fernandes, 1995]

\begin{tabular}{|c|c|c|c|c|}
\hline \multirow{2}{*}{\multicolumn{5}{|c|}{ Plataforma de Hardwaro }} \\
\hline & & & & \\
\hline \multicolumn{5}{|c|}{ Plataforma de Software } \\
\hline \multirow{2}{*}{\multicolumn{2}{|c|}{$\begin{array}{l}\text { Gerenciador de Banco de Dados } \\
\text { Monitor de TP }\end{array}$}} & \multicolumn{3}{|c|}{ : DB2 } \\
\hline & & \multicolumn{3}{|c|}{ : CICS } \\
\hline \multicolumn{2}{|c|}{ Linguagem de Programą̧ăo } & \multicolumn{3}{|c|}{ : CSP } \\
\hline \multicolumn{2}{|l|}{ Processo } & \multicolumn{3}{|c|}{ : Metodologia Eslrulurada } \\
\hline \multirow{2}{*}{ Itens } & \multicolumn{4}{|c|}{ Projetos } \\
\hline & A & $\mathbf{B}$ & C & $\mathbf{D}$ \\
\hline Tamanho & 300 & 500 & 800 & 1200 \\
\hline Esforco $H / M$ & 10 & 16,67 & 32 & 60 \\
\hline Prazo (meses) & 5 & 6 & 8 & 10 \\
\hline Custo $\$$ & 48,8 & 80,016 & 153 & 288 \\
\hline Equipe & 2 & 3 & 4 & 6 \\
\hline Produtividade PF/H/M & 30 & 30 & 25 & 20 \\
\hline
\end{tabular}

Para cstimar o prazo do projeto é comum encontrar valores de tamanho de software diferentcs dos existcntes no conjunto de dados e que estejam compreendidos entre as observações registradas. Nesse caso, emprega-se o método da interpolação aritmética, apresentado na Equaçào 3.3.

$$
Y=Y_{0}+\frac{X-X_{0}}{X_{1}-X_{0}} *\left(Y_{1}-Y_{0}\right)
$$


Supondo uma estimativa de tamanho de 600 PFs (situada entre 500 e 800 PFs na na escala de valores da base de dados) as variáveis da Equação 3.3 assumem os seguintes valorcs: $Y_{0}=6, Y_{1}=8, X=600, X_{0}=500$ e $X_{l}=800$. Aplicando-se a equação, obtém-sc a estimativa $Y=6,6$ meses.

O esforço estimado ć medido pcla alocação dos recursos humanos, em termos de pessoas/mês ou pessoa/hora. Podc-se efetuar a inferência na base de dados e obter a estimativa de csforço atravćs do método da interpolação aritmética (Equação 3.3) ou através do método da transformação direta (Equação 3.4).

$$
\text { Esfor }{ }^{\circ} \circ=\frac{(\text { Tamanho Estimado do Software em PFs })}{(\operatorname{Produtividade~Média~em~PFs~} / H / M)}
$$

Para efetuar a transformação direta, é necessário que, para cada projeto, as taxas de produtividade média de deschvolvimento estejam contidas no conjunto de dados, conforme a plataforma de liardware/software e a metodologia de desenvolvimento utilizada. Supondo que a produtividade inćdia na base de dados para a plataforma e processo de desenvolvimento enpregados seja igual a 26,25 PFs/pessoas/mês e os PFs estimados sejam 500, o cálculo do esforço através do método da transformação direta (Equação 3.4) é: Esforço $=19$ pessoas $/$ mês $(500 / 26,26)$ (por arredondamento).

\subsection{Custo Estimado para o Projeto}

O custo cstimado para o projeto é, basicamente, o produto do custo de pessoas/mês ou pessoas/hora pelo esforço previsto. De acordo com Fernandes [Fernandes, 1995], duas abordagens podem ser utilizadas para calcular o custo do esforço em pessoas/mês: o custeio direto e o custeio por absorção total.

O custeio direto considera apenas o salário mais encargos, ou em termos de valores médios, ou aqucle que represcnta o recurso específico a ser empregado no projeto, de acordo com a respectiva faixa salarial.

$\Rightarrow$ (salário + encargo) médio de homens-mês x esforço estimado;

O custeio por absorção total é mais complexo, pois considera um rateio entre diversos tipos de despesas incidentes sobre o desenvolvimento do software, tais como: recursos computacionais, equipamcntos auxiliares, serviços contratados, custos administrativos, custos com materiais de consumo, custos de pessoal referentes às áreas de assessoria, etc. 
$\Rightarrow$ (salário + encargo + parcela de rateio) $x$ esforço estimado;

A estrutura de divisĩo de trabalho pode ser utilizada para elaborar estimativas de custos das fascs do projeto e até de todo o projeto (Figura 3.7). O custo da fase é a soma dos custos das atividades a ela pertencentes e o custo total do projeto é a soma dos custos de suas fases. Esse processo também ć conhecido como Botton Up Estimating [Vargas, 2000].

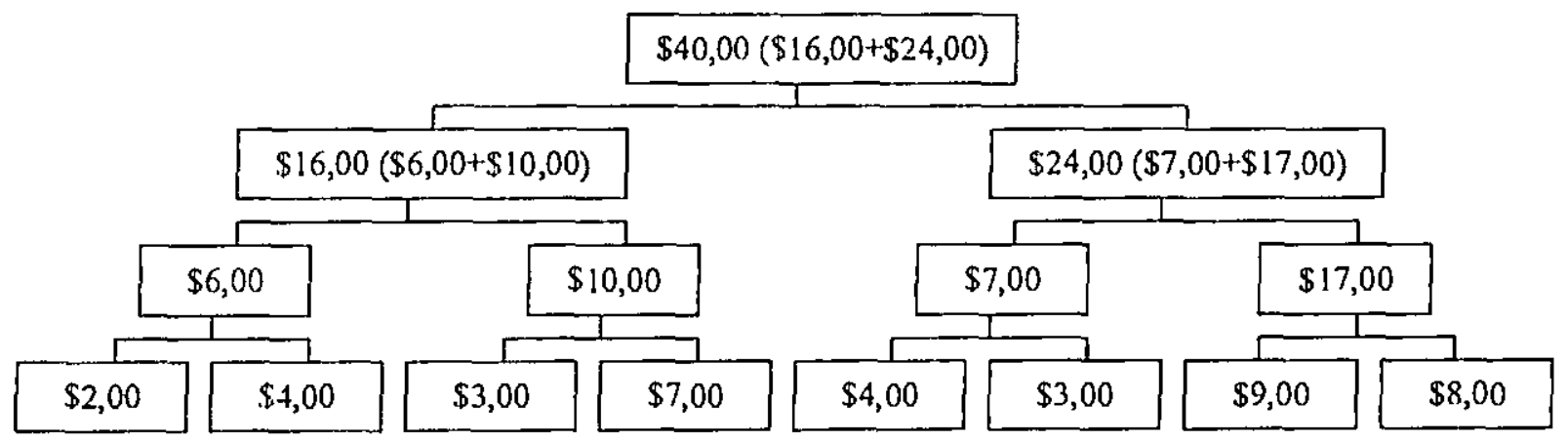

Figura 3.7 - WBS como ferramenta para cálculo do custo do projeto [Vargas,2000]

\subsection{Considerações Finais}

Este capítılo aprescntou a etapa de elaboração de estimativas, estruturada na forma de um modelo de processo. Foram apresentadas também métricas de tamanho de software e técnicas de estimativa para cálculo de tamanho de aplicações, tcmpo, esforço e custo de desenvolvimento. O capítulo seguinte apresenta os modelos de estimativa COCOMO e COCOMO II. 


\section{OS Modelos DE Estimativa COCOMO E COCOMO II}

\subsection{Considerações iniciais}

Estc capítulo descreve o modelo COCOMO para claboração de estimativas c a sua nova versão, o modelo COCOMO II, que considera elementos mais modernos de desenvolvimento de software. Também são apresentadas algumas ferramentas automatizadas que implementam csses modelos e outras técnicas de estimativa.

\subsection{O Modelo COCOMO}

Apresentado em 1981 por Barry Boehm [Boehm, 1981], o COCOMO é um modelo para cstimar esforço, prazo, c tamanho da equipe para um projcto de software. Todas as referências ao COCOMO encontradas na literatura publicada até 1995 são citaçõcs desse modelo.

O COCOMO apresenta uma sćric de equações derivadas a partir do estudo de uma base de dados de 63 projetos realizados de 1964 até 1979, em sua maior parte na empresa TRW Systems, Inc.. As aplicações pertenciam a diferentes domínios, entre eles negócios, aplicações cientificas, sistemas de controle e sistemas operacionais e foram implementadas em várias linguagens diferentes, cujas dimensões que variavam de 2.000 até de 1.000 .000 de linhas de código (comentários excluídos) [Conte, 1985]. Para obter as equações do COCOMO, Boehm fez uso da combinação de expcriência com resultados de outros modclos de estimativa de custo con a opinião subjetiva de gerentes de software experientes. O COCOMO é apresentado na forma de um conjunto de modelos divididos hicrarquicamente em três níveis: Básico, Intermediário c Avançado.

O Modelo COCOMO Básico calcula o esforço do desenvolvimento de software em função do tamanho estimado do programa expresso em linhas de código. 
Essa versão é aplicável à grande maioria dos projetos de software, de pequeno ou médio porte, apesar de ser limitada por não considerar fatores que interferem no desenvolvimento do projeto, do tipo: restrições de hardware, qualificação e experiência do pessoal de desenvolvimento e uso de ferramentas técnicas modernas, entre outros.

O Modelo COCOMO Intermediário calcula o esforço de desenvolvimento de software em função do tamanho do programa e de um conjunto de direcionaclores de custo, alternativanente chanados atributos ou fatores de software, que incluem avaliações subjetivas do produto, do hardware, do pessoal e dos atributos do projeto. Evidentcinente, esse modelo exige informações além do mero tamanho do sistema computacional e proporciona capacidade mais precisa de estimar.

O Modelo COCOMO Avançado incorpora todas as características da versão intermediária, incluindo a avaliação do impacto dos atributos do software e da equipe desenvolvedora cm cada passo do processo de desenvolvimento.

A aplicação do método começa pela classificação do produto a ser mensurado, categorizando o software em um de três tipos fundamentais de desenvolviınento identificados por Boehm: orgânico, embutido ou semidestacado.

No modo orgânico, também chamado de modo convencional, equipes relativamente pequenas desenvolvein sistemas num ambiente altanente "familiar", in-house. Nesse modo de desenvolvimcnto, a maior parte das pessoas engajadas no projeto tem experiência prévia com sistemas similares na organização e entendimento completo do sistenta. $O$ ambiente desenvolvimento é estável, com pouca necessidade de inovação, são utilizados algoritınos simples, não existindo requisitos de entrega rígidos. O tamanho dos projetos abrange até 50.000 linhas de código.

O principal fator que distingue um projeto de software de modo embutido, também conhecido cono modo restrito, é a necessidade de seguir restriçōes rigorosas. O produto a ser desenvolvido deverá operar dentro de um contexto complexo de hardware, software, regras e procedimentos operacionais. São projetos de software caracterizados por serem relativamente grandes, com muita necessidade de inovação, que demandam altos custos de verificação e validação. 
Exemplos de projetos do modo embutido são: projetos de sistemas de transferência elctrônica de fundos e projetos de sistemas de controle de tráfcgo aérco.

O modo semidestacado, também chamado de modo difuso, é aplicado em projetos de software com características situadas entre os modos orgânico e embutido. Suas características básicas são: a cquipe mescla grande e pouca experiência com a aplicação com a tecnologia, e o tamanho do software pode chegar a 300.000 linhas de código.

\subsubsection{Fórmulas de Cálculo do COCOMO 81}

As equações de estimativa de esforço de desenvolvimento em homens-mês são da forma aprescntada na Equação 4.1, onde $S$ é o tamanho ${ }^{1}$ do software expresso em milhares de linhas de código, excluídos os comentários, e $m(X)$, um multiplicador composto que depende de 15 direcionadores de custo. No COCOMO Básico, $m(X)=l$ para cada direcionador de custo; no COCOMO Intermediário devem ser atribuídos valores específicos para cada atributo.

$$
E=a_{i} S^{b_{l}} m(X)
$$

Os modos de desenvolviniento e os valores de $\mathrm{a}_{i}$ e $\mathrm{b}_{i}$ para os níveis Básico e Intermediário são apresentados na Tabela 4.1 .

Tabela 4.1 - Parâmetros do COCOMO - Estimativa de Esforço
\begin{tabular}{|c|c|c|c|c|}
\hline Modo & $\begin{array}{c}\text { COCOMO } \\
\text { Básico }\end{array}$ & \multicolumn{2}{c|}{$\begin{array}{c}\text { COCOMO } \\
\text { Intermedlário }\end{array}$} \\
\hline & $a i$ & $b i$ & $a i$ & $b i$ \\
\hline Orgânico & 2.4 & 1.05 & 3.2 & 1.05 \\
\hline Semidestacado & 3.0 & 1.12 & 3.0 & 1.12 \\
\hline Embutióo & 3.6 & 1.20 & 2.8 & 1.20 \\
\hline
\end{tabular}

Além de cstinar o esforço, o COCOMO também apresenta equações para estimar o prazo de desenvolvimento nominal do projeto em mescs e a divisão do esforço por fascs e atividades do projcto. Os modos de desenvolvimento Básico e Intermediário utilizam as mesmas equaçõcs para determinação de prazo.

IDeterminar o tamanho no inicio do projeto é uma das linitaçòes do COCOMO. Uma alternativa viável é a utilização da técnica de contagem de Pontos de Função, por ser facilmente efetuada logo no início do projeto. Pontos de função não ajustados podem ser convertidos $\mathrm{cm}$ linhas de código utilizando-se tabelas de conversão [Fernandes, 1995]. 
As equações de estimativa de prazo de desenvolvimento são da forma apresentada na Equação 4.2., onde $T$ é o tempo de desenvolvimento em meses, e $E$, o esforço já calculado. Os modos de desenvolvimento e os valores de $j$ e $k$ para os níveis Básico e Intermediário são apresentados na Tabela 4.2 .

$$
T=a_{j} E^{k}
$$

Tabela 4.2 - Parâmetros do COCOMO - Estimativa de Prazo [Fernandes, 1995]

\begin{tabular}{|c|c|c|}
\hline \multicolumn{3}{|c|}{ Modelos Básico e intermediário } \\
\hline Modo & $j$ & $k$ \\
\hline Orgánico & 2.5 & 0,38 \\
\hline Semideslacado & 2.5 & 0,35 \\
\hline Embutido & 2.5 & 0,32 \\
\hline
\end{tabular}

Segundo Conte, os 15 fatores de software do COCOMO representam uma redução substancial dos 29 fatores considerados por Walston e Felix, obtida em parte pela combinação de alguns atributos que parecem ser fortemente correlacionados, e em parte, pela omissão de outros fatores [Conte, 1985].

Os 15 atributos de software do modelo COCOMO Intermediário estão agrupados dentro de 4 categorias, apresentadas no Quadro 4.1. Boelım usou abordagem heurística para determinar o efeito dos direcionadores de custo. $\mathrm{O}$ efeito dos direcionadores foi quantificado em escalas de classificação que variam de cinco a seis pontos (Muito Baixo, Baixo, Nominal, Alto, Muito Alto e Extra Alto), dependendo do atributo e valores numéricos, foram atribuidos a cada ponto da escala.

Quadro 4.1 - Atributos Direcionadores de Custo do COCOMO [Conte, 1985]

\begin{tabular}{|c|c|c|c|}
\hline Atributos & & & Nível de Influência \\
\hline \multirow[t]{3}{*}{ do Produto } & RELY & Confiabilidade requerida pelo software & de muilo baixo $(0,75)$ a muilo allo \\
\hline & DATA & Tamanho da base de dados & de baixo $(0,94)$ a muito alto $(1,15)$ \\
\hline & CPLX & Complexidade do software & de muito baixo $(0,70)$ a extra alto $(1,65)$ \\
\hline \multirow[t]{4}{*}{ Computacionais } & TIME & Restriçōes relativas ao lempo de máquina & de nominal $(1,00)$ a extra allo $(1,66)$ \\
\hline & STOR & Restriçסes quanto ao uso de memória & de nominal $(1,00)$ a extra alto $(1,56)$ \\
\hline & VIRT & Mudanças do ambiente de software & de balxo $(0,87)$ a muito allo $(1,30)$ \\
\hline & TURN & Tempo de resposla & de baixo $(0,87)$ a muito alto $(1,15)$ \\
\hline \multirow{5}{*}{$\begin{array}{l}\text { da Equipe de } \\
\text { Desenvolvimento }\end{array}$} & ACAP & Capacidade dos analislas & de mullo baixo $(1,46)$ a muito allo $(0,71)$ \\
\hline & $\overline{A E X P}$ & Experềncia na aplicaçăo & de muito baixo $(1,29)$ a muito alto $(0,82)$ \\
\hline & PCAP & Capacidade dos programadores & de muito baixo $(1,42)$ a muito alto $(0,70)$ \\
\hline & VEXP & Experiência no ambiente de hardware & de muito baixo $(1,21)$ a alto $(0,90)$ \\
\hline & LEXP & Experiência com a linguagem de prog. & de muito baixo $(1,14)$ a alto $(0,95)$ \\
\hline \multirow[t]{3}{*}{ do Projeto } & MODP & Técnicas modernas de programaçāo & de muito baixo $(1,24)$ a muilo allo $(0,83)$ \\
\hline & TOOL & Uso de ferramenlas de software & de muilo baixo $(1,24)$ a muilo allo $(0,83)$ \\
\hline & SCED & Prazo requerido para o desenvolvimenlo & de muito baixo $(1,23)$ a muito allo $(1,10)$ \\
\hline
\end{tabular}


O ınodelo COCOMO ainda provê as distribuições de esforço e prazo calculados em quatro fases de desenvolvimento da aplicação. A fase de planos e requisitos considera: a etapa dc análise e modelagem lógica do sistema e as atividades que levaram à dimensão do software, em KDSI (mil instruções de código entregues). Esforço e prazo colocados nessa fase sempre extrapolam os $100 \%$, ou scja, todo esforço e prazo calculados anteriormente scrão distribuídos nas fases seguintes a essa. Essa prática serve, ao analista, para conhecimento dimensional do esforço e do custo provável das atividades que são necessárias desempenhar para se atingir um estágio que permita definição das métricas para o planejamento do que ainda há por vir no cmpreendimento.

$\mathrm{Na}$ fasc de projeto do produto é cfetivado o projeto técnico do algoritmo que pernitirá a implementação do sistema lógico que se tem até então. A fase de programação é onde a implementação do software cstá em execução. Pode ser, ainda, subdividida em uma etapa de detalhamento do projeto c outra da codificação propriamente dita. Na última fase, integração e testes, são planejadas e programadas as baterias de testes para os fragmentos do produto prontos e também do sistema operante no ambiente de destino.

Para essas distribuições, o método classifica os projetos em tamanhos referenciais: pequenos (2 KDSI), intermediários ( $8 \mathrm{KDSI}$ ), médios (32 KDSI), grandes (128 KDSI) ou muito grandes (512 KDSI) (Tabela 4.3).

Tabela 4.3 - Distribuiçāo de Prazo [Fernandes, 1995]

\begin{tabular}{|c|c|c|c|c|c|c|}
\hline \multicolumn{2}{|c|}{ Prazo } & \multicolumn{5}{|c|}{ Distribulcăo de Prazo (\%) } \\
\hline Modo & Fase & $2 K D S I$ & $8 K D S I$ & $32 K D S I$ & $128 \mathrm{KDSl}$ & $512 \mathrm{KDSI}$ \\
\hline \multirow{4}{*}{ Orgânico } & Planos e Requisitos & 10 & 11 & 12 & 13 & $\ldots .$. \\
\hline & Projelo do Produto & 19 & 19 & 19 & 19 & $\ldots \ldots$ \\
\hline & Programaçăo & 63 & 59 & 55 & 51 & $\ldots$ \\
\hline & inlegração e teste & 18 & 22 & 26 & 30 & $\ldots$ \\
\hline \multirow{4}{*}{ Semidestacado } & Planos e Requisitos & 16 & 18 & 20 & 22 & 24 \\
\hline & Projeto do Produto & 24 & 25 & 26 & 27 & 28 \\
\hline & Programaçăo & 56 & 52 & 48 & 44 & 40 \\
\hline & integraçăo e teste & 20 & 23 & 26 & 29 & 32 \\
\hline \multirow{4}{*}{ Embutido } & Planos e Requisitos & 24 & 28 & 32 & 36 & 40 \\
\hline & Projeto do Produto & 30 & 32 & 34 & 36 & 38 \\
\hline & Programaçăo & 48 & 44 & 40 & 36 & 38 \\
\hline & integraçäo e teste & 22 & 24 & 26 & 28 & 30 \\
\hline
\end{tabular}


Para tamanhos de software diferentes dos tamanhos da tabela padrão, mas dentro dos limites de 2 a 512, pode-se empregar o método da interpolação aritmética (Equação 3.1). Boehm definiu tabelas baseadas na distribuição de Rayleigh, para associar a distribuição percentual de prazo (Tabela 4.3) e esforço (Tabela 4.4) aos tamanhos de projetos, de acordo com as fases.

Tabela 4.4 - Distribuiçăo de Esforço [Fernandes, 1995]

\begin{tabular}{|c|c|c|c|c|c|c|}
\hline \multicolumn{2}{|c|}{ Esforco } & \multicolumn{5}{|c|}{ Distribuição de Esforco (\%) } \\
\hline Modo & Fase & 2KDSI & $8 K D S I$ & $32 \mathrm{KDSI}$ & $128 \mathrm{KDSI}$ & $512 \mathrm{KDSI}$ \\
\hline \multirow{6}{*}{ Orgânico } & Planos e Requisitos & 6 & 6 & 6 & 6 & $\ldots .$. \\
\hline & Projeto do Produto & 16 & 16 & 16 & 16 & $\ldots .$. \\
\hline & Programaçăo & 68 & 65 & 62 & 59 & $\ldots .$. \\
\hline & Projeto Detalhado & 26 & 25 & 24 & 23 & $\ldots .$. \\
\hline & Codificação & 42 & 40 & 38 & 36 & $\ldots .$. \\
\hline & Integraçăo e teste & 16 & 19 & 22 & 25 & $\ldots . .$. \\
\hline \multirow{6}{*}{ Semidestacado } & Planos e Requisitos & 7 & 7 & 7 & 7 & 7 \\
\hline & Projeto do Produto & 17 & 17 & 17 & 17 & 17 \\
\hline & Programaçăo & 64 & 61 & 58 & 55 & 52 \\
\hline & Projeto Detalhado & 27 & 26 & 25 & 24 & 23 \\
\hline & Codificaçāo & 37 & 35 & 33 & 31 & 29 \\
\hline & Integraçăo e teste & 19 & 22 & 25 & 28 & 31 \\
\hline \multirow{6}{*}{ Embutido } & Planos e Requisitos & 8 & 8 & 8 & 8 & 8 \\
\hline & Projeto do Produto & 18 & 18 & 18 & 18 & 18 \\
\hline & Programaçāo & 60 & 57 & 54 & 51 & 48 \\
\hline & Projeto Detalhado & 28 & 27 & 26 & 25 & 24 \\
\hline & Codificaçăo & 32 & 30 & 28 & 26 & 24 \\
\hline & Integraçăo e teste & 22 & 25 & 28 & 31 & 34 \\
\hline
\end{tabular}

\subsubsection{Exemplo de aplicação do modelo COCOMO}

A seguir é apresentado um exemplo [Teixeira, 2000b] de uso do modelo COCOMO Intermediário para estimativa de esforço, tempo e distribuição de pessoal por fase de desenvolvimento.

\section{Exemplo de aplicação do modelo COCOMO}

Foi solicitado o desenvolvimento de um sistema de baneo de dados para um projeto de automąão de escritório. Segundo o documento de requisitos, o sistema deverá ser composto de quatro módulos, cujo tamanho foi estimado em: módulo de entrada de dados $-0.6 \mathrm{KLOC}$, módulo de atualização de dados - $0.6 \mathrm{KLOC}$, módillo de consiilia - $0.8 \mathrm{KLOC}$ e móclulo de relatórios - $1.0 \mathrm{KLOC}$. O tamanho nominal do sistema é 3.0 KDSI. 
O COCOMO Intermediário foi considerado o modelo mais adcquado, pois é necessário computar o esforço associado a um conjunto de "direcionadores de custo" que adeqücm o resultado das fórmulas às características ambientais. Pela dimensão estimada do produto e caractcrísticas dos desenvolvedores, utilizar-se-ão as prerrogativas do modo orgânico $(\mathrm{a}=3.2 \mathrm{e} \mathrm{b}=1.05)$. Aplicando a fórmula de cálculo do esforço, tem-se:

Esforço: $\mathrm{E}_{(\mathrm{HM})}=3,2(\mathrm{KDSI})^{1,05}=3,2(3,0)^{1,05}=10,142$ Homens-Mês

O gercnte avaliou os 15 direcionadores dc custo e chegou ao seguinte resultado, como fruto de análisc ambicntal: Complexidade Alta (1.15), Armazenamento Alto (1.06), Experiência Baixa (1.13) e Capacidades dos Programadores Baixa (1.17). Os outros atributos foram considcrados nominais. De posse de tais dados, pode-se calcular:

Esforço: $\mathrm{E}_{(11 / \mathrm{M})}=10,142 \times 1,15 \times 1,06 \times 1,13 \times 1,17=16,345$ Homens-Mês

Aplicando a fórmula de cálculo do prazo, tem-se:

Prazo: $P_{(M)}=2,5 \times E^{0,38}=2,5 \times 16,345^{0,38}=7,22$ Meses.

Diante de tais números, é possível calcular:

Tamanho da Equipe $=$ esforço/prazo $=16,345 / 7,22=2$ Pessoas (por arredondamento) .

Considerando que, conforme prediz o modelo, o mês é constituído de 19 dias úteis, o prazo definido corresponde a 122 dias de trabalho. As distribuições de prazo, para um projeto orgânico, próximo dos $2 \mathrm{KDSI}$, e prazo 7,20 meses ou 216 dias, são, aproximadamentc, as seguintes: Planos e Requisitos: 10\% (já realizado), Projeto do Produto: 19\% - 41 dias, Programação: $63 \%$ - 136 dias, Integração e Testes: $18 \%$ - 38 dias.

De acordo com Trindade [Trindade, 2000a], os pontos fortes desse modelo de estimativa são o embasamento em experimentações, em derivações matemáticas e em tabelas de dados cruciais para que quaisquer profissionais da área de desenvolvimento possam realizar os cálculos necessários ao planejamento e à gestão da produção. Há critérios bem definidos para a determinação do nível de influência do ambiente profissional e da capacidade produtiva dos profissionais envolvidos com o projeto. Por outro lado, alguns pontos para a determinação dos direcionadores de custo flutuam num nível bastante alto de generalização, enquanto outros mais detalháveis, de significativo impacto sobre custos, ficam de fora. 


\subsection{O Modelo COCOMO II}

O projeto COCOMO II, introduzido em 1994, foi uma iniciativa do desenvolvedor do COCOMO, o prof. Dr. Barry Boehm da University of Southern California - USC, contando inicialmente com a colaboração das empresas Bellcore, Texas Instruments e Xerox Corporation como membros afiliados. Posteriormente, outras grandes organizações se juntaram ao projeto.

O COCOMO II é também um método para estimar esforço, prazo, tamanho de equipe e custo necessários para o desenvolvimento de uma aplicação, partindo-se da premissa de que o software ou os módulos que o compõem, já foram dimensionados. A maioria das referências ao COCOMO encontradas na literatura publicadas a partir de 1995 referem-se a esse modelo.

O novo método para estimativa de projetos é um conjunto de derivações matemáticas constituído de modelo algorítmico composto, classificado segundo uma estrutura com três modelos (ou submodelos) subsequentes [Teixeira, 2000b], identificados como Composição da Aplicação (Application Composition), Pré-Projeto (Early Design) e Pós-Arquitetura (PostArchitecture), apresentados a seguir.

O modelo Composição da Aplicação é voltado a aplicações desenvolvidas por equipes pequenas em poucas semanas ou meses. Esse modelo foi projetado para prever esforço de prototipação envolvido no uso de ambientes integrados de composição rápida de aplicações de software auxiliados por computador ou ICASE - Integrated Computer Aided Software Environment, que se "encarregam" da produção, provocando grande economia de esforço e prazo. Para estimar tamanho de aplicações são usados dados de contagem de Pontos de Objeto $^{2}$. Segundo os projetistas do COCOMO II, estimativas de Pontos de Objeto foram comparadas a estimativas de Pontos de Função e apresentaram resultados mais adequados aos tipos de aplicação a que se destina o modelo Composição da Aplicação.

2 Pontos de Objeto são uma abordagem de medição funcional de tamanho de software baseada na contagem funcional de telas, relatórios e de módulos de linguagem de terceira geração, onde cada um dos elementos conta 'os recebe uma classificação em niveis de complexidade (simples, média ou alta) [Teixeira, 2000B]. 
Nas etapas posteriores às fases iniciais de projetos e em ciclos de vida espirais pode haver a necessidade de pesquisa de arquiteturas alternativas ou estratégias de desenvolvimento incremental. O modelo Pré-Projeto foi desenvolvido para elaborar estimativas iniciais de esforço e prazo, a partir de análise de requisitos ou modelagem de produto, ainda que incompletas, onde a estimativa nào pode se apoiar $\mathrm{em}$ um dimensionamento do software a construir. O nível de detalhes que o modelo utiliza é consistente com o nível de informações disponíveis e com o nível de precisão necessária nessa fase. As principais variáveis de entrada para o modelo são: o tamanho estimado do sistema e os direcionadores de custo. O tamanho da aplicação que vai ser desenvolvida é a principal variável de entrada para cálculo de esforço e tempo, podendo ser estimado em linhas de código (KLOC) ou em pontos de função brutos ou não ajustados [Teixeira, 2000b].

As equações para cálculo de esforço (4.3) e tempo (4.4) de desenvolvimento de projeto são básicas para os modelos Pré-Projeto e Pós-Arquitetura. As principais variáveis de entrada são: o tamanho, a constante $a$ e o fator escalar $b$. As equações de esforço de desenvolvimento dos modelos Pré-Projeto e Pós-Arquitetura diferem apenas no número de direcionadores de custo (sete ou dezessete, respectivamente).

O modelo Pós-Arquitetura foi projetado para ser utilizado em estimativas quando o projeto está pronto para ser desenvolvido. Nessa etapa, informações mais precisas para as entradas dos direcionadores de custo estão disponíveis e proporcionam estimativas mais precisas. Esse modelo prevê a utilização de linhas de código e/ou pontos de função para estimar o tamanho inicial do projeto, componentes para reuso de software e 17 direcionadores de custo (Quadro 4.6), combinados com o cálculo de 5 fatores de escala de projeto. Fórmulas de cálculo do COCOMO II

O COCOMO II tem fórmulas de cálculo unificadas para esforço e para prazo (equações 4.3 e 4.4). A fórmula para cálculo de esforço é praticamente a mesma que no modelo predecessor, porém agora agrega maior número de ponderações para o ajuste ambiental e o acréscimo de uma fração para casos de reformas algorítmicas [Trindade, 1999]. 
Os clementos diferenciados $a, b, j$ e $k$, cujos valores são estáticos e dependentes das classificações de modo e de tipo, na versão de 1981, são agora totalmente variáveis e adaptáveis às condições ambientais dos desenvolvedores, nesta versão.

$$
\begin{array}{cc}
\text { Esforço } & \mathrm{E}_{(\mathrm{HM})}=a S^{b} \mathrm{C} i+\mathrm{F}_{\text {re-eng }} \\
\text { Tempo } & \mathrm{P}_{(\mathrm{M})}=j E^{k}
\end{array}
$$

nas quais:

- $\mathbf{E}_{(1 \mathrm{im})}$ represcnta o esforço em Homens-Mês;

- $l_{(M)}^{s}$ representa o prazo em Meses;

- S representa o tamanho do software, que pode agora ser expresso em: SLOC linhas de código-fonte, Pontos de função ou Pontos de objetos;

口 $\mathrm{C} i$ representa os "direcionadores de custo" aplicáveis, correspondentes ao submodelo;

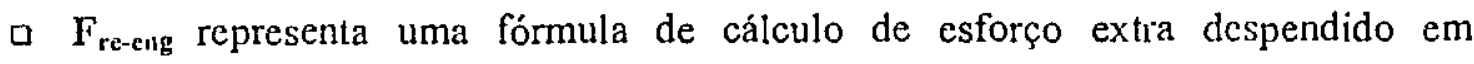
atividades de re-engenharia.

As constantes $a$ e $j$ nas equações 4.3 e 4.4 são dinâmicas e únicas para todos os submodelos da métrica, ajustáveis à evolução da pesquisa contínua, tanto acadêmica quanto particular. Aos resultados destas pesquisas contínuas é dado o nome de "calibrações". O centro de pesquisas da USC - University of Southern California manténı estudos com a finalidade de publicação de calibrações. A calibração mais recente por eles publicada é identificada como "1999.0". Na calibração da versão 1999.0: $a=2,94$ e $j=3.67$. Os expocntes $b$ e $k$ também são dinâmicos: $k$ baseado em uma calibração e $b$, além da calibração, en 5 fatores de equilíbrio ou escala (particularizações de "direcionadores de custo"). Ambas as siluações são aplicadas às fórmulas matemáticas específicas, a saber:

ㅁ $\quad \mathbf{b}=\alpha+0,01$ EFatores de Equilíbrio no submodelo Composição da Aplicação: $\mathrm{b}=1$

ㅁ $k=\beta+0,2(b-1,01)$

ㅁ. $\alpha=0,91$ e $\beta=0,28$ (também na calibração 1999.0) 
Os fatores de escala detalhados no modelo COCOMO II (Tabola 4.5) substituom os modos de desenvolvimento do nodelo COCOMO original Orgânico, Semidestacado e Enbutido, refinando também os quatro fatores de escala do modelo Ada COCOMO.

O proccdimento para determinação do fator de escala Maturidade do Processo está baseado no modelo de maturidade CMM da SEI.

Tabela 4.5 - Fatores de Escala do Modelo COCOMO II [Teixeira, 2000b]

\begin{tabular}{|c|l|l|}
\hline \multicolumn{2}{|c|}{ Fator } & Escala \\
\hline PREC & Precedéncia em aplicaçōes & $\begin{array}{l}\text { de muito baixo }(6,20) \\
\text { a extra alto }(0,00)\end{array}$ \\
\hline FLEX & Flexibilidade de desenvolvimento & $\begin{array}{l}\text { de muito baixo }(5,07) \\
\text { a extra alto }(0,00)\end{array}$ \\
\hline RESL & Resoluçōes de arquitetura đó riscos & $\begin{array}{l}\text { de muito baixo }(7,07) \\
\text { a extra alto }(0,00)\end{array}$ \\
\hline TEAM & Coesð̊o da equipe de desenvolvimento & $\begin{array}{l}\text { de muito baixo }(5,4 \overline{8}) \\
\text { a extra alto }(0,00)\end{array}$ \\
\hline PMAT & Maturidade do processo (nivel CMM) & $\begin{array}{l}\text { de muito baixo }(7.80) \\
\text { a extra alto }(0,00)\end{array}$ \\
\hline
\end{tabular}

No parâmctro $\mathrm{C} i$, os direcionadores de custo também mudam com calibrações. A versão 1999.0 do modelo COCOMO II apresenta os direcionadores calibrados com valores de nivel de influĉncia conforme apresentado na Tabela 4.6. A fórmula de cálculo, destinado à reengenharia, ainda não devidamente detalhada [Trindade, 2000a], refere-se ao esforço extra para conversões ou reformas algorítmicas em produtos de software já desenvolvidos, e tem a composição: $F_{\text {re-cng }}=[$ ASLOC $($ AT / 100 ) / ATPROD], na qual:

- ASLOC é uma medida quantitativa de linhas de código a alterar pela atividade;

口 ATPROD é medida de produtividade. Até a calibração 1999.0 tem valor: 2400 declaraçõcs-fontc / pessoas-mês;

- AT / 100 é um percentual de código recriado por tradução automática. Alguns percentuais possíveis, publicados pelos pesquisadores da USC: Processamento simples, cm batch: 96\%, Processamento batch, com classificação (SORT): $90 \%$, Processamento batch, com SGBD's: $88 \%$, Processamento batch, com SORT e SGBDs: $82 \%$, Processamento interativo (on-line): $50 \%$. 
Tabela 4.6 - Direcionadores de Custo do Modelo COCOMO II

\begin{tabular}{|c|c|c|c|c|}
\hline \multicolumn{4}{|c|}{ Atributos } & Nivel de Influência \\
\hline \multirow{6}{*}{ Produto } & PA & RELY & Confiabilidade requerida pelo software & de muito baixo $(0,82)$ a muito alto $(1,26)$ \\
\hline & PA & DATA & Tamanho da base de dados & de baixo $(0,90)$ a muito alto $(1,28)$ \\
\hline & PA & CPLX & Complexddade do software & de muito baixo $(0,73)$ a extra alto $(1,74)$ \\
\hline & PA & DOCU & Documentaçăo & de muito baixo $(0,81)$ a muito alto $(1,23)$ \\
\hline & PAED & RUSE & Reusabilidade requerida & de baixo $(0,95)$ a extra alto $(1,24)$ \\
\hline & ED & RCPX & Confiabilidade e complexidade do software & de extra balxo $(0,73)$ a extra alto $(2,38)$ \\
\hline \multirow{4}{*}{ da Plataforma } & PA & TIME & Restriçoes relativas ao tempo de máquina & de nominal $(1,00)$ a extra aito $(1,63)$ \\
\hline & PA & STOR & Restriçoess quanto ao uso de memória & de nominal $(1,00)$ a extra alto $(1,46)$ \\
\hline & PA & PVOL & Mudanças de plataforma & de baixo $(0,87)$ a muito alto $(1,30)$ \\
\hline & ED & PDIF & Dificuldades com a plataforma & de baixo $(0,87)$ a extra alto $(2,61)$ \\
\hline \multirow{8}{*}{$\begin{array}{l}\text { da Equipa } \\
\text { de Desenvollto }\end{array}$} & PA & ACAP & Capacidade dos analistas & de muito baixo $(1,42)$ a muito alto $(0,71)$ \\
\hline & PA & AEXP & Experiência na aplicaçăo & de muito balxo $(1,22)$ a muito alto $(0,81)$ \\
\hline & PA & PCAP & Capacldade dos programadores & de muito baixo $(1,34)$ a muito alto $(0,76)$ \\
\hline & PA & PEXP & Experiencla com a plataforma & de muito balxo $(1,19)$ a muito alto $(0,85)$ \\
\hline & PA & LTEX & Experiência com linguagem e ferramental & de muito baixo $(1,20)$ a muito allo $(0,84)$ \\
\hline & PA & PCON & Continuidade do pessoal & de muito baixo $(1,29)$ a muito alto $(0,81)$ \\
\hline & ED & PERS & Capacidade do pessoal & de extra baixo $(2,12)$ a extra alto $(0,50)$ \\
\hline & ED & PREX & Experiência profissional & de extra balxo $(1,59)$ a extra alto $(0,62)$ \\
\hline \multirow{4}{*}{$\begin{array}{c}\text { do } \\
\text { Projeto }\end{array}$} & PA & TUOL & Uso de ferramentas de software & de muito baixo $(1,17)$ a muito alto $(0,78)$ \\
\hline & PA & SITE & Desenvolvimento multi-iocal & de muito baixo $(1,22)$ a extra alto $(0,80)$ \\
\hline & PAED & SCED & Prazo requerido para o desenvolvimento & de muito baixo $(1,43)$ a muito alto $(1,00)$ \\
\hline & ED & FClL & Instalaçoes & de extra baixo $(1,43)$ a extra aito $(0,62)$ \\
\hline \multirow{2}{*}{\multicolumn{2}{|c|}{ LEGENDA: }} & ED & Modelo Early Design ("Pró-Projeto") & \\
\hline & & PA & Modelo Post Architecture ("Pós-Arquitetura") & \\
\hline
\end{tabular}

O COCOMO II ainda provê as distribuições de esforço e prazo calculados pelas fases de desenvolvimento da aplicação, conforme apresentado em seu modelo antecessor (planos e requisitos, projeto do produto, programação e integração e testes). Ainda são utilizados os mesmos percentuais do COCOMO em sua versão de 1981, que agrupa projetos de softwares nos tamanhos referenciais: peq̣uenos ( $2 \mathrm{KDSI}$ ), intermediários ( $8 \mathrm{KDSI})$, médios (32 KDSI), grandes (128 KDSI) ou muito grandes $(512 \mathrm{KDSI})$ e sugerindo as distribuições de esforço e prazo apresentadas nas tabelas 4.7 e 4.8 .

Tabela 4.7 - Percentuais de Distribuiçâo de Esforço do COCOMO II [Trindade, 2000a]

\begin{tabular}{|c|c|c|c|c|c|}
\hline \multicolumn{7}{|c|}{ Dlstribulção de Esforco, em \% } \\
\hline fase & 2 KDSI & $8 \mathrm{KDSI}$ & $32 \mathrm{KDSI}$ & $128 \mathrm{KDSI}$ & 512 KDSI \\
\hline Planos e Requisitos & 8 & 8 & 8 & 8 & 8 \\
\hline Projeto do Produto & 18 & 18 & 18 & 18 & 18 \\
\hline Programaçăo & 60 & 57 & 54 & 51 & 48 \\
\hline Integraçăo Testes & 22 & 25 & 28 & 31 & 34 \\
\hline
\end{tabular}


Tabela 4.8 - Percentuais de Distribuição de Prazo do COCOMO II [Trindade, 2000a]

\begin{tabular}{|c|c|c|c|c|c|}
\hline \multicolumn{7}{|c|}{ Distribuiçăo de Prazo, em \% } \\
\hline fase & 2 KDSI & 8 KDSI & 32 KDSI & 128 KDSI & 512 KDSI \\
\hline Planos e Requisitos & 24 & 28 & 32 & 36 & 40 \\
\hline Projeto do Produto & 30 & 32 & 34 & 36 & 38 \\
\hline Programaçăo & 48 & 44 & 40 & 36 & 38 \\
\hline Integraçäo e Testes & 22 & 24 & 26 & 28 & 30 \\
\hline
\end{tabular}

\subsubsection{Exemplo de aplicação do modelo COCOMO II}

A seguir é apresentado um exemplo [Trindade, 2000a] de uso do modelo COCOMO II Intermediário para estimativa de esforço, tempo e distribuição de pessoal por fase de desenvolvimento.

Uma aplicação pcquena e dirigida, com uma dimensão estimada em cerca de 7.500 linhas de código-fonte, devc ser desenvolvida por uma equipe que, embora pequena, conta com profissionais especializados c experientes. Para a aplicação do método, é necessário classificar o submodelo e, considerando que a dimensão já é conhecida, o desenvolvimento será sobre dados e prerrogativas do "Pós-Arquitetura".

Fatores de escala:

- $\quad \operatorname{PREC}=1,24$ - Há muita familiaridade com o tipo de aplicação a desenvolver, portanto a precedência tem um nível muito alto;

a FLEX $=2,03$ - Alguma flexibilidade é perceptível para estabelecimento e conformidade de uso de padrões, o que determina um nível al to;

$\operatorname{RESL}=0,00$ - As especificações do projeto estão totalmente sob domínio, portanto o nível é extra alto;

- $\operatorname{TEAM}=1,10$ - A cquipe de desenvolvimento tem uma coesão excelente, portanto as condições altaniente cooperativas estabelecem um nível muito alto;

a $\mathrm{PMAT}=4,68$ - A contagem especial (e parcial) das KPAs cumpridas pela equipe de desenvolvimento a coloca no nível 2 do CMM, portanto o nível é nominal;

Então, a soma dos Fatores de Equilibrio $=9,05$ e $b=0,91+0,01 \times 9,05=1,0005$.

Aplicando a fórmula de cálculo do esforço, tem-se:

Esforç: $\mathbf{E}_{(\mathrm{H} / \mathrm{M})}=a S^{b}=2,94 \times 7,5^{\mathrm{t}, 0005}=22,073$ Homens-Mês 
Observando-se os direcionadores de custo, tem-se, como fruto cle análise ambiental:

a RELY $=0,92$ - O sistema pode trabalhar com um índice de perdas facilmente recuperáveis, portanto a confiabilidade requerida tem um nível baixo;

ㅁ $\mathrm{DATA}=1,00-\mathrm{A}$ razão dimensional entre o banco de dados e o produto está entre 10 e 100, portando o tamanho da base remete a um nivel nominal;

ㅁ $\operatorname{DOCU}=1,00-$ A documentação a ser gerada o será na medida certa, para a quantidade necessária de ciclos de vida do projeto, portanto o nível é nominal;

ㅁ $\quad$ CPLX $=0,87$ - O software não é considerado complexo na análise dos 8 pressupostos correspondentes, portanto o nível é baixo;

ㅁ $\operatorname{RUSE}=1,07$ - Pretende-se a utilização de linhas de código entre programas gerados no mesmo projeto, portanto a reusabilidade requerida terá nível alto;

口 TIME $=1,00-\mathrm{A}$ disponibilidade en tempo de execução não ultrapassará os $50 \%$, portanto as restrições relativas ao tempo dos dispositivos são nominais;

a $\operatorname{STOR}=1,00-\mathrm{O}$ uso de áreas de armazenamento disponíveis não ultrapassará os $50 \%$, portanto as restrições relativas à memória são nominais;

口 $P V O L=0,87$ - A previsibilidade de grandes mudanças da plataforma não são menores que 12 meses, portanto o nível é baixo;

- $\mathrm{ACAP}=0,85-\mathrm{O}$ escore acumulado de competências atinge o $75^{\circ}$ percentil, portanto a capacidade dos analistas é alta;

口 AEXP $=0,81$ - Profissionais atuam, no tipo de aplicação, há, aproximadamente, 6 anos, portanto a experiência conta com nivel muito alto de influência;

․ $\mathrm{PCAP}=1,00-\mathrm{O}$ escore acunılado de competências atinge $055^{\circ}$ percentil, portanto a capacidade dos programadores apresenta nível nominal;

$\operatorname{PEXP}=0,91$ - Os desenvolvedores conhecem os recursos da plataforma há mais de 3 anos, portanto esta experiência tem nível alto;

․ $\operatorname{LTEX}=1,00$ - A programação se utilizará de recurso aplicável há, aproximadamente, 1 ano, portanto a experiência com linguagem e ferramental é nominal;

ㅁ $\mathrm{PCON}=0,81$ - A rotatividade de pessoal é baixíssima, cerca de $3 \% /$ ano, portanto a capacidade produtiva é incontestável e este nível de influência é muito alto;

口 TOOL $=0,90$ - A equipe conta com pesado ferramental para execução de suas tarefas de programação e testes, com bom nível de interatividade, portanto o nível é alto; 
- $\operatorname{SITE}=0,80$ - Desenvolvimento planejado para ser desenvolvido em rede local, com um comunicabilidade significativa, portanto o requerido tem nível de influência cxtra alto.

- $\operatorname{SCED}=1,43$ - Tempo contratado de desenvolvimento é $75 \%$ do nominal (desejável), portanto o requerido tem nível de influência muito baixo.

De posse de tais dados, pode-se calcular:

Esforç: $\mathrm{E}_{(\mathrm{H} / \mathrm{M})}=22,073 \times 0,92 \times 1,00 \times 1,00 \times 0,87 \times 1,07 \times 1,00 \times 1,00 \times 0,87$ $\times 0,85 \times 0,81 \times 1,00 \times 0,91 \times 1,00 \times 0,81 \times 0,90 \times 0,80 \times 1,43=8,594$ Homens-Mês.

A aplicação da fórmula de cálculo do prazo precisa dos parâmetros:

ㅁ $\mathbf{j}=3,67$

$\beta=0,28$

ㅁ. $\mathbf{k}=\beta+0,2 \times(b-1,01)=0,28+0,2 \times(1,0005-1,01)=0,278$

Daí, tcm-sc:

Prazo: $P(\mathbf{M})=\mathbf{j} \times \mathrm{E}^{\mathrm{k}}=3,67 \times 8,594^{0,278}=6,674$ Meses.

Diante de tais númerios, é possível calcular:

Tamanho da Equipe $=$ esforço/prazo $=8,594 / 6,674=2$ Pessoas (por arrcdondamento).

O COCOMO II não prevê novas determinações sobre o uso dos resultados para a distribuição de esforços e prazos calculados pclas etapas do ciclo de vida do desenvolvimento. O método conserva a proposição, conforme a vcrsão de 1981, baseada na filosofia de desenvolvimento em modo cascata.

Considerando o método de distribuição da primeira versão, as distribuições de prazo, para o projeto, pela proximidade com a faixa dos $8 \mathrm{KDSI}(7,5 \mathrm{SLOC}=12,5 \mathrm{KDSI} \sim$ 8KDSI), são, então, as scguintes: Planos c Rcquisitos: $28 \%$ (já realizado), Projeto do Produto: $32 \%$ - 41 dias, Programação: 44\% - 56 dias, Intcgração e Testes: $24 \%$ - 30 dias. Ciente de tais distribuições, planejamentos podem scr definidos, utilizando ferramentas como elaboração de rede PERT/CPM ou gráfico de Gantt. Cálculos de custo, considerando despesas com cada profissional envolvido, podem ser efetuados. 
Segundo Trindade [Trindade, 1999], apesar de muitos pontos apontados como evoluções do COCOMO II ainda carecem de detalhes, como é o caso da insipiência de dados sobre os submodelos Composição da Aplicação e Pré Projeto e da fórmula do esforço em reengenharia, a evolução do COCOMO torna-se muito mais sensível às condições ambientais e às características profissionais e técnicas das organizações e equipes de desenvolvimento. Além disso, a ampliação da gama de situações e circunstâncias analisadas para os devidos ajustes de valores calculados contribui para uma maior precisão, adequando o modelo ao desenvolvimento de software sob filosofias modernas e futuristas.

\subsection{Ferramentas de Estimativa do Modelo COCOMO}

Existem várias ferramentas de estimativa automatizadas que implcmentam os modelos COCOMO e COCOMO II, disponíveis em versões comerciais e versões de domínio público. Ferramentas de estimativa conslituem ferramentas importantes para o planejador estimar custo, esforço e cronograma e rcalizar análises «los resultados e representam um bom método para checagem com estimativas derivadas manualmente [Software, 1996]. Os exemplos de ferramentas de estimativa de software apresenfados a seguir são: REVIC, COSTAR, USC COCOMO 2000.0 e Cost Xpert.

\subsubsection{REVIC}

REVIC - REVised Intermediate COCOMO [REVIC, 2000] é uma ferramenta de domínio público desenvolvida pelo Departamento de Defesa dos Estados Unidos, derivada do modelo COCOMO original e disponibilizada na Internet. Essa ferramenta, que opera no ambiente DOS, é relativamente fácil de ser utilizada, operável por menus apresentados ao usuário. Vários parâmetros podem ser modificados pelo ustário para simular o ambiente do desenvolvimento mais próximo da realidade da organização.

\subsubsection{COSTAR}

COSTAR [COSTAR, 2000] é uma ferramenta comercial para cálculo de estimativa de esforço, custo, prazo e distribuição de equipe. A versão demonstrativa, disponibilizada na Internet, implenenta os modelos COCOMO original, Ada COCOMO e COCOMO II. O tamanho do sistema pode ser expresso em pontos de função (Figura 4.1) ou em linhas de código. 


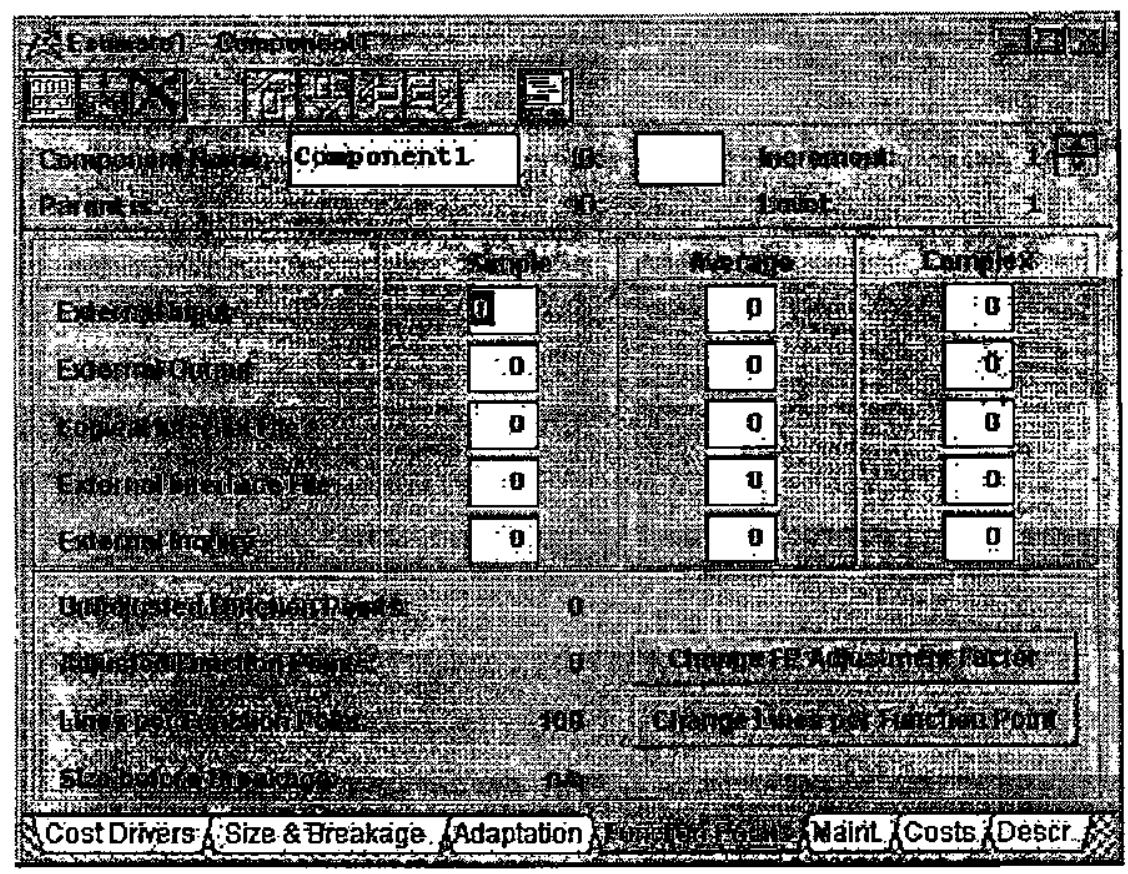

Figura 4.1 - Tela de Entrada de Pontos de Funçăo da Ferramenta COSTAR

Após a inserção dos dados de pontos de função, deve-se informar a linguagem escolhida para implementação do sistema (Figura 4.2).

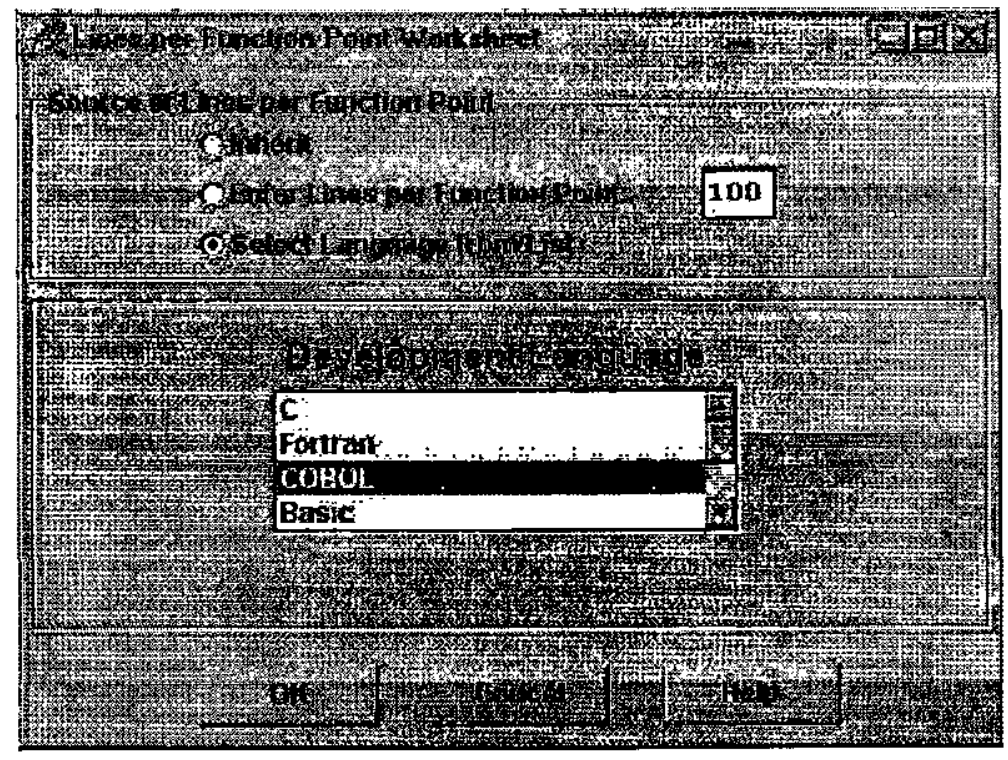

Figura 4.2 - COSTAR - Seleçăo da Linguagem de desenvolvimento

Os direcionadores de custo do modelo COCOMO $\Pi$ devem ser informados na tela apresentada na Figura 4.3. 


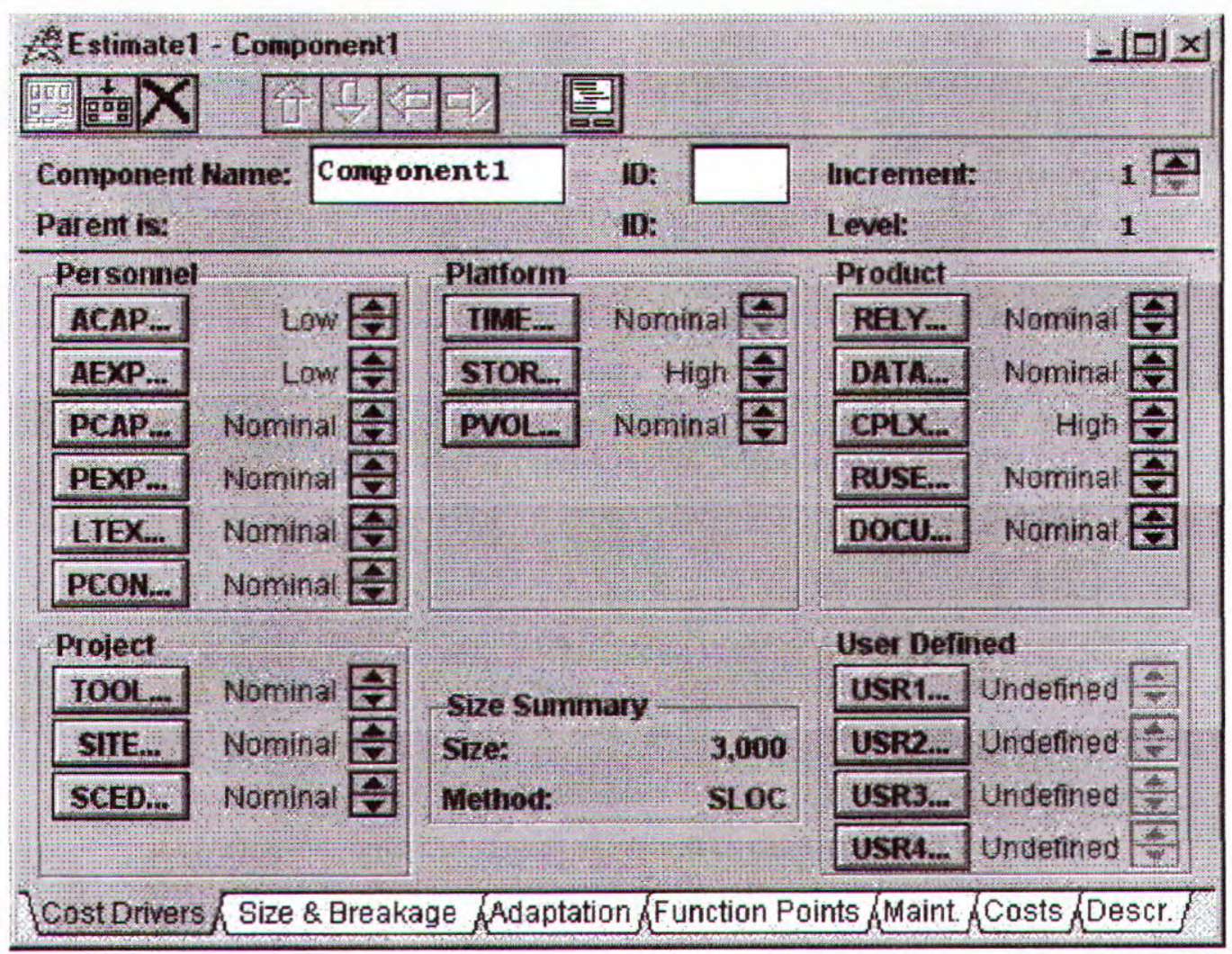

Figura 4.3 - COSTAR - Tela de ajuste dos direcionadores de custo

A Figura 4.4 apresenta o menu principal da ferramenta. Nessa tela deve-se selecionar o modelo implementado e, no caso de escolha do COCOMO II, informam-se os fatores de escala. O resultado global do cálculo das estimativas para o projeto é mostrado nessa tela.

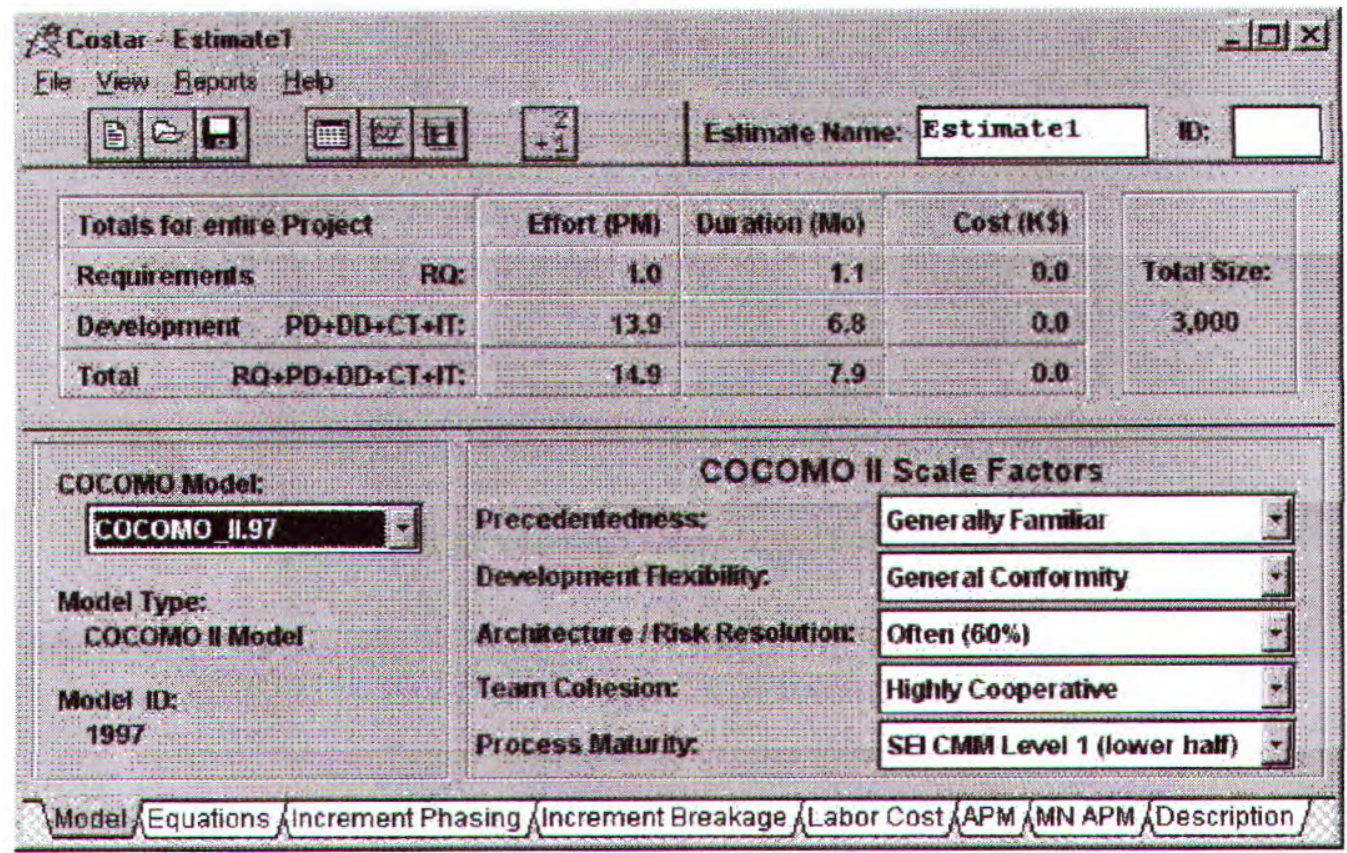

Figura 4.4 - COSTAR - Menu principal 
A ferramenta COSTAR gera uma série de relatórios para estudo das estimativas calculadas. A Figura 4.5 apresenta o relatório em detalhes da distribuição do esforço em fases e sua duração.

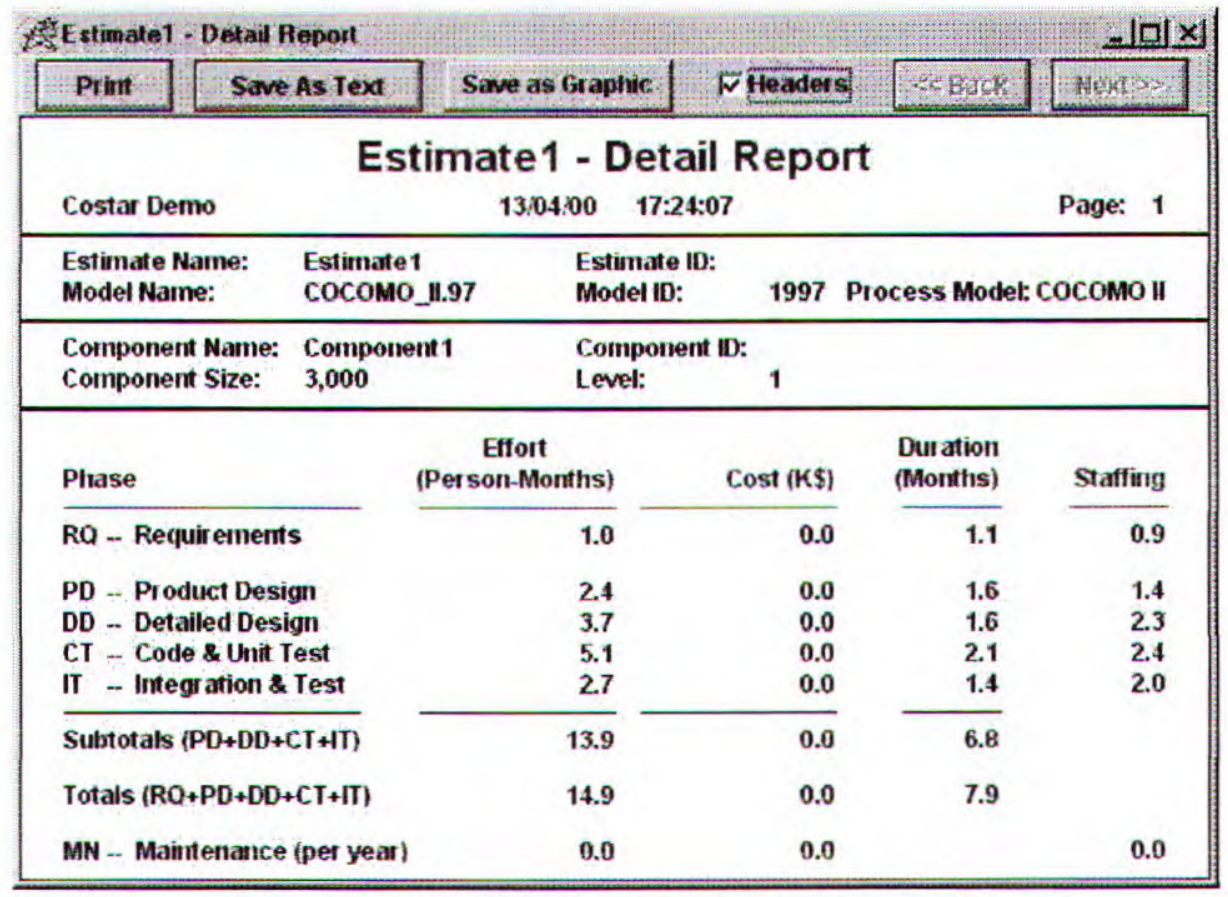

Figura 4.5 - COSTAR - Relatório de Estimativa por Fase

As ferramentas que implementam o modelo COCOMO levam em consideração as atividades de Gerenciamento de Configuração e Garantia de Qualidade de Software (CM/QA) na distribuição de esforço e cálculo de custo do projeto (Figura 4.6).

\begin{tabular}{|c|c|c|c|c|c|c|c|c|c|}
\hline \multicolumn{3}{|c|}{ As Estimate1-Activity Report } & \multicolumn{7}{|c|}{$-101 x$} \\
\hline Print & & As Text: & Save a & Graphic & $\sqrt{\gamma}$ Headers: & s & Sack & & the \\
\hline \multicolumn{10}{|c|}{ Estimate1 - Activity Report } \\
\hline \multicolumn{2}{|c|}{ Costar Demo } & & \multicolumn{3}{|c|}{$18: 04: 00 \quad 15: 52: 47$} & & \multicolumn{3}{|c|}{ Page: 1} \\
\hline \multicolumn{2}{|c|}{$\begin{array}{l}\text { Estimate Name: } \\
\text { Model Name: }\end{array}$} & \multicolumn{2}{|c|}{$\begin{array}{l}\text { Estimate1 } \\
\text { Cocomo_Il.97 }\end{array}$} & $\begin{array}{l}\text { Estimate ID: } \\
\text { Model ID: }\end{array}$ & $1997 \mathrm{P}$ & \multicolumn{4}{|c|}{ Process Modet: COCOMO II } \\
\hline \multirow{2}{*}{\multicolumn{2}{|c|}{ Activity }} & \multicolumn{4}{|c|}{ Effort in Person-Morths } & & & & \\
\hline & & RQ & PD & DD & CT & IT & $\begin{array}{r}\text { To } \\
\text { Ra to }\end{array}$ & & MN \\
\hline \multirow{8}{*}{\multicolumn{2}{|c|}{$\begin{array}{l}\text { Requir ements } \\
\text { Product Design } \\
\text { Programming } \\
\text { Test Plans } \\
\text { V \& V } \\
\text { Project Office } \\
\text { CM/OA } \\
\text { Manuals }\end{array}$}} & 0.5 & 0.3 & 0.1 & 0.2 & 0.1 & & 1.2 & 0.0 \\
\hline & & 0.2 & 1.0 & 0.3 & 0.4 & 0.1 & & 2.0 & 0.0 \\
\hline & & 0.0 & 0.3 & 2.1 & 2.9 & 0.9 & & 5.2 & 0.0 \\
\hline & & 0.0 & 0.1 & 0.2 & 0.2 & 0.1 & & 9.6 & 0.0 \\
\hline & & 0.1 & 0.1 & 0.3 & 0.4 & 0.9 & & 1.7 & 0.0 \\
\hline & & 0.1 & 0.3 & 0.3 & 0.4 & 0.2 & & 1.3 & 0.0 \\
\hline & & 0.0 & 0.1 & 0.3 & 0.4 & 0.2 & & 0.9 & 0.0 \\
\hline & & 0.1 & 0.2 & 0.2 & 0.3 & 0.2 & & 1.0 & 0.0 \\
\hline \multicolumn{2}{|l|}{ Totals } & 1.0 & 2.4 & 3.7 & 5.1 & 2.7 & & 4.9 & 0.0 \\
\hline
\end{tabular}

Figura 4.6 - COSTAR - Relatório de Estimativa por Atividade 


\subsubsection{USC COCOMO 2000.0}

A ferramenta USC COCOMO 2000.0 [USC COCOMO, 2000] (Figura 4.7) é uma implementação do modelo Post Architecture do COCOMO II, com características funcionais semelhantes às da ferramenta COSTAR.

Ela calcula esforço, prazo e distribuição do esforço e encontra-se disponível para plataformas Sun Sparc Unix, Microsoft Windows 95/NT, e plataformas que habilitam a linguagem Java. O manual de referência do modelo COCOMO II e da ferramenta de versão pública que a impleménta encontram-se disponíveis na Internet.

Os parâmetros dos direcionadores de custo podem ser calibrados na ferramenta. $O$ ideal é que cada organização, cada equipe de desenvolvimento, desenvolva seus próprios valores direcionadores. Todos os parâmetros podem ser alterados, utilizando-se para isso resultados de uma nova calibragem publicada pela equipe de pesquisa do centro de pesquisas da USC, por calibragem desenvolvida por empresas privadas, ou ainda, por calibragem desenvolvida pela própria empresa que utilize a ferramenta. Vários tipos de relatórios podem ser gerados.

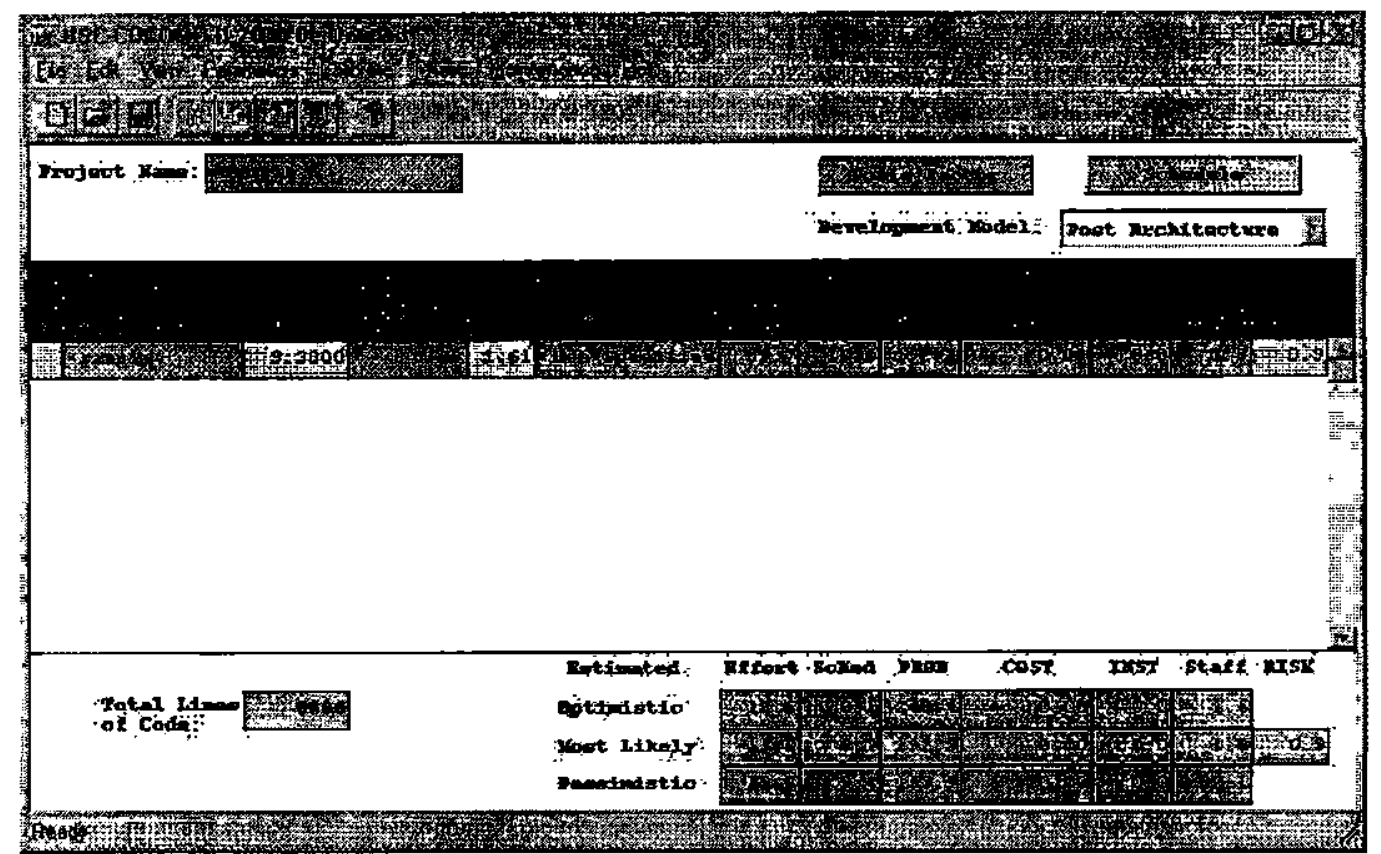

Figura 4.7 - USC COCOMO - Menu principal do sistema 


\subsubsection{COST XPERT 2.1}

Cost Xpert [COST XPERT, 2000] (Figura 4.8) é uma ferramenta comercial que implementa vários métodos de estimativa, além do modelo COCOMO.

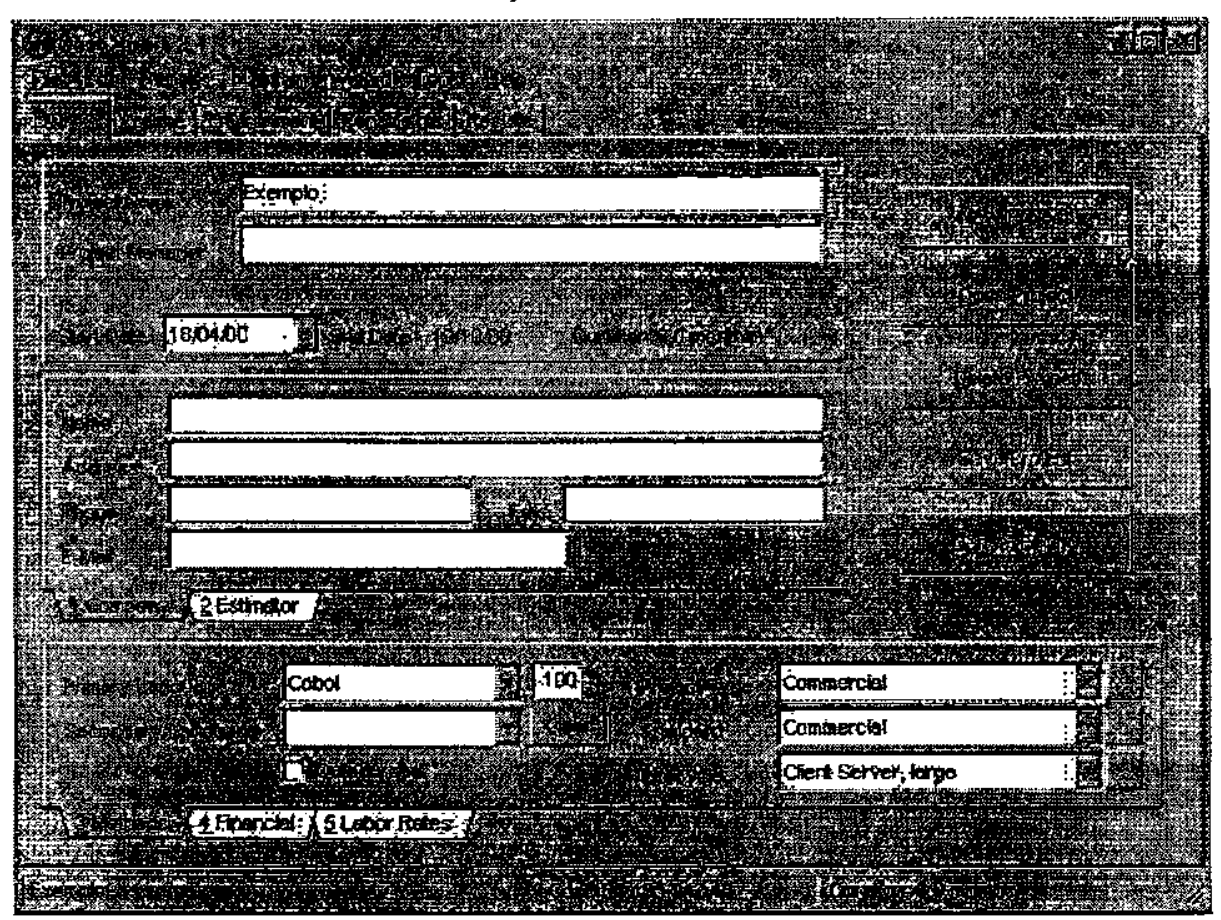

Figura 4.8 - Cost Xpert - Menu Principal

A ferramenta utiliza dados coletados de 7.000 projetos, comerciais e militares, para assegurar maior precisão nas estimativas. Várias técnicas para estimar o tamanho (Volume) da aplicação podem ser utilizadas e a(s) mais adequada(s) pode(m) ser selecionadas (Figura 4.9).

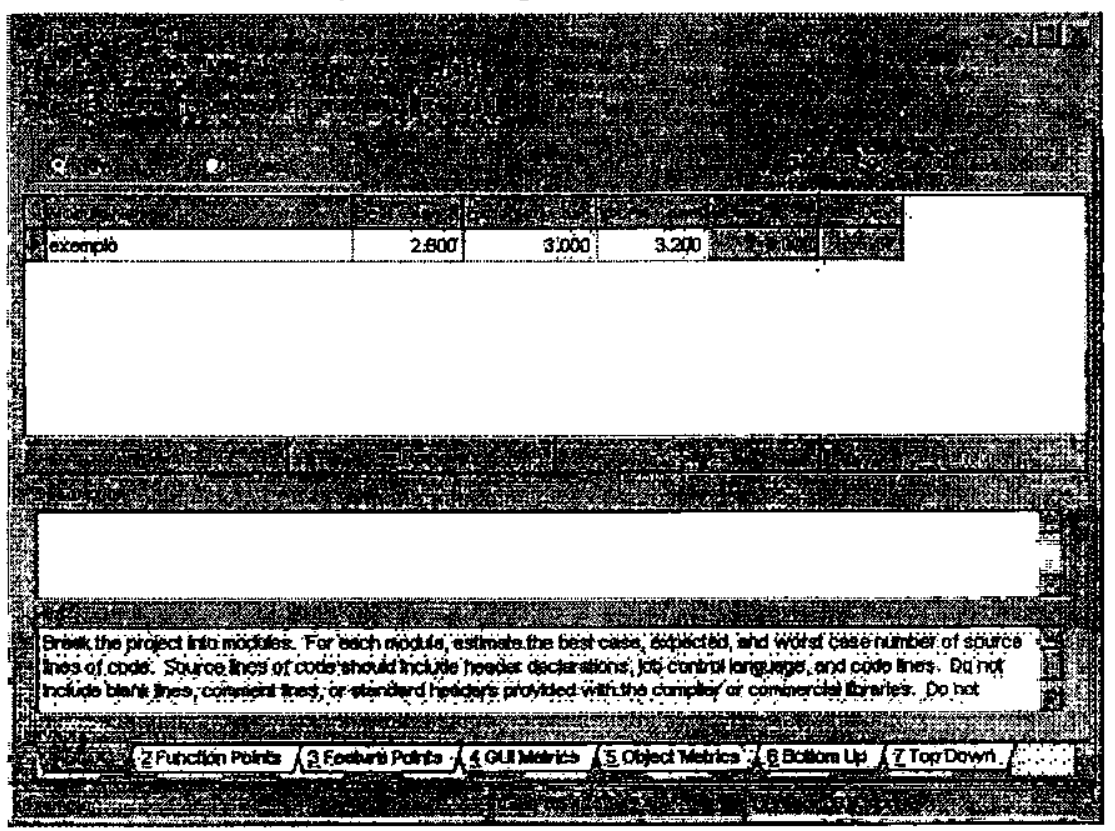

Figura 4.9 - Cost Xpert - Estimativa de Tamanho 
A Figura 4.10 apresenta a tela de seleção dos parâmetros dos direcionadores de custo do modelo COCOMO $\amalg$, juntamente com uma breve descrição.

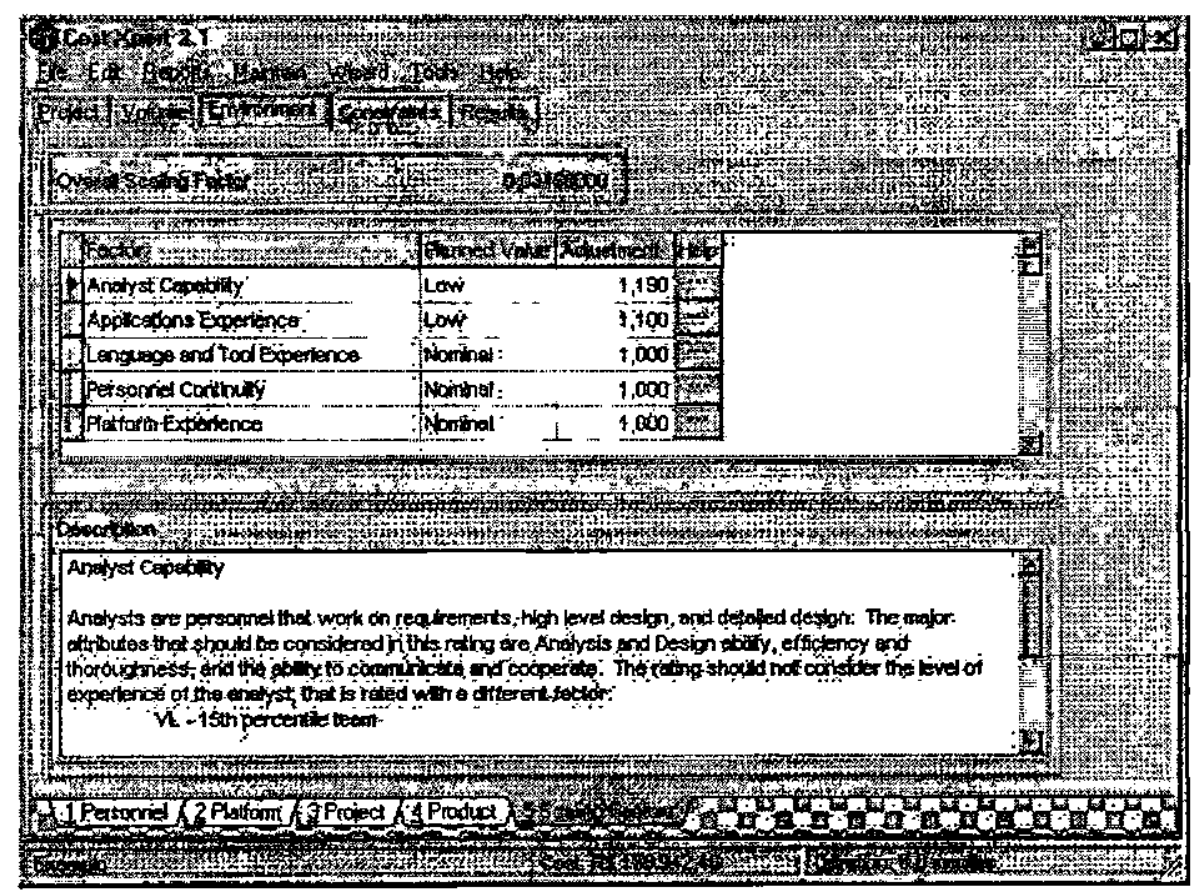

Figura 4.10 - Cost Xpert - Direcionadores de Custo

Além do ajuste dos direcionadores de custo do COCOMO II, a ferramenta possibilita um ajuste mais refinado das estimativas, baseado em um conjunto de 8 fatores, apresentados na Figura 4.11.

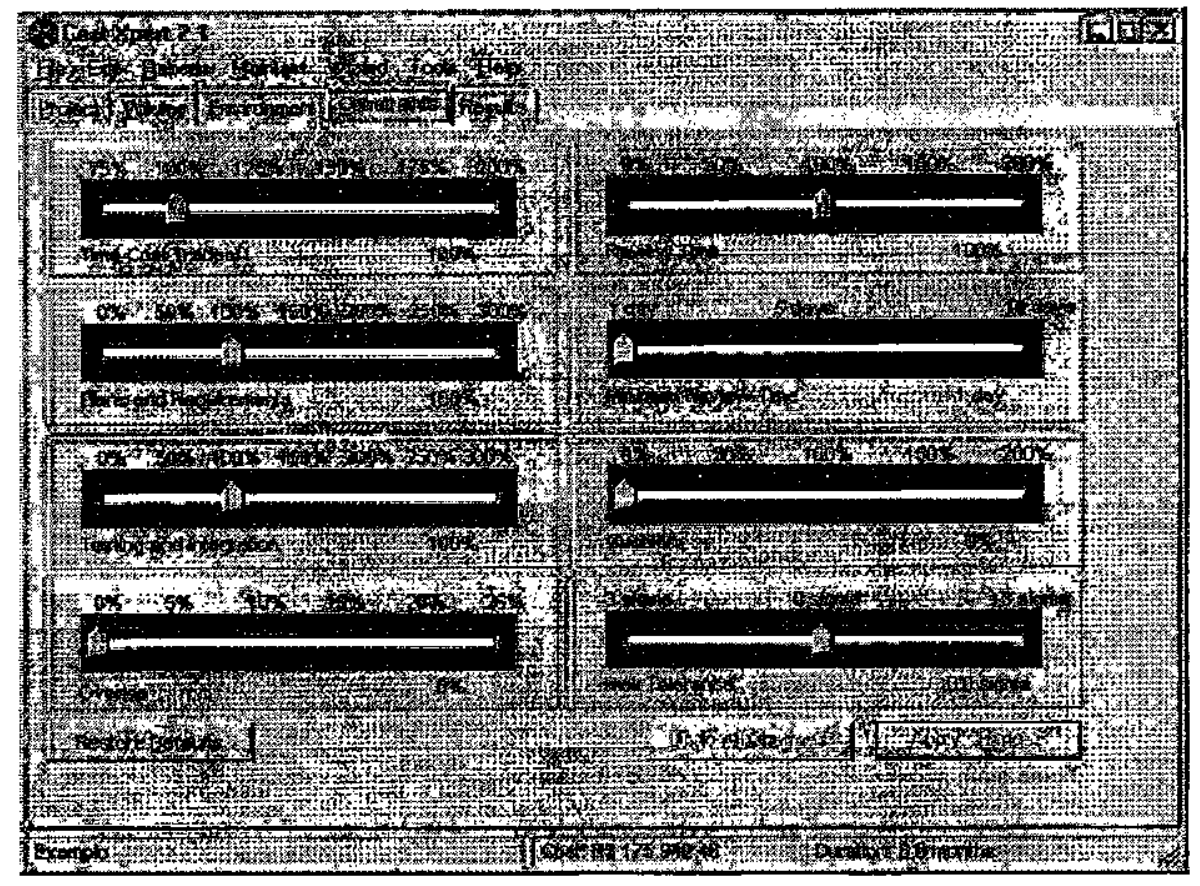

Figura 4.11 - Cost Xpert - Outros Fatores Direcionadores de Custo 
A Figura 4.12 apresenta a tela de resultados parciais das estimativas, de acordo com o método de estimativa de tamanho utilizado.

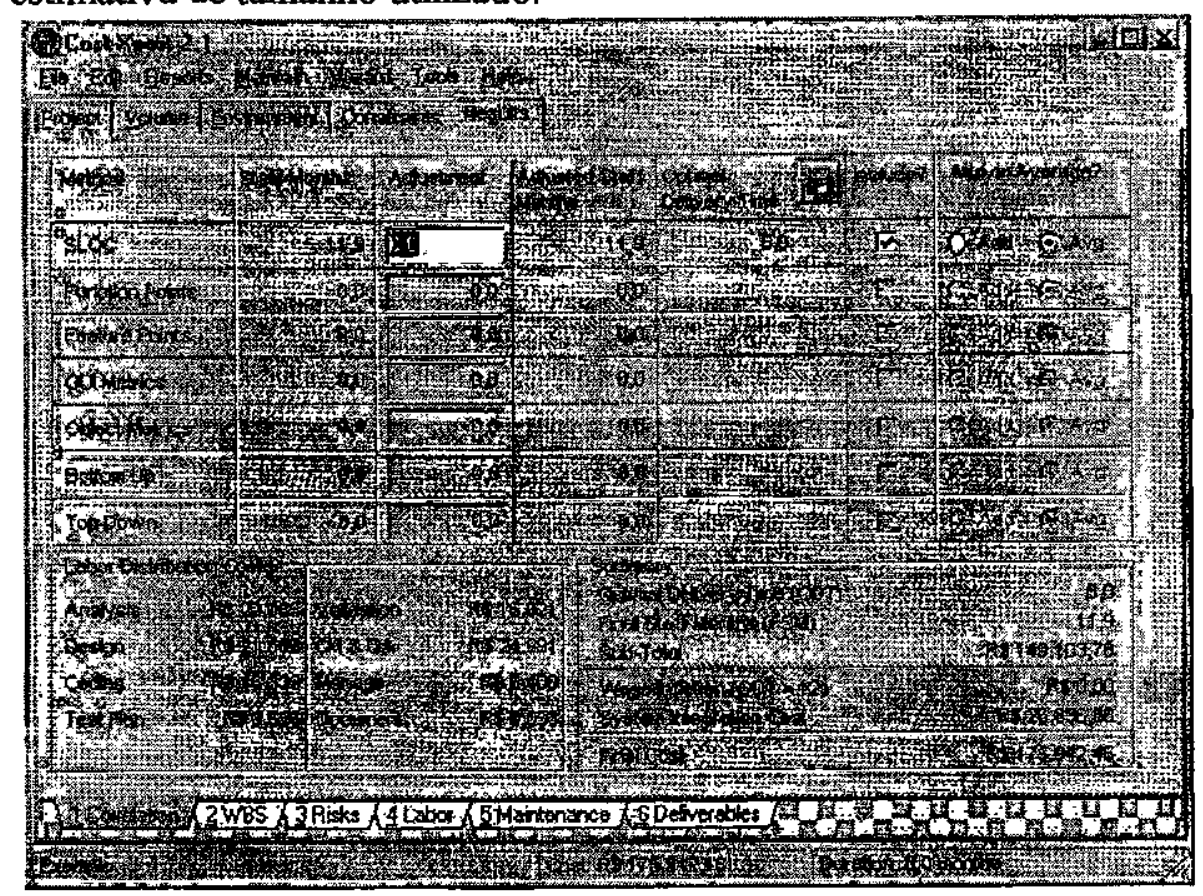

Figura 4.12 - Cost Xpert - Estimativas Parciais

Além dos relatórios de divisão de esforço por fases e atividades, a ferramenta gera gráficos da estrutura de divisão funcional do trabalho e gráficos de distribuição do esforço (Figuras 4.13 e 4.14).

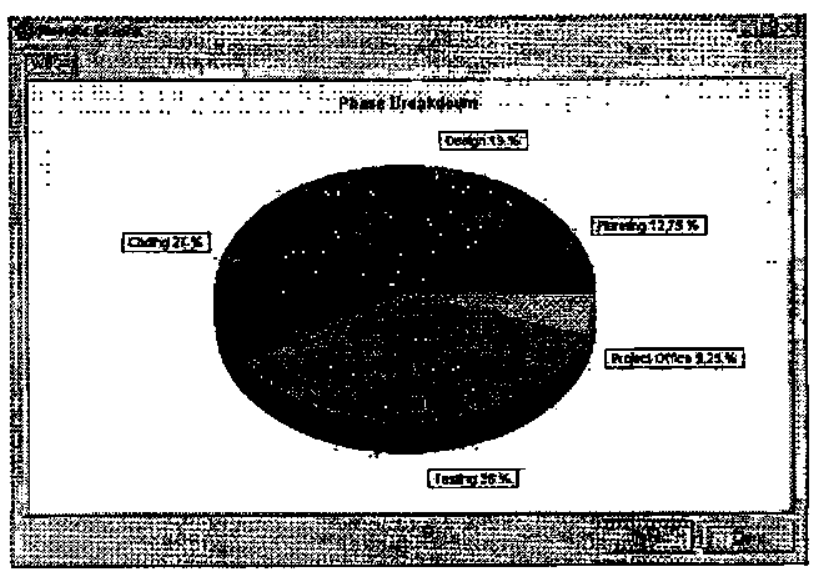

Figura 4.13 - Cost Xpert - Gráfico de Distribuição 


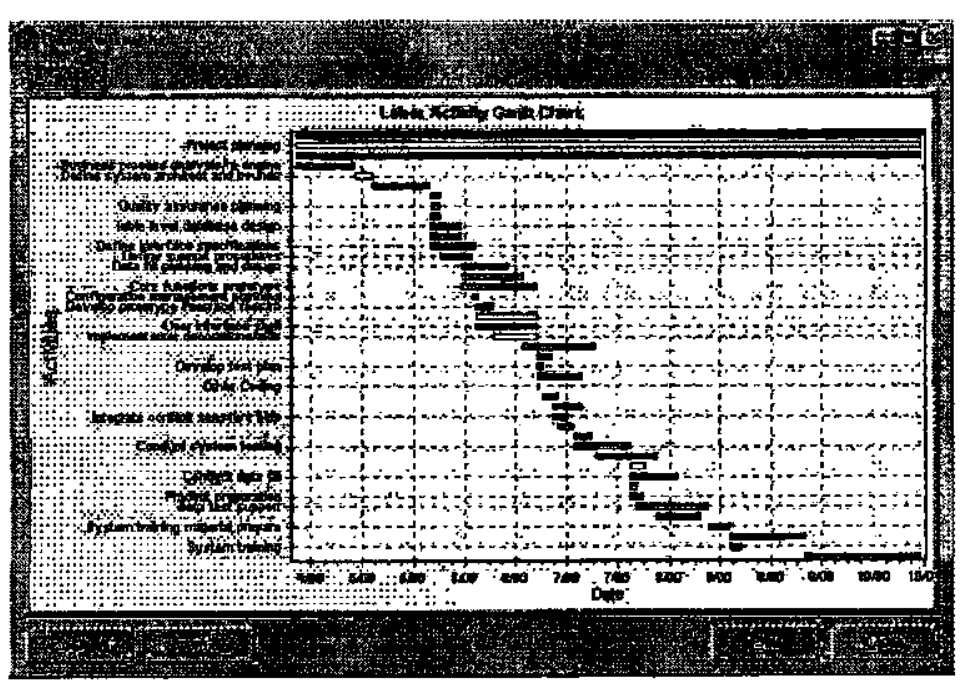

Figura 4.14 - Cost Xpert - Gráfico de Gantt

\subsection{Considerações Finais}

Concluindo um estudo e levantamento de técnicas de estimativa para planejamento de projetos de software, este capítulo apresentou o modelo COCOMO para estimar esforço, prazo, custo e composição de equipe de desenvolvimento de software, a partir do tamanho de um sistema, e sua versão atualizada: o modelo COCOMO II. Foram também apresentadas ferramentas de software que implementam esses dois modelos.

No próximo capítulo, descreve-se um modelo de processo de planejamento que integra as técnicas até então apresentadas. 


\section{Capitulo}

\section{Proposta de um modelo Processo de Planejamento}

\subsection{Considerações Iniciais}

Objetivando auxiliar as organizações a definir e implementar um processo de planejamento, é proposto, neste capítulo, um modelo padrão de planejamento. Apresentam-se as fases do processo, detalhadas em atividades globais e tarefas individuais. A cada passo, o uso de técnicas, modelos e ferramentas de estimativa e planejamento são sugeridos.

\subsection{O Modelo de Processo de Planejamento Proposto}

O modelo de processo de planejamento apresentado a seguir é baseado nos modelos Software Project Planning Process [Groark, 1997] e Software Estimation Process [Software, 1996], apresentados nos capítulos 2 e 3, respectivamente. O objetivo do modelo proposto é descrever etapas de planejamento e propor diretrizes para a execução das atividades. São também apresentados modelos para a documentação de estimativas e elaboração do plano de projeto, visto que a existência de um modelo formal de processo, procedimentos padronizados e modelos para documentação das atividades podem auxiliar a empresa a organizar e documentar o planejamento do projeto.

O modelo de processo proposto é constitúdo de fases que, por sua vez, são compostas por atividades. O modelo apresentado na Figura 5.1 é constituído de seis fases: Inicialização, Elaboração de Estimativas, Elaboração do Cronograma, Cálculo de Custos, Análise de Riscos, Elaboração do Plano do Projeto e Finalização. Além dessas fases, existe ainda a etapa de Implantação do Processo, que tem como objetivo estabelecer na organização uma estrutura adequada para que o processo de planejamento possa ser efetivamente implementado. 


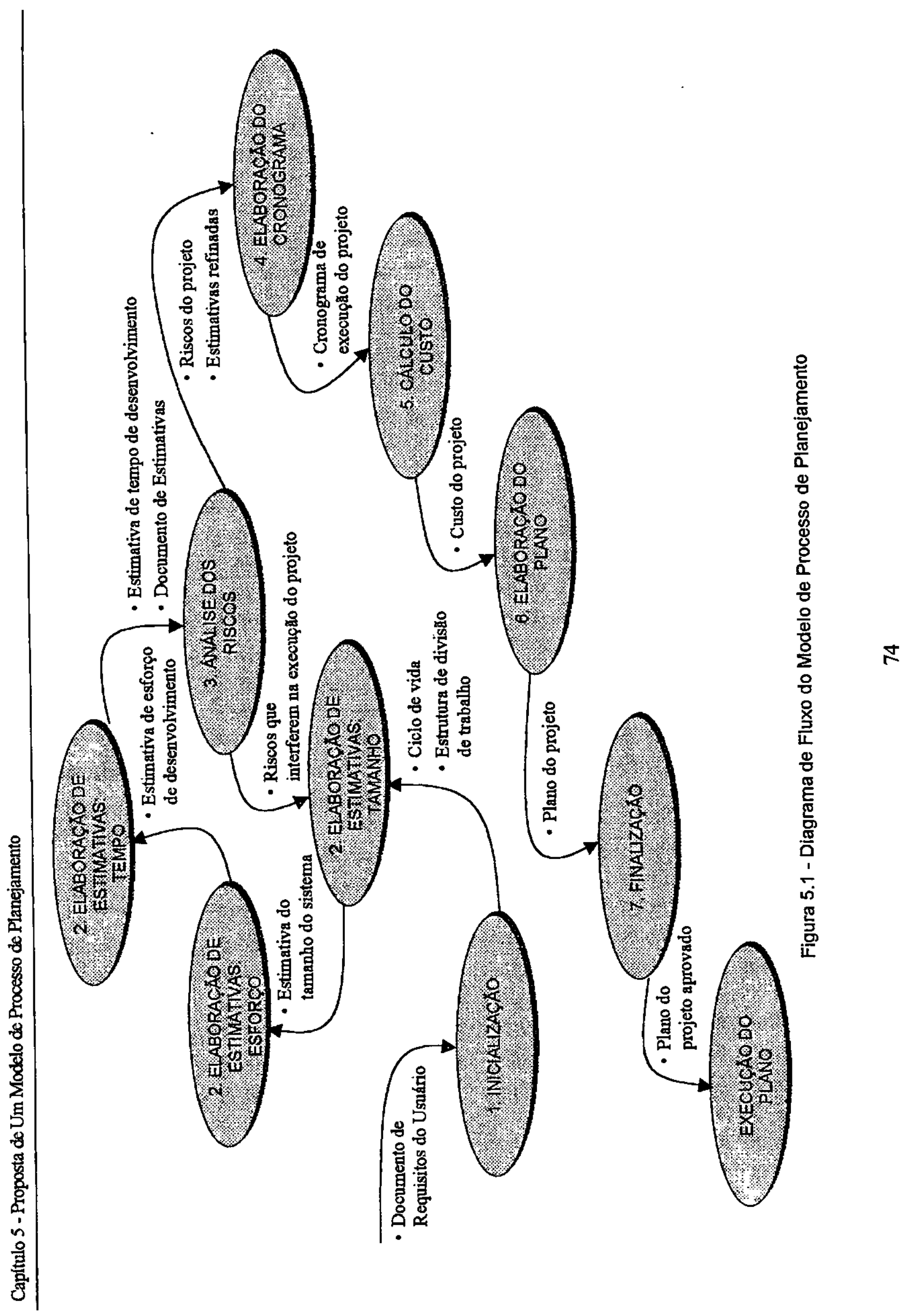


A fasc de Implantação tem com objetivo planejar e estabclccer na organização uma estrutura adequada para que $o$ processo de planejamento possa ser efetivamente implementado. Nessa fase, recursos (equipamentos, ferramentas de software, pessoas) são identificados e selecionados, e um plano de treinamento é preparado.

Na fase de Inicialização do Processo o ciclo de vida de software mais adequado ao desenvolvimento do projeto deve ser detcrminado. As fases de desenvolvimento e as atividades são descritas e constituem um framework para o gerente administrar o desenvolvimento do projeto, a partir do qual é possivel estimar custos e recursos para as diversas fases, definir pontos de controle, monitorar o avanço, ctc.. A estrututa de divisão de trabalho em atividades também é elaborada nessa fase.

A fase de Elaboração de Estimativas inicia com a elaboração de estimativas iniciais de tamanho do sistema a ser desenvolvido, as quais são preparadas utilizando-se o escopo do projeto ou o documento de requisitos funcionais do software. Estimativas de tamanho são utilizadas nas atividades de elaboração de estimativas de esforço de tempo de desenvolvimento. A estrutura de divisão de trabalho em atividades é utilizada para detalhar ainda mais a elaboração de estimativas de esforço e duração do projeto. No final da fase de Elaboração de Estinativas, todas as estimativas são registradas em um documento apropriado, o Documento de Estimativas. Nesse documento também são registradas informações sobre o processo de planejamento $\mathrm{em}$ questão - tempo e recursos utilizados - objetivando o registro de informaçōes para futuras melhorias.

Os riscos do projeto são identificados na etapa seguinte do processo. Essa atividade tem como objetivo a identificação e avaliação de determinados fatores capazes de interferir ou atrapalhar a execução do projeto e que consequentemente podem modificar as estimativas elaboradas inicialmente. Essa atividade deve ser feita toda vez que as estimativas do projeto forem atualizadas.

Em seguida, a fase de Elaboração do Cronograma do projeto é executada. Essa etapa tem como objetivo determinar exatamente qual a data de início e término de cada atividade, e, consequentemente, as datas de inicio e término do projeto. A partir das estimativas de tempo, esforço e cstrutura de divisão de trabalho elaboradas previamente, recursos e profissionais são identificados e alocados. As atividades são inter-relacionadas e precedências são definidas. 
Uma rede PERT é elaborada e o caminho crítico do projeto (CPM) é calculado. Depois que os recursos, durações e as interdependências forem estabelecidas, um cronograma do projeto é elaborado.

O cálculo de casto do projeto é efetuado na fase seguinte. O custo para o projeto é, inicialnente, a despesa financeira realizada com o esforço, em pessoas/mês ou pessoas/hora, alocado para o desenvolvimento do projeto. O cálculo mais preciso do projeto envolve a considcração de diversos tipos de despesas incidentes sobre o desenvolvimento do software, tais como: 1scursos computacionais, equipamentos auxiliares, etc..

Na fase de Elaboração do Plano dó Projeto, um modelo de referência é utilizado como guia para elaboração do plano. Ele apresenta a estrutura principal do plano, onde são registrados o ciclo de vida adotado, estimativas de tamanho, esforço e prazo, o custo calculado para o projeto, cronograma de desenvolvimento, composição de equipe desenvolvedora, e demais informações referentes ao projeto. No plano também podem ser refcrenciados documentos e planos secundáriq̣s que compõem o projeto, por exemplo: o plano de gerenciamento de configuração.

Na fase de Finalização do Processo, o plano de projeto é revisto e aprovado. O propósito da revisão é validar o plano de projpto, através de um processo de verificação para identificar os itens que por ventura tenham sido esquecidos, assegurar que as estimativas sejam razoáveis e que os dados de entrada possuam o maior grau de precisão possível, assegurar que todas as possiveis incertezas e hipóteses assumidas para as estimativas e para o plano possuam o maior grau possíveł de precisão, assegurar também que os dados utilizados na elaboração do plano e quaisquer suposições assumidas sejam corretas.

Pessoas da equipe de Garantia de Qualidade (se houver grupo constituído na organização), juntı;nente com o gerente de projeto e as pessoas que trabalharam no processo de planejamento podem compor a equipe responsável pela revisão e aprovação do plano. Depois de aprovado, o plano do projeto é incorporado como item de configuração de software, através do processo de Gerenciamento de Configuração, executado em paralelo. A partir desse ponto, o plano será executado.

O plano será utilizado peło gerente para administrar o progresso do projeto em um outro processo da organização: o Processo de Acompanhamento. 
O progresso do projeto é inicialmente determinado pela comparação do plano com novas informaçõcs de cstimativas de tamanho do sistema, esforço $\mathrm{c}$ tempo de descuvolvimento, agora bascadas em dados reais do projeto. As comparações ocorrem em periodos prcviamente determinados, quando produtos de trabalho intermediários são concluídos $\mathrm{c}$ marcos de referĉncia são atingidos, ou após alguma mudança no dirccionamento do projcto. O processo de planejamento é então repetido e o Documento de Estimativas ć atualizado.

\subsection{Apresentação das Atividades}

Para facilitar a visualização e compreensão do processo de planejamento que scrá detalhado nos próximos itens deste capitulo, utiliza-se o Diagrama Descritivo de Fase (Figura 5.2).

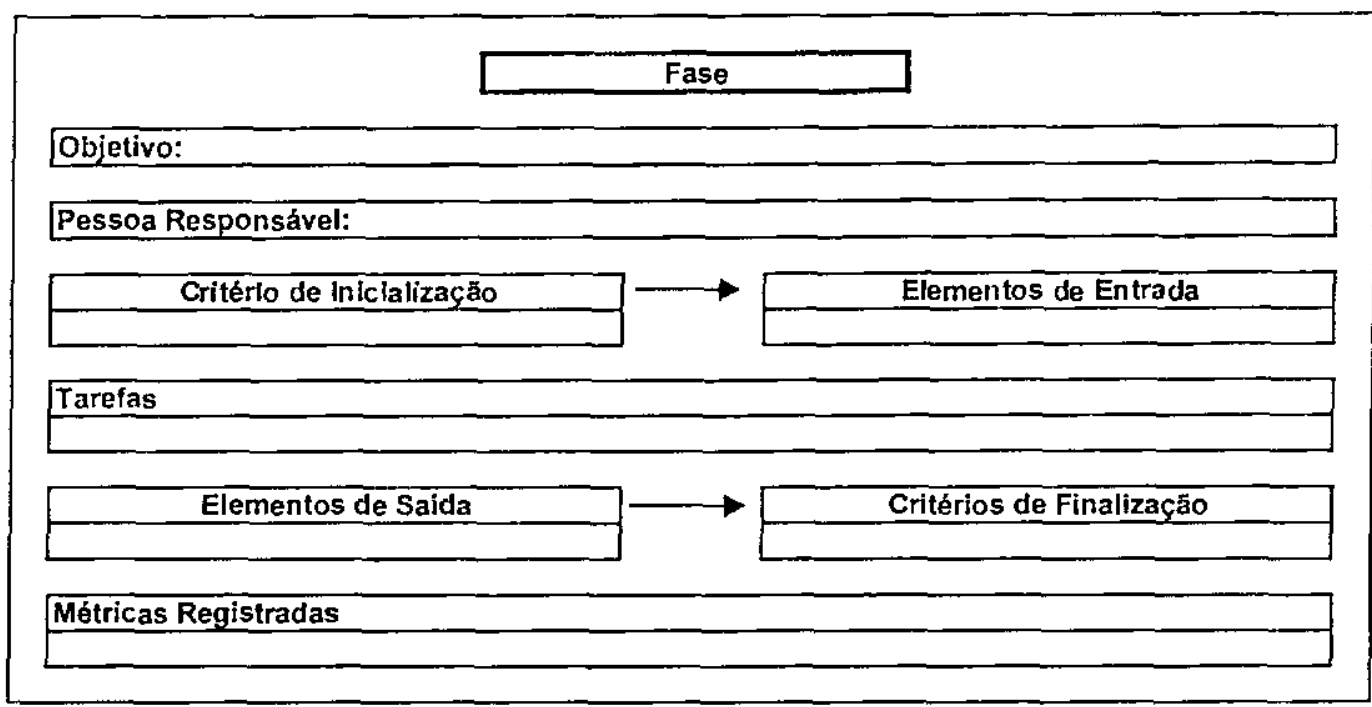

Figura 5.2 - Diagrama Descritivo de Fase

Com rclação ao diagrama, na scção:

a. Objetivo. Descreve-se o propósito da execução da fase do processo.

b. Pessoa Responsável. São apresentados os responsáveis pela execução das tarefas.

c. Critérios de Inicialização. Descrevem-se as condições ou pré-requisitos necessários para que as tarefas possam ser executadas. Descrevem-se também as habilidades em técnicas, ferramentas de software, etc., que se fizerem necessárias.

d. Elementos de Entrada. Descrevem-se dados, informações, documentos, etc., necessários para a execução das tarefas. 
Capítulo 5 - Proposta de Um Modelo de Processo de Planejamento

e. Tarefas. Descrevem-se as ações necessárias para processar as entradas e apresentar resultados necessários ao planejamento.

f. Elementos de Saida. Descrevem-se as informações e outros elementos resultantes das tarefas realizadas.

g. Critérios de Finalização. Descrevem-se as condições necessárias para que a fase possa ser considerada encerrada.

h. Métricas Registradas. Descrevem-se métricas que devem ser registradas para o planejamento efetivo do projeto e para futuras melhorias do processo.

Utilizando-se então o Diagrama Descritivo de Fase da Figura 5.2, as fases do processo de planejamento são apresentadas a seguir.

\subsection{Preparação para Implantação do Processo}

A seguir são descritas as diretrizes para condução da fase de preparação para implantação do processo de planejamento, apresentadas resumidamente na Figura 5.3.

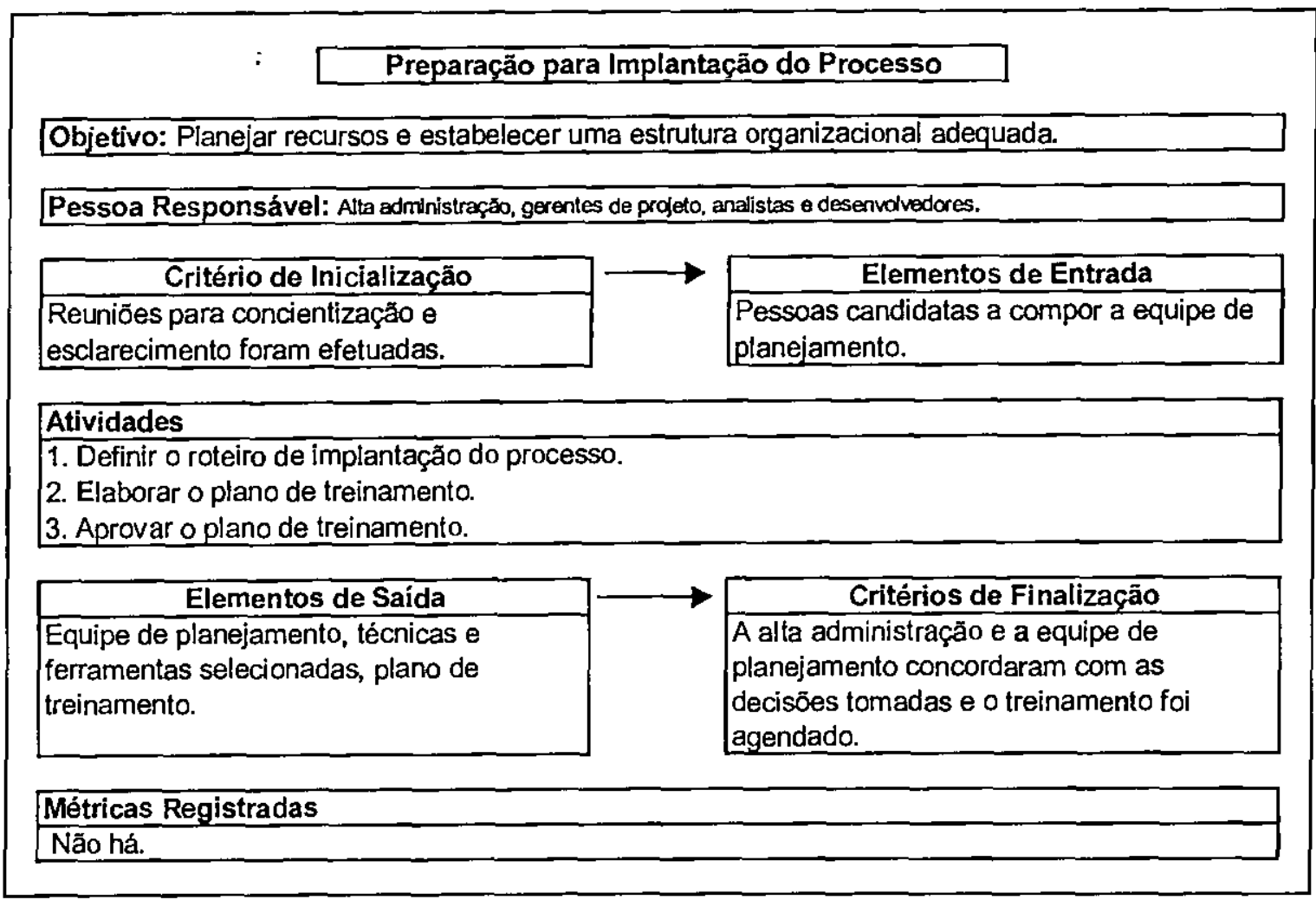

Figura 5.3 - Diagrama Descritivo da Fase de Preparação 
a. Objetivo. O objetivo dessa fase é plancjar recursos e estabelecer na organização uma estrutura organizacional adequada para que o processo de planejamento possa ser efetivamente implementado.

A necessidade dessa fase deve-se:

- em primeiro lugar à disciplina que o processo de plancjamento impõe, porque planejar exige a identificação precisa de objetivos, a definição e o ordenamento prévios de todas as atividades necessárias que $\operatorname{dev} \mathrm{cm}$ ser cxecutadas para atingir propósitos e objetivos;

- em segundo lugar, por tratar-se de um processo apoiado em técnicas, modelos e ferramentas que, quando recém implantadas, podem trazer inicialmente algumas dificuldades de uso e operação.

b. Pessoa Responsável. A innplantação do processo de planejamento é de responsabilidade da alta administração, que pode indicar un ou mais gerentes de projeto para coordenar o desenvolvimento dos trabalhos. São responsáveis todas as pessoas selecionadas para compor a equipe inicial de planejamento.

c. Critérios de Iniclalização. A organização deve realizar reuniões para conscientização dos funcionários com relação ao objetivo do processo de planejamento e de sua importância para o desenvolvimento bem sucedido de um projeto.

d. Elementos de Entrada. Pessoas candidatas a compor a equipe inicial de planejamento (gerentes, analistas, desenvolvedores, etc.). As pessoas envolvidas no planejannento são as já existentes na cinpresa.

e. Tarefas. As tarcfas realizadas nessa fase são:

\section{Definir o roteiro de implantação do processo.}

Para o planejamento efetivo da implantação do proccsso é necessário estabelecer uma sequêencia lógica de atividades que configura um roteiro de trabalho a ser seguido durante a implantação do projeto. Esse roteiro é necessário para estabelecer tempos, recursos a serem empregados, responsabilidades, estrutura de coordenação do projeto, cronograma de execução e cronograma de desembolso de recursos financeiros. Um exemplo de roteiro de implantação é fornecido a seguir. 
i. Estruturar a equipe de planejamento. Designar pessoas para compor a equipe inicial de planejamento, sendo que as tarefas de planejamento de projeto de software serão atribuídas de acordo com a competência e a disponibilidade das mesmas.

ii. Capacitar a equipe em métricas de software. Capacitar gerentes c equipe de planejamento na coleta e análise de métricas.

iii. Capacitar a equipc em pontos de função. Capacitar gerentes e equipe de planejamento na aplicação de técnicas de contagem de pontos de função.

A técnica de Análise de Pontos de Função e um plano de métricas baseado em pontos de função podem ser uma escolha interessante para a organização. Essa métrica, além de identificar o tamanho de um sistema e auxiliar na estimativa do esforço de desenvolvimento, pode auxiliar na monitoração de produtividade e no gerenciamento da qualidade.

iv. Capacitar a equipe em planejamento de projetos de software. Capacitar gerentes e equipe de planejamento na aplicação de métodos, ferramentas de estimativa de esforço, prazos, custos e recursos.

É fundamental que sejam definidas as técnicas de cstimativas (pelo menos duas) e de plinejamento, ferramentas de apoio e recursos necessários à implantação do processo. Cabe à alta administração optar pela adequação de suas próprias formas de elaboração de estimativas de software no processo proposto, até então utilizadas, ou então efetuar estudos para determinar a viabilidade de implantação de novas técnicas e/ou aquisição de ferramentas. Caso a organização utilize apenas a experiência dos desenvolvedores, é imprescindível a adoção de uma técnica nova.

As seguintes questões devem ser respondidas: Como a organização elabora estimativas de: Tamanho do sistema, Esforço. Cronograma e Custo ? São utilizadas ferramenta(s) de estimativa? A organização utiliza ferramenta(s) de planejamento $e$ acompanhamento (elaboração de cronogramas, etc.)?

v. Selecionar produtos disponíveis no mercado. Selecionar produtos disponíveis no mercado para elaboração de estimativas e gerenciamento de projetos.

Ferramentas de estimativas normalmente funcionam como "calculadoras" espccializadas que ajudam a estimar prazos e custos do projeto. Várias opções de ferramentas estão disponíveis, em versões comerciais e versões de domínio público (Quadro 5.1). 
Quadro 5.1 - Ferramentas de Estimativas de Software

\begin{tabular}{|c|c|}
\hline Nome & Referência \\
\hline REVIC* & http://scpo.nosc.mil/revic.rip \\
\hline USC COCOMO $2.0^{*}$ & hitp://sunselusc cedu/j cocomo/cocomo.himl \\
\hline COSTAR & http://www: softstarsystems.com/demo htm \\
\hline COSMOS & htop:/osvaxsrvecast-enn-st.cdu/-dsgnstudio/cosmos/download.himl \\
\hline CONSTRUX & htho://www.construx.com/cstimatc/download.htm \\
\hline COST XPERT & hitp://www'custxpert.com/uscrform.htm?cxdownload \\
\hline
\end{tabular}

Encontram-se no mercado muitas ferramentas de gerenciamento de projetos, disponíveis em vários níveis de sofisticação, a preços variando de dezenas a milhares de dólares. A organização deve estudar com cuidado os beneficios que essas ferramentas proporcionam. Sugere-se também observar a interface gráfica, a facilidade de uso e compatibilidade com o sistema Windows. Exemplos dessas ferramentas são apresentados no Quadro 5.2.

Quadro 5.2 - Ferramentas de Planejamento e Gerenciamento de Projetos

\begin{tabular}{|c|c|}
\hline Nome & Referência \\
\hline ***Primavera Project Planner & http://www.primavera.com/products/p3.htm | \\
\hline ***Open Ptan & http://www'welcom.com/products/opp/index.html \\
\hline ***Cobra & IItp://www.welcon.com/producis/cobra/index.hinl \\
\hline ***Micro Planner X-Pert & h11p:/wwiv.mpi.com.au/products.asp \\
\hline **Microsoft Project & 1ittp://www microsolt.com.br \\
\hline **Micro-Planmer Manager & ht1p:/www.mpi.com.au/producls.asp \\
\hline **Primavera's Suretrak & http://wwiv.primavera.com \\
\hline *Milestone Simplicity & flp://ftp.kidasa.nct/sinp.cxe \\
\hline *Quick Gantt & hllp://www.ballanline-inc.com/index.hum \\
\hline *Project Quick Start & http://www projectkickstart.com/ny htnl/Downdeno.htm \\
\hline \multicolumn{2}{|c|}{$\begin{array}{l}\text { ***Ferramentas mais sofisticadas } \\
\text { **Ferramentas em um nivel intermediário de sofisticação c custo } \\
\text { *Fcramentas que requerem pouco investimento e cuja funcionalidade è reduzida apenas à implementações } \\
\text { de simples gráficos Gantt and PERT }\end{array}$} \\
\hline
\end{tabular}

Basicamente, todas as ferramentas implementam gráficos PERT e Gantt, porém são cncontradas ferramentas que implementam muitas funcionalidades para atividades de planejamento e acompanhamento de projetos, apresentando custo elevados, e requerendo investimento substancial em treinamento [Hampton, 1999]. 
É preciso considerar que o uso de uma ferramenta é apenas um meio que auxilia no planejamento de projetos, na facilidade em organizar tarefas, fazer simulações e gerar diversas formas de resultados que auxiliam na avaliação do plano, até resultar no melhor plano possível, reservando sempre para o técnico o mérito $\mathrm{c}$ a obrigação de formular o plano.

vi. Desenvolver ferramentas. Desenvolver ferramentas complementares para apoio ao processo.

vii. Capacitar equipe em inspeção em software. Capacitar gerentes e equipe de planejamento na técnica de inspeção formal de software.

\section{Elaborar o plano de treinamento.}

Uma vez identiftcadas as pessoas que comporão a equipe de planejamento identificasc também a habilidade requerida para a utilização de técnicas, métodos c ferramentas de planejamento selecionadas e um plano de treinamento deve ser elaborado. Um modelo de plano de treinamento para atividades do processo de planejamento é apresentado no Apêndice A. O processo de planejamento só deve ser iniciado quando a equipe de planejamento possuir treinamento adequado e conhecer completamente o processo de planejamento.

\section{Aprovar o plano de treinamento.}

O plano de treinamento deve ser revisto e aprovado pela alta administração e pclas pessoas designadas para compor a equipe inicial de planejamento.

f. Elementos de Saída. Como resultado da execução das tarefas dcssa fase, a equipe inicial de planejamento está definila, técnicas e ferramentas que serão utilizadas no processo foram selecionadas e um plano de treinamento foi elaborado.

g. Critérios de Finalizaçăo. A alta administração e as pessoas que compõcm a equipe de planejamento revisaram e concordaram com as decisões tomadas com relação à seleção $c$ adoção de tćcnicas de estimativa, ferramentas de estimativa e planejamento para apoio às tarefas, diretrizes do plano de treinamento, elc.. A data de início de treinamento para os membros da equipe de planejamento foi agendada.

h. Métricas Registradas. Não são registradas métricas. 


\subsection{Fase 1: Inicialização do Processo}

A seguir são descritas as diretrizes para condução de fase de Inicialização, apresentadas resumidamente na Figura 5.4.

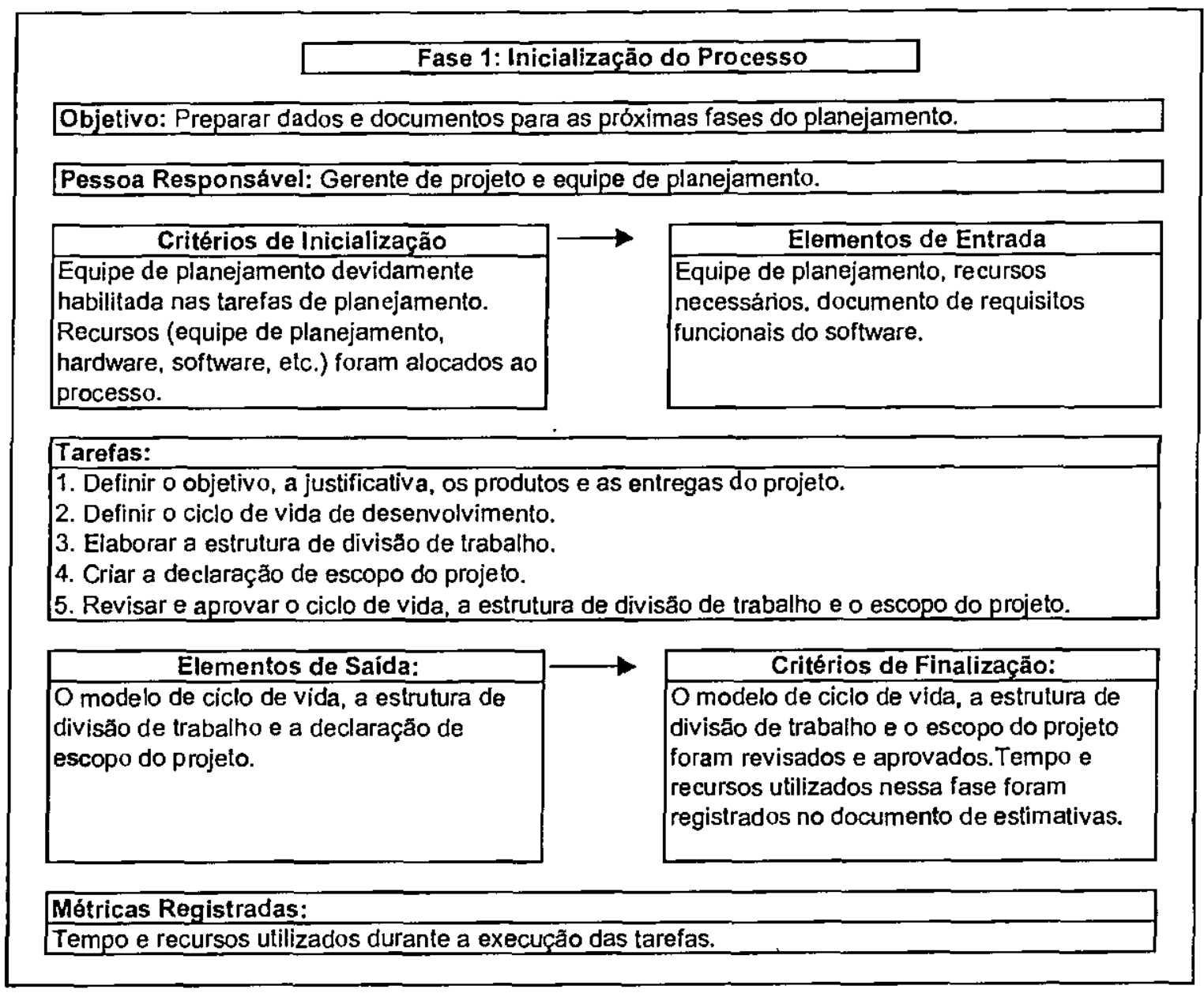

Figura 5.4 - Diagrama Descritivo da Fase de Inicialização

As tarcfas realizadas nessa fase estão apresentadas a seguir.

\section{Definir o objetivo, a justificativa, os produtos e as entregas do projeto.}

O planejamento deve iniciar com a definição dos objetivos, pois é através deles que se poderá estruturar todo o projeto, garantindo que as necessidades dos usuários sejam atendidas. Os objetivos derivam diretamente dos requisitos funcionais do software, que por sua vez derivam dos requisitos funcionais de negócio. Portanto, é importante o papel da gerência e análise de requisitos como principal identificador dos objetivos do sistema. 
O objetivo definido é a representação formal daquilo que se quer atingir com o término de um projeto, devendo expressar declarações mensuráveis e controláveis. Normalmente, o objetivo é definido por verbos de ação e nele são descritos parâmetros numéricos de tempo, custo e performance.

A justificativa é tudo aquilo que está oculto no objetivo, a razão de ser do projeto, o beneficio gerado por ele. Ela representa, na maioria das vezes, um sentimento ou intenção da organização, tambćm conhecida como missão da organização.

Os produtos são todos os resultados físicos obtidos na conclusão do projcto e as entregas por sua vez representam todos os resultados obtidos ao longo do projeto. As entregas servem para medir e avaliar a performance do projeto e serão definidas através de marcos ou etapas no cronograma.

\section{Definir o ciclo de vida de desenvolvimento.}

A definição de fases e atividades de desenvolvimento é a base para se estimar prazos e custos, definir pontos de verificação de qualidade antes da conclusão do projeto e permitir o acompanhamento. O ideal é que a organização possua um modelo de processo de desenvolvinento ou ciclo de vida de desenvolvimento adequado aos projetos da organização para simplinicar essa definição.

Alguns critérios que podem ser observados para a escolha do ciclo de vida mais adequado ao desenvolvimento do projeto são: a complexidade do problema e da solução, freqüiências e magnitude de mudança de requisitos esperadas, grau de ccrteza dos requisitos funcionais conhecidos e a probabilidade de que muitos dos requisitos funcionais do sistema possam ser conhecidos somente depois do uso do sistema.

\section{Elaborar a estrutura de divisão de trabalho.}

O objetivo principal dessa atividade é decompor o projeto em fases de execução de acordo com o modelo de ciclo de vida adotado e, para cada fase identificada, detalliar hierarquicamente até atingir atividades de pequeno porte passíveis de estimativas e controle.

\section{Criar a declaração de escopo do projeto.}

Essa tarefa tem como objetivo criar um documento que formaliza os trabalhos a serem desenvolvidos no projeto, servindo de base para futuras decisões do projeto. 
Ao longo do desenvolvimento do projeto, é possível que a declaração de escopo seja revisada, ou refinada, para refletir as mudanças ocorridas no projeto. Normalmente a Declaração de Escopo do Projeto contém: a justificativa do projeto; produto do projeto; principais entregas do projeto com suas datas prcvistas; objetivos do projeto; missão do projeto; formas de condução do projcto.

5. Revisar e aprovar o ciclo de vida, a estrutura de divisão de trabalho e a declaração de escopo do projeto.

O gerente de projcto e a cquipe de planejamento devem revisar e aprovar o modelo de ciclo de vida adotado, a estrutura de divisão de trabalho e a declaração do escopo do projeto.

\subsection{Fase 2: Elaboração de Estimativas}

As atividades que compõcm essa fase tem como objetivo:

- Elaborar estimativas do tamanho do sistema;

- Elaborar estimativas de esforço de desenvolvimento; $\mathrm{c}$

- Elaborar estimativas de tempo de desenvolvimento.

Estimativas são elaboradas a partir dos requisitos funcionais do software. Embora a definição dos requisitos logo no início do projeto possa ser uma tarefa difícil de ser executada, é impossivel calcular estimativas com um grau de precisão razoável sem conhecê-los. Quando houver requisitos funcionais incertos ou desconhecidos, os envolvidos no projeto devem ser esclarecidos $\mathrm{e}$ informados de que as estimativas foram baseadas apenas nos requisitos conhecidos. Em estratégias de desenvolvimento evolutivo ou incremental, as estimativas devem ser baseadas nos requisitos funcionais definidos para o incremento a ser desenvolvido.

Os seguintes fatores contribuem diretamente para um maior grau de precisão das estimativas:

口 As estimativas devem ser baseadas primeiramente em dados históricos, quando disponíveis, e na experiência dos desenvolvedores.

- Aconselham-se utilizar sempre dois métodos para elaborar estimativas de tamanho do sistema, esforço e tempo de desenvolvimento. Um dos métodos utilizados pode ser a forma usual que a organização utiliza; 
- É importante que um dos métodos utilizados na primeira estimativa, elaborada no início do projeto, seja manual, pois estimativas derivadas manualmente possibilitam a compreensão dos processo e parâmetros utilizados pelas ferramentas automatizadas;

- É desejável que, no mínimo, duas pessoas, sejam designadas para elaborar estimativals de tamanho, esforço e tempo de desenvolvimento. O envolvimento de mais de uma pcssoa nessits tarefas, preferencialmente com experiência no desenvolvimento de aplicaşões similares, pode contribuir para melhorar a precisão das estimativas. As cstimativas podem ser elaboradas isoladamente, por cada um dos "estimadores" e depois comparadas.

Entre os diversos tipos de estimativas e as respectivas técnicas c modelos passiveis de serem utilizados (não limitadas ao conjunto apresentado abaixo) durante o planejamento do projeto destacan-se o uso da contagem de pontos de função c o modelo COCOMO (Quadro 5.3).

Quadrc 5.3 - Técnicas e modelos de estimativas [Fernandes, 1995]

\begin{tabular}{|c|c|c|}
\hline \multirow{2}{*}{ Tipo de Estimativa } & \multicolumn{2}{|l|}{ Técnicas e Modelos } \\
\hline & Pontos de Funçāo & COCOMO I e II \\
\hline Tamanho do Sistema & Contagem Indicativa, Contagem Estimada, FPA & Inferência \\
\hline Prazo do Projeto & Inferência em base histórica & Modelo Próprio \\
\hline Prazo das Fases & Inferência em base histórica & Modelo Próprio \\
\hline Esforco do Projeto & Inferência em base hislórica & Modelo Próprio \\
\hline Esforco por Fase & Inferência em base histórica & Modelo Próprio \\
\hline Custo do Projeto & Inferência em base histórica & Modelo Próprio \\
\hline Custo por Fase & Inferência em base histórica & Modelo Próprio \\
\hline Número de Linlıas de Código & Conversảo em Linhas de Códićo & 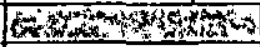 \\
\hline Número de Profissionais & Inferência em base histórica & Modelo Próprio \\
\hline
\end{tabular}

Pontos de função c o modelo COCOMO podem ser utilizados como dois métodos de elaboração de estimativas diferentes, porém em combinação com inferências em bases de dados históricas para suprir as deficiências de cada alternativa. Porćm, conforme sugerido por Trindade [Trindade, 2000B], pontos de função e o modelo COCOMO também podem se integrar e formar um encaminhamento natural de procedimentos que se originam no conhecimento do modelo do sistema e têm, como destino, os dados necessários ao planejamento do projeto (Figura 5.5).

O uso integrado de pontos de função e do COCOMO não isenta a organização do ônus de dados históricos, e a recomendação de utilização de mais de uma técnica para elaboração de estimativas reforça ainda mais a necessidade do registro de dados históricos. 


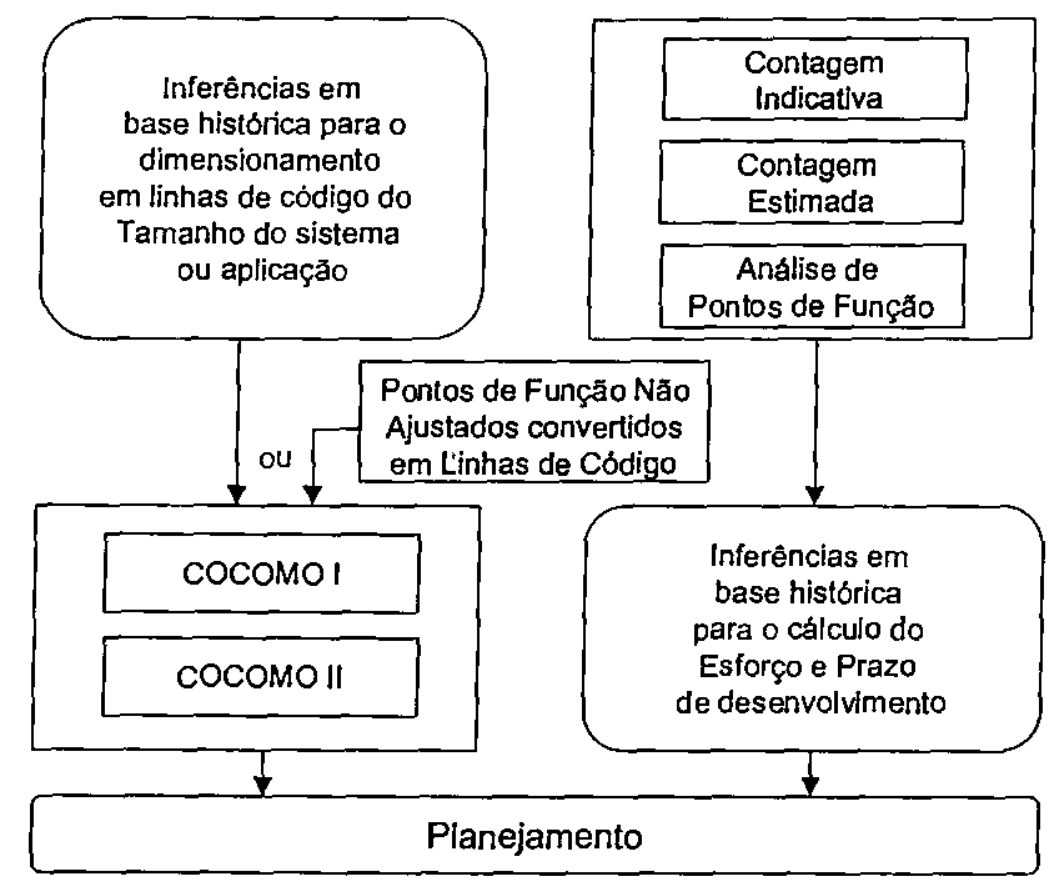

Figura 5.5 - O uso integrado de Pontos de função e COCOMO

Para estimativas com naior grau de precisão, uma das técnicas de estimativa recomendada é estimativa por Analogia. Essa técnica enfatiza a necessidade de dados históricos para comparação do projeto proposto com projetos de natureza similar anteriormente desenvolvidos.

Para mclhor compreensão, as tarefas executadas nessa fase estão agrupadas em quatro etapas principais: elaboração de estimativa de tamanho, elaboração de estimativa de esforço, elaboração de estimativa de tempo e elaboração de estimativa de custo, apresentadas resumidamcnte na Figura 5.6. 


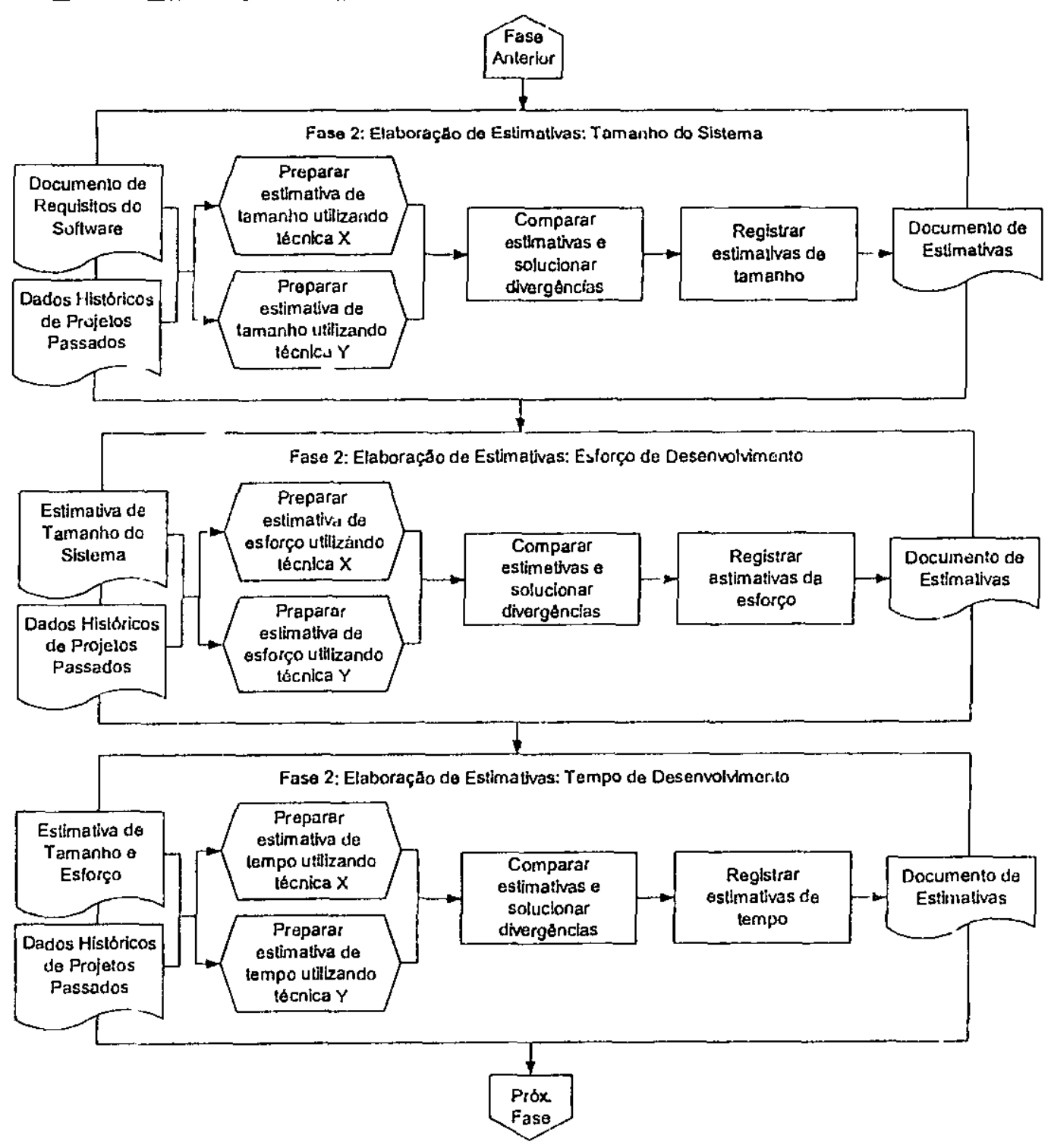

Figura 5.6 - Diagrama de Fluxo da Fase de Elaboração de Estimativas

\subsubsection{Fase 2: Elaboração de Estimativas: Tamanho do Sistema}

A scguir sî̃o descritas as diretrizes para condução da etapa de Elaboração de Estimativa de Tamanho do Sistema, apresentadas resumidamente na Figura 5.7.

As tarefas realizadas ncssa fase estão apresentadas a seguir.

\section{Elaborat estimativas de tamanho do sistema.}

Estimativas de tamanho devem ser elaboradas para o sistema a ser descnvolvido. Dependendo do grau de complexidade ou do porte do projeto, uma estimativa global do sistcma pode ser elaborada a partir de estimativas individuais dos módulos que compõem o sistema. 
Fase 2: Elaboração de Estimativas: Tamanho do Sistema

Objetivo: Dimensionar o tamanho do sistema que será desenvolvido.

Pessoa Responsável: Duas ou mais pessoas da equipe de planejamento.

\begin{tabular}{|l|}
\hline \multicolumn{1}{|c|}{ Critério de Inicialização } \\
\hline O escopo do projeto e o documento de \\
requisitos funcionais do software foram \\
preparados. Habilidades com técnicas e \\
ferramentas de estimativa.
\end{tabular}

$\rightarrow$\begin{tabular}{l|}
\hline \multicolumn{1}{|c|}{ Elementos de Entrada } \\
\hline $\begin{array}{l}\text { Escopo do projeto, estrutura de divisāo de } \\
\text { trabalho, documento de requisitos, } \\
\text { ferramentas de apoio, dados históricos, } \\
\text { quarıdo disponiveis. }\end{array}$ \\
\hline
\end{tabular}

Tarefas:

1. Elaborar estimativas de tamanho utilizando dois ou mais métodos.

2. Comparar estimativas obtidas e solucionar divergérıcias.

3. Registrar estimativas̀ de tamanho.

\begin{tabular}{|l|l|}
\hline \multicolumn{1}{|c|}{ Elementos de Saida } & \multicolumn{1}{c|}{ Critérios de Finalizaçāo } \\
\hline Estimativa de tamanho do sistema. & $\begin{array}{l}\text { A estimativa do tamanho do sistema e } \\
\text { métricas de tempo e recursos utilizados } \\
\text { nessa atividade foram registradas no } \\
\text { documento de estimativas. }\end{array}$ \\
\hline
\end{tabular}

Métricas Registradas

1. Tamanho do sistema em linhas de código ou pontos de função.

2. Tempo e recursos utilizados durante a execução das tarefas.

Figura 5.7 - Diagrama Descritivo da Fase de Elaboraçāo de Estimativa de Tamanho

Nesses casos, a estrutura de divisão funcional do sistema deve ser elaborada. Ela indica como os vários componentcs do software estão organizados para compor o sistema que será desenvolvido e representa unı instrumento de grande auxílio na elaboração de estimativas de tamanho de sistemas. O seguinte procedimento pode ser utilizado:

$\Rightarrow$ Elaborar um diagrama de alto nível da arquitetura do sistema (top-down), apresentando os principais módulos ou subsistemas que compõem o sistema;

$\Rightarrow$ Elaborar a estrutura de divisão funcional (WBS funcional) do sistema, detalhando as funções de cada nívcl da arquitetura do sistema;

$\Rightarrow$ Elaborar estimativa manual de tamanho em linhas de código ou pontos de função do nível de detalhes mais baixo possivel (bortom-up) para cada módulo ou subsistema, baseado na experiência com aplicações similares e dados históricos; 


\section{- Estimativas de tamanho em Pontos de Fuņ̧ão}

Três técnicas de contagem podem ser utilizadas para elaborar estimativas de tatmanho em pontos de função, dependendo do grau de informações disponíveis: Contagem Indicativa de Pontos de Função, a Contagem Estimada de Pontos de Função e a Contagem Detalhada ou Análise de Pontos de Fiınção.

Em mutas aplicaşões a contagem indicativa e a contagem estimada de pontos de função pode resultar em uma estimativa do tamanho da aplicação conı grau de precisão satisfatório, em um curto período de temıo e baseando-se em poucas informações disponíveis. No entanto, a contagem detalhada de pontos de função é mais precisa que as contagens indicativa e estimativa, mas também é um pouco mais dcmorada, além de necessitar de especificações mais detalhadas do sistema que será desenvolvido (por exemplo, layouts de telas, relatórios, etc.), muitas vezes ainda não disponiveis nessc momento. Cabc ao gercntc de projeto decidir qual das técnicas deve ser utilizada, baseando-se em critírios como documentos e informações disponíveis ou etapa do ciclo de vida em que a contagem será efetuala.

\section{ㅁ Estimativas de tamanho em Linhas de Código}

O tamanho do sistema em linhas de código pode ser estimado a partir do julgamento subjetivo do tamanlı do sistema ou dos módulos que irão compor a aplicação, efetuado por pcitos, ou seja, pessoas com experiência en descnvolvimento de aplicnções similares. A tćcnica Wideband Delphi é utilizada para consenso entre as estimativas quando houvcr a participação de várias jıcssoas no processo de estiınativa.

Pode-sc utilizar o método de Analogia para estimar o tamanho quando exislirem dados históricos disponiveis. Una vez que uma base de dados de projetos tenha sido construída ao longo do tcmpo, é possível estimar novos projetos procurando na base informações de projetos análogos ao sistema que será desenvolvido. Para a elaboração de estimativas por analogia, o projeto dove ser caracterizado de acordo com informações disponíveis no momento $\mathrm{cm}$ que as estimativas forem elaboradas para posterior comparação com dados rcgistrados anteriormenle. A escolha das variáveis de caracterização depende do tipo de aplicação do projelo, do ambiente de desenvolvimento e das informações contidas na basc de in formações históricas. 
A técnica Pert Sizing pode ser utilizada depois que estimativas de linhas de código foram elaboradas. A estimativa nominal ou esperada do tamanho do sistema deve ser somada e subtraída com o desvio padrão calculado com a equação da técnica Pert. A variação entre a estimativa mais baixa possivel e a mais alta possivel deve refletir o grau de incerteza da estimativa nominal.

\section{Comparar estimativas obtidas e solucionar divergências.}

Estimativas obtidas com a utilização de técnicas diferentes devem ser comparadas. Estudos sugerem que 0 grau de divergência entre as estimativas deve ser algo em torno de 30 a $50 \%$ nas fases iniciais do projeto [Software, 1996]. Esse grau pode ser maior se houver risco técnico ou se a experiência dos desenvolvedores com aplicą̧ões semelhantes for baixa. Se houver grandes discrepâncias entre as estimativas elaboradas, deve-se rever dados e técnicas utilizados.

\section{Registrar estimativas de tamanho no documento de estimativas.}

Registrar as estimativas de tamanho no Documento de Estimativas, informando a data, o nome das pessoas encarregadas, os métodos e ferramentas de estimativa utilizados e a linguagem escolhida para implementação do sistema. O Apêndice A apresenta um modelo de documento de estimativas.

\subsubsection{Fase 2: Elaboraçāo de Estimativas: Esforço de Desenvolvimento}

A seguir são descritas as diretrizes para condução da etapa de Elaboração de Estimativa de Esforço de Desenvolvimento, apresentadas resumidamente na Figura 5.8.

As tarefas realizadas nessa fase estão apresentadas a seguir.

\section{Elaborar estimativas de esforço de desenvolvimento.}

Estimativas de esforço de desenvolvimento devem ser elaboradas para todas as atividades diretamente relacionadas com o desenvolvimento. As estimativas de esforço são usualmente expresso em pessoas ou homens-mês e podem ser obtidas com a utilização de métodos manuais ou com 0 auxílio de ferramentas automatizadas. 
Fase 2: Elaboração de Estimativas: Esforço de Desenvolvimento

Objetivo Determinar o esforco necessário para completar o projeto.

Pessoa Responsável: Duas ou mais pessoas da equipe de planejamento.

\begin{tabular}{|l|}
\hline \multicolumn{1}{|c|}{ Critérios de tnicializaçãa: } \\
\hline A estrutura de divisão de trabalho e a \\
estimativa de tamanho foram \\
elaboradas. Habilidades com técnicas \\
ou ferramentas de estimativa de \\
esforço. \\
\hline
\end{tabular}

$\rightarrow$\begin{tabular}{l|}
\hline \multicolumn{1}{|c|}{ Elementos de Entrada: } \\
\hline $\begin{array}{l}\text { Escopo do projeto, documento de } \\
\text { requisitos, estimativa do tamanho do } \\
\text { sistema, estrutura de divisão de } \\
\text { trabalho, ferramentas de estimativa. }\end{array}$ \\
\hline
\end{tabular}

\section{Tarefas:}

1. Elaborar estimativas de esforço utilizando dois ou mais métodos.

2. Comparar estimativas obtidas e solucionar divergências.

3. Registrar estimativas de esforco.

\begin{tabular}{|l|l|}
\hline \multicolumn{1}{|c|}{ Elementos de Saída } & \multicolumn{1}{|c|}{ Critérios de Finalizaçäo } \\
\hline $\begin{array}{l}\text { Estimativa de esforço de } \\
\text { desenvolvimento. }\end{array}$ & $\begin{array}{l}\text { A estimativa de esforço de } \\
\text { desenvolvimento e métricas de tempo } \\
\text { e recursos utilizados nessa atividade } \\
\text { foram registradas no documento de } \\
\text { estimativas. }\end{array}$ \\
\hline
\end{tabular}

\section{Métricas:}

1. Métrica de esforço em pessoas-mês ou pessoas-semana.

2. Registrar mútricas de tempo e recursos utilizados nessa atividade.

Figura 5.8 - Diajrama Descritivo da Atividade de Estimativa de Esforço

\section{․ Elaboração de estinntivas com métodos manuais}

O esforço de desenvolvimento pode ser estimado manualmentc a partir do julgamento subjetivo do tamanho sistena nu dos módulos que irão compor a aplicação, efetuado por peritos, ou seja, pessoas com experiência em desenvolvimento de aplicações similares.

A técnica Wideband Delphi é utilizada para consenso entre as estimativas quando houver a participação de várias pessoas no processo de estimativa.

Podc-se utilizar o método de Analogia para estimar o esforço quando existirem dados históricos disponíveis. Uma vez que uma base de dados de projetos tenha sido ccinstruída ao longo do tcmpo, é possivel estimar novos projetos procurando na base informações de projetos análogos ao sistcma que será desenvolvido. 
Quando existem registros com dados em pontos de função ou linhas de código de projetos passados e dados de esforço, pode-se estimar o esforço efetuando-se inferências em base de dados histórica através da transformação por interpolação aritmética. Caso a base histórica possua dados registrados da produtividade média de desenvolvimento, pode srealizar a transformação direta.

A estrutura de divisão de trabalho é utilizada para claborar estimativas pelo métudo Bottom-Up. Cada componente ou tarefa dc desenvolvimento é estimada separadamentc e os resultados são agregados para produzir uma estimativa global de esforço de desenvolvimentr.

Estimativas de esforço podem ser calculadas com o uso de modelos algorítmicos. Estimativas são elaboradas através da aplicação de equaçōes específicas em função de unnúmcro de variáveis ou direcionadores de custo. O COCOMO, por exemplo, pode ser utilizado para elaboração de cstimativas de esforço manuais.

Uma estimativa nominal ou esperada do esforço de desenvolvimento pode ser derivada com a técnica PERT Sizing. A estimativa nominal ou esperada do tamanho do sistema deve ser somada e subtraída com o desvio padrão calculado com a equação da técnica PERT. A variação entre a estimativa mais baixa possível $\mathrm{e}$ a mais alta possivel deve refletir o grau de incerteza da estimativa nominal.

\section{- Elaboração de estimativas com ferramentas de estimativa}

Estimativas de esforço podem ser obtidas com o uso de ferramentas automatizadas e representam um bom método para checagem com estimativas derivadas manualmente. Grande parte das fcrramentas geram relatórios detalhados da distribuição do esforço por fases.

O modelo COCOMO implementado nas ferramentas considera as atividades de Gerenciamento dc Configuração, Garantia de Qualidade de Software, Esforço cie documentação e Esforço de Gerenciamento no cálculo das estimativas de esforço, tempo e custo de projeto.

\section{Comparar estimativas obtidas e solucionar divergências.}

Os resultados das duas estimativas devem ser comparados e as razões para grandes divergências deven ser esclarecidas. 
Capítulo 5 - Proposta de Um Modelo de Processo de Planejamento

O grau de variância das estimativas depende do estágio do ciclo de vida em que o processo é cxecutado. No início do projeto, estinativas variando entre $20 \%$ apresentam um grau de aceitaçăo razoável [Sofiware, 1996]. Se houver grandes discrepâneias entre as estinativas elaboradas nas duas formas, deve-se rever e investigar o processo de claboração.

\section{Registrar estimativas de esforço no documento de estimativas.}

Registrar as estimativas de esforço de desenvolvimento no Documento de Estimativas, informando a data, o nome das pessoas encarregadas e os métodos e ferramentas de estimativa utilizados.

\subsubsection{Fase 2: Elaboração de Estimativas: Tempo de Desenvolvimento}

$\Lambda$ seguir são descritas as diretrizes para condução da etapa dc Elaboração de Estimativa de Tempo de Desenvolvimento, apresentadas resumidamente na Figura 5.9

\begin{tabular}{|c|c|}
\hline \multicolumn{2}{|c|}{$\begin{array}{l}\text { Fase 2: Elaboração de Estimativas: Tempo de Desenvolvimento } \\
\text { minar a duração de tempo necessário para complelar o projelo. }\end{array}$} \\
\hline \multicolumn{2}{|c|}{ Pessoa Responsável: Duas ou mais pessoas da equipe de planejamento. } \\
\hline Critérios de inicialização: & Elementos de Entrada: \\
\hline $\begin{array}{l}\text { Estimalivas de lamanho do sistema, esforço } \\
\text { de desenvolvimento e a estrulura de divisăo } \\
\text { de lrabalho foram elaboradas. Habilidades } \\
\text { em técnicas e ferramentas de estimativa de } \\
\text { tempo. }\end{array}$ & $\begin{array}{l}\text { Estimaliva de lamanho, estimaliva de } \\
\text { esforço, estrulura de divisão de trabalho, } \\
\text { ferramentas de estimaliva. }\end{array}$ \\
\hline \multicolumn{2}{|c|}{ Tarefas: } \\
\hline \multicolumn{2}{|c|}{$\begin{array}{l}\text { 1. Elaborar estimalivas de tempo ulilizando dois ou mais mélodos. } \\
\text { 2. Comparar estimativas obtidas e solucionar divergências. } \\
\text { 3. Registrar estimativas de lempo. }\end{array}$} \\
\hline Elementos de Saida: & Critérios de Finalizaçăo: \\
\hline Eslimaliva de tempo de desenvolvimento. & $\begin{array}{l}\text { A eslimaliva de tempo de desenvolvimento } \\
\text { do projeto e mérricas de tempo e recursos } \\
\text { ulitizados nessa atividade foram registradas } \\
\text { no documento de eslimativas. }\end{array}$ \\
\hline \multicolumn{2}{|c|}{ Métricas: } \\
\hline \multicolumn{2}{|c|}{$\begin{array}{l}\text { 1. Tempo de desenvolvimento, usualmente em mêses ou semanas de desenvolvimento. } \\
\text { 2. Registrar mélricas de tempo e recursos utilizados nessa atividade. }\end{array}$} \\
\hline
\end{tabular}

Figura 5.9 - Diagrama Descritivo da Atividade de Estimativa de Tempo 
As tarefas realizadas nessa fase estão apresentadas a seguir.

\section{Elaborar estimativas de tempo de desenvolvimento.}

Estimativas de tempo de desenvolvimento devem ser elaboradas da seguinte forma:

- O tempo ou prazo de desenvolvimento deve ser estimado para cada grupo de funções desenvolvidas independentemente; por exemplo, uma estimativa para cada etapa de desenvolvimento incremental;

a Para cada conjunto de funções independentes, devem ser derivadas estimativas de tempo por fase de desenvolvimento: análise, projeto, codificação \& teste de unidade, integração e teste;

- Uma estimativa global de tempo de desenvolvimento do projeto deve ser elaborada, incluindo estimativas para as atividades de documentação e revisões.

As estimativas de tempo são usualmente expressas em meses ou semanas de desenvolvimento e podem ser obtidas com a utilização de métodos manuais ou com o auxílio de ferramentas automatizadas.

\section{ㅁ Elaboração de estimativas com métodos manuais}

O tempo de desenvolvimento pode ser estimado manualmente a partir do julgamento subjetivo do tamanho sistema ou dos módulos que irão compor a aplicação e das atividades e tarefas que compõem a estrutura de divisão de trabalho. A técnica Wideband Delphi é utilizada para consenso entre as estimativas quando houver a participação de várias pessoas no processo de estimativa.

Pode-se utilizar o método de Analogia para estimar o tempo de desenvolvimento quando existirem dados históricos disponíveis. Uma vez que uma base de dados de projetos tenha sido construida ao longo do tempo, é possivel estimar novos projetos procurando na base informações de projetos análogos ao sistema que será desenvolvido.

Quando existem registros com dados em pontos de função ou linhas de código de projetos passados e dådos de tempo ou duração das atividades ou fases, pode-se estimar o esforço efetuando-se inferências em base de dados histórica através da transformação por interpolação aritmética. 
A estrutura de divisão de trabalho é utilizada para elaborar estimativas pelo método Bottom-Up. Cada componente ou tarefa de desenvolvimento é estimada separadamente e os resultados são agregados para produzir uma estimativa global de tempo de desenvolvimento.

Estimativas de tempo podem ser calculadas com o uso de modelos algorítmicos. Estimativas são elaboradas através da aplicação de equações específicas $\mathrm{cm}$ função de um número de variáveis ou direcionadores de custo. O COCOMO, por exemplo, é um modelo que pode ser utilizado para elaboração de estimativas de tempo manuais.

\section{a Elaboraçño de estimativas com ferramentas de estimativa}

Estimativas de tempo podem ser obtidas com o uso de ferramentas automatizadas e representam um bon método para checagem com estimativas derivadas manualmente. Grande parte das ferramentas geram relatórios detalluados da distribuição do tempo por fases. $O$ modelo COCOMO implementado nas ferramentas considera as atividades de Gerenciamento de Configuração, Garantia de Qualidade de Software, Esforço de documentação e Esforço de Gerenciamento no cálculo das estimativas de esforço, tempo e custo de projeto.

\section{Comparar estitnativas obtidas e solucionar divergências.}

Os resultados das duas estimativas devem ser comparados e as razões para grandes divergências devem ser esclarecidas. Se houver grandes discrepâncias entre as estimativas elaboradas nas duas formas, deve-se rever o processo de elaboração.

\section{Registrar estinativas de tempo no documento de estimativas.}

Registrar as estimativas de tempo no Documento de Estimativas, informando a data, o nome das pessoas encarregadas, os métodos e ferramentas de estimativa utilizados. 


\subsection{Fase 3: Avaliação dos Riscos do Projeto}

A seguir são descritas as diretrizes para condução da etapa de Avaliação dos Riscos do Projeto, apresentadas resumidamente na Figura 5.10.

\begin{tabular}{|c|c|}
\hline \multicolumn{2}{|c|}{ Fase 3: Avaliação dos Riscos do Projeto } \\
\hline \multicolumn{2}{|c|}{ Objetivo: identificar e avaliar riscos envoividos no desenvoivimento na execuçāo do projeto. } \\
\hline \multicolumn{2}{|c|}{$\begin{array}{l}\text { Pessoa Responsável: Gerente de projeto e equipe de planejamento. Poderá haver participação da } \\
\text { alta administração. }\end{array}$} \\
\hline Critérios de Inicialização: & \begin{tabular}{|l} 
Elementos de Entrada: \\
\end{tabular} \\
\hline $\begin{array}{l}\text { Estimativas de tamanho, esforço, tempo e } \\
\text { custo e a estrutura de divisão de trabalho } \\
\text { foram elaboradas. }\end{array}$ & $\begin{array}{l}\text { Tamanho, esforço, tempo e custo de } \\
\text { desenvolvimento estimados. Estrutura de } \\
\text { divisão de trabalho. }\end{array}$ \\
\hline \multicolumn{2}{|l|}{ Atividades: } \\
\hline \multicolumn{2}{|c|}{$\begin{array}{l}\text { 1. identificar riscos do projeto. } \\
\text { 2. Availiar riscos e revisar estimativas. } \\
\text { 3. Registrar fatores de risco do projeto e estimativas revisadas. }\end{array}$} \\
\hline Eiementos de Saida: & Critérios de Finailização: \\
\hline $\begin{array}{l}\text { Riscos do projeto. Estimativas revisadas } \\
\text { baseadas nos fatores de risco identificados. }\end{array}$ & $\begin{array}{l}\text { Riscos do projeto foram registrados. } \\
\text { Estimativas de tamanho, esforço, tempo e } \\
\text { custo foram revisadas baseando-se nos } \\
\text { fatores de risco identificados. Métricas de } \\
\text { tempo e recursos utilizados nessa atividade } \\
\text { foram registradas no documento de } \\
\text { estimativas. }\end{array}$ \\
\hline $\begin{array}{l}\text { Métricas: } \\
\text { 1. Número e ciassificação dos riscos. } \\
\text { 2. Registrar métricas de tempo e recursos uti }\end{array}$ & sa atividade. \\
\hline
\end{tabular}

Figura 5.10 - Diagrama Descritivo da Fase de Análise de Riscos do Projeto

As tarefas realizadas ncssa fase estão apresentadas a seguir.

\section{Identificar riscos do projeto.}

A equipe de planejamento deve identificar os riscos de projeto envolvidos na execução do projeto. A identificação e avaliação de diversos fatores de risco do projeto também é requerida no cálculo dos direcionadores de custo do modelo de estimativa COCOMO e na avaliação das 14 características gerais do sistcma, requerida pela técnica de Análise de Pontos de Função. Portanto, se foi utilizada uma técnica de contagem de pontos de função ou o modelo COCOMO, a equipe de planejamento pode iniciar a tarefa de identificação dos riscos baseando-se nos fatores previamente identificados. 
Um método eficiente para auxiliar a identificação de riscos é a criação de um checklist de itens, um conjunto de perguntas que seja pertinente aos fatores de tamanho do produto, impacto do negócio, características do cliente, definição do processo, ambiente de desenvolvimento, tecnologia de implementação e experiência da equipe. Un modelo de checklist para identificação de riscos é apresentado no Apêndice B.

Tamanho, prazos, custos, uso de novas tecnologias, hardware, software, pessoas (clientes e fornecedores; usuários e equipe de desenvolvimento) são as áreas de risco potencial mais comuns. $O$ mais conhecido fator de risco de estimativa é a estimativa de tamanho. É comum haver alto grau de incerteza a respeito do tamanho da aplicação quc será desenvolvida, logo no início do projeto. Estimativas para a quantidade de código reutilizado é também outra fonte de risco. É comum planejadores subestimaren a quantidade de esforço necessário à adaptação de código existente. Avaliações otimistas da equipe c do ambiente de desenvolvimento são fatores que contribuem para aumentar o risco das estimativas.

\section{Avaliar riscos e revisar estimativas.}

Una vez identificados os riscos, novas estimnativas deven ser elaboradas. A projeção dos riscos, tenta ćlassificar cada risco de duas maneiras - a probabilidade de que o risco seja real e as conseqüêneias dos problemas associados ao risco, caso ele ocorra.

As técnicas Wicleband Delphi e PERT Sizing são dois métodos comumente utilizados para determinação do grau de incerteza no tamanho do sistema. Se a volatilidade dos requisitos for um fator de risco, pode-se elaborar uma estimativa assunnindo-se baixa volatilidade de riscos, e outra, assumindo-se alta volatilidade. Desse modo, o gerente de projeto pode calcular o impacto da volatilidade dos requisitos do projeto, conhecendo os efeitos desse risco no custo e no cronograma do projeto.

A avaliação de riscos também deve ser feita toda vez que as estimativas do projeto forem atıalizadas. Baseando-se nos riscos identificados e nos efeitos estimados no projeto, a organização deve estudar pontos de controle e prevenção de erros.

\section{Registrar riscos e estimativas revisadas.}

Os fatores de risco devem ser registrados no Plano do Projeto. 
A organização pode criar um plano secundário - o Plano de Gerenciamento de Riscos - um documento formal que descreve os procedimentos que serão utilizados para gerenciar os riscos através do projeto. No plano de gerenciamento de riscos devem estar documentados os seguintes dados: a lista dos principais eventos de risco; a quantificação de risco de cada um dos eventos; quais as respostas serão dadas aos cventos de riscos; quais serão as contingências a serem adotadas quando as respostas convencionais não forem efetivas; como serão controlados os riscos (relatórios, etc.); como e com que freqüência o plano de gerenciamento de riscos será revisto; quem scrá o responsável pelo gerenciamento e pelo controle do plano de riscos.

\subsection{Fase 4: Elaboração do Cronograma do Projeto}

A seguir são descritas as diretrizes para condução da etapa de Elaboração do Cronograma, apresentadas resumidamente na Figura 5.11.

\begin{tabular}{|c|c|}
\hline \multicolumn{2}{|c|}{ Fase 4: Elaboraçāo do Cronograma do Projeto } \\
\hline \multicolumn{2}{|c|}{ Pessoa Responsável: Gerente de projeto, equipe de planejamento. } \\
\hline Critérios de inicialização: & Elementos de Entrada: \\
\hline $\begin{array}{l}\text { Estimativas de tempo e a estrutura de } \\
\text { divisão de trabalho foram elaboradas. } \\
\text { Habilidades em técnicas e ferramentas de } \\
\text { contruçăo de cronogramas. }\end{array}$ & $\begin{array}{l}\text { Estimativa de tempo de desenvolvimento, a } \\
\text { estrutura de divisão de trabalho. } \\
\text { Ferramentas de construçāo de } \\
\text { cronogramas. }\end{array}$ \\
\hline 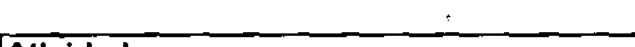 & \\
\hline \multicolumn{2}{|l|}{ Atividades: } \\
\hline \multicolumn{2}{|c|}{$\begin{array}{l}\text { 1. Identificar e selecionar recursos para o projeto. } \\
\text { 2. Alocar recursos nas alividades. } \\
\text { 3. Inter-relacionar as atividades e definir precedências (rede PERT). } \\
\text { 4. Calcular o caminho critico (CPM). } \\
\text { 5. Preparar cronograma de desenvolvimento }\end{array}$} \\
\hline \multirow{2}{*}{\multicolumn{2}{|c|}{$\begin{array}{l}\text { Critérios de Finalizaçăo: } \\
\begin{array}{l}\text { Recursos e profissionais foram } \\
\text { selecionadose designados para as } \\
\text { atividadades. O cronograma foi elaborado e } \\
\text { métricas de tempo e recursos utilizados } \\
\text { nessa atividade foram registrados. }\end{array}\end{array}$}} \\
\hline & \\
\hline \multicolumn{2}{|l|}{ Métricas: } \\
\hline Tempo e recursos utilizados nessa atividad & \\
\hline
\end{tabular}

Figura 5.11 - Diagrama Descritivo da Fase de Estimativa de Tempo 


\section{Identificar e selecionar os recursos para o projeto.}

Para se calcular a duração mais precisa do projeto, é necessário que se conheçam todos os recursos alocados nas atividades e a produtividade de cada um deles. A identificação e seleção de recursos para o projeto é usualmente conduzida em paralelo com a elaboração de estimativas de tempo, devido à dependência intrínseca entre duração e quantidade de recursos.

Devem ser identificados e selecionados todas os recursos humanos (quantos e quais profissionais), materiais de consumo e equipamentos (quantos, quando e quais os tipos de equipamentos) e financeiros (quanto e quando) necessários à execução do projeto.

\section{Alocar recursos nas atividades.}

Após serem determinados os recursos que serão empregados no projeto, é preciso que sejam atribuídos a cada atividade do projeto. Essa tarefa é trabalhosa e demorada, mas é a base de todo o cálculo de orçamentos e custos do projeto, bem como a única maneira de gerenciar a disponibilidade/alocação de cada recurso do projeto e gerenciar o recurso humano do projeto.

\section{Inter-relacionar as atividades e definir precedências (rede PERT).}

O objetivo dessa tarefa é identificar atividades interdependentes para que o cronograma do projeto seja elaborado. As atividades definidas na estrutura de divisão de trabalho são associadas e precedências entre elas são estabelecidas. A rede PERT Program Evaluation and Review Techinique é uma técnica que evidencia os inter-relacionantentos entre as atividades no projeto global. Uma rede ou malha de execução é definida, apresentando atividades que dependem da execução de outras e atividades realizadas em paralelo. En meio a essa malha, além das dependências, as atividades podem apresentar folgas, ou seja, prazos variáveis que não comprometem o projeto.

\section{Calcular o caminho crílico (CPM).}

Essa tarefa tcm como objetivo identificar a seqüência de atividades que não podem sofrer atrasos sem atrasar o projeto. O CPM Critical Path Method é uma técnica utilizada nessa tarefa. 


\section{Preparar cronograma do projeto.}

Essa tarefa tem como objetivo apresentar graficamente as datas de início e término de cada atividade, uma vez que os recursos, durações e as interdependências já cstão estabelecidas. $O$ cronograma do projeto pode ser apresentado de diferentes formas e as mais comuns são: redes PERT, tabelas com listas de atividades, gráficos de Gantt, gráficos de marcas ou etapas, etc. O Apêndice A apresenta um modelo simplificado para elaboração de cronograma. O uso de ferramentas de estimativa automatizadas pode ser de grande auxilio nessa tarefa.

\subsection{Fase 5: Cálculo de Custo do Projeto}

A seguir são descritas as diretrizes para condução da etapa de Cálculo de Custo do Projeto, apresentadas resumidamente na Figura 5.12.

\section{Fase 5: Calculo de Custo do Projeto}

Objetivo: Determinar o custo necessário para o projeto.

\section{Pessoa Responsável: Gerenle de projeto e equipe de planejamento.}

Criténios de Inicializaçāo: Estimativas de tamanho do sistema, esforço e tempo de desenvolvimento e a estrutura de divisāo de trabalho foram elaboradas.
Eiementos de Entrada: Estimativa de tamanho, estimativas de esforço e tempo, estrutura de divisão de trabalho.

\section{Tarefas:}

1. Calcular o custo das atividades do projeto.

2. Revisar e aprovar estimativas de custo do projeto.

3. Registrar estimativas de custo.

\begin{tabular}{|l|l|}
\hline \multicolumn{1}{|c|}{ Elementos de Saida: } \\
\hline Estimativas de custo do projeto.
\end{tabular}$\quad$\begin{tabular}{l|l}
$\mid \begin{array}{l}\text { Critérios de Finalizaçāo: } \\
\text { A estimativa de custo do projeto } \theta \text { métricas } \\
\text { de tempo e recursos utilizados nessa } \\
\text { atividade foram registradas no documento } \\
\text { de estimativas. }\end{array}$ \\
\hline
\end{tabular}

\section{Métricas:}

1. Custo do projeto, por fases e atividades de desenvolvimento.

2. Registrar métricas de tempo e recursos utilizados nessa atividade.

Figura 5.12 - Diagrama Descritivo da Fase de Estimativa de Custo do Projeto 
As tarefas realizadas nessa fase estão apresentadas a seguir.

\section{Calcular o custo das atividades do projeto.}

O custo das atividades do projeto é calculado utilizando-se a estrutura de divisão de trabalho e as estimativas de esforço e tempo de desenvolvimento. Se houver necessidade de um detalhamento maior, os custos do projeto podem ser obtidos com a elaboração de uma planilha de custos.

Para calcular os custos de recursos humanos, as abordagens de custeio direto e o custeio por absorção total podem ser utilizados.

O custeio direto considera apenas o salário + encargos, em ternios de valores médios ou aquele que representa o recurso específico a ser empregado no projeto, de acordo com a respectiva faixa salarial. O custeio por absorção total, mais complexo, considera o rateio entre diversos tipos de despesas incidentes sobre o desenvolvimento do software, tais como: recursos computacionais, equipamentos auxiliares, serviços contratados, custos administrativos, custos com materiais de consumo, custo de pessoal referentes às áreas de assessoria, chefia do desenvolvimento, etc..

Pode-se calcular o custo financeiro do projeto quando existir uma base de dados histórica com registros do custo unitário em pontos de função para cada projeto, de acordo com a plataforma e o processo de desenvolvimento. Nesse caso, para determinar o custo estimado do projeto, utiliza-se o custo médio de projetos similares e o método de transformação direta. Outra alternativa é o emprego da interpolação aritmética para determinarmos o custo do projeto para tamanhos intermediários na tabela.

Outra abordagem é o custo por empreitada, utilizado para calcular recursos que irão cobrar por um determinado trabalho, independentemente do tempo que se gaste para fazê-lo. A estrutura de divisão de traballıo também pode ser utilizada para calcular estimativas de custos das fases do projeto e até de todo o projeto. Nessa técnica, conhecida como estimativa de custos por pacotes de trabalho, o custo de uma fase é calculado com a soma dos custos das atividades a ela pertencentes e o custo total do projeto é a soma dos custos de suas fases. 


\section{Revisar e aprovar estimativas de custo.}

O gerente de projeto e a equipe de planejamento devem revisar e aprovar as estimativas de custo para o projeto.

\section{Registrar estimativas de custo.}

Registrar as estimativas de tempo no Documento de Estimativas, informando a data, o nome das pessoas encarregadas, os métodos e ferramentas de estimativa utilizados.

\subsection{Fase 6: Elaboração do Plano de Projeto}

A seguir são descritas as diretrizes para condução da etapa de Elaboração do Plano do Projeto, apresentadas resumidamente na Figura 5.13.

\section{Fase 5: Avaliação dos Riscos do Projeto}

Objetivo: Identificar e avaliar riscos envolvidos no desenvolvimento na execução do projeto.

\section{Pessoa Responsável: Equipe de planejamento.}

\begin{tabular}{|l|}
\hline \multicolumn{1}{|c|}{ Critérios de Inicialização: } \\
\hline A estrutura de divisão de lrabalho foi \\
preparada, estimativas de tamanho, esforço \\
e tempo foram elaboradas, o custo do \\
projeto foi calculado, os riscos foram \\
identificados e avaliados, e o cronograma \\
foi preparado.
\end{tabular}

\begin{tabular}{|c|}
\hline Elementos de Entrada: \\
\hline $\begin{array}{l}\text { Escopo do projeto. Estrutura de divisāo de } \\
\text { trabalho. Estimativs de tamanho, esforço e } \\
\text { tempo de desenvolvimento. Custo do } \\
\text { projeto. recursos identificados e alocados. } \\
\text { Cronograma de desenvolvimento. }\end{array}$ \\
\hline
\end{tabular}

Atividades:

1. Elaborar o plano do projeto.

\begin{tabular}{|c|}
\hline Elementos de Saída: \\
\hline Plano do Projeto.
\end{tabular}$\rightarrow$\begin{tabular}{l|}
\multicolumn{1}{c|}{ Critérios de Finalizaçāo: } \\
$\begin{array}{l}\text { O Plano do Projeto foi elaborado, contendo } \\
\text { vários outros documentos a ele anexados. }\end{array}$ \\
\hline
\end{tabular}

\section{Métricas:}

1. Registrar métricas de tempo e recursos utilizados nessa atividade.

Figura 5.13 - Diagrama Descritivo da Fase de Elaboraçăo do Plano de Projeto

As tarefas realizadas nessa fase estão apresentadas a seguir.

\section{Elaborar o plano do projeto.}

Essa tarefa consiste no preenchimento de todas as seç̃es do plano de projeto. Um modelo de plano é apresentado no Apêndice B. Outras seções ou itens que sejam considerados necessários podem adicionados. 
Seção I Introdução: registrar o escopo do projeto. A primeira seção do plano é a Introdução. Nos itens dessa seção descrevem-se as principais informações relacionadas ao sistema e aos objetivos do projeto:

1.1 Descrever o escopo, o propósito e os objetivos do projeto. Descrever o relacionamento com outros projetos, se for apropriado.

1.2 Descrever resumidamente como o sistema será estruturado funcionalmente, os subsistemas e/ou módulos que o compõem, e as principais funções de cada um deles.

1.3 Referenciar o número da folha onde consta o documento de requisitos do sistema.

1.4 Descrever resumidamente eventuais questões de desempenho impostas ao sistema.

1.5 Descrever resumidamente eventuais restrições técnicas e administrativas impostas ao projeto.

Seção II Estimattivas: registrar as estimativas de projeto. Nos itens dessa seção dcserevem-se as fontes utilizadas para elaboração de estimativas e as técnicas e ferramentas utilizadas.

2.1 Descrever as estimativas de tamanho, esforço, tempo e custo e a data da elaboração.

2.2 Descrever os dados históricos utilizados, quais projetos anteriormente utilizados foram consultados e comparados, etc.

2.3 Descrever as téenicas e ferramentas utilizadas para elaborar estimativas do projeto.

2.4 Referenciar o número da folha onde consta o Documento de Estimativas.

Seçăo III Riscos: registrar os riscos do projeto. Nos itens dessa seção descrevem-se os riscos identificados no projeto, os efeitos de eventuais ocorrências, bem como mecanisnos planejados para prevenção e controle.

3.1. Deserever (ou referenciar o número da folha onde consta) os riscos identificados, justificando-se os critérios considerados.

3.2 Descrever (ou referenciar o número da folha onde consta) a projeção dos efeitos provocados pela ocorrência dos riscos no desenvolvimento do projeto. Essas informações podem constar no Documento de Estimativas ou em um plano específico para o gerenciamento de riscos. 
3.3 Descrever (ou referenciar o número da folha onde constam) os mccanismos de prevenção e os pontos de controle para o gerenciamento dos riscos no desenvolvimento do projeto. Essas informações podem constar enı un plano cspecífico para o gerenciamento de riscos.

Seção IV Cronograma: registrar o cronograma elaborado para o projeto. Nos itens dessa seção referencia-se o cronograma de desenvolvimento do projeto, incorporado ao plano como documento ancxo.

4.1 Referenciar o número da folla onde consta a estrutura de divisão de trabalho do projeto.

4.2 Referenciar o número da folha onde consta o cronograma do projeto.

4.3 Descrever técnicas e eventuais ferramentas utilizadas para elaboração de cronograma de desenvolvimento do projeto.

Seção V Recursos: registrar os recursos utilizados no projeto. Nos itens dessa seção descrevem-se todos os recursos (pessoas, equipamentos, software) e custos associados, necessários ao desenvolvimento do projeto.

5.1 Identificar as pcssoas que compõem a equipe de desenvolvimento, informando o nome, função e outros dados considerados importantes.

5.2 Identificar e descrever os recursos de instalações, hardware, software e outros equipamentos alocados ou necessários ao desenvolvimento do projeto.

5.3 Identificar e descrever cventuais recursos especiais ou críticos que se fizerem necessários ao desenvolvimento do sistema. Pode ocorrer, por exemplo, a necessidade de uma linha telefônica exclusiva, uso exclusivo e integral de equipamentos, viagens, treinamento em alguma nova habilidade requerida, etc.. Esse item deve identificar $o$ recurso necessário, a justificativa para ele e um ponto de controle desse recurso para o gerente de projeto.

5.4 Referenciar o número da folha onde consta a planilha de custos elaborada. 
Seção VI Organização do Pessoal: registrar a organização do pessoal. Nessa seção descreve-se a estrutura organizacional para o desenvolvimento do software, se a organização optar por formalizar sua existência. Todavia, a preocupação com as consequiências práticas e políticas da mudança organizacional não está dentro do escopo de responsabilidades do planejador de projetos de software.

6.1 Referência a um documento que apresente uma estrutura de equipe formalizada (se necessário).

Seção VII Mecanismos de Rastreamento e Controle. Nessa seção descrevem-se os mecanismos de rastreamento e controle definidos para o processo de acompanhamento de projeto. Essa seção também pode fazer referência a um documento especialmente elaborado para rastreamento e controle para ser utilizado pelo gerente.

Seção VIII Plano de Gerenciamento de Configuração. Nessa seção descrevem-se o nome e função do gerente $e$ da equipe de gerência de configuração do software (se houver equipe formalmente definida) e outros dados que se fizerem necessários. Essa seção pode fazer referência ao Plano de Gerencianento de Configuraçño.

Seção IX Plano de Garantia de Qualidade. Nessa seção descreven-se o nome e função do gerente e da equipe de garantia de qualidade (se houver equipe formalmente definida) e outros dados que se fizerem necessários. Essa seção pode fazer referência ao Plano de Garantia de Qualidade.

Seção X Apêndices. Nessa seção descrevem-se informações elucidativas e ilustrativas, mas não imprescindíveis ao entendimento do projeto. Pode haver a necessidade de um glossário (opcional), com a significação de palavras ou expressões utilizadas para descrever o sistema e o projeto. 


\subsection{Fase 7: Finalização do Processo}

A seguir são descritas as diretrizes para condução da etapa de Finalização do Processo, apresentadas resumidamente na Figura 5.14.

\begin{tabular}{|c|c|}
\hline \multicolumn{2}{|c|}{ Fase 7: Finalização do Processo } \\
\hline \multicolumn{2}{|c|}{$\begin{array}{l}\text { Objetivo: Objetivo: aumentar a qualidade das estimativas e e do plano, integrar a participação da } \\
\text { geréncia no processo de planejamento, estabelecer compromissos. }\end{array}$} \\
\hline \multicolumn{2}{|c|}{$\begin{array}{l}\text { Pessoa Responsável: Alta gerência, equipe de planejamento, membro(s) da equipe de garantia de } \\
\text { qualidade (se houver grupo constituido). }\end{array}$} \\
\hline Critérios de Inicialização: & \begin{tabular}{|c|} 
Elementos de Entrada: \\
\end{tabular} \\
\hline $\begin{array}{l}\text { Estimativas foram devidamente registradas } \\
\text { no Documento de Estimativa e o plano do } \\
\text { projeto foi concluido. }\end{array}$ & $\begin{array}{l}\text { Plano do Projeto } \theta \text { documentos a ele } \\
\text { anexados. }\end{array}$ \\
\hline \multicolumn{2}{|c|}{ Tarefas: } \\
\hline \multicolumn{2}{|c|}{$\begin{array}{l}\text { 1. Conferir o documento de estimativas. } \\
\text { 2. Conferir o cronograma de desenvolvimento do projeto. } \\
\text { 3. Conferir todas as seçōes do plano. } \\
\text { 4. Aprovar o plano. }\end{array}$} \\
\hline Elementos de Saida: & Critérios de Finalizaçāo: \\
\hline $\begin{array}{l}\text { Plano do projeto revisado e aprovado, } \\
\text { contendo assinatura da alta gerência, do } \\
\text { gerente de projeto, da equipe de } \\
\text { planejamento, e de todos envolvidos direta } \\
\text { e indiretamente na execução do projeto. }\end{array}$ & $\begin{array}{l}\text { Estimativas do projeto foram revisadas e } \\
\text { aprovadas por todas as pessoas envolvidas } \\
\text { no projeto. }\end{array}$ \\
\hline $\begin{array}{l}\text { Métricas: } \\
\text { 1. Número de defeitos/problemas encontrados } \\
\text { 2. Esforco e recursos gastos na inspeção e ap }\end{array}$ & $\begin{array}{l}\text { ativas e no plano. } \\
\text { plano. }\end{array}$ \\
\hline
\end{tabular}

Figura 5.14 - Diagrama Descritivo da Fase de Finalização do Processo

É muito importante que o documento de estimativas, o cronograma e o plano do projeto passem por um processo de revisão. Muitos gerentes de projeto não inspecionam nem aprovam estimativas de projeto, o que contribui para o baixo nível de precisão das mesmas. Pode-se melhorar a precisão das estimativas simplesmente incluindo as pessoas certas no processo de validação.

A inspeção é executada em uma reunião que deve ter como participantes todas as pessoas que trabalharam na elaboração das estimativas e planejamento do projeto, incluindo um representante da alta administração, um desenvolvedor com experiência em aplicações similares, o gerente de projeto e um ou mais membros da equipe de garantia de qualidade. 
As tarefas realizadas nessa fase estão apresentadas a seguir.

\section{Conferir o documento de estimativas.}

$\checkmark$ Verificar os métodos utilizados para derivar estimativas de tamanho, esforço e tempo;

$\checkmark$ Conferir as estimativas de tamanho, esforço, tempo e custo do projeto, incluindo parâmetros de entrada, riscos de projeto, restrições e quaisquer suposições assumidas associadas com as estimativas;

\section{Conferir o cronograma de desenvolvimento do projeso.}

$\checkmark$ Conferir o cronograma de desenvolvimento do projeto, incluindo uma revisão das atividades relacionadas, folgas, caminho crítico do projeto, etc., relacionados com o desenvolvimento do projeto.

\section{Conferir todas as sȩ̧ōes do plano.}

$\checkmark$ Conferir todas as seções do Plano do Projeto, incluindo planos de gerenciamento complementares, tais como riscos, qualidade, etc.

\section{Aprovar o Plano do Projeto}

Depois do processo dc inspeção terminar, os problemas encontrados devern ser solucionados e todos os cnvolvidios no projeto devem concordar com as informações contidas no plano e com a viabilidade do cronograma das atividades. O plano do projeto deve ser assinado pela alta administração, pelas pessoas que participaram da fase de planejamento e inspeção, e por todas as pessoas envolvidas direta ou indiretamente no projeto. Depois de aprovado e devidamente assinado, o plano deve ser incorporado como item de configuração do software, através do processo de Gercnciamento de Configuração e está pronto para ser executado.

\subsection{Consideraçöes Finais}

Neste capítulo apresentou-se um modelo de processo de plancjamento. Foram apresentadas e cletalhadas as fases principais do inodelo e uma ĉnfasc maior de detalhamento foi dada às tarefas envolvidas em cada passo do processo. O próximo capítulo apresenta um estudo de caso onde será exemplificada a utilização do modelo de processo. 


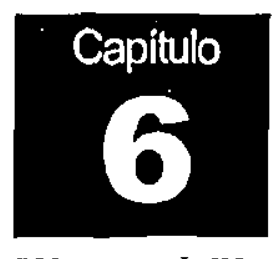

\section{Planejamento de um Projeto: Um estudo de Caso}

\subsection{Considerações Iniciais}

Neste capitulo, apresenta-se um estudo de caso da aplicação do modelo de processo no planejamento de um projeto de sistema para controlar o acervo de desenhos e documentos técnicos de engenharia de uma empresa privada. O projeto foi realizado pelo departamento de desenvolvimento da própria empresa.

\subsection{O Ambiente de Desenvolvimento de Software do Estudo de Caso}

O estudo de caso foi realizado em um ambiente de desenvolvimento de software de uma das unidades de uma empresa privada do ramo de Agribusiness. Essa empresa possui muitos procedimentos internos controlados por sistemas de computador distribuídos em uma rede de computadores relativamente grande. São utilizados diversos sistemas operacionais, comunicação via satélite, links de alta velocidade, acesso via rádio, Internet, intranet e redes locais, dependendo da localização e necessidade de utilização de recursos de cada unidade da empresa, distribuida em todo o país.

A empresa possui diversos sistemas adquiridos, dos quais contrata mão-de-obra externa, ou repassa a manutenção para os fabricantes quando há necessidade de manutenção. A enpresa também desenvolve c mantém sistemas próprios de computador. Os sistemas tipicamente desenvolvidos pela empresa são: Faturamento, Contas a Pagar, Logística, Fretes, Controle de Estoques, Controle de Acesso e MDA - Manual de Delegação de Autoridade, entre outros.

$\mathrm{Na}$ área de desenvolvimento, a empresa possui um grupo composto por um diretor, quatro gerentcs, quatro coordenadores e cerca de 35 profissionais envolvidos na área de sistemas (Diretoria de Informática). O grupo da Diretoria de Informática (Sistemas de Informações) é composto pelos subgrupos: Informações Gerenciais, Novas Tecnologias, Desenvolvimento e Manutenção de Sistemas. e Rede e Suporte, divididos por áreas de atuação. 


\subsection{Aplicação do Modelo de Processo em um Planejamento de Projeto}

A área de desenvolvimento da unidade da empresa onde o estudo de caso foi realizado executa planejamento informal de desenvolvimento e manutenção de seus sistemas. O prazo de desenvolvimento é estimado subjetivamente para cada programador, sendo posteriormente computado em um cronograma de entrega. Os riscos envolvidos nos projetos normalmente sĩo de baixo nível e o custo de desenvolvimento não é calculado.

Todavia, a empresa sente a necessidade de melhorar scus processos gerenciais e atualmente está considerandu a adoção de um sistema de métricas para apoiar os processos gerenciais de desenvolvimento de software. Segundo o gerente geral de dcsenvolvimento, um estudo está sendo realizado para a inclusão da métrica de pontos de fulção nas metas administrativas da empresa para o próximo ano.

O planejamento foi efetuado tomando-se como base um projeto (já realizado) da organização, cuja função é controlar o acervo de desenhos c documentos técnicos de engenliaria da empresa. O sistema é, basicamente, una ferramenta de ajuda de localização física de documentos, composta de quatro módulos: Tabelas, Dısenhos, Relatórios e Diversos.

Nenhum registro formal de métricas de tempo, esforço e tempo foi realizado. São conhecidos porém o tamanho efetivo do sistema que é de 8.750 linhas de código, (considerando-se comentários incluídos), o tempo de desenvolvimento que foi de aproximadamente 3 meses e o esforço de desenvolvimento de 9 hontens-mês (um analista e dois programadores trabalhando num regime de 8 horas por dia, 5 dias por semana).

\subsubsection{A fase de Preparação para a Implantação do Processo}

Na realidade, o processo de planejamento não foi implantado pela empresa. As etapas foram realizadas com o objetivo de exemplificar o processo de plancjamento para a empresa. Portanto, a sequêencia de atividades do roteiro preparação para a execução do processo é apresentada nos itens seguintes apenas para ilustrar essa fase.

i. Estrutura da equipe de planejamento. As pessoas indicadas para compor a equipe inicial de planejamento são as pessoas que compõem a equipe de desenvolvinento: Um gerente de projetos, um analista de sistemas e dois programadores. 
ii. Capacitação da equipe em métricas de software. Inicialmente, a equipe inicial de plancjamento foi treinada na aplicação das técnicas de contagem indicativa, contagem estimada e Análise de Pontos de Função.

iii. Capacitação da equipe em planejamento de projetos de software. $O$ modo usual de elaboração de estimativas da empresa é o Julgamento de Especialistas. A empresa não utiliza nenhuma outra técnica nem ferramentas para elaboração de estimativa ou para elaboração de cronograma. A empresa também não registra dados de seus projetos. A equipe de desenvolvimento foi treinada nas seguintes técnicas de elaboração de estimativas: estimativa por analogia e estimativas de esforço e tempo com o uso do modelo COCOMO II.

iv. Seleção de produtos disponíveis no mercado. Foram selecionadas as versões demonstrativas das ferramentas COSTAR, para elaboração de estimativas de esforço e tempo de desenvolvimento, e a ferramenta Project Quick Start, para elaboração de cronograma com gráficos de Gantt. Pelo fato de screm versões demonstrativas, as ferramentas apresentam limitações de uso. $O$ desempenho das ferramentas será analisado com o objetivo de estudo viabilidade de adoção/aquisição.

v. Plano de treinamento. O plano de treinamento proposto (Figura 6.1).

\subsubsection{A fase de Inicialização do Processo}

O escopo do projeto foi definido, contendo o objetivo, a justificativa e os produtos produzidos, sendo registrados em papel para ser utilizado na elaboração do plano. $O^{\circ}$ ciclo de vida adotado para o projeto foi o ciclo de vida Clássico ou Cascata. A estrutura de divisão de trabalho foi elaborada (Figura 6.2).

A equipe de planejamento revisou e aprovou a declaração do cscopo do projeto, o modelo de ciclo de vida adotado e a estrutura de divisão de trabalho. 


\section{Plano de Treinamento}

\section{Propósito}

O propósito deste treinamento é:

- Desenvolver e melhorar as habilidades atuais do gerente de projeto, possibilitando planejar e gerenciar projetos de forma bem sucedida.

- Desenvolver e melhorar as habilidades atuais de elaboração de estimativas e planejamento de projeto dos analistas e programadores.

\section{Objetivos}

Os objetivos a serm alcançados com o treinamento estipulado são:

- Desenvolver e melhorar as habilidades necessárias ao planejamento e gerenciamento do desenvolvimento de projetos.

- Compreender as fases e atividades do cielo de vida do software cascata e atividades de apoio.

- Enfatizar as fases iniciais do ciclo de desenvolvimento de softwa re: definição dos requisitos e planejamento de projeto.

- Mellorar o processo de desenvolvimento através do uso de processos e princípios de planejamento

III Participuntes de projeto, melhorando a qualidade do processo nas fases iniciais de desenvolvimento.

\section{Tópicos}

Equipe de desenvolvimento.

- Modelo de ciclo de vida cascata.

- Atividades de Planejamento de Desenvolvimento de Software.

- Estrutura de divisão de trabalho e Estrutura de divisão funcional do sistema.

- Contagein de Pontos de Função: Contagem Indicativa, Contagem Estimada e Arálise de Pontos de Função.

- Estimativa por Analogia e Modelo COCOMO.

- Ferramenta de estimativa: COSTAR.

- Definiçāo dos Recursos (pessoas, equipamentos, etc.).

$V$ Local

- Ferramenta para elaboração de cronograma: Project Quick Start.

Local de treinamento: sala de desenvolvimento

Data: Jullio de 2000.

Duração: I semana (14:00 às 16:00).

VI Material de Treinamento

Ferramentas:

COSTAR, PROJECT QUICK START.

Bibliografia:

BRAGA, Antônio. Análise de pontos por função. Rio de Janeiro: Infobook, 1996.

PRESSMAN, R. Engenharia de Software. 3 ed. Rio de Janeiro. Makron Books, 1995.

TEIXEIRA, W.; SANCHES, R. Pontos de Função: uma medida funcional de tamanho de software.

São Carlos, ICMC, 2000. (Relatório Técnico do ICMC-USP, 105).

TEIXEIRA, W.; SANCHES, R. Modelos de Estinativa de Custo de software - COCOMO e

COCOMO II. São Carlos, ICMC, 2000. (Relatório Técnico do ICMC-USP, 106).

VII Responsáuel pelo Treinamentu

Waine Teixeira Júniur

VIII Custo Estimato

Não consiclerado

Figura 6.1 - Plano de Treinamento Proposto para Implantaçåo do Processo de Planejamcnto 
Estrutura de Divisão de Trabalho - Projeto Desenhos Folha 04

1. Gerenciamento

1.l Planejamento do projeto

1.2 Revisão e aprovação

1.3 Acompanhaniento do projeto

2. Projeto

2.1 Revisar especificações do sistema

2.2 Elaborar DFD's

2.3 Elaborar MER

2.4 Elaborar Documentos de Descrição de Arquivos

2.5 Elaborar Documentos de Descrição do Programa

2.6 Especificar telas

2.7 Especifiear relatórios

2.8 Revisão da Gerĉncia

3. Codificaçăo e Teste de Unidade

3.1 Codificar Módulo Tabelas

3.2 Codificar Módulo Desenhos

3.3 Codificar Módulo Relatórios

3.4 Codificar Módulo Diversos

3.5 Testar Módulo Tabelas

3.6 Testar Módulo Desenhos

3.7 Testar Módulo Relatórios

3.8 Testar Módulo Diversos

3.9 Revisão da Gerência

4. Documen tação

4.1 Elaborar Manual do Usuário

4.2 Revisão da Gerência

5. Integraçăo e Teste

5.1 Intcgrar módulos do sistema

5.2 Testar sistema

5.3 Revisão da Gerência

6. Implantaçāo

6.1 Treinar usuários

6.2 Instalar sistema

6.3 Revisão da Gerência

Figura 6.2 - Estrutura de Divisão de Trabalho do Projeto Desenhos 


\subsubsection{A fase de Elaboração de Es timativas: Tamanho do Sistema}

Estimativas do tamanho do sistema foram elaboradas utilizando-se as métricas de pontos de função e linhas de código.

- Estimativas de tamanho em Pontos de Função: A Análise de Pontos de Função foi realizada e resultou nas informações apresentadas na tabela 6.1 . De acordo com a tabela de conversão em linhas de código [Jones, 1996b] e a linguagem Clipper definida para implementação do sistema, foi utilizado o fator de conversão de 40 linhas de código por pontos de função, que resultou em uma estimativa de 10.600 linlas de código.

Tabela 6.1 - Resultado da Análise de Pontos de Função

\begin{tabular}{|l|c|c|c|c|}
\hline Módlulo: & Tabelas & Desenhos & Relatórios & Diversos \\
\hline Entradas Externas: & 15 Simples & 3 Simples, 3 Média & 0 & I Simples \\
\hline Saidlas Extcrmas: & 5 Simples & 5 Média & 6 Simples, 5 Média & 1 Simples \\
\hline Arquivos Internos: & 5 Simples & 2 Simples & 0 & t Simples \\
\hline Arqnivos Externas: & 0 & 0 & 0 & 0 \\
\hline Consullas Externas: & 5 Simples & 6 Média & 0 & 1 Simptes \\
\hline PF's Não Ajustados & 115 & 84 & 49 & 17 \\
PF's Ajustados & 95 & 69 & 40 & 13 \\
\hline Conversão em LOC & 4600 & 3360 & 1960 & 680 \\
\hline \multicolumn{7}{|l}{ Total de pontos de função não ajustados: 265} & \\
\hline
\end{tabular}

Uma base de dados contendo informações históricas dos projetos da organização será construída. Para a claboração de estimativas de esforço e prazo utiltzando a variável tamanho em pontos de função serão registradas métricas de pontos de função ajustados. Portanto, foi necessário o cálculo do Fator de Ajuste de Pontos de Função (Tabela 6.2).

Tabela 6.2 - Resultado da Avaliaçăo das 14 Características Gerais do Sistema

\begin{tabular}{|c|c|c|c|}
\hline \multicolumn{4}{|c|}{ Características Gerais do Sistema } \\
\hline 1- Comunicação de dados & 3 & 8 - Atualização on-line & 2 \\
\hline 2 - Funçōes distribuídas & 0 & 9-Processamento complexo & 0 \\
\hline 3-Performance & 0 & 10 - Reusabilidade & 0 \\
\hline 4 - Configuraçăo do equipamento & 0 & 11 - Facilidade de implantaçâo & 0 \\
\hline 5-Volume de transações & 0 & t2 - Facilidade de operaç̃̃o & 2 \\
\hline 6-Entrada de dados on-line & 5 & 13-Múltiplos locais & 1 \\
\hline 7 - Interface com o usuário & 4 & 14 - Facilidade de mudanças & 0 \\
\hline
\end{tabular}

Fator de ajuste $=(17 * 0,01)+0,65=0,82$

PF Ajustados $=265^{*} 0,82=217,3 \mathrm{PF}$

$\mathrm{PF}$ Ajustados $=217$ pontos de função 
- Estimativas de tamanho em Linhas de Codigo: A estimativa do tamanho do sistema em linhas de código foi estimada a partir do Julgamento Subjetivo dos funcionários da empresa, contando com experiência em desenvolvimento de aplicações similares.

A técnica Pert Sizing foi utilizada depois que estimativas de linhas de código foram elaboradas. As estimativas sugeridas foram: Tamanho otimista (a): 6.000, Tamanho mais provável (b): 7.000, Tamanho pessimista (c): 8.000 .

Estimativa de Tamanho $=(a+4 b+c) / 6=(6.000+4 \times 7.000+8.000) / 6=7.000$ linhas

Desvio Padrão $=(c-a) / 6=(8.000-6.000) / 6=333.33$

As estimativas obtidas com a utilização das duas técnicas diferentes foram comparadas. Optou-se pela adoção do tamanho nominal do sistema estimado em 10.600 linhas de código, a maior estimativa de tamanho, por constituir o principal elemento de risco para o projeto.

As estimativas de tamanho foram registradas no Documento de Estimativas (Figura $6.12)$

\subsubsection{As fases de Elaboração de Estimativas: Esforço e Tempo de Desenvolvimento}

Para a elaboração de estimativas de esforço foram utilizados: a técnica de Julgamento de Especialista e o modelo COCOMO II.

Julgamento de Especialista: o esforço e o tempo necessário ao desenvolvimento do sistema foi estimado a partir do julgamento subjetivo dos funcionários da empresa, considerando-se a experiência dos programadores em desenvolvimento de aplicações similares. $O$ esforço de desenvolvimento foi estimado em: 9 homens/mês e a duração em 3 meses.

Modelo COCOMO II: As estimativas foram elaboradas com o submodelo "PósArquitetura", considerando-se que a dimensão do tamanho do sistema já é conhecida. As estimativas foram elaboradas com a ferramenta COSTAR. Foram estimados os quatro módulos separadamente: Tabelas, Desenhos (Figura 6.3), Relatórios e Diversos. A limitação da versão demonstrativa da ferramenta não permite estimar módulos ou sistemas maiores que 5.000 linhas de código. Os fatores de escala e os direcionadores de custo devidamente ponderados estão apresentados nos quadros 6.1 e 6.2 . 


\section{Quadro 6.1 - Fatores de Escala Ponderados para o Projeto}

\begin{tabular}{|l|l|}
\hline PREC & $\begin{array}{l}\text { lá muita faniliaridade com o tipo de aplicação a desenvolver, portanto a precedência ten um nível } \\
\text { muito alto. }\end{array}$ \\
\hline FL;X & $\begin{array}{l}\text { Alguma flexibilidade é perceptível para estabelecimento e conformidade de uso de padrões, o que } \\
\text { determina um nível alto. }\end{array}$ \\
\hline RESL & As especificações do projeto tstão tolalmente sob domínio, portanto o nível é extra alto. \\
\hline TEAM & $\begin{array}{l}\text { A equipe de desenvolvimento tem uma eoesão excelente, portanto as condições altanente eooperativas } \\
\text { estabclecen un nivvel muito alto. }\end{array}$ \\
\hline PMAT & $\begin{array}{l}\text { A contagem especial das KPA's cumpriclas pela equipe de desenvolvimento coloca a empresa no nivel } \\
\text { I do CMM. }\end{array}$ \\
\hline
\end{tabular}

Quadro 6.2 - Direcionadores de Custo Ponderados para o Projeto

\begin{tabular}{|c|c|}
\hline RELY & $\begin{array}{l}\text { O sistema pode trabalhar com um indice de perdas facilmente recuperáveis, portanto a confiabilidade } \\
\text { requerida tem um nivel baixo. }\end{array}$ \\
\hline DATA & $\begin{array}{l}\Lambda \text { razão dimensional entre o banco de dados e o produto está entre } 10 \text { e } 100 \text {, portanto o tamanho da } \\
\text { base remete a um nivel baixo. }\end{array}$ \\
\hline DOCU & $\begin{array}{l}\text { A documentação a ser gerada será na medida certa, para a quantidade neccssária de ciclos de vida do } \\
\text { projeto, portanto o uível é nominal. }\end{array}$ \\
\hline CPLX & $\begin{array}{l}\text { O software não é considerado complexo na análise dos } 8 \text { pressupostos correspondentes, portanto } 0 \\
\text { nivel é baixo. }\end{array}$ \\
\hline RUSE & $\begin{array}{l}\text { A utilização de linhas de código entre programas gerados no mesmo projeto nãu é pretendida, portanto } \\
\text { a reusabilidade requerida terá nivel baixo. }\end{array}$ \\
\hline TIML & As restrições relativas ao tempo dos dispositivos são nominais. \\
\hline STOR & $\begin{array}{l}\text { O uso de áreas de armazenamento disponiveis não ultrapassará os } 50 \% \text {, portanto as restrições relativas } \\
\text { à mcmória são nominais. }\end{array}$ \\
\hline PVOL & $\begin{array}{l}\text { A previsibilidade de grandes mudanças da plataforma não são menores que } 12 \text { meses, portanto o nível } \\
\text { ć baixo. }\end{array}$ \\
\hline ACAP & O cseore acumulado de competências atinge o $75^{\circ}$ pereentil, portanto a capacidade dos analistas é alta. \\
\hline AEXP & $\begin{array}{l}\text { Profissionais atuam, no tipo de aplicação, há, aproximadamente, } 3 \text { anos, portanto a experiência conta } \\
\text { com nivel alto de influência. }\end{array}$ \\
\hline $\mathrm{PCAP}$ & $\begin{array}{l}\text { O eseore acumulado de competências atinge o } 75^{\circ} \text { percentil, portanto a capacidade dos programadores } \\
\text { apresenta nível alto. }\end{array}$ \\
\hline PEXP & $\begin{array}{l}\text { Os desenvolvedores conhecem os recursos da plataforna ha mais de } 3 \text { anos, portanto esta experiência } \\
\text { tem nivel alto. }\end{array}$ \\
\hline LTEX & $\begin{array}{l}\text { A programaçāo se utilizará de recurso aplicável há, aproximadamente, I ano, portanto a experiència } \\
\text { com linguagem e ferramental é nominal. }\end{array}$ \\
\hline PCON & $\begin{array}{l}\text { A rotatividade de pessoal é baixissima, cerca de } 3 \% / a n o \text {, portanto a capacidade produtiva é } \\
\text { incontestável e este nivel de influência é muito alıo. }\end{array}$ \\
\hline TOOL & $\begin{array}{l}\text { A equipe conta com ferramental básico para execução de suas tarefas de programação e testes, portanto } \\
\text { o nível é nominal. }\end{array}$ \\
\hline SITE & $\begin{array}{l}\text { Desenvolvimento planejado para ser desenvolvido na própria empresa, portanto tenı nível de influêneia } \\
\text { muito alto. }\end{array}$ \\
\hline SCED & $\begin{array}{l}\text { Tempo contratado de desenvolvimento é } 75 \% \text { do nominal (lesejivel), poitanto o requerido tem nível } \\
\text { de influĉncia muito baixo. }\end{array}$ \\
\hline
\end{tabular}

De posse de tais dados, ajustout-se os fatores de escala c os direcionadores de custo da ferramenta utilizada (Figuras 6.5 e 6.6 ). 


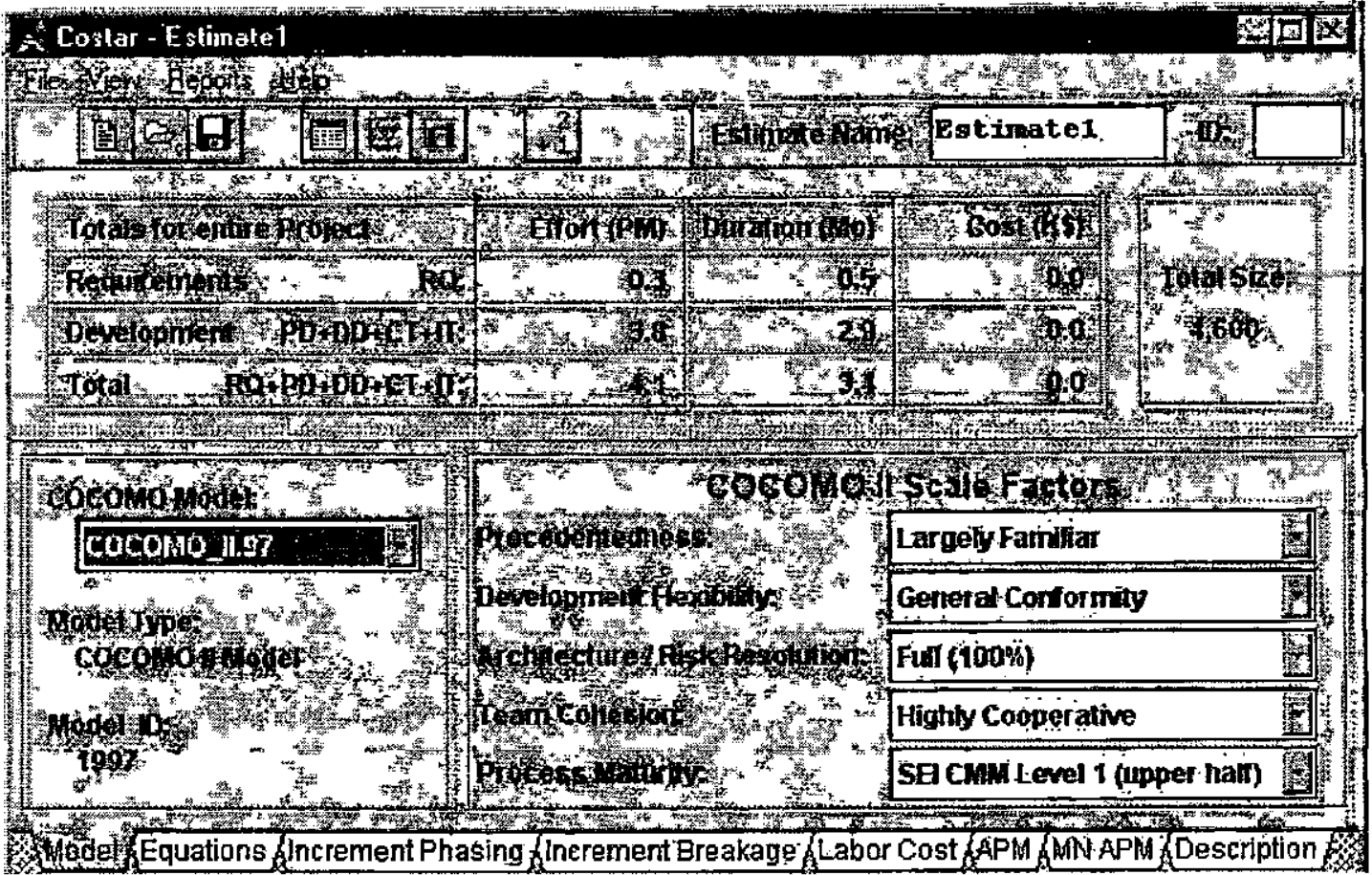

Figura 6.3 - COSTAR - Tela Principal do Sistema

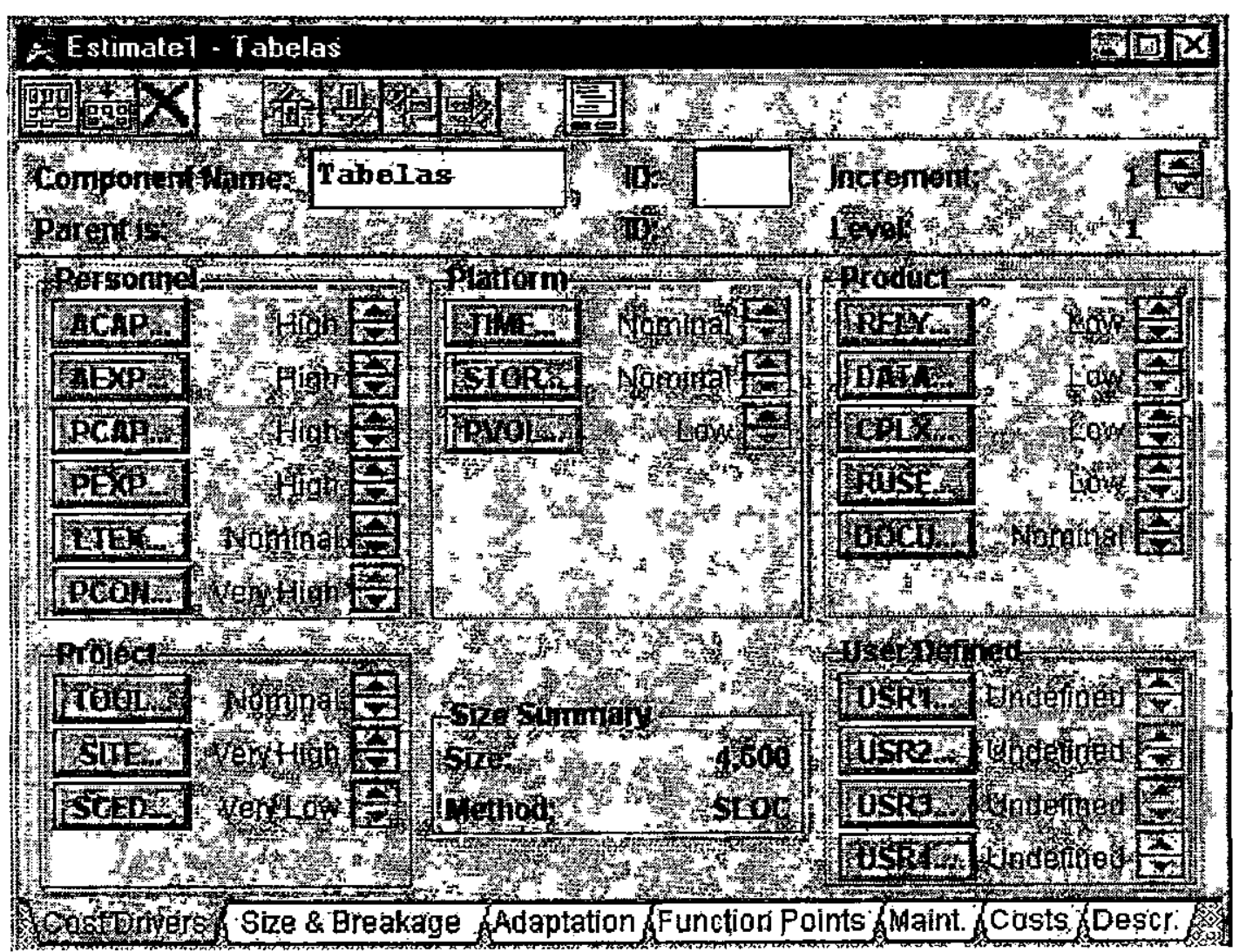

Figura 6.4 - COSTAR - Tela de Ajuste dos Direcionadores de Custo do COCOMO II 
Os dados estimados de esforço e tempo de desenvolvimento de cada módulo (Figura 6.5) foram somados e resultaram em uma estimativa de esforço de 7.1 homens-mês e duração de 6.8 meses (Tabela 6.3).

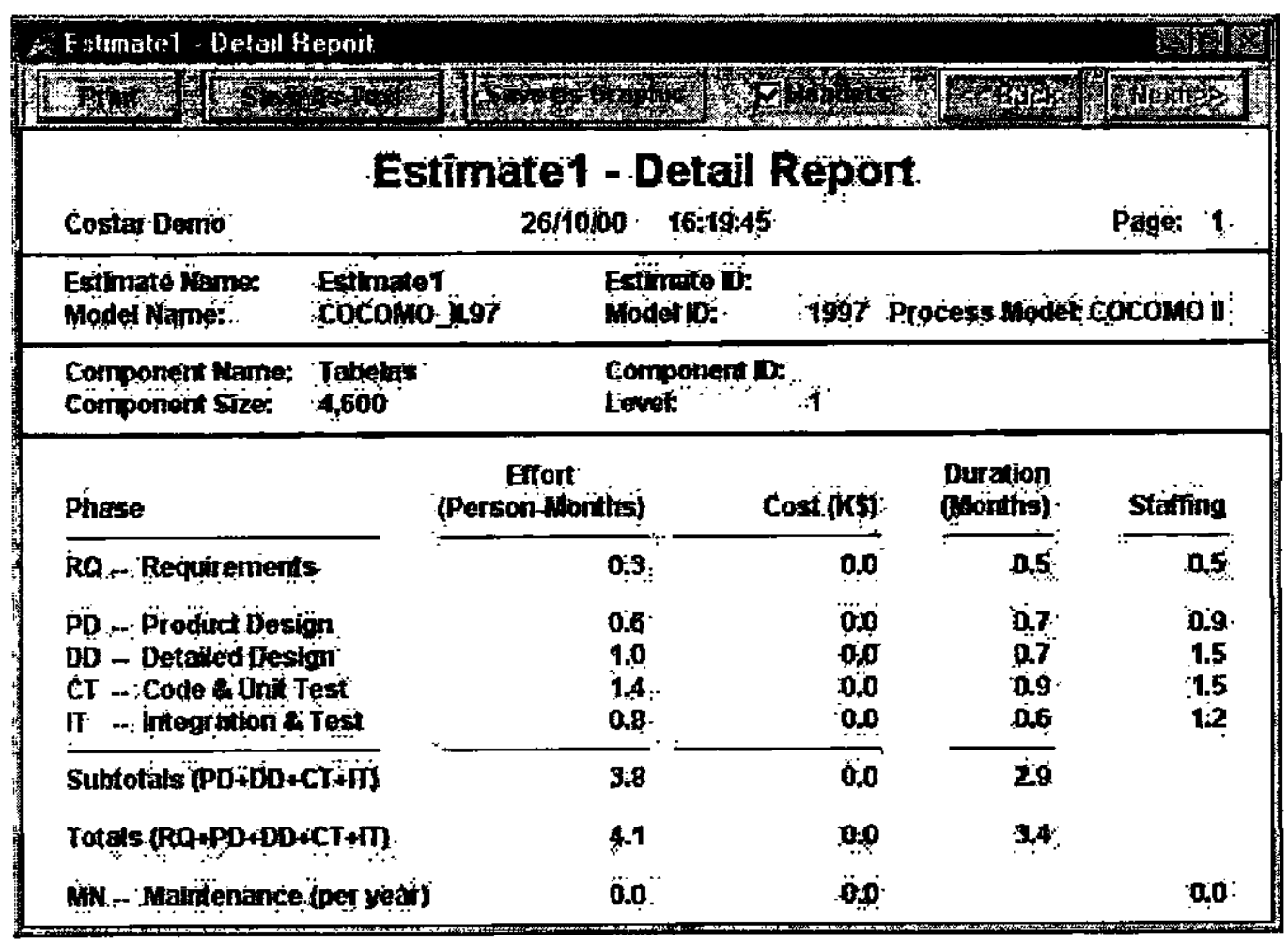

Figura 6.5 - COSTAR - Relatório de Estimativas de Esforço e Duraçăo do Módulo Tabelas

Tabela 6.3 - Totais das Estimativas de Esforço e Duraçåo (Ferramenta COSTAR)

\begin{tabular}{|c|c|c|c|c|c|c|c|c|c|c|}
\hline Fase & \multicolumn{2}{|c|}{ Tabelas } & \multicolumn{2}{c|}{ Desenhos } & \multicolumn{2}{c|}{ Relatórios } & \multicolumn{2}{c|}{ Diversos } & \multicolumn{2}{c|}{ Total do Sistema } \\
\hline & $\begin{array}{c}\text { Esforço } \\
\text { (PM) }\end{array}$ & $\begin{array}{c}\text { Duração } \\
\text { (Mês) }\end{array}$ & $\begin{array}{c}\text { Esforço } \\
\text { (PM) }\end{array}$ & $\begin{array}{c}\text { Duração } \\
\text { (Mês) }\end{array}$ & $\begin{array}{c}\text { Esforço } \\
\text { (PM) }\end{array}$ & $\begin{array}{c}\text { Duração } \\
\text { (Mês) }\end{array}$ & $\begin{array}{c}\text { Esforço } \\
\text { (PM) }\end{array}$ & $\begin{array}{c}\text { Duração } \\
\text { (Mês) }\end{array}$ & $\begin{array}{c}\text { Esforço } \\
\text { (PM) }\end{array}$ & $\begin{array}{c}\text { Duração } \\
\text { (Mês) }\end{array}$ \\
\hline RQ & 0.3 & 0.5 & 0.2 & 0.4 & 0.1 & 0.3 & 0.0 & 0.2 & 0.6 & 1.4 \\
\hline PD & 0.6 & 0.7 & 0.5 & 0.6 & 0.3 & 0.5 & 0.1 & 0.3 & 1.5 & 2.1 \\
\hline DD & 1.0 & 0.7 & 0.7 & 0.6 & 0.4 & 0.5 & 0.1 & 0.3 & 2.2 & 2.1 \\
\hline CT & 1.4 & 0.9 & 1.0 & 0.8 & 0.6 & 0.7 & 0.2 & 0.5 & 3.2 & 2.9 \\
\hline IT & 0.8 & 0.6 & 0.5 & 0.5 & 0.3 & 0.4 & 0.1 & 0.3 & 1.7 & 1.8 \\
\hline Total & $\mathbf{3 . 2}$ & $\mathbf{2 . 2}$ & $\mathbf{2 . 2}$ & $\mathbf{1 . 9}$ & $\mathbf{1 . 3}$ & $\mathbf{1 . 6}$ & $\mathbf{0 . 4}$ & $\mathbf{1 . 1}$ & $\mathbf{7 . 1}$ & $\mathbf{6 . 8}$ \\
\hline
\end{tabular}

Os resultados das duas estimativas foram comparados. Assumiu-se como estimativa nominal de desenvolvimento os valores estimados pela ferramenta, excluindo-se as fases de levantamento de requisitos e projeto lógico (RQ e PD). Considerando-se que o recurso humano disponível para a execução do projeto é maior que o esforço estimado pela ferramenta, as estimativas de esforço e duração de cada fase foram recalculadas manualmente (método "regra de três") (Tabela 6.9). A duração em dias foi calculada levando-se em consideração 19 dias úteis de trabalho por mês [Trindade, 2000a]. 
Tabela 6.4 - Ajuste de Estimativas de Duração de Fases

\begin{tabular}{|c|c|c|c|c|c|}
\hline Fase & $\begin{array}{c}\text { Esforço } \\
\text { Estimado (PM) }\end{array}$ & $\begin{array}{c}\text { Esforço } \\
\text { Disponivel (PM) }\end{array}$ & $\begin{array}{c}\text { Duração } \\
\text { Estimada (Mês) }\end{array}$ & $\begin{array}{c}\text { Duração } \\
\text { Ajustada } \\
\text { (Mês) }\end{array}$ & $\begin{array}{c}\text { Duração } \\
\text { Ajustada } \\
\text { (Dias) }\end{array}$ \\
\hline DD & 2.2 & 3 & 2.1 & 1.5 & 28 \\
\hline CT & 3.2 & 3 & 2.9 & 3.1 & 59 \\
\hline IT & 1.7 & 3 & 1.8 & 1 & 19 \\
\hline \multicolumn{6}{|c|}{ Totais Aproximados: } \\
\hline
\end{tabular}

Assumiu-se também que o modelo COCOMO II considera esforço e tempo relativos à atividades de Gerenciamento de Configuração e Garantia de Qualidade, atividades ainda não executadas pela empresa. A estimativa de esforço assumida foi de 9 homens-mês e o tempo de desenvolvimento de 106 dias úteis.

As estimativas de tamanho foram registradas no Documento de Estimativas (Figura 6.12).

\subsubsection{A fase de Avaliação dos Riscos do Projeto}

A identificação e análise detalhada dos riscos envolvidos no projeto não foi executada como é sugerido pelo modelo. A organização considerou que os riscos primariamente identificados representam baixo grau de probabilidade ocorrência para comprometer de alguma forma os objetivos do projeto. $\mathrm{O}$ risco primário identificado pela equipe de planejamento foi o tamanho do sistema, devido à ausência de registros e à alta subjetividade do julgamento de especialistas na elaboração do tamanho. Foram também estudados os fatores de risco do estudo e avaliação dos direcionadores de custo do modelo de estimativa COCOMO II e da avaliação das 14 características gerais do sistema, requerida pela técnica de Análise de Pontos de Função.

\subsubsection{A fase de Elaboração do Cronograma do Projeto}

Os recursos disponíveis para a execução do projeto foram alocados, distribuídos e registrados. Não houve necessidade de novas aquisições de recursos materiais. As dependências da empresa e o recurso humano da área de desenvolvimento foram considerados adequados e alocados em tempo integral para a execução do projeto.

O cronograma do projeto foi preparado com o auxílio da ferramenta Project Kick Start, para elaboração de gráficos de Gantt (Figura 6.6). $\mathrm{O}$ gráfico foi considerado adequado para o porte do projeto. 


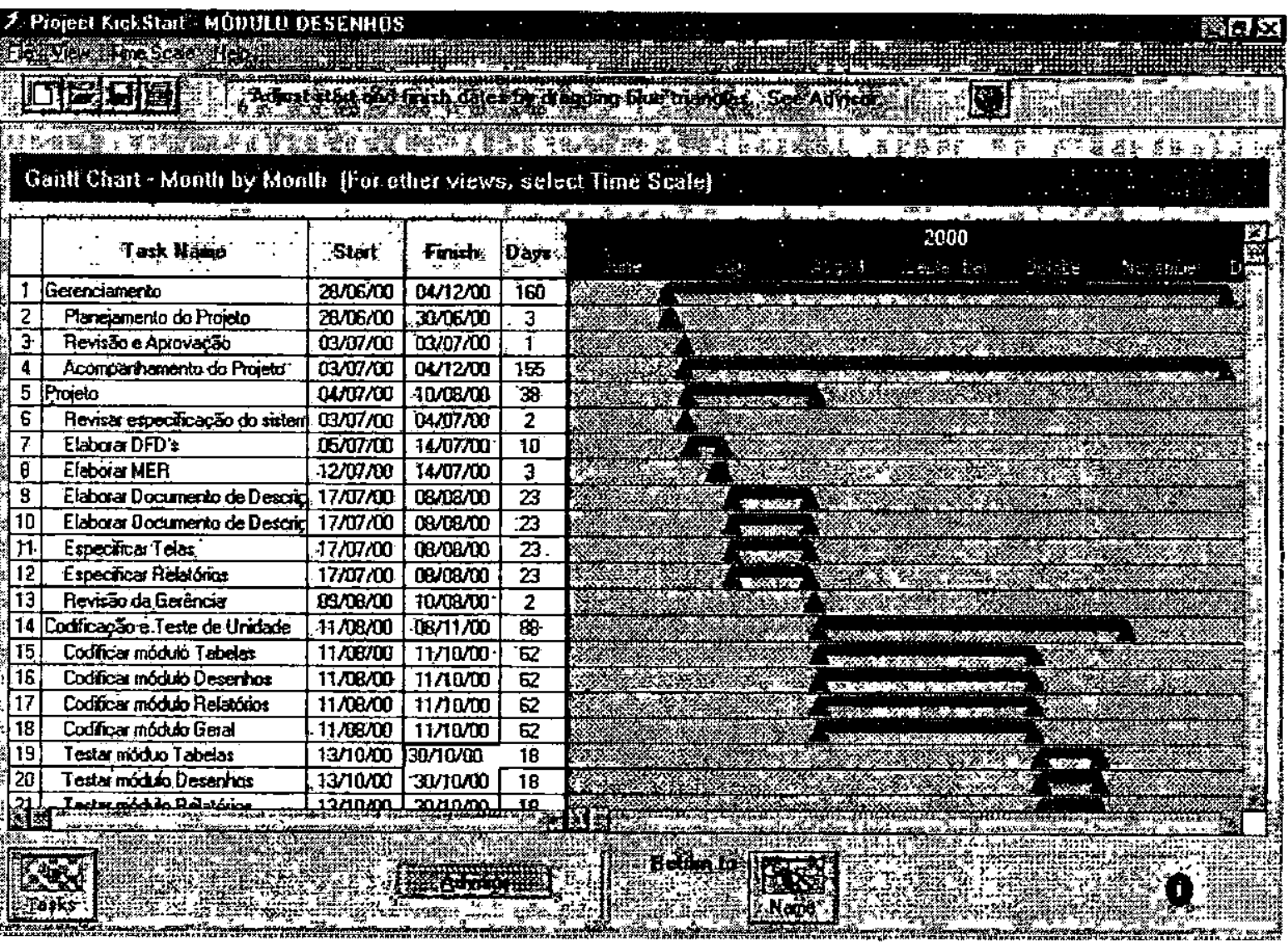

Figura 6.6 - Cronograma de Execuçăo do Projeto

\subsubsection{A fase de Cálculo de Custo do Projeto}

A empresa decidiu não considerar o cálculo do custo do projeto, por motivos particulares. Porém, variáveis básicas para o cálculo do custeio direto foram levantadas.

\subsubsection{Elaboração do Plano de Projeto}

O plano do projeto foi elaborado a partir do modelo sugerido neste trabalho (Figura 6.7). 


\section{Plano do Projeto: Desenhos}

Gerente Responsável: Analista

Data de Elaboração: 30/06/00

Equipe de Planejamento: Analista, Programador 1, Programador 2

Data de Revisão e Aprovação: 03/07/00

Aprovado por: Gerente de Desenvolvimento, Analista, Programador 1, Programador 2

\section{Introdução}

\subsection{Escopo, propósito e objetivos do projeto.}

Objetivos: O objetivo desse sistema é controlar o acervo de desenhos e documentos técnicos de engenharia da empresa.

Justificativa: Esses documentos são necessários ao histórico e posterior acompanhamento de uma obra executada pela empresa. Deverá funcionar basicamente como um sistema de ajuda de localização fisica desses documentos, quando necessário.

Produtos: Documento de requisitos do sistema, DFD's, MER, Plano do Projeto, Documento de Estimativas, Documento de Descrição dos Arquivos, Documento de Descrição dos Programas, Código Fonte, Código Executável, Manual do Usuário.

Implementação: Sendo para um fim básico de consultas, esse sistema deverá ser desenvolvido em Clipper (Versão Summer '87) e implantado em rede, para cerca de 40 usuários.

\subsection{Funções principais do sistema.}

As principais funções identificadas no sistema são: Cadastramento de desenhos e documentos técnicos do acervo da enipresa, cadastramento de catálogos de documentos, controle de revisão de documentos, localização rápida dos documentos no arquivo/acervo, levantamento de documentos e desenhos por local e localização de documentos por equipamento. Quatro módulo serão desenvolvidos para implementar as funcionalidades requeridas: Tabelas, Desenhos, Relatórios e Diversos (para manutenção de back-up e reindexação de arquivos).

\subsection{Documento de requisitos funcionais do sistema. Folha (s): 01}

\subsection{Questōes de desempenho.}

Não foram relatadas exigências quanto ao desempenho do sistema.

\subsection{Restrlçōes técnicas e administrativas.}

Não há restrições técnicas ou administrativas.

\section{Estimativas}

\subsection{Est/mativas elaboradas.}

Tamanho estimado do sistema: 10.600 linhas de código.

Prazo para instalação: 105 dias (úteis)

\subsection{Dados histórlcos.}

Não foram utilizados dados históricos.

\subsection{Técnicas e ferramentas utilizadas.}

Estimativa de tamanho: Julgamento de Especialistas e Análise de Pontos de Função Versão 5 .

Estimativa de tempo e esforço: Julgamento de Especialistas e COCOMO II - ferramenta COSTAR

\subsection{Documento de Estimativas. Folha (s): 02 e 03}




\section{Plano do Projeto: Desenhos}

III Riscos do projeto

Análise dos riscos.

3.1 Identificação e justificativa. Folha (s): não

3.2 Estimativa dos riscos. Folha (s): nâo

Administraçāo dos riscos.

3.3 Prevenção e pontos de controle. Folha (s): não

\section{Cronograma}

4.1 Estrutura de divisão de trabalho. Folha (s): 04

4.3 Cronograma. Folha (s): 05

4.4 Técnicas e ferramentas utilizadas.

Gráfico de Gantt - ferramenta Project Kick Start.

V Recursos de projeto

5.1 Equipe de desenvolvimento.

Analista, Programador 1, Programador 2.

\subsection{Hardware e software.}

Três computadores, impressora, compilador Clipper (Versão Summer '87).

VI Organização do Pessoal

6.1 Estrutura de equipe. Folha (s): não

VII Mecanismos de rastreamento e controle. Folha (s): 03 (Cronograma)

VIII Plano de Gerenciamento de Configuração. Folha (s):não

IX Plano de Garantia de Qualidade. Folha (s): não

X Apêndices. Folha (s): não

Figura 6.7 - Plano do Projeto Módulo de Desenhos (Cont.) 


\section{Projeto Desenhos - Documento de Estimativas}

Formulário de Registro e Acompanhamento de Estimativas de Projeto

Nome do Projeto: Módulo Desenhos

Gerente Responsável: Analista Data: inieio em 28/06/2000

Cielo de vida: Modelo Caseata

\section{1 Éstimativa de Tamanho}

Linguagem: Clipper (Versão Sunmer' 87)

Método Utilizado para Estimativa Manual: Julgamento de Especialista, Análise de Pontos de Funçào.

Ferramenta Automatizada: Nào.

Dados históricos utilizados: Não foram utilizados.

Observaçes: O índiee para conversão de pontos de funcão em linhas de código em Clipper é 40.

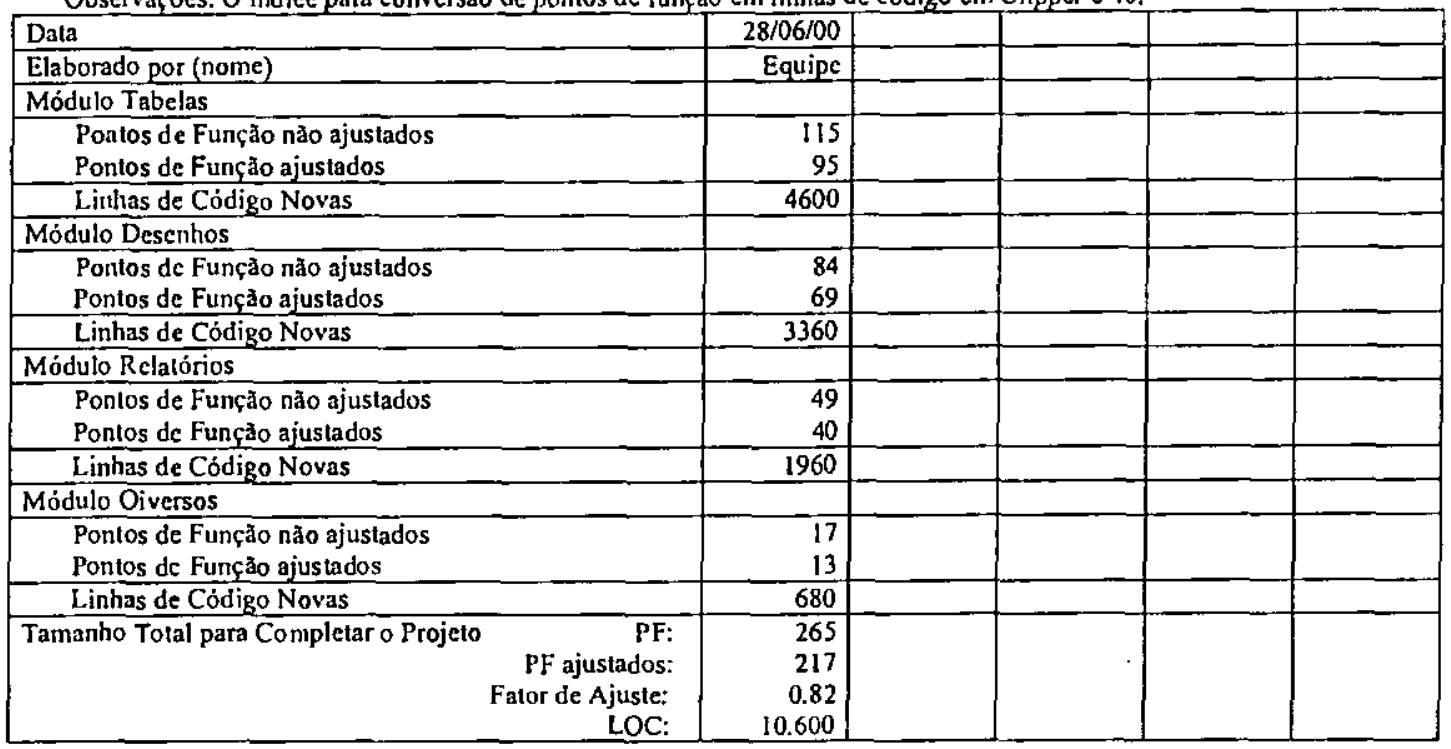

\section{Estimativa de Esforço}

Método Utilizado para Estimativa Manual: Julgamento de Espeeialista.

Ferramenta Automatizada: COSTAR.

Dados históricos utilizados: Nào foram utilizados.

Observaçôes: Desconsiderou-se a ctapa de anàlise e modelagen lógica do sistema e as atividades que levaram à đimensào do software, já realizadas.

\begin{tabular}{|l|c|c|}
\hline Data & $29 / 06 / 00-$ COSTAR & 29/06/00- Es forco por Fase \\
\hline Elaborado por (nome) & Equipe & Equipe \\
\hline Esforço para Módulo Tabelas & 3.2 & Projeto Detalhado: 3 \\
\hline Esforço para Módulo Oesenhos & 2.2 & Codificaçąo e Teste: 3 \\
\hline Esforço para Módulo Relatórios & 1.3 & Integraçäo e Teste: 3 \\
\hline Esforço para Módulo Diversos & 0.4 & \\
\hline Esforço Total para Conpletar o Projeto & 7.1 & 9 hornens-més \\
\hline
\end{tabular}

\section{Estimativa de Tempo}

Mćtodo Utilizado para Estimativa Mamual: Julgamento de Especialista.

Ferramenta Autontatizada: COSTAR.

Dados histórieos utilizados: Nåo foram utilizados.

Observaçốcs: Deseonsiderou-se a ctapa de análise e modelagem lógiea do sistema e as atividades que levaram à dimensão do software, já realizadas.

\begin{tabular}{|l|c|c|}
\hline Data & $29 / 06 / 00-$ COSTAR & 29/06/00 - Tempo por Fase \\
\hline Elaborado por (nome) & Equipe & Equipe \\
\hline Temipo (em meses) para Módulo Tabelas & 2.2 & Projeto Detalhado: 1.5 (28 dias úleis) \\
\hline Tempo (em meses) para Módulo Oesenhos & 1.9 & Codificaçào e Teste: 3.1 (59 dias úteis) \\
\hline Tempo (emm meses) para Módulo Relatórios & 1.6 & Integraçàoe Testc: 1 (19 dias úteis) \\
\hline Tempo (cern meses) para Módulo Diversos & 1.1 & \\
\hline Tempo (em meses) Total para Completar o Projeto: & 6.8 & 105 dias \\
\hline
\end{tabular}




\section{Projeto Desenhos - Documento da Estimativas}

IV Cálculo de Custo

Metodo Utitizado para Estimativa Manual:

Ferramenta Autornatizada:

Dados históricos utîlizados:

Observações: Não considerado.

\begin{tabular}{|l|l|l|l|l|}
\hline Data & & & & \\
\hline Elaborado por (nome) & & & & \\
\hline Custo para Funcăo ou Módulo 1 & & & \\
\hline Custo Total para Completar o Projeto & & & & \\
\hline
\end{tabular}

\begin{tabular}{|c|c|c|c|c|c|c|c|}
\hline & \multicolumn{7}{|c|}{ Atividadt: } \\
\hline & Elabo & açảo de est & Lativas & Recursos/ & & & \\
\hline & Tamanho & Esforço & Teinpo & Cronograma & & & \\
\hline Dala & $28 / 06 / 00$ & $29 / 06 / 00$ & $29 / 06 / 00$ & $30 / 06 / 00$ & & & \\
\hline Horas c recursos ulilizados: & 8 horas & 4 & 4 & 8 & & & \\
\hline Nímero de Pessoas Envolvidas: & 2 & 2 & 2 & 3 & & & \\
\hline
\end{tabular}

VI Dados de Conclusăo do Projeto

Observaços:

\begin{tabular}{|l|c|l|l|}
\hline Dados Efetivos & Sistema: Módulo Desenhos & & \\
\hline Tamanho & 8750 & & \\
\hline Esforco & 9 homens-mès & & \\
\hline Tempo & 3 meses & & \\
\hline
\end{tabular}

Figura 6.12 - Modelo de Documento de Registro de Estimativas (Cont.)

\subsubsection{A fase de Finalização do Processo}

Nessa fase, foram conferidos todos os documentos produzidos no processo de planejamento: a estrutura de divisão de trabalho, o cronograma, o plano do projeto e o documento de estinativas. Em seguida, o plano foi aprovado pela equipe de planejamento e pelo encarregado do departamento.

\subsection{Comentários Finais sobre o Estudo de Caso}

Observoul-se que a condição encontrada para realizar o cstudo de caso reflete uma realidade conum em muitos ambientes de desenvolvimento de software de organizações brasileiras: o uso de estimativas subjetivas e a ausência de registros de projetos anteriores contribuem significativamente para o baixo grau de precisão nas estimativas.

As estimativas gcradas com a variável tamanho esıimada a partir da contagem de pontos de função apresentaram um resultado além do executado, porém o modelo COCOMO II considera distribuição de esforço em atividades não executadas pela organização, como o Gerenciamento de Configuração. 
A métrica de pontos de função mostrou-se adequada ao dimensionamento de sistemas, principalmente quando se utiliza apenas dados subjetivos de pessoas com experiência em desenvolvimento. Além disso, a combinação da métrica de pontos de função com o modelo COCOMO II simplificou o processo, mesmo considerando a falta de domínio da técnica e da ferramenta que implementa o modelo. Constatou-se um certo grau de dificuldade no ajuste do esforço estimado pela ferramenta com o recurso humano disponivel na organização.

\subsection{Considerações Finais}

Neste capítulo foram apresentadas as condições em que foi desenvolvido o estudo de caso, bem como todos os detalhes que foram considerados para planejar um projeto de software. No capítulo seguinte, uma breve conclusão com algumas considerações sobre a realização do trabalho e trabalhos futuros são apresentados. 


\section{CONCLUSÕES}

\subsection{Considerações Gerais}

Atualmente, o processo técnico de desenvolvimento de software é auxiliado por métodos, técnicas e ferramentas que facilitam a vida dos desenvolvedores, porém ainda existem deficiências no processo gerencial. A simples ausência de práticas gerenciais no desenvolvimento de software, entre elas o planejamento, é a principal causa de atraso em cronogramas, custo maior do que o esperado e presença de defeitos. $O$ planejamento, atividade recomendado pclos principais modelos e padrões de qualidade, é usualmente executado de forma superficial, devendo-se principalmente à ausência de conhecimento e treinamento dos engenheiros de software.

\subsection{Contribuições}

Este trabalho investigou modelos para elaboração de estimativas e modelos para o planejamento de projetos, definidos com o objetivo de adequação do processo de software aos requisitos do modelo CMM de qualidade de processo de software. Foram estudados modelos, técnicas e ferramentas de apoio aos processos, visando um estudo detalhado para a devida compreensão da forma de execução de todas as etapas dos processos.

O estudo resultou na proposta de um modelo de processo com o objetivo de auxiliar a compreensão e execução do planejamento de projetos. O modelo é detalhado em fases e atividades, ilustradas com sugestões de técnicas, modelos e ferramentas de apoio à execução de tarefas em cada passo do processo. Para atingir os objetivos de cada fase, a organização pode adotar as técnicas mais adequadas à sua realidade, considerando também a forma usualmente utilizada.

Outra contribuição é a apresentação de um estudo de caso que foi efetuado com o objetivo de ilustrar a aplicação do modelo de processo em um caso real de planejamento. 
As dificuldades surgidas na aplicação do modelo, entre elas a ausência de informações históricas de projetos passados, indicaram $o$ forte relacionamento do processo de planejamento com o estabelecimento de um plano de métricas. Observou-se que a adoção de um plano de métricas para apoiar os processos gerenciais da emprcsa pode melhorar a precisão de estimativas, e, consequentemente, melhorar a qualidade do planejamento.

Também foi constalado uma estimativa de tempo maior do que o tempo real de execução do projeto, sugerindo uma investigação maior da adequação dos fatores de ajustc de cálculo do esforço e tempo de desenvolvimento, e ainda, das atividades não realizadas pela organização, como Gerenciamento de Configuração, por exemplo, consideradas no cálculo pelo modelo COCOMO.

O levantamento, de forma organizada e didática, dos conceitos, técnicas e ferranıentas relacionados ao processo de planejamcnto, modelos ou templates para apoiar o processo, que constituem a revisão bibliográfica, são outra contribuição obtida com a realização do trabalho. Apresentou-se um estudo do estado da arte de técnicas e ferramentas de estimativa e de apoio às demais atividades de planejamento de projetos presentes na literatura.

\subsection{Trabalhos Futuros}

Como linhas de pesquisa em continuidade a este trabalho, pode-se citar:

- Acompanhamento e avaliação da implantação do modelo de processo em uma organização;

- Acompanhamento do registro de informações de projetos realizados na empresa para compor uma base de dados histórica;

- Pesquisa de um plano de métricas adequado ao modelo de processo de planejamento;

- Integração do modelo de processo com um plano de métricas;

- Pesquisa de parâmetros pari direcionadores de custo adequados ao tipo de organização;

- Desenvolvimento de uma ferramenta simples e objetiva para apoiar o processo de claboração de estimativa. 


\section{ANEXo A - DETERMINAÇÃo DA COMPLEXIDADE DAS FUNÇÕES}

Este anexo trata da classificação das funções especificas do sistema. Cada função possui uma classificação formal que permite determinar a sua complexidade, onde são associados valores. A seguir apresenta-se a classificação das funções e seus pesos.

\section{A.1 Arquivos Lógicos Internos}

Segundo Azevedo [Azcredo, 1999] e Braga [Braga, 1996], os Arquivos Lógicos Internos (ALI) representam os requerimentos dc armazenamento de dados, cuja manutenção é feita pela própria aplicação. Um ALI é um grupo de dados logicamente relacionados, ou informações de controle, identificados e modificados pelo usuário, mantidos dentro da fronteira da aplicação que cstá scndo contada, como por exemplo, um arquivo de clientes.

\section{Complexidade de Arquivo Lógico Interno}

A complexidade de un Arquivo Lógico Interno é calculada a partir da quantidade de Dados Elementares Referenciados c de Registros Lógicos Referenciados.

Dado Elementar Referenciado (DER) é um campo, reconhecido pelo usuário, que está presente em unn Arquivo Lógico Interno (ALI) ou em um Arquivo de Interface Externa (AIE). Suas regras de contagem são:

- Considerar um DER para cada campo, reconhecido pclo usuário, presente em cada ALI.

$\square$ Considerar as seguintes implemenlaçõcs técnicas como um DER, para um conjunto completo de campos:

- Campos que aparecem mais de uma vez em um ALI por causa de tecnologia ou implementação. Exemplo: se um código de funcionário aparecer duas vezes, inicialmente no registro de funcionário $\mathrm{e}$, posteriomente, como chave eslrangeira em um registro dependente, contar somente um DER.

- Campos repetitivos que são idênticos em formato e existem para permitir múltiplas ocorrências de um mesmo dado. Exemplo: se um ALI possui 12 campos de venda mensal e um total anual, considerar apenas dois itens de dados, um para o valor mensal e o segundo para o total anual.

Registro Lógico Referenciado (RLR) é um subgrupo de elementos de dados, reconhecido pelo usuário, dentro de um Arquivo Lógico Interno (ALI) ou de um Arquivo de Interface Externa (AIE). Suas regras de contagem são:

- Caso não haja subgrupo de informações (referentes à outro ALI), contar um RLR para cada ALI. 
- Contar um RLR para cada subgrupo de dados de um ALI independentemente de ser o subgrupo opcional ou mandatório.

Os Arquivos de Interface Externa contribuem para o cálculo de Pontos por Função com base $\mathrm{em}$ sua quantidade e cumplexidade funcional relativa de cada um deles, conforme demonstrado nas Tabelas A.I $<$ A.2.

Tabela Anexo A.1 - Classificação de Arquivo Lógico Interno

\begin{tabular}{|l|c|c|c|}
\hline & I a 19 DER & 20 a SO DER & SI ou mois DER \\
\hline 1 RLR & Simples & Simples & Média \\
\hline 2 a 5 RLR & Simples & Média & Complexa \\
\hline 6 ou mais Rt_R & Média & Complexa & Comilexa \\
\hline
\end{tabular}

Tabela Anexo A.2 - Grau de Complexidade Funcional - Arquivo Lógico Interno

\begin{tabular}{|c|c|c|c|c|}
\hline \multirow{2}{*}{ Tipo de funçso } & \multicolumn{2}{|c|}{ Complexidade Funcional } & $\begin{array}{c}\text { Total } \\
\text { Compiexldade }\end{array}$ & $\begin{array}{c}\text { Total do tipo de } \\
\text { funçáo }\end{array}$ \\
\hline \multirow{2}{*}{ Arquivo Lógico Interno } & Simples & $\times 07=$ & & \\
\cline { 2 - 5 } & & Mudia & $\times 10=$ & \\
\cline { 2 - 6 } & Complexa & $\times 15=$ & & \\
\hline
\end{tabular}

\section{A.2 Arquivos de Interface Externa}

Scgundo Azevedo [Azevedo, 1999] e Braga [Braga, 1996], um Arquivo de Interface Externa (AIE) é, segundo a visão do usuário, um grupo de dados logicamente relacionados out informações de controle neccssárias à aplicação, mas mantidas fora das frontciras da aplicação que está sendo contada. Isto significa que um Arquivo de Interface Externa contado cm uma aplicação deve estar classificado como Arquivo Lógico Interno (ALI) em outra aplicação, a sua complexidade.

\section{Complexidade de Arquivo de Interface Externa}

A complexidade de um Arquivo de luterface Externa também é calculada cm função da quantidade de Dados Elementares Referencindos e de Registros Lógicos Referenciados. $\Lambda$ s regras para contagem para Dados Elementares Referenciados e de Registros Lógicos Referenciados são as mesnas aplicadas em Arquivos Lógicos Internos.Os Arquivos de Interface Exierna contribuem para o cálculo de Pontos por Função com base em sua quantidade c complexidade funcional relativa de cada um deles, conformc demonstrado nas Tabelas A.l c A.3.

Tabela Anexo A.3 - Grau de Complexidade Funcional - Arquivo Interface Externa

\begin{tabular}{|c|c|c|c|c|}
\hline \multirow{2}{*}{ Tipo de função } & \multicolumn{2}{|c|}{ Complexidade Funclonal } & $\begin{array}{c}\text { Total } \\
\text { Compiexidade }\end{array}$ & $\begin{array}{c}\text { Total do tipo de } \\
\text { funçăo }\end{array}$ \\
\hline \multirow{2}{*}{ Arquivo de Inlerface Externa } & Simples & $\times 05=$ & & \\
\cline { 2 - 6 } & Média & $\times 07=$ & \\
\cline { 2 - 6 } & Complexa & $\times 10=$ & & \\
\hline
\end{tabular}




\section{A.3 Entradas Externas}

Segundo Azevedo [Azevedo, 1999] e Braga [Braga, 1996], uma Entrada Externa (EE) processa dados ou informações de controle que vêm de fora das fronteiras da aplicação que está sendo contada. São transações que efetuam modificações nos dados armazenados no sistcma, usualmente inclusões, alterações e exclusões. A Entrada Externa é por si só um processo clementar. Através do processo lógico específico, os dados mantêm um ou mais Arquivos Lógicos Internos.

\section{Complexidade de Entradas Externas}

A complexidade das Entradas, Saídas e Consultas Externas é analisada segundo a quantidade de Dados Elementares Referenciados e de Arquivos Lógicos Referenciados.

Dado Elementar Referenciado (DER) é un único campo, não recursivo, identificado pelo usuário, mantido em um Arquivo Lógico Interno pela Entrada Externa. As regras para contagem para Dados Elementares Referenciados são:

- Contar um DER para cada campo não reeursivo, identificado pelo usuário, e mantido em um Arquivo Lógieo Interno por una Entrada Externa.

- Contar um DER para cada campo perteneente a um Arquivo Lógico Interno que não é digitado pelo usuário, mas é mantido por una Entrada Externa.

- Contar as seguintes técnicas de implementação fisicas como um único DER para o grupo de campos:

- Um campo lógico que é armazenado fisicamente em múltiplos campos, mas é requerido pelo usuário como uına peça única de informação. Exemplo: uma data que é fisicamente armazenada em múltiplos campos, mas que o usuário necessita como uma única peça de informação, é contado como um único DER.

- Campos que aparecem mais de uma vez em um ALI por necessidade da técnica ou tecnologia de implementação deve ser contados apenas uma única vez. Excmplo: se un código de cliente aparecer duas vezes en un ALl, printciro como ehave primária de acesso ao registro de funcionário e depois como clave externa do registro de dependente, contar como um DER somente.

- Campos que indicam condição de crro durante o processamento ou confirmação de que o processo está conpleto.

- Contar um único DER para linhas de comando ou teclas de função que provejam a ação a ser tomada pcla Entrada Externa.

- Em tela de atualização só contar os campos que possam sofrer atualização.

- Em telas de exclusão contar somente os campos-chave.

- Contar um DER quando uma ou mais mensagens de erro informarem ao usuário, através de um campo ou área da tela, que uma Enırada Externa não pode ser processada por erro de edição, erro de validação, ou ainda, houve urna mensagem de confırmação. 
Arquivo Lógico Referenciado (ALR) é um ALI, ou um AIE, lido ou mantido por um tipo de função. As regras para contagem para Dados Elementares Referenciados são:

a Contar um ALR para cada ALI manido.

- Contar um $A L R$ para cada $A L I$ ou AIE lido durante o processamento da Entrada Externa.

a Contar un ALR para cada ALl que é lido e mantido por uma Entrada Externa.

a Conlar un: ALR caso haja acesso a arquivo de mensagens de crro.

As Entradas Externas contribuem para o cálculo de Pontos por Função com base em sua quantidade e complexidade funcional relativa de cada um deles, conforme demonstrado nas Tabelas $A .4$ e $A .5$.

Tabela Anexo A.4 - Complexidade de Entradas Externas

\begin{tabular}{|l|c|c|c|}
\hline & $1.44 D E R$ & 5 A 15 DER & 16 OU MAIS DER \\
\hline 0 ou 1 ALR & Simples & Simples & Média \\
\hline 2 ALR & Simples & Média & Complexa \\
\hline 3 ou mais ALR & Média & Complexa & Complexa \\
\hline
\end{tabular}

Tabela Anexo A.5 - Grau de Cornolexidade Funcional - Entrada Exlerna

\begin{tabular}{|c|c|c|c|c|c|}
\hline \multirow{2}{*}{ Tipo de funçāo } & \multicolumn{3}{|c|}{ Complexidade Funclonal } & $\begin{array}{c}\text { Total } \\
\text { Complexidade }\end{array}$ & $\begin{array}{c}\text { Total do tipo do } \\
\text { funçáo }\end{array}$ \\
\hline \multirow{2}{*}{ Entradas Externas } & & Simples & $\times 03=$ & \\
\cline { 2 - 6 } & & Média & $\times 04=$ & \\
& & Complexa & $\times 06=$ & & \\
\hline
\end{tabular}

\section{A.4 Saídas Externas}

Segundo Azevedo [Azevedo, 1999] e Braga [Braga, 1996], uma Saída Externa (SE) é um processo elementar que gcra dados ou informações de controle para fora das fronteiras da aplicação. São transações que cxtraem informações do sistema para outros aplicativos. Por exemplo, uma função cálculo da folha de pagamento baseada na soma dos totais de horas trabalhadas de funcionários.

\section{Complexidade de Saídas Externas}

Devemos detcrminar a complexidade funcional relativa de cada Saĺda Externa baseando-se no númcro de Dados Elementares Referenciados e de Arquivos Lógicos Referenciados. 
Dado Elementar Referenciado (DER) é um único campo, não recursivo, identificado pelo usuário, e quc aparece em uma Saída Externa. Suas regras de contagem são:

a Contar um DER para cada canpo não rccursivo identificado pelo usuário, que apareça em uma Saida Externa. Exemplo: contar um DER para cada sumário ou campo de total que apareça em unı SE.

a Não contar liıerais como DER. Litcrais incluem: o nome do relatório, nome da tela, cabeçalhos de colunas e nome de campos.

口 Não contar núncro de páginas ou campos automáticos do sistema. Exemplo: número de página, comandos de paginação como Anterior, Próximo ou seta de paginação em uma aplicação Windows, campo de data ou hora.

a Contar as seguintes implementaçõcs fisicas como um único DER:

- Um campo lógico quc é armazenado como múltiplos campos, mas é requerido pelo usuário como uma única informação. Excmplo: uma data que é armazenada separada em três campos diferentes conı dia, mês e ano.

- Cada tipo de label e cada lipo equivalente de numero (valor) em um gráfico de saia. Exemplo: em um gráfico de pizza teríamos 2 (dois) DERs: un para designar a categoria (dcscrição da partição) e um para a percentagem de cada partição.

- Informação de texto quc poderia ser uma única palavra, sentença ou frase. Exemplo: uma mensagem que é incluida em un relatório para indicar por que uma transação de inclusão de produto não foi completada com sucesso.

Arquivo Lógico Referenciado (ALR) é um arquivo lido pela lógica de processamento da Saída Externa. A regra de contagem é:

- Contar un arquivo lógico referenciado para cada ALI, ou AIE, lido durante o processamento da Saída Externa (SE)

As Saídas Externas contribuem para o cálculo de Pontos por Função com base em sua quantidade e complexidade funcional relativa de cada um deles, conforme demonstrado nas Tabelas A.6 e A.7.

Tabela Anexo A.6 - Complexidade de Saidas Externas

\begin{tabular}{|l|c|c|c|}
\hline & 1 A 5 DER & 6 A 19 DER & 20 OU MAIS DER \\
\hline 0 au 1 RLR & Simples & Simples & Média \\
\hline 2 A 3 RLR & Simples & Média & Complexa \\
\hline 4 ou mais RLR & Média & Complexa & Complexa \\
\hline
\end{tabular}

Tabela Anexo A.7 - Grau de Complexidade Funcional - Saida Externa

\begin{tabular}{|l|c|c|c|c|c|}
\hline \multirow{2}{*}{ Tipo de funçăo } & \multicolumn{2}{|c|}{ Complexidade Funcional } & $\begin{array}{c}\text { Total } \\
\text { Complexidade }\end{array}$ & $\begin{array}{c}\text { Total do tipo do } \\
\text { funçáo }\end{array}$ \\
\hline \multirow{3}{*}{ Saidas Extemas } & & Simples & $\times 04=$ & \\
\cline { 2 - 6 } & & Média & $\times 05=$ & \\
\cline { 2 - 5 } & & Complexa & $\times 07=$ & & \\
\hline
\end{tabular}




\section{A.5 Consultas Externas}

Segundo Azevedo [Azevedo, 1999] e Braga [Braga, 1996], as Consultas Externas (CE) representam as necessidades de recuperação imediata de dados da aplicação, combinando trimsações de entrada e saída. Um relatório com os dados de um cliente é um exemplo típico

\section{Complexidade de Consulta Externa}

A determinação da complexidade funcional de cada Consulta Extcrna é feita baseando-se no número de Arquivos Lógicos Referenciados e no número de Dados Elementares Referenciados para a parte de entrada e para a parte de saida.

Dado Elementar Referenciado (DER), para a parte de entrada da consulta externa, é um campo, não recursivo, identificado pelo usuário, e que aparece em uma Consulta Externa. As regras para contagem de DER da parte de entrada são:

- Contar um DER para cada campo não recursivo que aparece na parte de entrada de uma Consulta Externa.

- Contar um DER para cada campo que especifica o critério de seleção de dados.

- Contar as seguintes técnicas de implementação fisica como um único DER para todo o grupo de compos:

- Campos utilizalos para indicar que o processamento foi realizado com sucesso.

- Campos que permitan a capacidade de especificar que a consulta externa deve ser executada. Exemplo: contar como um DER o botĩo de OK que deve ser apertado pelo usuário para efelivar a consulta.

c Contar uın DER quando umiı ou muis mensagens de erro informarem ao usuńrio que a consulta não foi efetivada por erro de edição ou validação, ou se ainda uma mensagen de confimação ocorrcr.

Arquivo Lógico Referenciado (ALR), para a parte de entrada da consulta externa, é um arquivo lido quando a consulta cxterna é processada. As regras de contagem de ALR para a parte de cntrada são:

- Contar a quantidade de Arquivos Lógicos Referenciados na lógica de processamento da Consulta Externil.

A Tabela A.8 deve ser utilizado para a deftnição da complexidade da parte de entrada de uma Consulta Extema.

Tabela Ancxo A.8 - Complexidade da Parte de Entrada de uma Consulta Externa.

\begin{tabular}{|l|c|c|c|}
\hline & 1 A 4 DER & 5 A 15 DER & 16 OU MAIS DER \\
\hline O ou 1 ALR & Simples & Simples & Média \\
\hline 2 ALR & Simples & Média & Complexa \\
\hline 3 ou mais AL.R & Média & Complexa & Complexa \\
\hline
\end{tabular}


Dado Elementar Referenciado, para a parte de saida da consulta externa, é um campo não recursivo, identificado pelo usuário, que aparece em uma Consulta Externa. As regras para a parte de saida são:

․ Contar como um DER um cada campo não recursivo, identificado pelo usuário, que aparece na parte de saida da consulta.

․ Não contar literais como DER. Literais incluem: nome do relatório, nome da tela, cabeçalho de coluna e nome dos campos.

口 Não contar variáveis de paginação ou variáveis automáticas do sistema, tais como número de páginas, informações de posicionamcnto do cursos, comandos de paginação (próximo, anterior e setas de página $\mathrm{cm}$ aplicações de interface gráfica como Windows), campos de data ou hora.

- Contar as seguintes téenicas dc inplementação fisica como um único DER, para o inteiro conjunto de campos:

- Um campo lógico que ć armazenado fisicamente como múltiplos campos, mas é requerido pelo usuário como uma única informação.

- Camipos, que por causa da tccnologia empregada no desenvolvimento do sistema, aparecem mais de uma vez em um Arquivo Lógico Interno.

Arquivo Lógico Referenciado (ALR), para a parte de saida da consulta externa, é um arquivo lido quando a consulta cxterna é processada. A regra de contagem para a parte de saída é:

․ Contar a quantidade de Arquivos Lógicos Referenciados na lógica de processamento da Consulta Externa

A Tabela A.9 deve ser utilizado para a definição da complexidade da parte de saída de uma Consulta Externa.

Tabela Anexo A.9 - Complexidade da Parte de Saida de uma Consulta Externa

\begin{tabular}{|l|c|c|c|}
\hline & 1 A 5 DER & 6 A 19 DER & 20 OU MAIS DER \\
\hline 0 ou 1 RLR & Simples & Simples & Média \\
\hline 2 A 3 RLR & Simples & Média & Complexa \\
\hline 4 ou mais RLR & Média & Complexa & Complexa \\
\hline
\end{tabular}

Deve-se considerar a maior das duas complexidades funcionais (entrada e saída) da consulta como a complexidade final da consulta. As Saidas Externas contribuem para o cálculo de Pontos por Função com base em sua quantidade e complexidade funcional relativa de cada um deles, conforme demonstrado nas Tabelas A.8, A.9 e A. 10.

Tabela Anexo A.10 - Grau de Complexidade Funcional - Consulta Externa

\begin{tabular}{|c|c|c|c|c|}
\hline \multirow{2}{*}{ Tipo de função } & \multicolumn{2}{|c|}{ Complexidade Funcional } & $\begin{array}{c}\text { Total } \\
\text { Complexidade }\end{array}$ & $\begin{array}{c}\text { Total do tipo do } \\
\text { funçáo }\end{array}$ \\
\hline \multirow{2}{*}{ Consultas Externas } & & Simples & $\times 03=$ & \\
\cline { 2 - 6 } & & Média & $\times 04=$ & \\
\cline { 2 - 6 } & Complexa & $\times 06=$ & & \\
\hline
\end{tabular}




\section{Anexo B - Determinação do Fator de AJUSte de Pontos de FUNÇÃO}

Este anexo, trata da descrição das características gerais de sistemas, as quais permitem o cálculo do fator de ajuste, que é aplicado ao número de pontos por função não ajustado para o cálculo do tamanho em pontos por função ajustados. Cada característica possui una descrição formal que permite determinar seu grau de influência. A seguir apresenta-se as características e seu grau de influência [Azevedo, 1999][Braga, 1996].

\section{B.1 Comunicação de Dados}

$\mathrm{Na}$ característica de comunicação de dados, mostrada na Tabela B.1, os dados e informações de controle utilizados na aplicação são enviados ou recebidos através de recursos de comunicação de dados.

Tabela Anexo B.1 - Niveis de Influência de Comunicação de Dados

\begin{tabular}{c|l}
\hline Nível de Influência & \begin{tabular}{l} 
Descrição do Nivel de lnfluência \\
\hline 0
\end{tabular} \\
\hline 1 & $\begin{array}{l}\text { O processamento da aplicação é puramente batch ou executado em um } \\
\text { microcompulador pessoal isolado }\end{array}$ \\
\hline 2 & A aplicação é batch mas tem entrada de dados remota ou impressão remota \\
\hline 3 & $\begin{array}{l}\text { A aplicação é batch mas tem entrada de dados remota e impressão remota } \\
\text { Captura de dados on-line, via terminal, rede de micros ou front-end, para alimentar } \\
\text { processos em batch ou sistemas de consultas }\end{array}$ \\
\hline 4 & $\begin{array}{l}\text { Mais de um front-end, mas a aplicação suporta apenas um tipo de protocolo de } \\
\text { comunicação }\end{array}$ \\
\hline 5 & $\begin{array}{l}\text { Mais de um front-end, e a aplicação suporta vários tipos de protocolo de } \\
\text { comunicação }\end{array}$ \\
\hline
\end{tabular}

\section{B.2 Processamento Distribuído}

$\mathrm{Na}$ característica de processamento distribuído, mostrada na Tabela B.2, estão indicados os níveis de influência do processamento distribuído entre várias unidades de processamento (CPU's).

\section{B.3 Desempenho}

Na característica de desempenho, mostrada na Tabela B.3, identifica-se os objetivos da aplicação estabelecidos formalmente pelo usuário, que influenciaram 0 desenho, desenvolvimento, implantação e suporte da aplicação. 
Tabela Anexo B.2 - Niveis de Influência do Processamento Distribuido

\begin{tabular}{c|l}
\hline Nivel de Influência & Descrição do Nivel de Influência \\
\hline 0 & $\begin{array}{l}\text { A aplicação não efetua a transferência de dados ou de processamento entre as } \\
\text { CPU's da instalação }\end{array}$ \\
\hline 1 & $\begin{array}{l}\text { A aplicação prepara dados para o usuário final processar em outra CPU da } \\
\text { instalação utilizando-se de software genérico (planilhas eletrônicas, cditores de } \\
\text { texto, bancos de dados) }\end{array}$ \\
\hline 2 & $\begin{array}{l}\text { Os dados são preparados, transferidos e processados em outra CPU da instalação. } \\
\text { (Transferência de arquivos) }\end{array}$ \\
\hline 3 & $\begin{array}{l}\text { Processamento distribuido e transferência de dados on-line nuas en una única } \\
\text { direção. (Processa numa CPU e transfere para outra Clu) }\end{array}$ \\
\hline 5 & $\begin{array}{l}\text { Processamento distribuído e transferência de dados on-line em ambas as direção. } \\
\text { (Processamento eooperativo) }\end{array}$ \\
\hline 5 & $\begin{array}{l}\text { A aplicação a ser desenvolvida deve decidir clinamicamente qual a CPU mais } \\
\text { apropriada para executar a função }\end{array}$ \\
\hline
\end{tabular}

Tabela Anexo B.3 - Niveis de Influência do Desempenho

\begin{tabular}{c|l}
\hline Nivel de Influência & Descriçāo do Nivel de Infuência \\
\hline 0 & Nenhunı exigência especial de desempenho foi fixada pelo usuário \\
\hline 1 & $\begin{array}{l}\text { Requisitos de desempenho foram estabelecidos e revisados. Nenhuma ação } \\
\text { especial foi necessária }\end{array}$ \\
\hline 2 & $\begin{array}{l}\text { O tempo de resposta é eritico durante as horas de pico. Nenhuma consideração } \\
\text { especial de uso de CPU foi requerida. O tempo limite do processamento ć senpre } \\
\text { para o próximo dia útil }\end{array}$ \\
\hline 3 & $\begin{array}{l}\text { O tempo de resposta é eritico durante todo o horário de utilização. Não foi } \\
\text { necessário nenlum procedimento especial para utilização de CPU. Os limites de } \\
\text { prazo de processamento são outros aplicativos }\end{array}$ \\
\hline 4 & $\begin{array}{l}\text { Os requisitos de desenıenho estabelecidos pelo usuário são rigorosos o bastante } \\
\text { para requeren tarefas de análise de desempenho na fase de análise e desenlıo da } \\
\text { aplicação }\end{array}$ \\
\hline 5 & $\begin{array}{l}\text { Alén do mostrado no item quatro (4), ferramentas de análise de descmpenlıo foram } \\
\text { usadas na fase de desenho, desenvolvimento ou implementação da ap̣licação, a fim } \\
\text { de proporcionar a desempenho estabelecida pelo usıário }\end{array}$ \\
\hline
\end{tabular}

\section{B.4 Utilização de Equipamento}

Na característica de utilização de equipamento, mostrada na Tabela B.4, está representada a necessidade de fazer-se considerações especiais no desenho dos aplicativos, para que a configuração do equipamento escolhido suporte-o sem que fique sobrecarregado.

\section{B.5 Volume de Transações}

Na característica de volume de transações, mostrada na Tabela B.5, a transação ć de tal magnitude que tem influência no desenho, desenvolvimento, implantação e manutenção da aplicação. 
Tabela Anexo B.4 - Niveis de Influência de Utilização de Equipamento

\begin{tabular}{c|l}
\hline Nivel de Influência & Descrição do Nivel de Influência \\
\hline 0 & Não há restriçōes operacionais implícitas ou explícitas \\
\hline 1 & $\begin{array}{l}\text { Existen restrições operacionais, mas são menos restritivas que aplicações } \\
\text { típicas. Nenlum esforço extra é necessário para suplantá-las }\end{array}$ \\
\hline 2 & Alguninas consideraçōes sobre tempo e segurança são necessárias \\
\hline 3 & Há necessidade especial de processador para uma parte específica da aplicação \\
\hline 4 & $\begin{array}{l}\text { Restrições operacionais requerem atenção especial a nivel de processador central } \\
\text { ou processador dcdicado para executar a aplicação }\end{array}$ \\
\hline 5 & $\begin{array}{l}\text { Restrições operacionais são agravadas pela existência de sobrecarga a nivel das } \\
\text { CPUs distribuidas da instalação }\end{array}$ \\
\hline
\end{tabular}

Tabela Anexo B.5 - Niveis de Influência do Volume de Transações

\begin{tabular}{c|l}
\hline Nivel de Influência & Descrição do Nivcl de Influência \\
\hline 0 & Nenlunn período de picos de transações é esperado \\
\hline 1 & Picos mensais de transações são espcrados \\
\hline 2 & Picos scmauais de transações são csperados \\
\hline 3 & Picos diários de transações são espcrados \\
\hline 4 & $\begin{array}{l}\text { Altos volumes de transaçōes são esperados, o que força a execução de tarefas de } \\
\text { análise de impactos na fase de desenho da aplicação }\end{array}$ \\
\hline 5 & $\begin{array}{l}\text { O alto volume de transação requer o uso de ferramentas de análise de desempenho } \\
\text { nas fases de desenlio e desenvolvimento da aplicação }\end{array}$ \\
\hline
\end{tabular}

\section{B.6 Entrada de Dados On-line}

Na característica de entrada de dados on-line, mostrada na Tabela B.6, a aplicação possui entrada de dados on-line, classificando o nível de influência desta característica na aplicação.

Tabela Anexo B.6 - Niveis de Influência de Entrada de Dados On-line

\begin{tabular}{c|l}
\hline Nivel de Influência & Descrição do Nivel de Influência \\
\hline 0 & Todas as transações são processadas em batch \\
\hline 1 & 1 a $7 \%$ das transações são entradas de dados interativas \\
\hline 2 & 8 a $15 \%$ das transações são entradas de dados interativas \\
\hline 3 & 16 a $23 \%$ das transações são entradas de dados interativas \\
\hline 4 & 24 a $30 \%$ das transações são entradas de dados interativas \\
\hline 5 & Mais de $30 \%$ das tran sações são entradas de dados interativas \\
\hline
\end{tabular}

\section{B.7 Eficiência do Usuário Final}

Com relação à característica de eficiência do usuário final, as funções da aplicação executadas on-line enfatizam que o desenho da aplicação foi voltado para a eficiência do usuário final, que é refletido pelo número e tipo de facilidades disponibilizadas na Tabela B.7. 
Anexo B - Fator de Ajuste de Pontos de Função

Tabela Anexo 8.7 - Consideraçōes do Ambiente Orientado a Documento - Usuário Final

\begin{tabular}{|c|c|c|c|}
\hline 1) & Navegação por Menus & $\Rightarrow$ & não se aplica \\
\hline 2) & Documentação / Help on-line & $\Rightarrow$ & aplica-se \\
\hline 3) & Movimento Automático do Cursor & $\Rightarrow$ & não se aplica \\
\hline 4) & Impressão Remota(via transações "on-line") & $\Rightarrow$ & não se aplica \\
\hline 5) & Teclas de Função (considerando botôes e navegadores) & $\Rightarrow$ & aplica-se \\
\hline 6) & Execução de $J o b$ 's Batch & $\Rightarrow$ & não se aplica \\
\hline 7) & Seleção de Dados na Tela Via Movimentação de Cursor & $=>$ & aplica-se \\
\hline 8) & Uso Intenso de Vídeo Reverso & $\Rightarrow$ & aplica-se \\
\hline 9) & Impressão de Documentação & $\Rightarrow$ & não se aplica \\
\hline 10) & Interface para Mouse & $\Rightarrow$ & 1ão se aplica \\
\hline 11) & Pop-Up Windows & $\Rightarrow$ & não se aplica \\
\hline 12) & O Mínino Possivel de Telas & $\Rightarrow$ & aplica-se \\
\hline 13) & Fácil Navegação entre Telas & $\Rightarrow$ & aplica-se \\
\hline 14) & Suporte Bilingiie & $\Rightarrow$ & não se aplica \\
\hline 15) & Suporte Multilingile & $\Rightarrow$ & não se aplica \\
\hline
\end{tabular}

Classifica-se o nível de influência desta característica na aplicação, conforme demonstrado na Tabela B.8.

Tabela Anexo B.8 - Níveis de Influência de Eficiência Final

\begin{tabular}{c|l}
\hline Nivel de Influência & Descrição do Nivel de Influência \\
\hline 0 & A aplicação não apresenta nenhum dos itens acima \\
\hline 1 & A aplicação apresenta de 1 a 3 dos ilens acima \\
\hline 2 & A aplicação apresenta de 4 a 5 dos itens acima \\
\hline 3 & $\begin{array}{l}\text { A aplicação apresenta } 6 \text { ou mais dos itens acima, mas não lá nenhun requisito do } \\
\text { usuário relicionado à eficiência }\end{array}$ \\
\hline 4 & $\begin{array}{l}\text { A aplicação apresenta } 6 \text { ou mais dos itens acina e os requisitos estabelecidos para } \\
\text { eficiência do usuário final são rigorosos o suficiente para que a fase de desenho da } \\
\text { aplicação inclua análise de fatores como maximizar o uso de defaults ou templates } \\
\text { para minimizar csforço de digitação }\end{array}$ \\
\hline 5 & $\begin{array}{l}\text { A aplicação apresenta } 6 \text { ou mais dos itens acima e os requisitos estabelecidos para } \\
\text { eliciência do usuário final são rigorosos o sufficiente para que sejam neccssário o } \\
\text { uso de ferramentas que demonstrem que os objetivos de eficiência exigidos foram } \\
\text { alcançados }\end{array}$ \\
\hline
\end{tabular}

\section{B.8 Atualização On-Line}

Em relação à característica de atualização on-line, a aplicação permite a atualização on-line dos arquivos lógicos internos. Classifica-se o nível de influência desta característica na aplicação, conforme demonstrado na Tabela B.9. 
Tabeia Anexo B.9 - Niveis de Influência de Atualização On-line

\begin{tabular}{c|l}
\hline Nivel de Influência & Descrição do Nivel de Influência \\
\hline 0 & Nenhuma atualização \\
\hline 1 & $\begin{array}{l}\text { Atualização on-line de I a } 3 \text { arquivos lógicos intemos. O volume de atualização é } \\
\text { baixo e a recuneração de dados é simples }\end{array}$ \\
\hline 2 & $\begin{array}{l}\text { Atualização on-line de } 4 \text { ou mais arquivos lógicos internos. O volume de } \\
\text { atualização é baixo e a recuperação de dados é simples }\end{array}$ \\
\hline 3 & Atualização on-line da maioria dos arquivos lógicos internos \\
\hline 4 & $\begin{array}{l}\text { Atualização on-line da maioria dos arquivos lógicos intemos. A proteção contra } \\
\text { perdas de dados é essencial e consta da aplicação }\end{array}$ \\
\hline 5 & $\begin{array}{l}\text { Além do item 4, altos volumes de dados trazem considerações sobre custo para o } \\
\text { processamento de recuperação e estes exigem procedimentos automatizados }\end{array}$ \\
\hline
\end{tabular}

\section{B.9 Processamento Complexo}

O processamento complcxo é uma característica da aplicação, podendo ser dividido nas scguintes categorias:

․ processamento especial de auditoria e/ou processamento especial de segurança;

․ processamento lógico extensivo;

口 processamento matemático extensivo;

- grande quantidade de processamento de exceções, resultando em transações incompletas que necessitam ser processadas novamente;

๑ processamento complexo para manipular múltiplas possibilidade de entrada/saída.

Classiftca-se o nível de influência desta característica na aplicação, conforme demonstrado na Tabela B.10.

Tabela Anexo B.10 - Niveis de Influência de Processamento Complexo

\begin{tabular}{c|l}
\hline Nivel de Influência & Descrição do Nivel de Influência \\
\hline 0 & A aplicação não apresenta nenhum dos itens acima \\
\hline 1 & A aplicação apresenta um dos itens acima \\
\hline 2 & A aplicação apresenta dois dos itens acima \\
\hline 3 & A aplicação auresenta três dos itens acima \\
\hline 4 & A aplicação apresenta quatro dos itens acima \\
\hline 5 & A aplicação apresenta os cinco itens acima \\
\hline
\end{tabular}

\section{B.10 Processamento Complexo}

Com relação à caractetística de reutilização de código, considera-se que o código da aplicação foi especificamente projetado, desenvolvido e mantido para ser reutilizado em outras aplicações. Classifica-se o nível de influência desta característica na aplicação, conforme demonstrado na Tabcla B.11. 
Tabela Anexo B.11 - Niveis de Influência de Reutilização de Código

\begin{tabular}{c|l}
\hline Nivel de Influência & Descrição do Nivel de Influência \\
\hline 0 & Não foram desenvolvidos códigos reutilizáveis \\
\hline 1 & O código reutilizável é usado somente dentro da própria aplicação \\
\hline 2 & $\begin{array}{l}\text { Menos de } 10 \% \text { dos módulos foram feitos levando-se em conta a sua utilização por } \\
\text { outras aplicações }\end{array}$ \\
\hline 3 & $\begin{array}{l}10 \% \text { ou mais dos módulos foram feitos levando-se em conta a sua utilização por } \\
\text { outras aplicaçôes }\end{array}$ \\
\hline 4 & $\begin{array}{l}\text { A aplicação foi projetada e documentada para facilitar a reutilização de código e a } \\
\text { aplicação é customizada a nível de código fonte }\end{array}$ \\
\hline 5 & $\begin{array}{l}\text { A aplicação foi projetada e documentada para facilitar a reutilização de código. } \\
\text { Sua customização (parâmetros) pode ser atualizada pelo usuário }\end{array}$ \\
\hline
\end{tabular}

\section{B.11 Facilidade de Implantação}

A facilidade de implantação e conversão de dados são características da aplicação. Um plano de implantação e conversão de dados e/ou ferramentas de conversão dc dados foi preparado e testado durante a fase de testes dos sistemas. Classifica-se o nivel de influência desta característica na aplicação, conforme demonstrado na Tabela B.12.

Tabela Anexo B.12 - Niveis de Influência de Facilidade de Implantaçăo

\begin{tabular}{c|l}
\hline Nivel de Influência & Descrição do Nivel de Influência \\
\hline 0 & $\begin{array}{l}\text { Nenhuına consideração especial foi feita pelo usuário, e nenhum procedimento } \\
\text { cspecial foi requerido para a implantação }\end{array}$ \\
\hline 1 & $\begin{array}{l}\text { Nenhuma consideração especial foi feita pelo usuário, nas um procedimento } \\
\text { especial foi requerido para implantação }\end{array}$ \\
\hline 2 & $\begin{array}{l}\text { Requisitos de implantação e conversão de dados foram fixados pelo usuário, e } \\
\text { roteiros de implantação e conversão de dados foram preparados. O impacto da } \\
\text { conversão de dados não é considerado importante }\end{array}$ \\
\hline 3 & $\begin{array}{l}\text { Requisios de implantação e conversão de dados foram fixados pelo usuário, e } \\
\text { roteiros de implantação e conversão de dados foran preparados. O impacio da } \\
\text { conversão de dados é considerado importante }\end{array}$ \\
\hline 4 & $\begin{array}{l}\text { Além do nostrado no item 2, ferramentas automatizadas de impilantação e } \\
\text { conversão de dados foran preparadas e testadas }\end{array}$ \\
\hline 5 & $\begin{array}{l}\text { Além do mostrado no item 3, ferramentas automatizadas de implantação e } \\
\text { conversão de dados foram preparadas e testadas }\end{array}$ \\
\hline
\end{tabular}

\section{B.12 Facilidade Operacional}

Facilidade operacional é uma característica da aplicação. Procedintuentos efetivos de inicialização, backup e recuperação devem ser desenvolvidos e testados durantc a fase de teste do sistema. A aplicação minimiza a necessidade de atividade manuais. Classifica-se o nivel de influĉncia desta caracteristica na aplicação, conforme demonstrado na Tabela B.13. 
Tabela Anexo B.13 - Niveis de Influência de Facilidade Operacional

\begin{tabular}{c|l}
\hline Nível de Influência & Descrição do Nivel de Influência \\
\hline 0 & $\begin{array}{l}\text { Nenluma consideração especial sobre facilidade, além dos procedimentos normais } \\
\text { de backup, foram requeridos pelo usuário }\end{array}$ \\
\hline 1 & $\begin{array}{l}\text { Procedinnentos eficientes de inieialização, backup e recuperação foram preparados, } \\
\text { mas a intervenção do operador é necessária }\end{array}$ \\
\hline 2 & $\begin{array}{l}\text { Procedimentos eficientes de inicialização, backup e recuperação foram preparados, } \\
\text { e nenlumua intervenção do operador é necessária }\end{array}$ \\
\hline 3 & A aplicação ninimiza a operação de montagem de meios magnéticos \\
\hline 4 & A aplicação ninimiza o manuseio de formulários \\
\hline 5 & $\begin{array}{l}\text { A aplicação foi projetada para não precisar de intervenção do operador no seu } \\
\text { funcionamento normal. Apenas a inicialização e parada ficam a seu encargo }\end{array}$ \\
\hline
\end{tabular}

\section{B.13 Múltiplos Locais}

Com relação à caractcrística de múltiplos locais, a aplicação deve ter sido especificamente projetada, desenvolvida e suportada para ser instalada em múltiplos locais de uma organização ou para divcrsas organizações. Classifica-sc o nível de influência desta característica na aplicação, conforme demonstrado na Tabela B.14.

Tabela Anexo B.14 - Niveis de Influência de Múltiplos Locais

\begin{tabular}{|c|c|}
\hline Nivel de Influência & Descrição do Nivel de Influência \\
\hline 0 & $\begin{array}{l}\text { Não foi feita nenhuma solieitação do usuário para considerar a necessidade de } \\
\text { instalar a aplicação em mais de um local }\end{array}$ \\
\hline 1 & $\begin{array}{l}\text { Necessidade de instalação em múltiplos locais foi considerada no projeto, e a } \\
\text { aplicação foi projetada para operar enı ambientes idênticos de hardware e software }\end{array}$ \\
\hline 2 & $\begin{array}{l}\text { Necessidade de instalaçāo em múltiplos locais foi levada em consideraçăo no } \\
\text { projeto do aplicativo e foi projetada para operar somente em ambientes similares } \\
\text { de hardware e sofnware }\end{array}$ \\
\hline 3 & $\begin{array}{l}\text { Necessidade de instalação em múltiplos locais foi considerada no projeto, e a } \\
\text { aplicação foi jrojetada para operar, inclusive, em ambientes diferentes de } \\
\text { hardware e soffware }\end{array}$ \\
\hline 4 & $\begin{array}{l}\text { Um plano de documentação e manutenção foi elabora do e testado para suportar a } \\
\text { aplicação em nuúltiplos locais, e esta pode operar em ambientes idênticos ou } \\
\text { similares de hardware e soffware }\end{array}$ \\
\hline 5 & $\begin{array}{l}\text { Um plano de documentação e manutenção foi elaborado e testado para suportar a } \\
\text { aplicação em múltiplos locais, e esta pode operar em ambientes diferentes de } \\
\text { hardware e soffware }\end{array}$ \\
\hline
\end{tabular}




\section{B.14 Facilidades de Mudanças}

Com relação a característica de facilidade de mudanças, presume-se que a aplicação foi especificamente projetada, desenvolvida e deve suportar manutenção, visando facilidade de mudanças. Por exemplo:

- capacidade de consultas flexíveis deve estar disponivel;

- dados de controle do negócio são agrupados em tabelas passiveis de manutenção pelo usuário.

Classifica-se o nível de influĉncia desta característica na aplicą̧ão, conforme dentonstrado na Tabcla B.15.

Tabela Anexo B.15 - Niveis de Influência de Facilidades de Mudanças

\begin{tabular}{|c|c|}
\hline Nivel de Influência & Descrição do Nivel de lnfluência \\
\hline 0 & $\begin{array}{l}\text { Nenhum requisito especial foi solicilado pelo usuário para projetar a aplicação, } \\
\text { visando minimizar ou facilitar nudanças }\end{array}$ \\
\hline 1 & $\begin{array}{l}\text { E. fornecido recurso flexível de consulta e de emissão de relatório capaz de } \\
\text { nanipular solicitações simples, conı lógica de and/or aplicada somente a um } \\
\text { arquivo lógico interno }\end{array}$ \\
\hline 2 & $\begin{array}{l}\text { E fornecido recurso flexível de consulta e de enissão de relatório capaz de } \\
\text { manipular solicitaçoes de média complexidade, com lógica de andlor aplicada } \\
\text { a mais de um arquivo lógico inlerno }\end{array}$ \\
\hline 3 & $\begin{array}{l}\text { E fornecido recurso flexivel de consulta e de cmissão de relatório capaz de } \\
\text { manipular solicilaçóes de alta complexidade, com lógica de anl/or aplicada a } \\
\text { um ou mais arquivos lógicos internos }\end{array}$ \\
\hline 4 & Alćm do item 3 , se estas alteraçōes só são efetivadas no próximo din útil \\
\hline 5 & Além do item 3, se estas alteraçōes são efetivadas imediatamente \\
\hline
\end{tabular}




\section{Referências Bibliográficas}

[Acosta, 2000]

[Agresti et. al., 1990]

[Albreclit. 1983]

[Azevedo, 1999]

[Belloquim, 1997]

[Belloquin, 1999]

[BFPUG, 2000]

[Boehm, 1981]

[Braga, 1996]

[COCOMO II, 2000]

[CONSTRUX, 2000]

[CONTE, I985]

[COSMOS, 2000]

[COST XPERT, 2000]

[COSTAR, 2000]
ACOSTA. W. REDES y PERT/CPM: método del camino crítico. Disponivel em: $<$ hittp://www. monografias.com>. Accsso em: [05/08/00].

AGRESTI, W. et. al Manager's Handbook for Software Development. Revision 1. Software Engineering Laboratory. Serics SEL-84-101. National Aeronautics and Space Administration. Maryland, November 1990. Disponivel em: $<$ http://scl.gsfc.nasa.gov//vcbsite/documcnts/onlinc-doc/84-101.pdf >. Acesso cm: $[17 / 10 / 00]$.

ALBRECHT, A. J., GAFFNEY, J. E. JR. Software Function, Source Lines of Code, and Developnent Effort Prediction. IEEE Transactions on Software Engineering. SE-9,6, p.639-648. 1983.

AZEVEDO. Douglas José Peixolo. Análise de pontos por funçăo para aplicações orientadas a documentos. Porto Alegre, 1999. 11lp. Dissertação (Mcstrado) Universidade Federal do Rio Grande do Sul.

BELLOQUIM, A. SEUCMM: O Caminho Parn o Nivel 2. Developers' Magazine, Julho, 1997. p. 20-21.

BELLOQUIM, A. CMM em Pequenas Organizaçðes: Seria Mcsmo Possivel? Developers' Magazine, Janeiro, 1999. p. 26-28.

Brazilian Function Points Users Group. Disponivel em: <iwww.bfpug.com.br>. Acesso cm: [05/02/00].

BOEHM, B. Software Engineering Economics Englewood Cliffs, Prentice-Hall Inc. 1981.

BRAGA, Antônio. Anállse de pontos por função. Rio de Janeiro: Infobook, 1996.

USC COCOMO II Model Manual. Disponivel em: <lttp://sunset.usc.edu/COCOMOIV/cocomo.html>. Acesso em: [05/02/00].

CONSTRUX Software. Disponivel em: <http://wwn.construx.com/estimate/download.htm>. Acesso em: [05/02/00].

CONTE, S.D.; SHEN V.Y. Software Engineering Metrics and Models. Menlo Park: Benjamin/Cummings Publishing, 1985.

COSMOS - Soft ware cost modeling system. Version 4.1. East Tennessee State University. Disponivel em: Lhttp://csvaxsrv. east-tenn-st.edu/-dsgnstudio/cosmos/download.html>. Acesso em: $[05 / 02 / 00]$.

COST XPERT. Disponivel em: <hitp://www: costxpert con/userform.him?cxdownload>. Acesso em: [05/02/00].

COSTAR 5. Disponivel en: <littp://www. softstarsystems,com/costar5d.zip z. Acesso em: [05/07/99]. 
[Dekkers, 1998$]$

[Descriplion, 1999]

[.:voluçส̃o, 1999]

[ienton, 199!]

[Fenaindes, 1925

[ivurey, 1997]

[Ghiezzi et. al., 1991]

[Grady, 1997]

[Ciroarke, 1997]

[Hampton, 1999]

[Hignera, 1996]

[Humphrey, 1989]

[Hunphrey, 1992]

[IEEE, 199]]

[IFPUF, 2000]
DEKKERS, C. Managing (the Size of Your Projects: A Project Management Look at Function Points. Quality Plus Technologies, Inc. Disponivel em: <inuw, bfgin,com,br>. Acesso ent: [05/02/00].

A Description of the Space and Naval Warfare System Center San Diego Software Process Assets. Version 1.0. Software Engineering Process Office, D 12. Space and Naval Warfare Systems Center San Diego. San Diego, CA. September, 15, 1999. Disponivel em: <http://sero nosc mil/SPA doc>. Acesso ent: [29/08/00].

I:VOLUÇÃO da Qualidade no Setor de Software Brasileiro - 1993/1999. Disponivel $\mathrm{cm}:<\underline{\text { http}}$ //Www met.gov.br/Temas/info/Dsi/pallestra/Quali99.pdf>. Acesso em: $[30 / 0+/ 00]$.

FENTON, N. E. Softn are Metrics: a rigorous approaclı. London: Chapman \& Ilall, 1991.

FERNANDES A. A. Gerência de Software através de métricas: garantindo a quialidade do projeto, processo e produto. São Paulo: Atlas, 1995.

FUREY, Sean. Why We Shonld Use Function Points. IEEE Software. v. 14, n² p. $3,1907$.

GHEZZI, C. et. al. Fundamentals of Software Engineering. New Jersey: Prentice Hall, I991.

GRADY, R. B. Successful software process improvement. New Jersey: Prentice Hall, 1997.

GROARKE, B., ROBERTSON, G. Software Project Planning Process. Version 1.2. Software Engineering Process Office (SEPO), D13. Space and Naval Warfare Systems Center. San Diego, CA. September 8, 1997. Disponivel en: $<$ http://sepo nosc mil/SPPProc. doc $>$. Acesso em: [05/02/00].

The HAMPTON Group. A Buyer' Guide to Selecting Project Managenent Software. Disponive! em: <hitn:/www. tpn .com/articles/selpmsw.html>. Acesso em: [29/07/00].

HIGUERA, R. P., HAIMES, Y. Y. Software Risk Management. ESC-TR-96-012. (Technical Report CMU/SEI-96-TR-012), 1996. Disponivel em: $<$ http://www.sei.cmu.edu/publications/documents/96.reports/96.tr.012.pdls. Acesso enr: [10/09/00].

HUMPIIREY, W. S. Managing the Softwarc Process. New York: AddisonWesley Publs, 1989.

HUMPHREY, W. S. Introduction to Software Process Improvement. Technical Report CMU/SE1-92-TR-7. Cantegie MelIon University: June 1993. Disponfiel $\mathrm{em}:<$ http://www. sei.cmul.edu/pub/documents/92.reports/pdr/tr07.92.pdf >. Acesso em: [10/02/99].

IEEE: Standurd for Software Project Management Plans: Std 1058.1-1987. TEEE Softwarc Engineering Standards Collection. New York: Computer Society, 1991.

International Munction Points Users Group. Disponivel em: <wuw.ifpug.org>. Acesso em: $[05 / 02 / 00 \mid$. 
[IFPUG. 1994]

[Joncs, 1996a]

[Jones, I996b]

[Jones, 1998]

[Juran, 1993]

[Kan, 1995]

[Krause, 1999]

[Marciariello, 1974]

[Mello, 1999]

[Moreno, 1999]

[NESMA, 2000]

[Oskarsson, 1996]

[Paulk et al., 1992]

[Paulk et al, 1997]

[PMBOK, 1996]

[Pressman, 1995]

[Pressman, 1997]

[Qualidade, 1997]
Function Points Counting Practice Manual. Rclease 4.0. Westerville, Ohio, 1994. Disponivel em: < www.ifpug.org>. Acesso em: [05/02/00].

JONES, C. Applied Software Mcasurement: assuring productivity and quality. New York: McGraw-Hill, 1996.

JONES, C. Programming Languages Table. Release 8.2. March 1996. Disponfvel en: <http://wwv.spr.com/library/0langtbl.htm>. Acesso em: [03/02/00].

JONES, C. Software Project Management in the $21^{\text {st }}$ Century. American Programmer, Volume XI, n. 2, February 1998. Disponível em: $<$ http://spr.com.html/ancrican progranumer.htm>. Acesso em: [03/02/99].

JURAN, J. M., GRYNA, F. Quality planning and analysis. New York: MacGraw Hill, 1993.

KAN, S.H. Metrics and Models in Software Quality Engineering. New York: Addison-Wesley, 1995.

KRAUSE, W. Gcrenciamento de Risco: Garantindo o Sucesso da TI. Developers' Magazine, Setembro, 1999. p. 22-23.

MARCIARIELLO, J. A. Making program management work. In: Reifer, D. J. Tutorial: Software management. 3 ed. Washington: IEEE Computer Society, 1986, p. $93-100$.

MELLO, M. C. F. Plancjamento de Projeto em Processo Itcrativo e Incremental. Developers' Magazine, Setcmbro, 1999. p. 38-40.

MORENO, R. O. M. O desafio do planejamento ... e o uso de Templates. Bate Byte, ed. 45. Dispontvel cm:

$<$ http://www.pr.gov.br/celepar/celepar/batebyte/bb45/desafio.htm>. Acesso em: [30/04/00].

Netherlands Function Point Users Group. Disponivel em: <http://www.nesma.nl/english/earlyfpa.htm>. Acesso em: [30/04/00].

OSKARSSON O., GRASS, R. L. An ISO 9000 Approaeh to building Quality Software. New Jersey: Prentice Hall, 1996.

PAULK, M., CURTIS, B., CHRISSIS, M., WEBER, C. The Capability Maturity Model for Software v. 1.1. Disponivel em: $<$ http://wnv. sei.cmu.edu/publications/documents/93,reports/93.tr.024html $>$. Acesso em: [23/08/98].

PAULK, M. et. al. Soffware Quality and the Capability Maturity Model. Communications of the ACM, v. 40. n. 6, p. 30-40, June 1997.

PMBOK - A Guide to Project Management Body of Knowledge. Project Management Institute. Disponivel em:

$<$ http://wwv.pmi. org/publictn/pmboktoc.htm>. Acesso cm: [23/08/98].

PRESSMAN, R. Engenharia de Software. 3 ed. Rio de Janeiro. Makron Books, 1995.

PRESSMAN, R. Software Engineering: A Practitioner's Approach. 4 ed. New York: McGraw-Hill, 1997.

Qualidade no Setor de Software Brasileiro. Brasilia. n.2, p.27, 1997. 
[Rcifer, 1986]

[REVIC, 2000]

[Risk, 1997].

[Slack, 1997]

[Softwarc, 1996]

[Sommerville, 1996]

[SPICl:2, 1997]

[Standish, 1999]

[Teixeira, 2000a]

[Tcixeira, 2000b]

[Trindade, 199')]

[Trindade, 2000a]

[Trindade. 2000b]

[USC COCOMO, 2000]

[Vargas, 2000]

[Vaz, 2000]
REIFER, D. J. Tutorial: Software Manigenent. 3 ed. Washington: IEEE Computer Society Press, 1986. p.83.

REVIC. Disponivel em: <http://sepo, 13osc,mil/revic.zip >. Acesso em: [05/02/00].

Risk Management Process. Version 2.0. Software Engineering Process Office (SEPO), Code DI3. Naval Command, Control and Ocean Surveillance Center (ivCCOSC) San Diego, CA. May, 1997. Disponivel em: <http://sepo.nosc.mil/Riskmemt.doc >. Accsso em: [05/02/00].

SLACK, N. et al. Administração da Produção. São Paulo: Atlas, 1997

Soflware Size, Cost and Schedule Estimation Process. v. 2.1. Software Engineering Process Office (SEPO), Code D13. San Diego, CA. June 5, 1996. Disponivel em: <http://sepo.nosc.mil/EstProc.doc>. Acesso em: [29/01/99].

SOMMERVILLE, I. Software Engineering. 5 ed. Wokinham: Addison-Wesley 1996.

ISO/FEC Software Process Assessment - Part 2: A Model for Process Management, Guide. Working Draft, versão 1.00, 1997. Disponivel en: $<$ http://www.sqi.cit.gu.edu.an/spice/suite dounnload.shtml>. Acesso em: [20/08/98].

Standish Group. Estimating: Art or Scienee? Disponivel em:

<http://www.marotz.com/cxrevieivs/standish/index.html>. Acesso em: $[05 / 02 / 00]$.

TEIXEIRA, W.; SANCHES, R. Pontos de Função: uma medida funcional de tamanho de software. São Carlos, ICMC, 2000. (Relatório Técnico do ICMCUSP, 105).

TEIXEIRA, W.; SANCHES, R. Modelos de Estimativa de Custo de software COCOMO e COCOMO II. São Carlos, ICMC, 2000. (Relaı́rio Técnico do ICMC-USP, 106).

TRINDADE, A L. P.; PESSÔA, M. S. P.; SPINOLA, M. S.

COCOMO II: Uma comparação de informaçðes sobre a nova métrica. Disponivel na Internet:

<iltp://metricas.tw eng.br/artigos/icie99-COCOMOii-ALPTMSPPMMS pdP. Acesso em: [05/02/00].

TRINDADE, A. L. P. Constructive COst Model. Disponivel em: http://metricas.tw.eng br/htunls/cocomo-b. html] . Acesso em: [05/02/00].

TRINDADE. A. L. P. Construetive COst MOdel. Disponivel em: <htt://netricas.tw.eng.br/htmls/cocomo-b. html >. Acesso em: [05/02/00].

USC COCOMO 2.0 Version 0. Disponivel em: $<$ litp://sunset.usc.edu/j_cocomo/cocomo.h(ml>. Acesso em: [05/02/00].

VARGAS, R. V. Gerenciamento de Projetos: Estabelecendo Diferenciais Competitivos. Rio de Janeiro: Brasport, 2000.

VAZ, R. Rumo ao Nivel II da Capability Maturity Model - CMM. Developers' Magazine, p. 20-223, Setembro, 2000. 
[Vigder, 1994]

Webcr, 1999]

[Wiegcrs, 2000]
VIGDER. M. R.: KARK. A. W. Software Cost Estimation and Control. National Research Council Canada. Institute for Information Technology, 1994.

Disponfvel em: <lhtp://wwwsel.iit.nrc.ca/abstracts/NRC371 [6.abs>. Acesso em: $[03 / 02 / 99 /$.

WEBER. K. C. Qualidade e Produtividade em Software. 3 ed. São Paulo: Makron Books do Brasil Ltda, 1999.

KARL, W. Stop Pronuising Miracles. Software Development, p. 49-54, February 2000. 


\section{Apêndice A - Modelos de Documentos}

\begin{tabular}{|c|c|}
\hline \multicolumn{2}{|r|}{ Plano de Treinamento } \\
\hline Tópicos & Descrição \\
\hline Propósilo & $\begin{array}{l}\text { Desenvolver e melhorar as habilidades atuais do gerente de projeto, possibilitando } \\
\text { planejar e gerenciar projetos de forma bem sucedida. } \\
\text { Desenvolver e melhorar as habilidades atuais de elaboração de estimativas e } \\
\text { planejamento de projeto dos analistas e desenvolvedores. }\end{array}$ \\
\hline Objetivos & $\begin{array}{l}\text { Desenvolver e melhorar as habilidades necessárias ao planejamento e } \\
\text { gerenciamento do desenvolvimento de projetos. } \\
\text { - Compreender as fases e atividades do ciclo de vida do software e atividades de } \\
\text { apoio. } \\
\text { - Enfatizar as fases iniciais do ciclo de desenvolvimento de software: definição dos } \\
\text { requisitos e plancjamento de projeto. } \\
\text { Mellorar o processo de desenvolvimento através do uso de processos e prineípios } \\
\text { de planejamento de projeto, melhorando a qualidade do processo nas fases iniciais } \\
\text { de desenvolvimento. }\end{array}$ \\
\hline Participantes & Gerente de projeto, equipe inicial de planejamento. \\
\hline Pré-requisitos & $\begin{array}{l}\text { Para o gerente de projetos, é desejável possuir experiência em desenvolvimento ou } \\
\text { manutenção de software. }\end{array}$ \\
\hline Tópicos & $\begin{array}{l}\text { Podem ser considerados os seguintes tópicos: } \\
\Rightarrow \text { Definição da arquitetura de processo, modelos de ciclo de vida. } \\
\Rightarrow \text { Métricas e Estimativas de Software: } \\
\text { - } \text { Montagem de Pontos de Função } \\
\text { - Analogia } \\
\text { - } \text { Delphi } \\
\Rightarrow \text { Perramentas automatizadas de Estimativa } \\
\text { Planejamento de Dcsenvolvimento de Software } \\
\text { - Técnicuras de divisão de trabalho } \\
\Rightarrow \text { Gefinição dos Recurão de cronograma (pessoas, equipamentos, etc.) } \\
\Rightarrow \text { Identificação, estimativas, prevenção. } \\
\Rightarrow \text { Gerenciamento de Configuração de Software } \\
\Rightarrow \text { Garantia de Qualidade de Software } \\
\end{array}$ \\
\hline Local & (a definir) \\
\hline Dala & (a definir) \\
\hline Duração & Horas, dias, etc. (a definir) \\
\hline $\begin{array}{l}\text { Material de } \\
\text { Treinamento }\end{array}$ & Slides, software, bibliografia, exercícios, etc. \\
\hline $\begin{array}{l}\text { Responsável pelo } \\
\text { Treinamento }\end{array}$ & $\begin{array}{l}\text { Empresa de treinamento, consultores, ete. } \\
\text { Uma forma de viabilizar treinamento muito adotada nas organizações é designar apenas } \\
\text { um funcionário para ser treinado, interna ou extemamente. Depois de habilitado, esse } \\
\text { funcionário torna-se um "multiplicador de conhecimento" na organização, } \\
\text { responsabilizando-se por treinamentos futuros. }\end{array}$ \\
\hline Custo Estimado & (a definir) \\
\hline
\end{tabular}

Figura Apêndice A.1 - Modelo de Plano de Treinarnento 


\section{Documen's de Estimativas}

Formulário de Registro e Acompanhameuto de Estimativas de Projeto

Nome do Projelo:

Gerente Responsávei:

Data:

C clo de visla:

I Es timativa do Tamanho

Linguagem:

Método Utilizndn para Estimativa Nanual:

Fer ramenla Automatizadi:

Dudus históricos utilizados:

Ols:ernactes:

Data

T:laborado pnr (nomc)

Funçăo ou Mòthulo !

Puntos de Função

Linilas de Código Novas

Linlas de Código Reutilizadas

Tamanhn Tosal para Completar o Prnjeto

\begin{tabular}{|c|c|c|c|c|c|}
\hline & & & & & \\
\hline & & & & & \\
\hline & & & & & \\
\hline & & & & & \\
\hline & & & & & \\
\hline & & & & & \\
\hline & & & 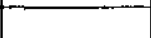 & 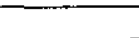 & 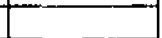 \\
\hline
\end{tabular}

II Estimativa de Esforço

Método Utilizado para Estimativa Manual:

Ferramenta Automatizada:

1)anlos lisstóricos utilizados:

Observarñes:

Dala

Elabi raslo por (nnme)

Esforço para Funz̧ào ou Módulo !

Esfor; Total para Completar $n$ Projetn

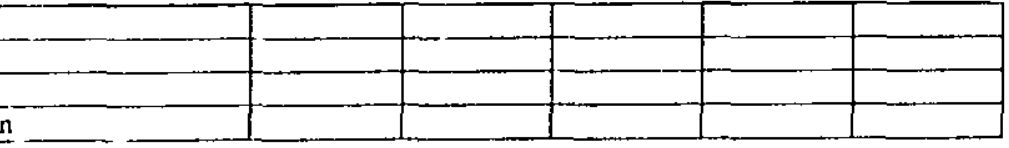

III Estimativa de Tempo

Mécodo Utilizado para Estimativa Manual:

ferramenta Automatizada:

Dadus históricos utilizadlos:

Observaches:

\section{Data}

Elaborado por (nome)

Tenino para Funça ou Mórlulo !

Tempo Tutal para Complet.ır u Projeco:

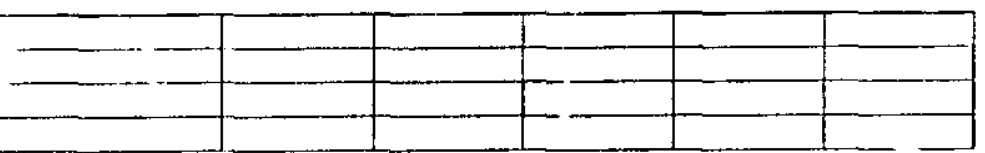

IV Cálculo de Custo

Métexto Utilizado para Ëstimativa Miamaal:

Ferrorneata Aulonatizada:

Dados hislóricos utilizados:

Observacôes:

Ditn

Elaboracl. por (nome)

Custo para Funçào ou Módulo I

Custo Tutal para Complctar o Projeto

V Mútricas do Processo

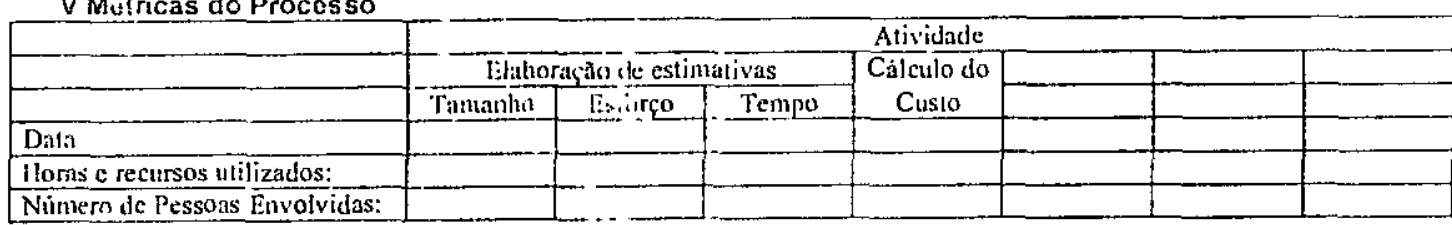

VI Dacios de Conciusão do Projeto

Ohservaches:

Ditulos Efetivos

Timantion

Es Forgo

Produtividacte

Termpo

$N^{\prime \prime}$ de defuilos eneontrados

\begin{tabular}{|c|c|c|}
\hline Funçxa ou Módulo ! & Fungtăo on Módulu 2 & Função ou Módulon \\
\hline & & \\
\hline & & \\
\hline & & \\
\hline & & \\
\hline & & \\
\hline
\end{tabular}

Figura Apêndice A.2 - Modelo de Documento de Registro de Estimativas 


\section{Plano do Projeto: (nome do sistema)}

Gerente Responsável: (nome)

Data de Elaboração: I I

Equipe de Planejamento: (membros)

Data de Revisão e Aprovação:

Aprovado por: (nomes e assinaturas)

I Introdução

1.1 Escopo, propósito e objetivos do projeto.

1.2 Funções principais do sistema.

1.3 Documento de requisitos funcionais do sistema. Folha (s)

1.4 Questões de desempenho.

1.5 Restriçōes técnicas e administrativas.

\section{Il Estimativas}

2.1 Estimalivas elaboradas.

2.2 Dados Históricos.

2.3 Técnicas e ferramentas utilizadas.

2.4 Documento de Estimativas. Folha (s)

III Riscos do projeto

Análise dos riscos.

3.1 Identificação e justificativa. Folha (s)

3.2 Estimativa dos riscos. Folha (s)

Administração dos riscos.

3.3 Prevenção e pontos de controle. Folha (s)

\section{Cronograma}

4.1 Estrutura de divisāo de trabalho. Folha (s)

4.3 Cronograma. Folha (s)

4.4 Técnicas e ferramentas utilizadas. Folha (s)

V Recursos de projeto

5.1 Equipe de desenvolvimento. Folha (s)

5.2 Hardware e software. Folha (s)

5.3 Recursos especiais. Folha (s)

5.4 Planilha de Custos. Folha (s)

VI Organização do Pessoal

6.1 Estrutura de equipe. Folha (s)

VII Mecanismos de rastreamento e controle Folha (s)

VIII Plano de Gerenciamento de Configuração Folha (s)

IX Plano de Garantia de Qualidade Folha (s)

$X$ Apêndices Folha (s)

Figura Apêndice A.3 - Modelo de Plano de Projeto de Software 

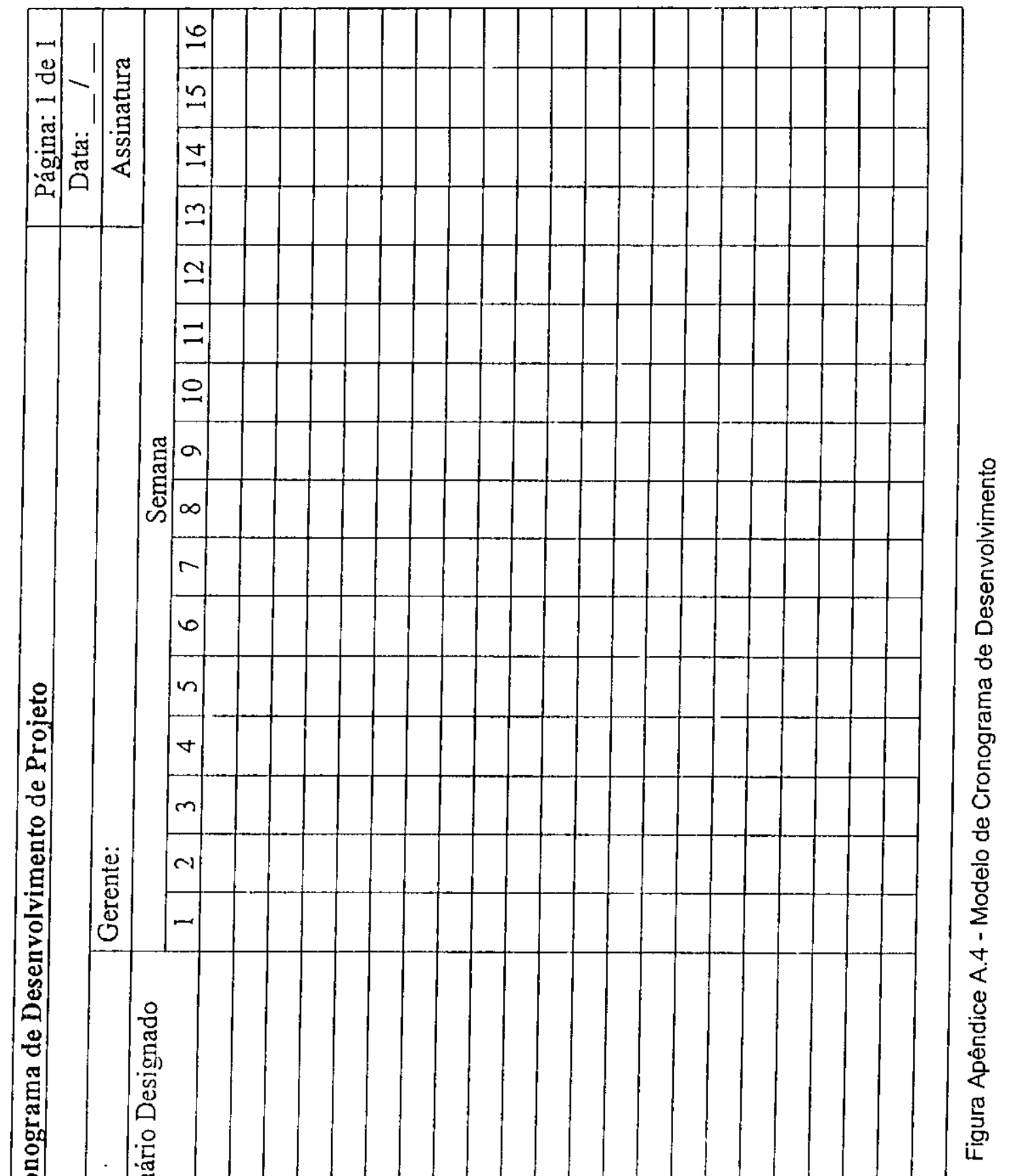

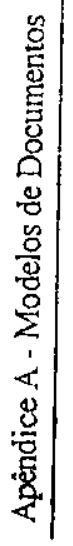

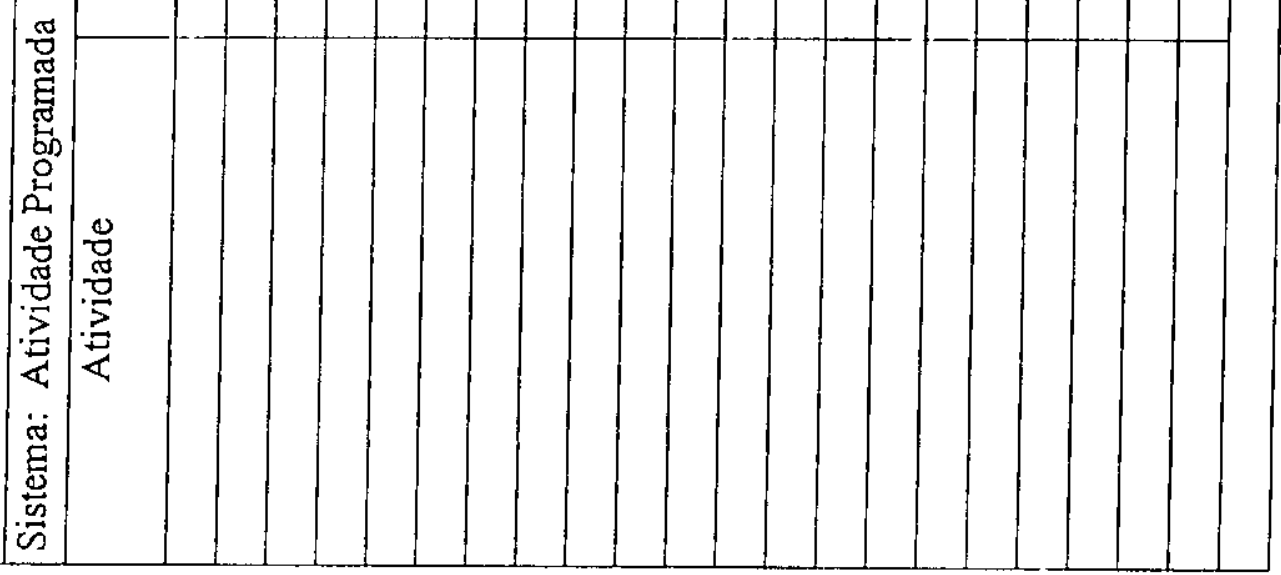




\section{Apêndice B - Checklist para Identificação de Riscos}

Este apêndice apresenta um checklist para auxiliar a identificação de riscos dc projetos de software na organização. O checklist é apresentado na forma de um conjunto de perguntas relacionadas a fatores de: tamanho do produto; impacto do negócio; características do clicnte; definição do processo; ambiente de desenvolvimento; tecnologia de implementação; e experiência da equipe [Pressman, 1997].

Itens de risco associados ao tamanho do software:

$\checkmark$ O tamanho do software foi estimado em linhas de código ou pontos de função?

$\checkmark$ Qual é o grau de precisão das estimativas de tamanho elaboradas?

$\checkmark$ Qual é a porcentagem de desvio do tamanho do produto com relação à média obtida na comparação com projetos passados?

$\checkmark$ Qual ć o tamanho da base de dados criada ou utilizada pelo produto?

$\checkmark$ Qual é o número de usuários do produto?

$\checkmark$ Qual é o número de mudanças esperadas para os requisitos do software antes e depois da entrega?

$\checkmark$ Qual é a quantidade de código reutilizado?

Cada resposta deve ser comparada com experiência prévia no desenvolvimento do produto. Se houver grande porcentagem de desvio ou se os números obtidos forem similares mas os resultados passados não forem considerados satisfatórios para a comparação, o risco pode ser alto.

Itens de risco associados ao impacto do negócio:

$\checkmark$ A data de entrega do sistema é razoável?

$\checkmark$ Qual é o número de usuários que utilização o sistema e qual a consistência das suas necessidades com relação ao sistema?

$\checkmark$ Qual é o número de sistemas com os quais o sistema a ser desenvolvido deve interagir?

$\checkmark$ Qual é o grau de sofisticação dos usuários finais?

$\checkmark$ Qual a quantidade e qualidade de documentação do produto que deve ser produzida e entregue ao cliente?

$\checkmark$ Quais os custos associados à demora da entrega do sistema?

$\checkmark$ Quais os custos associados a defeitos no sistema?

Cada resposta deve ser comparada com experiência prévia no desenvolvimento do produto. Se houver grande porcentagem de desvio ou se os números obtidos forem similares mas os resultados passados não forem considerados satisfatórios para a comparação, o riseo pode ser alto.

Itens de risco associados ao cliente:

$\checkmark$ A organização já trabalhou com o cliente anteriormente? 
$\checkmark$ O clicnte possui idéia sólida dos requisitos do sistema? O cliente dedicou algum tempo para escrever as ¿specificaçōes do sistema?

$\checkmark$ O cliente concordará em dedicar algum lempo em reuniōes para identificação do escopo do projeto?

$\checkmark$ O cliente deseja estabelecer um canal de comunicação rápido com o desenvolvedor?

$\checkmark$ Qual o grau de sofisticação tecnológica do cliente na área em que o sistenıa deverá atuar?

$\checkmark$ O cliente possui alguma compreensão do processo de software?

Se alguma resposta para as questões respondidas for "não", existe a necessidade de uma investigação mais detalhada para avaliar o risco polencial.

Iteus de risco associados ao processo:

Quesiñes relativas ao Processo

$\checkmark$ O processo de software é utilizado em outros irojetos?

$\checkmark$ A organização possui cursos ou programa de ıreinamento para gerentes e equipe ıécnica?

$\checkmark$ Existem revi sões regulares técnicas formais para especificação dos requisitos, projeto e codificação?

$\checkmark$ Os rcsultados das revisões técnicas formais são documentados, incluindo-se erros encontrados?

$\checkmark$ A organização executa gerenciamento de configuração?

$\checkmark$ Existe um mecanismo utilizado para controle de mudanças nos requisitos que causam impacto no sistema?

$\checkmark$ A organização documenta regularmente a declaração do trabalho, a especificação de requisitos e o plano de desenvolvimento?

\section{Questōes Técnicas}

$\checkmark$ Existen métodos específicos utilizados na análise do sistema?

$\checkmark$ A quantidade de código implementado em linguagem de alto nível é maior que $90 \%$ ?

$\checkmark$ Existem convenções definidas para documentação de código? São utilizadas?

$\checkmark$ risistcm métodos especificos para teste?

$\checkmark$ A organização utiliza ferramentas de software para apoio nas alividades de planejamento e acompanhamento de projeto?

$\checkmark$ A organização utiliza ferramentas de gerenciamento de configuração para controlar e acompanhar mudauças durante o processo de software?

$\checkmark$ A organização utiliza ferramentas de software para apoio ao processo e análise e projeto de sistemas?

$\checkmark$ A organização utiliza ferramentas de software para construção de protótipos?

$\checkmark$ A organização utiliza ferramentas de software para o processo de teste?

$\checkmark$ A organização utiliza ferramentas de software para produção e gerenciamento de documentação?

$\checkmark$ Existcm métricas de qualidade coletadas para todos os projetos de software?

Se a maior parte das respostas para as questões respondidas for "não", o processo de software é fraco e a risco é alto.

\section{Questôes relacionadas ao risco tecnológico}

$\checkmark$ A tecnologia a ser implementada ć nova para a organização?

$\checkmark$ Os requisitos do cliente requerem a criação de novos algoritmos ou tecnologia de entrada e saída? 
$\checkmark$ O software interage com hardware novo?

$\checkmark$ O software a ser desenvolvido interage com sistema de banco de dados cuja funçāo e performance ainda não foram devidamente testados na área de aplicação?

$\checkmark$ Existe a necessidade de uma interface especializada para o usuário, requerida pelo sistema?

$\checkmark$ Os requisitos do sistema demandam a criação de componentcs de programa diferentes daqueles previamente desenvolvidos pela organização?

$\checkmark$ Os requisitos funcionais necessitan de novos métodos de análise, projeto ou teste?

$\checkmark$ Os requisitos funcionais determinam restrição de performance excessiva ao sistema?

Se alguma das respostas para as questões respondidas for "sim", uma investigação mais detalhada deve ser feita para avaliar o riscos potencial.

Ilens de risco associados ao ambiente de desenvolvimento:

$\checkmark$ Existem ferramentas de gerenciamento de projeto disponiveis?

$\checkmark$ Existem ferramentas de gerenciamento de processo disponíveis?

$\checkmark$ Existem ferramentas para análise e projeto disponiveis?

$\checkmark$ Os métodos para análise e projeto implementado nas ferramentas utilizadas são apropriados para o desenvolvimento do software?

$\checkmark$ Existem compiladores e geradores de código disponíveis e apropriados para o desenvolvimento do software?

$\checkmark$ Existem ferramentas de teste disponiveis e apropriadas para o projeto?

$\checkmark$ Existem ferramentas de gerenciamento de configuração disponiveis?

$\checkmark$ ambiente de desenvolvimento utiliza base de dados?

$\checkmark \quad$ As ferramentas de desenvolvimento são integradas?

$\checkmark$ A equipe de desenvolvimento recebeu treinamento adequado para utilização das ferramentas?

$\checkmark$ Existem especialistas disponiveis para auxiliar na operação das ferramentas?

$\checkmark$ Existe help on-line e documentação adequada para as ferramentas?

Se a maior parte das questões respondidas forem "não", o ambiente de desenvolvimento pode ser considerado fraco e o risco é alto.

Itens de risco associadas com a equipe e a experiência de desenvolvinento:

$\checkmark$ As Pessoas escaladas são as mais indicadas?

$\checkmark$ Pessoas escaladas possuem as combinação de habilidades necessárias?

$\checkmark$ Existcm número de pessoas suficiente para o desenvolvimento do projeto?

$\checkmark$ A equipe está comprometida com o cronograma do projeto?

$\checkmark$ Haverá pessoas trabalhando em período parcial no projeto?

$\checkmark$ A equipe de desenvolvimento foi treinada nas habilidades requeridas?

$\checkmark$ A taxa de rotatividade de pessoas na equipe de desenvolvimento será baixa durante o projeto?

Se a resposta para alguma dessas questões for "não", existe a necessidade de uma investigação mas ampla para avaliação do risco associado com a questão. 
